This report was prepared as an account of work sponsored by an agency of the United States

Government. Neither the United States Government nor any agency thereof, nor any of their employees, makes any warranty, express or implied, or assumes any legal hability or responsibility for the accuracy, completeness, or usefulness of any information, apparatus, product, or process disclosed, or represents that its use would not infringe privately owned rights. Reference herein to any specific commercial product, process, or service by trade name, trademark, manufacturer, or otherwise does not necessarily constitute or imply its endorsement, recommendation, or favoring by the United States Government or any agency thereof. The views and opinions of authors expressed herein do not necessarily state or reflect those of the United States Government or any agency thereof.

\author{
SNC-3693-5 \\ RADIOISOTOPES AND RADIATION \\ APPLICATIONS \\ TID 4500 (55TH ED.) \\ UC.23
}

\title{
THULIUM OXIDE FUEL CHARACTERIZATION STUDY PART ॥ \\ ENVIRONMENTAL BEHAVIOR AND MECHANICAL, THERMAL AND CHEMICAL STABILITY ENHANCEMENT
}

Prepared By

C. A. Nelson

Prepared For

DIVISION OF ISOTOPES DEVELOPMENT

U.S. ATOMIC ENERGY COMMISSION

CONTRACT NUMBER: AT-(40-1)-3693

DECEMBER 1970

8y

SANDERS NUCLEAR CORPORATION

Nashua, New Hampshire 


\section{DISCLAIMER}

This report was prepared as an account of work sponsored by an agency of the United States Government. Neither the United States Government nor any agency Thereof, nor any of their employees, makes any warranty, express or implied, or assumes any legal liability or responsibility for the accuracy, completeness, or usefulness of any information, apparatus, product, or process disclosed, or represents that its use would not infringe privately owned rights. Reference herein to any specific commercial product, process, or service by trade name, trademark, manufacturer, or otherwise does not necessarily constitute or imply its endorsement, recommendation, or favoring by the United States Government or any agency thereof. The views and opinions of authors expressed herein do not necessarily state or reflect those of the United States Government or any agency thereof. 


\section{DISCLAIMER}

Portions of this document may be illegible in electronic image products. Images are produced from the best available original document. 


\section{TABLE OF CONTENTS}

Abstract

SECTION 1

Introduction

SECTION 2

Summary

SECTION 3

Fundamental stability study

Paragraph

$\underline{\text { Page }}$

3.1 objective

$3-1$

3. 2

Experimenta1

$3-1$

3.3

Results and Discussion

$3-3$

$3 \cdot 3 \cdot 1$

$100 \% \mathrm{Tm}_{2} \mathrm{O}_{3}, 80 \% \mathrm{Tm}_{2} \mathrm{O}_{3} / 20 \% \mathrm{Yb}_{2} \mathrm{O}_{3}, 100 \% \mathrm{Yb}_{2} \mathrm{O}_{3}$

Exposed to Air and Dynamic Vacuum at $1450^{\circ} \mathrm{C}$

for 5,24 and 100 hours

$3-3$

3.3.2 $100 \% \mathrm{Tm}_{2} \mathrm{O}_{3}, 80 \% \mathrm{Tm}_{2} \mathrm{O}_{3} / 20 \% \mathrm{Yb}_{2} \mathrm{O}_{3}, 100 \% \mathrm{Yb}_{2} \mathrm{O}_{3}$ Exposed to Static and Dynamic Vacuum at $1750^{\circ} \mathrm{C}$ for 5,24 and 100 hours

3.3.3 $100 \% \mathrm{Tm}_{2} \mathrm{O}_{3}, 80 \% \mathrm{Tm}_{2} \mathrm{O}_{3} / 20 \% \mathrm{Yb}_{2} \mathrm{O}_{3}$ and $100 \% \mathrm{Yb}_{2} \mathrm{O}_{3}$ Exposed to Static and Dynamic Vacuum at $2000^{\circ} \mathrm{C}$ for 5,24 and 100 hours 


\section{TABLE OF CONTENTS (COnt)}

Section 4

Mechanical, Thermal, Chemical Stability Enhancement

Paragraph

4.1

Bench Marks

Page

4.2

Process Variable Optimization

$4-2$

$4 \cdot 2.1$

Effects of Varying Chemical Reprocessing of

"As Received" $\mathrm{Tm}_{2} \mathrm{O}_{3}$

$4-12$

4.2.2 Effects of Sintering - Time/Temperature/

Atmosphere on $\mathrm{Tm}_{2} \mathrm{O}_{3}$

4.2.3 Effects of Aging on Mechanical, Chemical

and Therma1. Stability

$4-20$

Metal oxide Additives - A Means to Product

$4 \cdot 3$

Stability Enhancement

$4-28$

4.3 .1
4.3 .2
4.4

Experimental

$4-75$

$4-76$

Results and Discussion

$4-76$

An Assessment of Mechanical, Thermal and

Chemical Stability Enhancement

Section 5

Assessment of $\mathrm{Tm}_{2} \mathrm{O}_{3}$ as a Potential Heat Source Embodiment

Section 6

References

LIST OF ILLUSTRATIONS

Figure

Page

3-1 Air, $1450^{\circ} \mathrm{C}, 17$ hours (100X)

$3-6$

$3-2$

Air, $1450^{\circ} \mathrm{C}, 100$ hours ( $100 \mathrm{X}$ )

$3-7$

$3-3$

Dynamic Vacuum, $1450^{\circ} \mathrm{C}, 100$ hours ( $100 \mathrm{x}$ )

$3-8$

$3-4$

Static Vacuum, $1750^{\circ} \mathrm{C}, 100$ Hours (100X)

$3-10$ 


\section{LIST OF ILLUSTRATIONS (COnt)}

\section{Figure}

$3-5$

$3-6$

$3-7$

$3-8$

$3-9$

$3-10$

$3-11$

$3-12$

$4-1$

$4-2$

$4-3$

$4-4$

$4-5$

$4-6$

$4-7$

$4-8$

$4-9$

$4-10$

$4-11$

$4-12$

$4-13$

$4-14$
Dynamic Vacuum, $1750^{\circ} \mathrm{C}, 100$ hours (100X)

Page

$3-11$

$3-13$

$3-14$

$3-15$

$3-16$

$3-18$

$3-19$

$3-20$

Dynamic Vacuum, $2000^{\circ} \mathrm{C}, 100$ hours (100X)

$4-5$

$4-6$

$4-7$

for 17 hours Fractured Surface (100X)

$4-8$

Then 20 Minute Rise to $2000^{\circ} \mathrm{C}$ and Shut

Down (200X)

$X$-ray Composition and Scan of $80 \% \quad \mathrm{Tm}_{2} \mathrm{O}_{3} / 20 \%$

$\mathrm{Yb}{ }_{2} \mathrm{O}_{3}$ Wafers Aged at $1600^{\circ} \mathrm{C}$ for 500 Hours $(660 x)$

$4-10$

$100 \% \mathrm{Tm}_{2} \mathrm{O}_{3}$ Wafer Aged $1600^{\circ} \mathrm{C}$ for 500 Hours (100X)

$4-11$

$100 \%$ Th 0 Bench Mark Aged 500 Hours at $1600^{\circ} \mathrm{C}(500 \mathrm{X})$

$4-13$

4-19

$\mathrm{Tm}_{2} \mathrm{O}_{3}$ Powders Calcined at $950^{\circ} \mathrm{C}$

$4-29$

Sintered $1750^{\circ} \mathrm{C}$, Vacuum (As Polished - 70X)

$4-30$

Urea Process $\mathrm{Tm}_{2} \mathrm{O}_{3}$ Wafers, Pressedat 15 ts
Sintered $1750^{\circ} \mathrm{C}$, Vacuum (As Polished - $70 \mathrm{X}$ )

$4-31$

Urea Process $\mathrm{Tm}_{2} \mathrm{O}_{3}$ Wafers, Pressed at 29 ts
Sintered $1750^{\circ} \mathrm{C}$, Vacuum (As Polished - 70X)

$4-32$

Urea Process $\mathrm{Tm}_{2} \mathrm{O}_{3}$ Wafers, Pressed at $4.5 \mathrm{tsi}$,
Sintered $1750^{\circ} \mathrm{C}$, Hydrogen (As Polished $-70 \mathrm{X}$ )

$4-32$

Urea Process $\mathrm{Tm}_{2} \mathrm{O}_{3}$ Wafers, Pressed at $15 \mathrm{tsi}$,

Sintered $1750^{\circ} \mathrm{C}$, Hydrogen (As Polished - 70X)

$4-33$

Urea Process $\operatorname{Tm}_{2} \mathrm{O}_{3}$ Wafers, Pressed at $29 \mathrm{tsi}$,

Sintered $1750^{\circ} \mathrm{C}$, Hydrogen (As Polished - 70X) 
4-16 Urea Process $\mathrm{Tm}_{2} \mathrm{O}_{3}$ Wafers, Pressed at 15 tsi, Sintered $1750^{\circ} \mathrm{C}$, Vacuum (Fractograph 100X) 4-36

4-17 Urea Process $\mathrm{Tm}_{2} \mathrm{O}_{2}$ Wafers, Pressed at 29 tsi, Sintered $1750^{\circ} \mathrm{C}$, Vacuum (Fractograph 100X) 4-37

4-18 Urea Process $\mathrm{Tm}_{2} \mathrm{O}_{3}$ Wafers, Pressed at 4.5 tsi, Sintered $1750^{\circ} \mathrm{C}$, Hydrogen (Fractograph 100X) 4-38

4-19 Urea Process $\mathrm{T}_{2} \mathrm{O}_{3}$ Wafers, Pressed at 15 tsi, Sintered $1750^{\circ} \mathrm{C}$, Hydrogen (Fractograph 100X) 4-39

4-20 Urea Process $\mathrm{Tm}_{2} \mathrm{O}_{3}$ Wafers, Pressed at 29 tsi, Sintered $1750^{\circ} \mathrm{C}$, Hydrogen (Fractograph 100X)

$4-40$

4-21 Ammonium Oxalate Process $\mathrm{Tm}_{2} \mathrm{O}_{3}$ Wafers, Pressed at 4.5 tsi, Sintered $1750^{\circ} \mathrm{C}$, Hydrogen (As Polished - 70X)

4-22 Ammonium Oxalate Process $\mathrm{Tm}_{2} \mathrm{O}_{3}$ Wafers, Pressed at 15 tsi, sintered $1750^{\circ} \mathrm{C},{ }^{2}$ Hydrogen (As

Polished - 70X)

4-23 Ammonium Oxalate Process $\mathrm{Tm}_{2} \mathrm{O}_{3}$ Wafers, Pressed at 29 tsi, Sintered $1750^{\circ} \mathrm{C}, 2$ Hydrogen (As

Polished - 70X)

$4-43$

4-24 Ammonium Oxalate Process $\mathrm{Tm}_{2} \mathrm{O}_{3}$ Waters, Pressed at 15 tsi, Sintered $1750^{\circ} \mathrm{C}, 2$ Vacuum (As Polished - 70X)

4-25 Ammonium Oxalate Process $\mathrm{Tm}_{2} \mathrm{O}_{3}$ Wafers, Pressed at 29 tsi, Sintered $1750^{\circ} \mathrm{C},{ }^{2} \mathrm{Vacuum}$ (As Polished - 70X)

4-26 Ammonium Oxalate Process $\mathrm{Tm}_{2} \mathrm{O}_{3}$ Wafers, Pressed at $4.5 \mathrm{tsi}$, Sintered $1750^{\circ} \mathrm{C}$, Vacuum (Fractograph 100X)

4-27 Ammonium Oxalate Process $\mathrm{Tm}_{2} \mathrm{O}_{3}$ Wafers, Pressed at 15 tsi, Sintered $1750^{\circ} \mathrm{C},{ }^{2}$ Vacuum (Fractograph 100X)

4-28 Ammonium Oxalate Process $\mathrm{Tm}_{2} \mathrm{O}_{3}$ Wafers, Pressed at 29 tsi, sintered $1750^{\circ} \mathrm{C},{ }^{2}$ Vacuum (Fractograph 100X)

4-29 Ammonium Oxalate Process $\mathrm{Tm}_{2} \mathrm{O}_{3}$ Wafers, Pressed at 4.5 tsi, Sintered $1750^{\circ} \mathrm{C}$, Hydrogen

(Fractograph 100X) 


\section{LIST OF ILLUSTRATIONS (COnt)}

Figure

$4-30$

$4-31$

$4-32$

$4-33$

$4-34$

$4-35$

$4-36$

$4-37$

$4-38$

$4-39$

$4-40$

$4-41$

$4-42$

$4-43$

$4-44$

$4-45$
Ammonium oxalate Process $\mathrm{Tm}_{2} \mathrm{O}_{3}$ Wafers, Pressed at 15 tsi, Sintered $1750^{\circ} \mathrm{C}, 2^{2}$ Hydrogen

(Fractograph - 100X)

Page

$4-50$

$4-51$ at $29 \mathrm{tsi}$, Sintered $1750^{\circ} \mathrm{C},{ }^{2} \mathrm{Hydrogen}$

(Fractograph - 100X)

Pressed

$100 \% \operatorname{Tm}_{2} \mathrm{O}_{3}$, Pressed at $4.5 \mathrm{tsi}$, Sintered $1750^{\circ} \mathrm{C}$

8 Hours ${ }^{2}$ Vacuum, Aged 500 Hours, $1600^{\circ} \mathrm{C}(100 \mathrm{X})$

$4-54$

$80 \% \mathrm{Tm}_{2} \mathrm{O}_{3} / 20 \% \mathrm{Yb}_{2} \mathrm{O}_{3}$, Pressed at $4.5 \mathrm{tsi}$, Sintered $1750^{\circ} \mathrm{C}, 8$ Hours 2 acuum. Aged 500 Hours, $1600^{\circ} \mathrm{C}$ $(100 \mathrm{X})$

$4-55$

$100 \% \mathrm{Tm}_{2} \mathrm{O}_{3}$, Pressed at $4.5 \mathrm{tsi}$, Sintered $1750^{\circ} \mathrm{C}$

4 Hours, $\mathrm{Vacuum}$, Aged 500 Hours, $1600^{\circ} \mathrm{C}(100 \mathrm{X})$

$4-56$

$100 \% \operatorname{Tm}_{2} \mathrm{O}_{3}$, Pressed at $29 \mathrm{tsi}$, Sintered $1750^{\circ} \mathrm{C}$

8 Hours, Vacuum, Aged 500 Hours, $1600^{\circ} \mathrm{C}(100 \mathrm{X})$

$4-57$

$100 \% \mathrm{Tm}_{2} \mathrm{O}_{3}$, Pressed at $15 \mathrm{tsi}$, Sintered $1750^{\circ} \mathrm{C}$

6 Hours, Hydrogen, Aged 500 Hours, $1600^{\circ} \mathrm{C}$ (100X)

$4-58$

$100 \% \mathrm{Tm}_{2} \mathrm{O}_{3}$, Pressed at $29 \mathrm{tsi}$, Sintered $1750^{\circ} \mathrm{C}$

6 Hours, Hydrogen, Aged 500 Hours, $1600^{\circ} \mathrm{C}$ (100X)

$4-59$

$80 \% \mathrm{Tm}_{2} \mathrm{O}_{3} / 20 \% \mathrm{Yb}_{2} \mathrm{O}_{3}$, Pressed at $29 \mathrm{tsi}$, Sintered

$1750^{\circ} \mathrm{C}, 6$ Hours, ${ }^{2}$ Hydrogen, Aged 500 Hours,

$1600^{\circ} \mathrm{C},(100 \mathrm{X})$

$4-60$

$4-63$

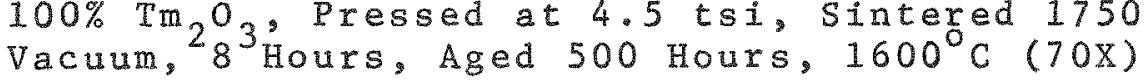

$4-63$

$80 \% \mathrm{Tm}_{2} \mathrm{O}_{3} / 20 \% \mathrm{Yb}_{2} \mathrm{O}_{3}$ Wafers, Pressed at $4.5 \mathrm{tsi}$, Sintered $1750^{\circ} \mathrm{C},{ }^{2} 8^{3}$ Hours, Vacuum, Aged 500 Hours $1600^{\circ} \mathrm{C}(70 \mathrm{X})$

$4-64$

$100 \% \mathrm{Tm} \mathrm{O}_{3}$, Pressed at $4.5 \mathrm{tsi}$, Sintered at $1750^{\circ} \mathrm{C}$

4 Hours ${ }^{2}$ vacuum, Aged 500 Hours, $1600^{\circ} \mathrm{C}$ (70X)

$4-65$

$100 \% \mathrm{Tm}_{2} \mathrm{O}_{3}$, Pressed at 29 ts 1 , sintered $1750^{\circ} \mathrm{C}$

8 Hours ${ }^{2}$ Vacuum, Aged 500 Hours, $1600^{\circ} \mathrm{C}(70 \mathrm{X})$

$4-66$

$100 \% \mathrm{Tm}_{2} \mathrm{O}_{3}$, Pressed at $15 \mathrm{tsi}$, Sintered at

$1750^{\circ} \mathrm{C},{ }^{2} 6^{3}$ Hours Hydrogen, Aged 500 Hours,

$1600^{\circ} \mathrm{C},(20 \mathrm{~min})$ Rise to $2000^{\circ} \mathrm{C}(70 \mathrm{X})$

$4-67$

$100 \% \mathrm{Tm}_{2} \mathrm{O}_{3}$. Pressed at $29 \mathrm{tsi}$, Sintered $1750^{\circ} \mathrm{C}$,

6 Hours ${ }^{2}$ Hydrogen, Aged 500 Hours, $1600^{\circ} \mathrm{C}(70 \mathrm{X})$

$4-68$

$80 \% \operatorname{Tm} 2{ }_{3} / 20 \% \mathrm{Yb}_{2}{ }^{\circ}$ Wafers, Pressed at 29 tsi,
Sintered $1750^{\circ} \mathrm{C},{ }^{3}$ Hours Hydrogen, Aged 500

Hours, $1600^{\circ} \mathrm{C}$ (7OX)

$4-69$ 


\section{LIST OF ILLUSTRATIONS (Cont)}

Figure

Page

$4-46$

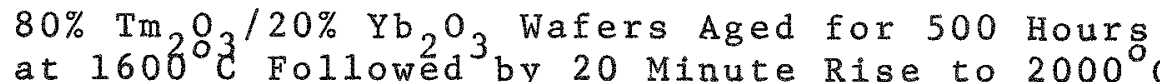

$4-71$

4-47 Pressing Pressure vs. \% Fines-sub 10 Micon.

Wafers Aged in $T-111, T Z M$ and Tungsten for

500 Hours at $1600^{\circ} \mathrm{C}$.

$4-72$

4-48 $\mathrm{Tm}_{2} \mathrm{O}_{3} / \mathrm{Yb}_{2} \mathrm{O}_{3}+1 \%$ Additive, Melt Samples ( $300 \mathrm{X}$ )

$4-78$

4-49 $\operatorname{Tm}_{2} \mathrm{O}_{3}$ and $80 \% \operatorname{Tm}_{2} \mathrm{O}_{3} / 20 \% \mathrm{Yb}_{2} \mathrm{O}_{3}+1 \%$ Additive.

Waters Aged 500 Hours in Tungsten Capsules

at $1600^{\circ} \mathrm{C}$.

$4-79$

4-50 $100 \% \mathrm{Tm}_{2} \mathrm{O}_{3}+1 \%$ Additive sintered at $1450^{\circ} \mathrm{C}$

in Air lor 17 Hours (100X)

$4-80$

4-51 $\mathrm{Tm}_{2} \mathrm{O}_{3}$ MeIt Sample Electron Microprobe

Composition and Sweep (300x)

$4-82$

4-52 $\operatorname{Tm}_{2} \mathrm{O}_{3}$ and $80 \% \mathrm{Tm}_{2} \mathrm{O}_{3} / 20 \% \mathrm{Yb}_{2} \mathrm{O}_{3}+1 \%$ Additive.

Waters Sintered in Air at $1450^{\circ} \mathrm{C}, 17$ Hours $4-83$

LIST OF TABLES

$\underline{T a b 1 e}$

Page

3-1 Test Matrix for Fundamental Stability Study and Product Post Environmental Exposure

Analyses (Matrix Applies to $\mathrm{Tm}_{2} \mathrm{O}_{3}, \mathrm{Tm}_{2} \mathrm{O}_{3}+$ $20 \% \mathrm{Yb}_{2} \mathrm{O}_{3}$, and $\mathrm{Yb}_{2} \mathrm{O}_{3}$

$3-2$

$3-2$

Experimental Data Summary - Fundamental Study

$3-4$

$3-3$

Increase/Decrease (\%) in Thickness of $100 \% \mathrm{Tm}_{2} \mathrm{O}_{3}$, $80 \% \mathrm{Tm}_{2} \mathrm{O}_{3} / 20 \% \mathrm{Yb}_{2} \mathrm{O}_{3}$ and $100 \% \mathrm{Yb}_{2} \mathrm{O}_{3}$ as a Result

of Environmental ${ }^{2}$ Exposure

$4-1$

Summary of Bench Mark Experimental Data

$4-3$

4-2 Summary of Conditions for Reprocessing

"As Received" $\mathrm{Tm}_{2} \mathrm{O}_{3}$

4-3 Conversion Efficiency of Chemical Reprocessing $\mathrm{Tm}_{2} \mathrm{O}_{3} \rightarrow \mathrm{Tm}_{2} \mathrm{O}_{3}$

4-4 Impurity Levels ( $\mathrm{ppm}$ ) of Iron, Magnesium, Aluminum and Silicon in "As Received", PreCalcined, Calcined $750^{\circ} \mathrm{C}$ and Calcined $950^{\circ} \mathrm{C}$ Powders 
4-5 Sursace Area of $\mathrm{Tm}_{2} \mathrm{O}_{3}$ Powders Calcined at $950^{\circ} \mathrm{C}$ Determined by BET Kitrogen Absorption Method 4-18

4-12 Melting Polnts, Valence state of Cations and Atomic Size Relative to Thulium of 3 Metal oxide Additives

4-14 Net Changes in Levels ( $\mathrm{ppm}$ ) of Aluminum, Iron and Magnesium in $100 \% \mathrm{Tm}_{2} \mathrm{O}_{3}$ and $80 \% \mathrm{Tm}_{2} \mathrm{O}_{3} / 20 \%$ $\mathrm{Yb}_{2} \mathrm{O}_{3}$ Wafers as a Consequence of Aging ${ }^{2}$ or 500 hours at $1600^{\circ} \mathrm{C}$ in a Tungsten Capsule

4-15 Comparison of Bench Mark and Additive Data for Pre and Post Aged $100 \% \mathrm{Tm}_{2} \mathrm{O}_{3}$ 


\section{ABSTRACT}

A study was performed to develop an understanding of the correlation between fuel form stability and exposure environment (temperature and atmosphere). $\quad 100 \% \mathrm{Tm}_{2} \mathrm{O}_{3}, 80 \% \mathrm{Tm}_{2} \mathrm{O}_{3} / 20 \% \mathrm{Yb}_{2} \mathrm{O}_{3}$ and $100 \% \mathrm{Yb}_{2} \mathrm{O}_{3}$ wafers were subjected to aix, dynamic vacuum and static vacuum at temperatures to $2000^{\circ} \mathrm{C}$ for times to 100 hours. Results of these experiments showed the $\mathrm{Tm}_{2} \mathrm{O}_{3} / \mathrm{Yb}_{2} \mathrm{O}_{3}$ cubic structure to be unaffected by elemental levels of iron, aluminum, magnesium and silicon and unaffected by the environmental conditions imposed on the wafers.

A second task emphasised the optimization of the thermal, mechanical and chemical stability of $\mathrm{Tm}_{2} \mathrm{O}_{3}$ fuel forms. Enhancement was sought through process variable optimization and the addition of metal oxides to $\operatorname{Tm}_{2}{ }^{\circ}{ }_{3}$. Process variables studied were chemical processing of "as received" $\operatorname{Tm}_{2} \mathrm{O}_{3}$, calcining temperature, cold pressing pressure, sintering time/temperature/atmosphere and aging. Properties assessed were physical appearance, microstructure, crystaline structure, grain size, lattice parameter, density, chemical purity as they affect "fines" generation upon impact. Results showed the properties of $\mathrm{Tm}_{2} \mathrm{O}_{3}$ to be primarily sensitive to temperature. $1750^{\circ} \mathrm{C}$ was selected as the optimum sintering temperature/time. Enchancement of resistance to fines generation was indicated in post-aged samples.

Three metal oxide additives $\mathrm{CaO}, \mathrm{TiO}_{2}$ and $\mathrm{Al}_{2} \mathrm{O}_{3}$ were studied with the objective of forming a grain boundary precipitate to control fines generation. The presence of $1 \%$ additive was inadequate to depress the melting point of $\mathrm{Tm}_{2} \mathrm{O}_{3}$ or to change the cubic crystalline 
structure of $\mathrm{Tm}_{2} \mathrm{O}_{3} / \mathrm{Yb}_{2} \mathrm{O}_{3} \cdot \mathrm{Tm}_{2} \mathrm{O}_{3} / \mathrm{Yb}_{2} \mathrm{O}_{3}$ wafers containing CaO

developed a grain boundary phase that improved the resistance to fines generation. The presence of $\mathrm{Yb}_{2} \mathrm{O}_{3}$ did not appear to measurably influence behavior. 


\section{SECTION 1}

\section{INTRODUCTION}

A fuel should exhibit mechanical, thermal and chemical stability in normal and accidental environments for time periods consistent with compatibility of containment material and mission duration. The safety design requirements of the fuel vary and depend on whether the application is terrestrial or extraterrestrial. The design specificàtions on fuel stability for space systems are more stringent because the severity of conditions that space missions can encounter during lauch, orbit, reentry and impact are greater than those ordinarily encountered in terrestrial applications. In either case, the first line of defense against potential accident is the fuel form.

The object of this phase of study was a continuation of the thulium oxide fuel characterization study. Primary emphasis was placed on optimization of the thermal, mechanical and chemical stability of thulia fuel forms with respect to operational and safety criteria; this included developing an understanding of the thulium-ytterbium-additive-oxygen systems. Three specific tasks were established to perform the study.

- Material Compatibility Testing

- Eundamental stability

- Mechanical, Thermal and Chemical Stability Study

Results of the materials compatibility testing portion performed under this phase have been included with the prior materials compatibility data and may be found in Part I of this report. 
The object of the fundamental study was the development of an understanding of the correlation between fuel form stability and exposure environment (temperature and atmosphere). Samples with compositions of $100 \% \mathrm{Tm}_{2} \mathrm{O}_{3}, 80 \% \mathrm{Tm}_{2} \mathrm{O}_{3} / 20 \% \mathrm{Yb}_{2} \mathrm{O}_{3}$ and $100 \%$ $\mathrm{Yb}_{2} \mathrm{O}_{3}$ were subjected to three different environments (air, dynamic vacuum and static vacuum) at three temperatures (1450, 1750 and $2000^{\circ} \mathrm{C}$ ) for times to 100 hours. An assessment of stability was obtained from analyses of x-ray diffraction data, microscopic examination of wafers and chemical analysis of selected samples. The chemical analysis also served as a measure of impurity control.

Stability in this study was understood to mean an absence of change in the properties of the test specimen when compared to the reference samples (bench marks). Changes were measured from analysis of data obtained from atomic absorption analysis, $x$-ray diffraction and metallographic observations. The process used for preparing the test specimens was selected on the basis of preliminary observations of the process variable optimization study (1). The environments to which the test coupons were exposed were representative of those to be encountered operationally. Although the times and temperatures do not encompass the most extreme conditions envisionable, they were sufficiently broad to induce changes in the $\mathrm{Tm}_{2} \mathrm{O}_{3}$ wafer. The results and discussion of this work are presented in section 3 .

The object of the mechanical, thermal and chemical stability study task was to assess improvement of mechanical, thermal and chemical stability of $\mathrm{Tm}_{2} \mathrm{O}_{3}$ through:

- Process Variable optimization

- Selective Addition of Metal Oxides

In each task, $\mathrm{Tm}_{2} \mathrm{O}_{3}$ wafers produced were subjected to visual examination, x-ray diffraction, metallography and chemical and fines analysis to obtain the following data points: 


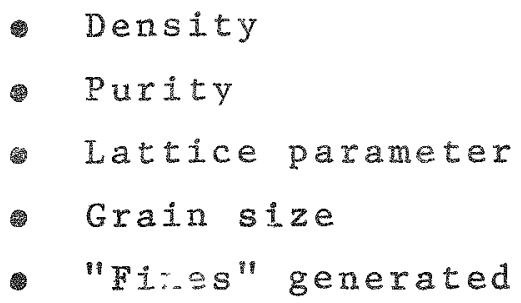

These data points were obtained in each study from both "as sintered" and "aged" wafers. The aging process consisted of exposing wafers encapsulated in tungsten, T-111 and TZM to static vacuum at $1600^{\circ} \mathrm{C}$ for 500 hours. This was followed by a twenty minute rise time to $2000^{\circ} \mathrm{C}$ and a three hour cool period to room temperature.

Stability enhancement was considered to be an improvement in any of the properties of $\mathrm{Tm}_{2} \mathrm{O}_{3}$ directly related to the data points obtained, providing that enhancement in one domain did not produce an unacceptable change in another, e.g., that an increase in grain size did not indirecty result in an increase in generation of fines in the respirable range.

The object of the Process Variable Optimization subtask was to observe the effects on wafer stability when varying several process parameters. These parameters were: precipitating agent used in processing "as received" $\mathrm{Tm}_{2} \mathrm{O}_{3}$, calcining temperature, surface area of calcined powder, method of binder addition, impurity levels of calcined powder, pressing pressure, sintering time, temperature and atmosphere. Ultimately, 54 sets of process variables were evaluated with s sets selected for further testing. Selection of the final process from these five sets was based on "fines" generation only. In light of the test matrix established, this process was considered to produce the most stable $\mathrm{Tm}_{2} \mathrm{O}_{3}$ wafer and was used to produce 30 specimens for further testing by AEC.

The object of the Metal Oxide Additives task was also to measure enhancement of mechanical, thermal and chemical stability, but through the addition of a metal oxide to $\mathrm{Tm}_{2} \mathrm{O}_{3}$ powder prior to pressing and sintering, rather than through the variation of 
several process parameters. The term mechanical strength in this task was interpreted in a different context, and influenced the experimental design and analysis.

Rather than using metal oxide additives that would be soluble in the $\mathrm{Tm}_{2} \mathrm{O}_{3} / \mathrm{Yb}_{2} \mathrm{O}_{3}$ matrix and hopefully improve stability by complement, additives were carefully selected whose properties ensured a high degree of insolubility, preferably precipitating at grain boundaries. The presence of a grain boundary phase would provide a means to absorb the energy created by impact of the fuel that would otherwise promote transgranular cracking. In addition, the additive might be instrumental in controling grain size such that population distribution of fines generated on impact would find the majority of particles equal to or larger than the grain size and fines (particles < 10 microns) much reduced. Such a result would provide a greater safety margin to the designer planning space missions.

Section 4 discusses the basis for selection of additives and the results of the studies. 


\section{SECTION 2}

\section{SUMMARY}

The object of the study was a continuation of the thulium oxide fuel characterization study begun in phases I and II. Primary emphasis was placed on optimization of the thermal, mechanical, and chemical stability of thulia fuel forms with respect to operational and safety criteria; this included developing an understanding of the thulium - ytterbium - additive - oxygen systems. Three specific tasks were established to perform the study.

- Material Compatibility Testing

- Fundamental Stability

- Mechanical. Thermal and Chemical Stability Study

Results of the materials compatibility testing portion performed under this phase have been included with the prior materials compatibility data and may be found in Phase I of this report.

\section{FUNDAMENTAL STABILITY}

$$
100 \% \mathrm{Tm}_{2} \mathrm{O}_{3}, 80 \% \mathrm{Tm}_{2} \mathrm{O}_{3} / 20 \% \mathrm{Yb}_{2} \mathrm{O}_{3} \text { and } 100 \% \mathrm{Yb}_{2} \mathrm{O}_{3} \text { wafers were }
$$
exposed to air, dynamic vacum and static vacuum (tungsten capsules) at temperatures to $2000^{\circ} \mathrm{C}$ for times to 100 hours. The stability of the $\mathrm{Tm}_{2} \mathrm{O}_{3}-\mathrm{Yb}_{2} \mathrm{O}_{3}$ cubic structure was unaffected by the elemental levels of iron, aluminum, silicon and magnesjum present in the wafers and unaffected by the environmental conditions imposed on the wafers. Vapor phase mass transport was observed in static vacuum tests for al1 three compositions. Dimensional swelling developed in several wafers including $100 \% \operatorname{Tm}_{2} \mathrm{O}_{3}$ and may be a potential problem because the behavioral pattern is not known. 
MECHANICAL, THERMAL AND CHEMICAL STABILITY ENHANCEMENT

Enhancement of the mechanical, thermal and chemical stability of $\mathrm{Tm}_{2} \mathrm{O}_{3}$ was sought as the end product of

- Process Variable Optimization

- Selective Addition of Metal Oxides

Enhancement was defined as improvement in the properties of the end products of process variable optimization and selective addition of metal oxides when compared with bench mark properties. Properties investigated were:

- Physical Appearance

- Crystaline structure and Lattice Parameter

- Grain Size

- Microstructural Appearance

- Sintered Density

- Chemical Purity

- Impact Resistance to Fines Generation

$\mathrm{Tm}_{2} \mathrm{O}_{3}$ was exposed to the following process variables:

- Chemical Processing

- Calcining Temperature

- Pressing Pressure

- Sintering Time/Temperature/Atmosphere

- Aging

- Metal Oxide Additives

Enhancement was assessed from macroscopic, microscopic, $x-r a y$ diffraction, electron microprobe, chemical and impact-particle sizing analyses; density, grain size, surface area and lattice parameter measurements.

\section{Process Variable Optimization}

Four methods of chemical processing evaluated with respect to conversion efficiency, purity and surface area of product and bulk sintered density of $\mathrm{Tm}_{2} \mathrm{O}_{3}$ wafers prepared from these powders provided two final chemical processes for continued study. The 
two processes selected were: (1) a homogeneous precipitation method utilizing urea as a precipitating agent, and (2) a heterogeneous precipitation method utilizing ammonium oxalate as a precipitating agent. Conversion efriciencies (oxide to oxide) on batches utilizing $500 \mathrm{gm}$ of starting oxide were consistently an acceptable $90 \%$ or better. Wafers prepared from powders produced from these two processes achieved sintered densities to $90 \%$ theoretical.

54 sets of processing conditions including these two methods of processing "as received" $\mathrm{Tm}_{2} \mathrm{O}_{3}$ were analyzed with respect to cold pressing of wafers at $4.5,15$ and 29 tsi and sintering at $1450^{\circ} \mathrm{C}$ and $1750^{\circ} \mathrm{C}$ for times to 32 hours in air, vacuum and hydrogen. Results showed the cubic $\operatorname{Tm}_{2} \mathrm{O}_{3}$ crystalline structure to be insensitive to this broad processing matxix, thereby providing flexibility in selection of fabrication conditions.

Chemical processing, pressing pressure, sintering, atmosphere and time were a secondary influence on levels of impurity, sintered density, grain size and "fines" generation. The major influence on these properties was temperature. $1750^{\circ} \mathrm{C}$ was selected as the optimum temperature for sintering $\mathrm{Tm}_{2} \mathrm{O}_{3}$ wafers. At this temperature, bulk sintered densities of $95 \%$ of theoretical or better were achievable with many sets of process conditions and populations of particles of less than 149 microns in size were as low as $0.2 \%$ of total weight. Five sets of process conditions representing the optimum with respect to sintered density and small particle generation were selected from several possible sets for studying the effects of aging. The processes were:

- Ammonium oxalate $-* 1750^{\circ} \mathrm{C}, 29 \mathrm{tsi,} 6$ hovrs, hydrogen

- Ammonium oxalate $-1750^{\circ} \mathrm{C}, 29$ tsi, 8 hours, vacuum

- Ammonium oxalate - $1750^{\circ} \mathrm{C}, 15 \mathrm{tsi}, 6$ hours, hydrogen

- Ammonium oxalate - $1750^{\circ} \mathrm{C}, 4.5 \mathrm{tsi}, 4$ hours, vacuum

- Urea - $* 1750^{\circ} \mathrm{C}, 4.5$ tsi, 8 hours, vacuum

* Selected for preparing $80 \% \mathrm{Tm}_{2} \mathrm{O}_{3} / 20 \% \mathrm{Yb}_{2} \mathrm{O}_{3}$ wafers.

Wafers prepared by these processes were encapsulated in TZM, T-111 and tungsten, aged for 500 hours at $1600^{\circ} \mathrm{C}$ and given a thermal 
spike to $2000^{\circ} \mathrm{C}$ over a 20 minute period. Evidence of vapor phase mass transport was observed in all capsules. The absence of infused elements related to the metal matrix and of evidence of chemical reaction with the encapsulant support the excellent chemical stability of $\mathrm{Tm}_{2} \mathrm{O}_{3}$. Impact resistance of aged wafers as measured by fines generated was superior to preaged wafers. Within the test matrix, particles of < 10 micron size were as 10 as $0.04 \%$ of total weight. Populations of particles in this size range were observed to correlate with initial pressing pressure. It was concluded that $\mathrm{Tm}_{2} \mathrm{O}_{3} / \mathrm{Yb}_{2} \mathrm{O}_{3}$ has excellent thermal, chemical and mechanical stability when exposed to nominal operational mission conditions and that resistance to fines generation was enhanced by the aging process. Metal Oxide Additives - A Means To Product Stability Enhancement

Stability enhancement was interpreted in this study as an enhancement of resistance to fines generation through the use of additives. Criteria for selection of metal oxide additives were established to provide the greatest potential for grain boundary precipitation of the additive thereby encouraging fracture to follow grain boundaries rather than propagating through the grains. Atomic size, valence state of cation, melting point, additive concentration and radiation contribution were the criteria evaluated. Calcium oxide $(\mathrm{CaO})$, aluminum oxide $\left(\mathrm{Al}_{2} \mathrm{O}_{3}\right)$ and titanium dioxide $\left(\mathrm{TiO}_{2}\right)$ were selected.

The behavior of three additive metal oxides suggest the correctness of the original selection criteria as each additive proved to be insoluble in the $\mathrm{Tm}_{2} \mathrm{O}_{3} / \mathrm{Yb}_{2} \mathrm{O}_{3}$ matrix and did not effect the crystalline structure or melting point of $\mathrm{Tm}_{2} \mathrm{O}_{3} / \mathrm{Yb}_{2} \mathrm{O}_{3}$. The original rationale, the presence of a grain boundary phase that would provide an alternate means of dissipating the kinetic energy of impact so as to reduce transgranular cracking, was also successfully achieved by means of CaO addition. This additive produced a grain boundary phase that reduced the particle population in the $10-149 \mu$ range and proved to be a sintering aid as we11.

Comparison of additives with bench marks suggested that mechanical stability was improved to some degree with additives and 
offered potentially greater enhancement in the case of calcium oxide. The presence of $\mathrm{Yb}_{2} \mathrm{O}_{3}$ did not appear to influence behavior in any measurable way.

$\operatorname{Tm}_{2} \mathrm{O}_{3}$ possesses excellent thermal, chemical and mechanical stability by vixtue of the insensitivity of the cubic structure to environmental conditions, process variables, compatibility couples and the presence of $\mathrm{Yb}_{2} \mathrm{O}_{3}$. Avaliability of raw material, ease and reproducibility of fabrication; and activation provide a means to achieve a relatively low cost fuel. Excellent containment, characteristics chemical inertness and thermal stability provide a high margin of safety for operational applications and recommend $\mathrm{Tm}_{2} \mathrm{O}_{3}$ as the fuel form of choice for short term mission applications. 


\author{
SECTION 3 \\ FUNDAMENTAL STABILITY STUDY
}

\title{
3.1 OBJECTIVE
}

The objective of the fundamental stability study was to develop an understanding of the correlation between fuel form stability and exposure environment (temperature and atmosphere). Samples were prepared and analyzed to determine the possible loss of oxygen as a function of time, temperature and atmosphere (air, static vacuum and dynamic vacuum) and to assess the effects of such oxygen loss on the structure of $\mathrm{Tm}_{2} \mathrm{O}_{3}-\mathrm{Yb}_{2} \mathrm{O}_{3}$. Controls were used to establish reference properties. The test matrix appears in Table $3-1$.

The impurity contents of samples were measured before and after testing to determine the effects of impurity content and to measure posible contamination diring test. Impurity contents were determined by atomic absorption spectrophotometry techniques. Specifically, iron, aluminum, magnesium and silicon levels and changes thereof were determined.

The oxygen content of the samples was to be measured before and after testing by means of an inert gas analyzer. The possible effects of oxygen loss on the structure of the $\operatorname{Tm}_{2} \mathrm{O}_{3} \mathrm{Yb}_{2} \mathrm{O}_{3}$ were determined by $x$-ray diffraction. Metallographic analyses were used to determine the morphology of possible new phases and other effects such as porosity and microcracking.

\subsection{EXPERIMENTAL}

Samples consisted of wafers approximately 0.6 inch in diameter and approximately 0.06 inch thick. Wafers were fabricated from 
TABLE $3-1$

TEST MATRIX FOR UNDAMENTAL STABILITY STUDY AND PRODUCT

POST ENVIRONMENTAL EXPOSURE ANALYSES

(MATRIX APPLIES TO $\operatorname{Tm}_{2} \mathrm{O}_{3}, \mathrm{Tm}_{2} \mathrm{O}_{3}+20 \% \mathrm{Yb}_{2} \mathrm{O}_{3}$, and $\mathrm{Yb}_{2} \mathrm{O}_{3}$ )

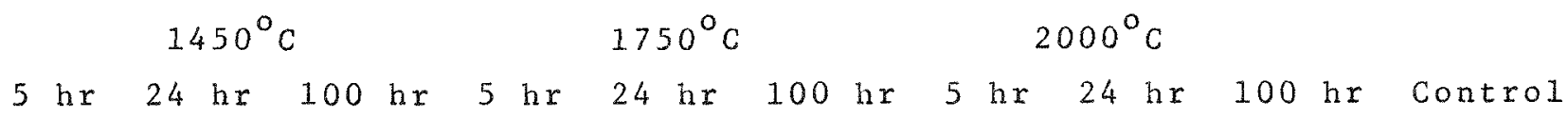

Testing Atmosphere

Air

Dynamic Vacuum

$\mathrm{x}^{*} \mathrm{x} \quad \mathrm{x}$

Static Vacuum

\section{Analyses}

1. Purity (Emission Spectroscopy or AA)

2. Metal/Oxygen Ratio

$x$

$\mathrm{x}$

$x$

$\begin{array}{ll}\mathrm{x} & \mathrm{x} \\ \mathrm{x} & \mathrm{x}\end{array}$

$\mathrm{x}$

$\mathrm{x}$

$\mathrm{x}$

3. Phase Determination, morphology, porosity and micro-

structure
a. X-ray diffraction

$\mathrm{x}$

b. Meta1lography

$\mathrm{x}$

$\begin{array}{lllll}\mathrm{x} & \mathrm{x} & \mathrm{x} & \mathrm{x} & \mathrm{x} \\ \mathrm{x} & \mathrm{x} & \mathrm{x} & \mathrm{x} & \mathrm{x}\end{array}$

*x-indicates samples exposed and/or analysed under conditions specified 
"as received" $\mathrm{Tm}_{2} \mathrm{O}_{3}$ and $\mathrm{Yb}_{2} \mathrm{O}_{3}$ powder reprocessed using the urea precipitation method developed in another phase of this work (see Section 4.2 of this report) and subsequent 1 y calcined at $950^{\circ} \mathrm{C}$. Mixed oxide powder was prepared by mixing appropriate amounts of $\mathrm{Tm}_{2} \mathrm{O}_{3}$ and $\mathrm{Yb}_{2} \mathrm{O}_{3}$ prior to the addition of $4 \%$ Carbowax $4000^{*}$ as binder. Powders were pressed at 29 tsi and sintered in air at $1450^{\circ} \mathrm{C}$ for 17 hours subsequent to binder burn off treatment at $325^{\circ} \mathrm{C}$. Bulk sintered densities were obtained by weighing each sample and calculating the volume from micrometer measurements. A control. representative of each composition was retained for reference.

Prior to environmental exposure, wafers to experience a static vacuum environment were placed in tungsten capsules and sealed by electron beam welding. All capsules were leaked checked for integrity of the weldment prior to test.

The oxygen content of wafers was measured by inert gas analyser techniques. The data obtained on test specimens as we 11 as that on the standards were not reproducible and therefore were not included in this study.

\subsection{RESULTS AND DISCUSSION}

A summary of the experimental data may be found in Table 3.2 . A simple numerical code was used to denote the degree of change in appearance of the samples; the key is given below.

$$
\begin{aligned}
& \text { 1. No change } \\
& \text { 2. Minor change } \\
& \text { 3. Major change }
\end{aligned}
$$

3.3.1 $100 \% \mathrm{Tm}_{2} \mathrm{O}_{3}, 80 \% \mathrm{Tm}_{2} \mathrm{O}_{3} / 20 \% \mathrm{Yb}_{2} \mathrm{O}_{3}, 100 \% \mathrm{Yb}_{2} \mathrm{O}_{3}$ EXPOSED TO AIR AND DYNAMIC VACUUM AT $1450^{\circ} \mathrm{C}$ FOR 5,24 and 100 HOURS

Wafers of both compositions exposed to air were off-white in color. $100 \% \mathrm{Tm}_{2} \mathrm{O}_{3}$ and $80 \% \mathrm{Tm}_{2} \mathrm{O}_{3} / 20 \% \mathrm{Yb}_{2} \mathrm{O}_{3}$ in vacuum were pale green. Vacuum treated wafers exhibited somewhat more shrinkage, primarily diametric shrinkage than those exposed to air and as a result, the

*Carbowax 4000 is a registered trademark of the Union Carbide Corporation. 
final bulk sintered densities were slightly higher for comparable test times. The impurity levels after the 100 hours exposure were not significantly different from the controls except a slight decrease in iron level in the $100 \% \mathrm{Yb}_{2} \mathrm{O}_{3}$ sample treated in vacuum. The silicon levels throughout these experiments were many times higher (by two orders of magnitude) than the controls levels and very erratic. This was attributed to the method of sample preparation required to dissolve the sample; it was necessary to grind extensively and subsequently treat with strong nitric acid for many hours. For this reason, silicon data points would not be considered meaningful although silicon levels might be a factor.

X-ray diffraction patterns were typically those of the controls; no change in the lattice parameters as calculated from these patterns was observed.

Metallographic examination of the 100 hour exposure test specimens showed varying degrees of cracking that was typical of high pressure - cold pressing methods. The micro-structure appeared similar to the controls, with the exception of the $100 \% \mathrm{Yb}_{2} \mathrm{O}_{3}$ sample exposed in air, in which a different porosity behavior was noted from the control. All samples appeared to have a fine grained texture. Figures $3-1,3-2$ and $3-3$ are micrographs of the controls and $1450^{\circ} \mathrm{C}$ treated specimens.

$3.3 .2100 \% \mathrm{Tm}_{2} \mathrm{O}_{3}, 80 \% \mathrm{Tm}_{2} \mathrm{O}_{3} / 20 \% \mathrm{Yb}_{2} \mathrm{O}_{3}, 100 \% \mathrm{Yb}_{2} \mathrm{O}_{3}$ EXPOSED TO STATIC AND DYNAMIC VACUUM AT $1750^{\circ} \mathrm{C}$ FOR 5,24 and 100 HOURS

\section{Static Vacuum}

$100 \% \mathrm{Tm}_{2} \mathrm{O}_{3}$ and $80 \% \mathrm{Tm}_{2} \mathrm{O}_{3} / 20 \% \mathrm{Yb}_{2} \mathrm{O}_{3}$ wafers treated in a static environment were pale green, while $100 \% \mathrm{Yb}_{2} \mathrm{O}_{3}$ wafers were white. Some areas of enhanced translucency were observed primarily at edges and cracks. No bonding of the ceramic to the encapsulant was observed, however, a very small amount of vapor deposited crystals on the tungsten surface was noted in each composition. The wafers were all intact, but laminations were present at the edges.

$$
X \text {-ray diffraction patterns were again typically those of }
$$
the controls; the same being true for lattice parameters calculated for the $\mathrm{x}$-ray data. The iron content increased for $100 \% \mathrm{Tm}_{2} \mathrm{O}_{3}$ but 
SANDERS NUELEAT COAPORATION

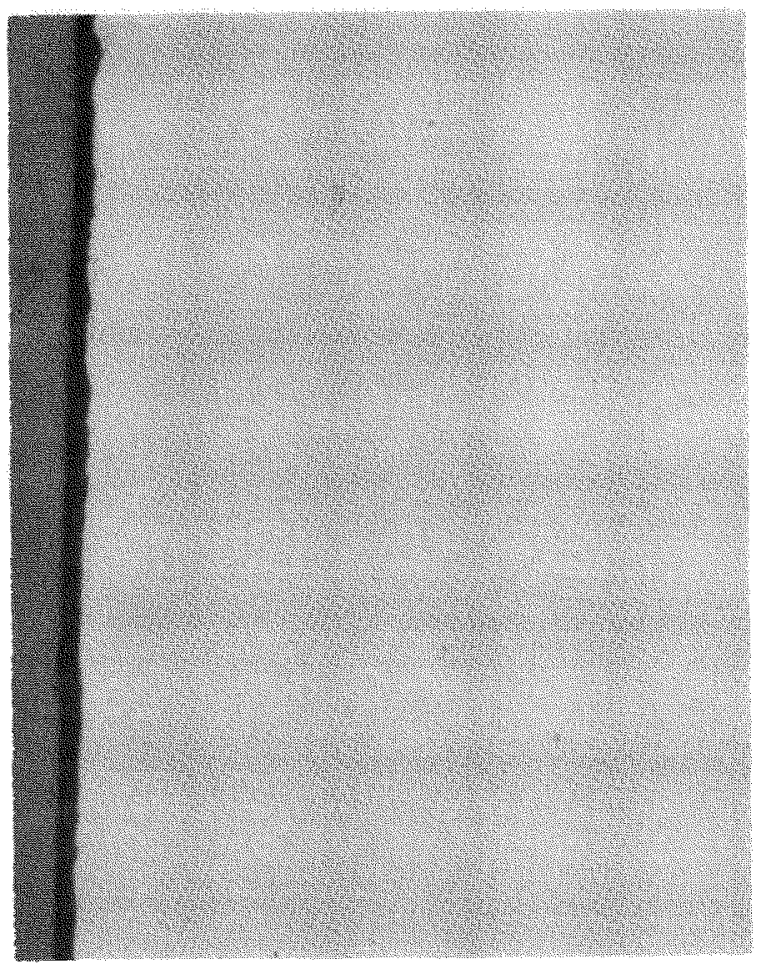

A. $100 \% \operatorname{Tm}_{2} \mathrm{O}_{3}$

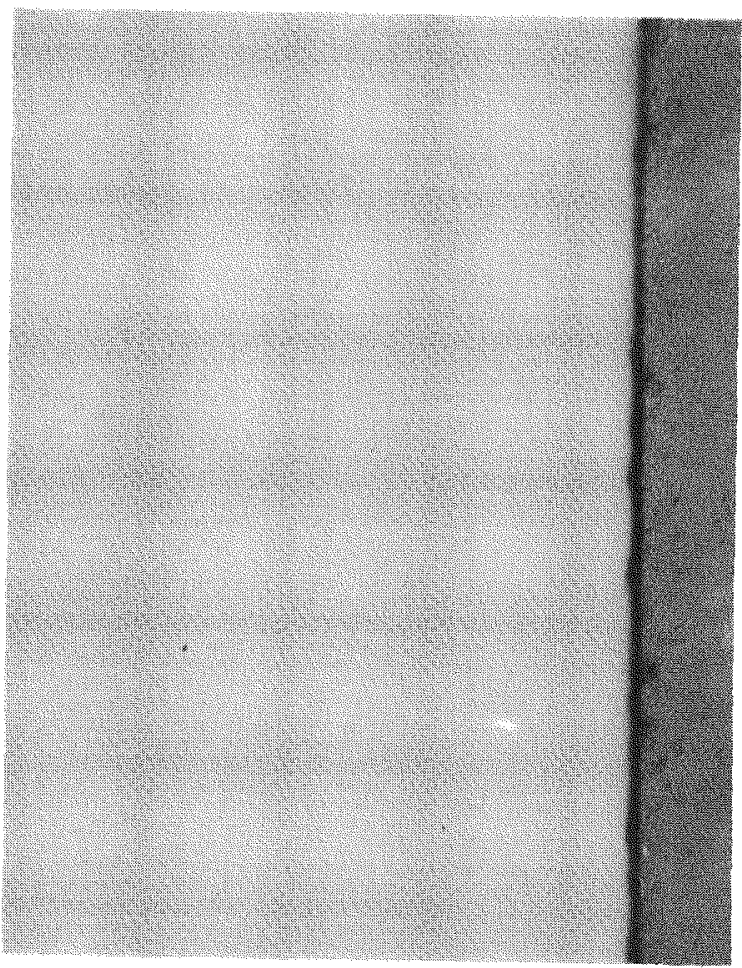

B. $80 \% \operatorname{Tm}_{2} \mathrm{O}_{3} / 20 \% \mathrm{Yb}_{2} \mathrm{O}_{3}$

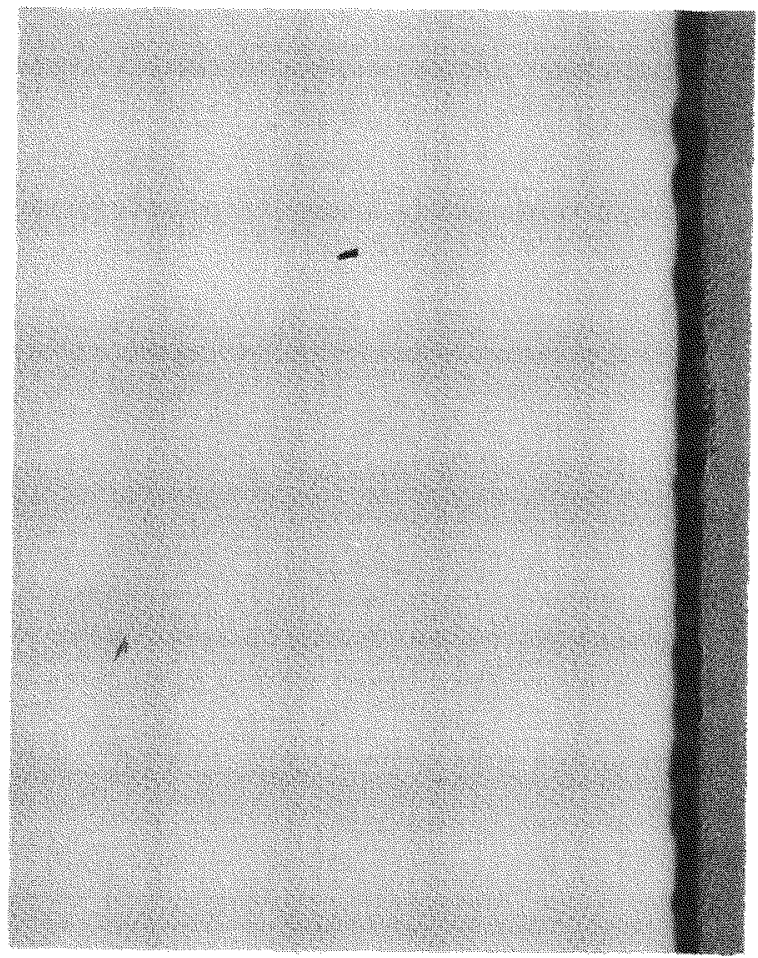

C. $100 \% \mathrm{Yb}_{2} \mathrm{O}_{3}$

Figure 3-1 Air, $1450^{\circ} \mathrm{C}, 17$ Hours (100X). 

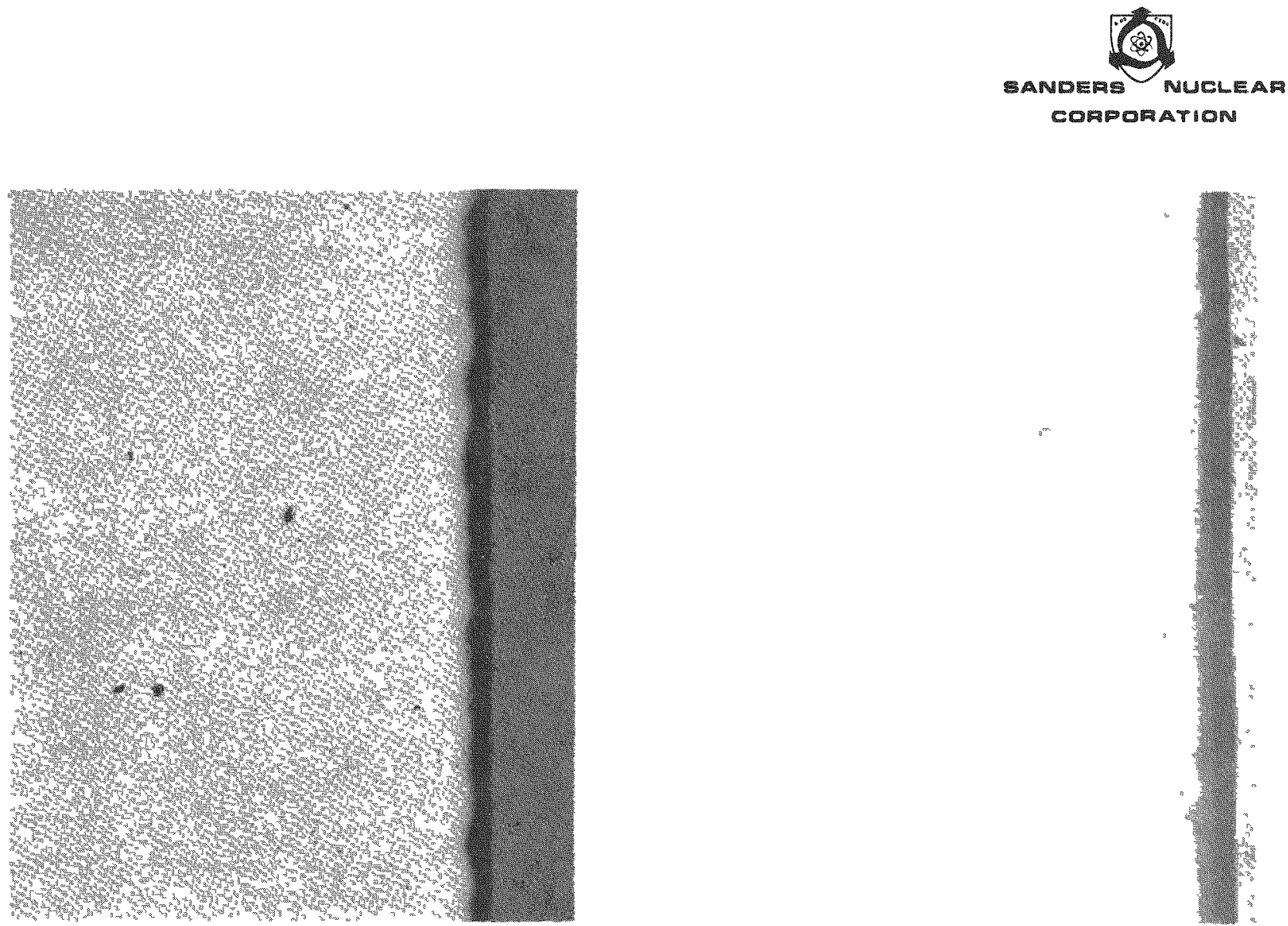

A. $100 \% \operatorname{Tm}_{2} \mathrm{O}_{3}$

B. $80 \% \operatorname{Tm}_{2} \mathrm{O}_{3} / 20 \% \mathrm{Yb}_{2} \mathrm{O}_{3}$

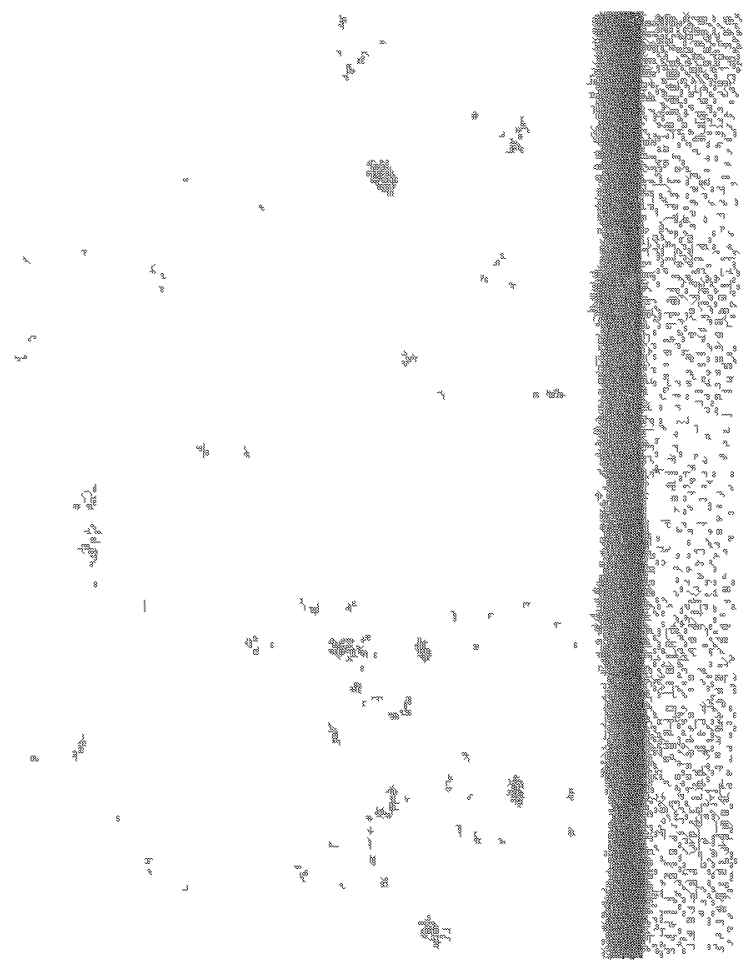

C. $100 \% \mathrm{Yb}_{2} \mathrm{O}_{3}$

Figure 3-2 Air, $1450^{\circ} \mathrm{C}, 100$ Hours (100X). 


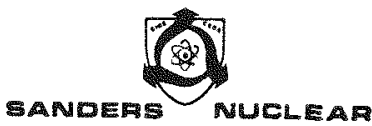

COMPOAATION
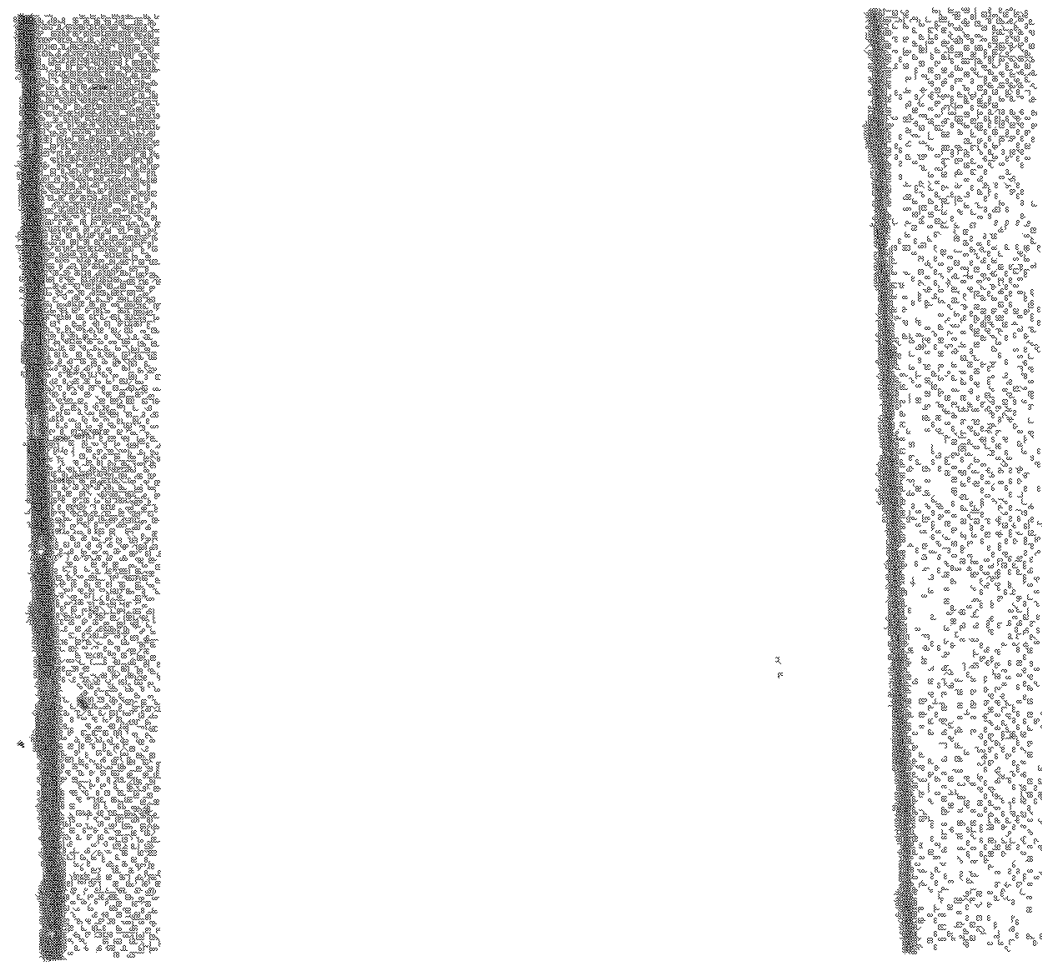

A. $100 \% \operatorname{Tm}_{2} \mathrm{O}_{3}$

B. $80 \% \operatorname{Tm}_{2} \mathrm{O}_{3} / 20 \% \mathrm{Yb}_{2} \mathrm{O}_{3}$

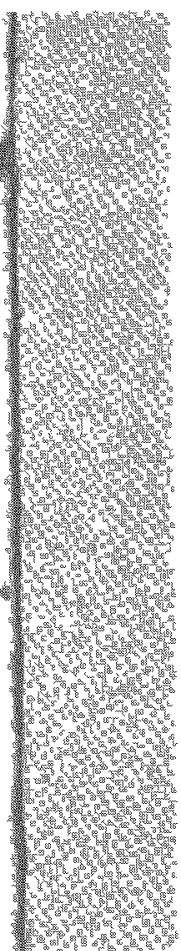

C. $100 \% \mathrm{Yb}_{2} \mathrm{O}_{3}$

Figure 3-3 Dynamic Vacuum, $1450^{\circ} \mathrm{C}, 100$ Hours (100X). 
decreased for $100 \% \mathrm{Yb}_{2} \mathrm{O}_{3}$ in each comparative time frame. Net changes in magnesium and aluminum content were generally small and erratic.

Figures 3-4 a, b, and $c$ show the microstructure of wafers treated for 100 hours. Appearance of individual grains, in all compositions, attested to additional grain growth at this timetemperature condition over that observed at $1450^{\circ} \mathrm{C} . \quad 80 \%^{\mathrm{Tm}} \mathrm{O}_{3} / 20 \%$ $\mathrm{Yb}_{2} \mathrm{O}_{3}$ and $100 \% \mathrm{Yb}_{2} \mathrm{O}_{3}$ wafers contained large voids that caused some swelling, otherwise, high degree of density was observed. The surfaces were irregular and showed evidence of behavior of selective surfaces vaporization. Enhanced translucency at surface and laminar crack areas was again observed. Laminations were extensive in $100 \% \mathrm{Yb}_{2} \mathrm{O}_{3}$ wafers. No insoluble phases were observed.

\section{Dymamic Vacuum}

The observations noted above for static vacuum apply equally well to the dynamic vacuum environment with some exceptions. The microstructure did not exhibit the same population of individual transparent grains observed in the static vacuum environment (Figure $3-5$ a, b, and c). $100 \% \mathrm{Tm}_{2} \mathrm{O}_{3}$ (Figure $3-5$ a) shows very few of these grains, but yet the material appears very dense. No insuluble phases were observed and the diffraction patterns were the same as the controls.

The surface of the $100 \% \mathrm{Yb}_{2} \mathrm{O}_{3}$ wafer was very irregular and characteristic of vaporization. The thickness had been reduced and after 100 hours, approximately a $30 \%$ weight reduction had resulted.

3.3.3 $100 \% \mathrm{Tm}_{2} \mathrm{O}_{3}=80 \% \mathrm{Tm}_{2} \mathrm{O}_{3} / 20 \% \mathrm{Yb}_{2} \mathrm{O}_{3}$ AND $100 \% \quad \mathrm{Yb}{ }_{2} \mathrm{O}_{3}$ EXPOSED TO STATIC AND DYNAMIC VACUUM AT $2000^{\circ} \mathrm{C}$ FOR 5,24 AND 100 HOURS

\section{Static Vacuum}

Wafers exposed in a static vacuum environment were not broken during test, nor did the ceramic bond to the metal capsule. Three had changed color; the $100 \% \quad \mathrm{Tm}_{2} \mathrm{O}_{3}$ wafer was black after 5 hours exposure and the $80 \% \mathrm{Tm}_{2} \mathrm{O}_{3} / 20 \% \mathrm{Yb}_{2} \mathrm{O}_{3}$ and $100 \% \mathrm{Yb} \mathrm{O}_{3}$ wafers were purple after 100 hours. Vapor deposited crystals were observed 


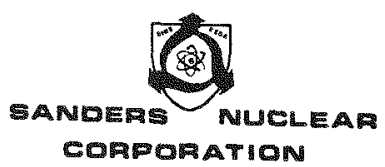

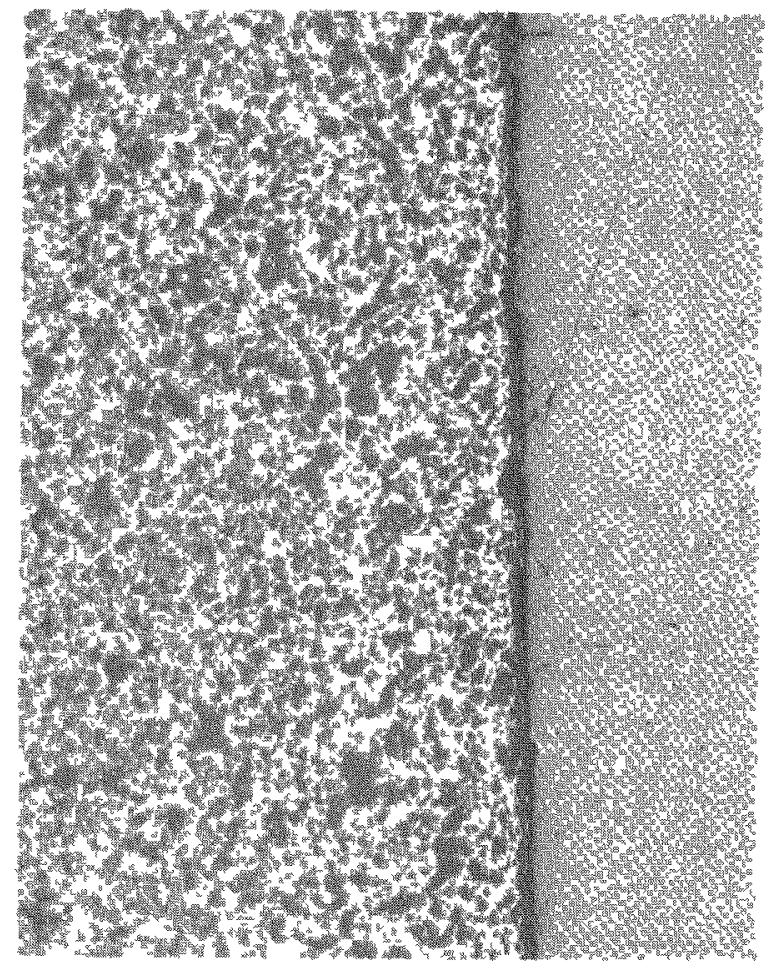

A. $100 \% \operatorname{Tm}_{2} \mathrm{O}_{3}$

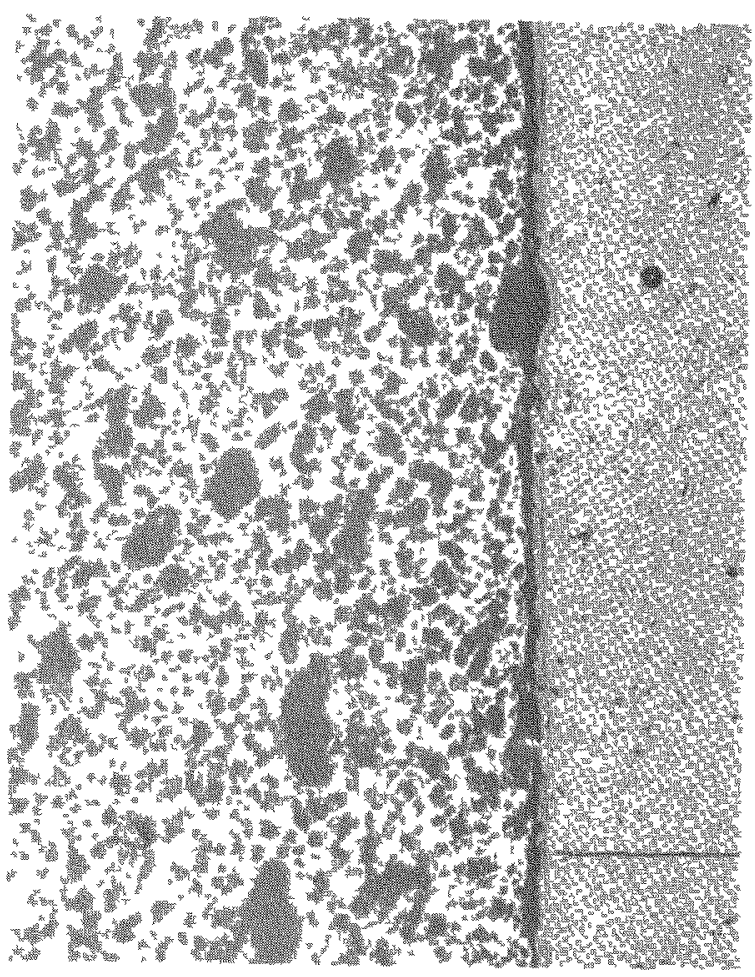

\section{B. $80 \% \mathrm{Tm}_{2} \mathrm{O}_{3} / 20 \% \mathrm{Yb}_{2} \mathrm{O}_{3}$}

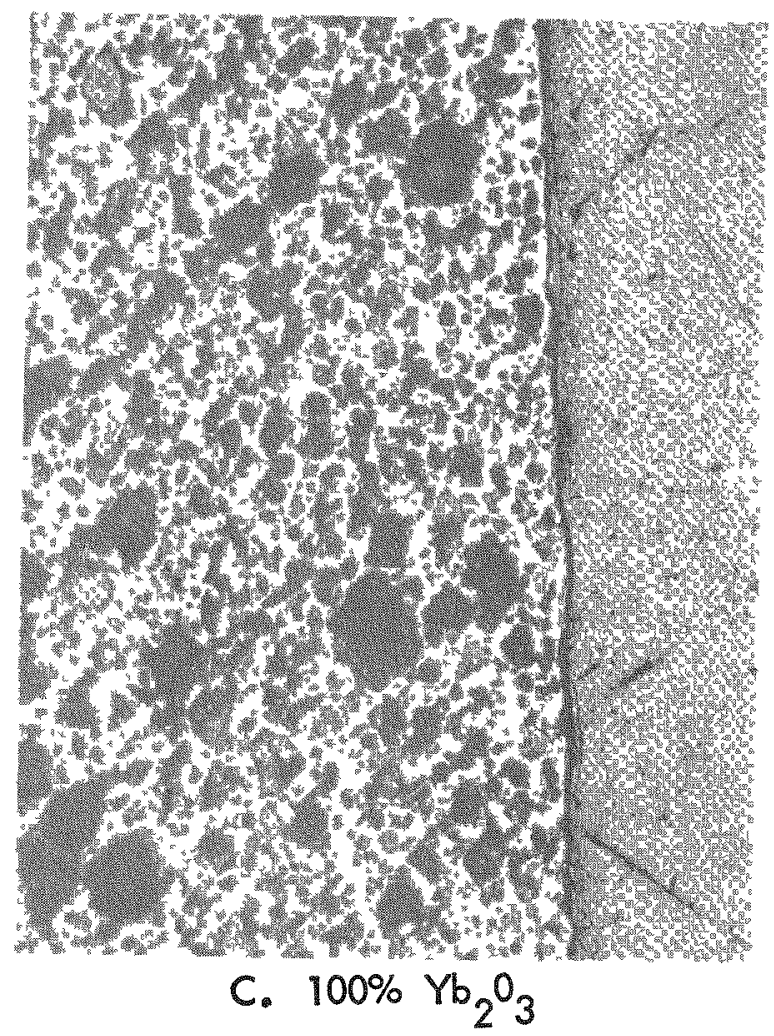

Figure 3-4 Static Vacuum, $1750^{\circ} \mathrm{C}, 100$ Hours (100X). 

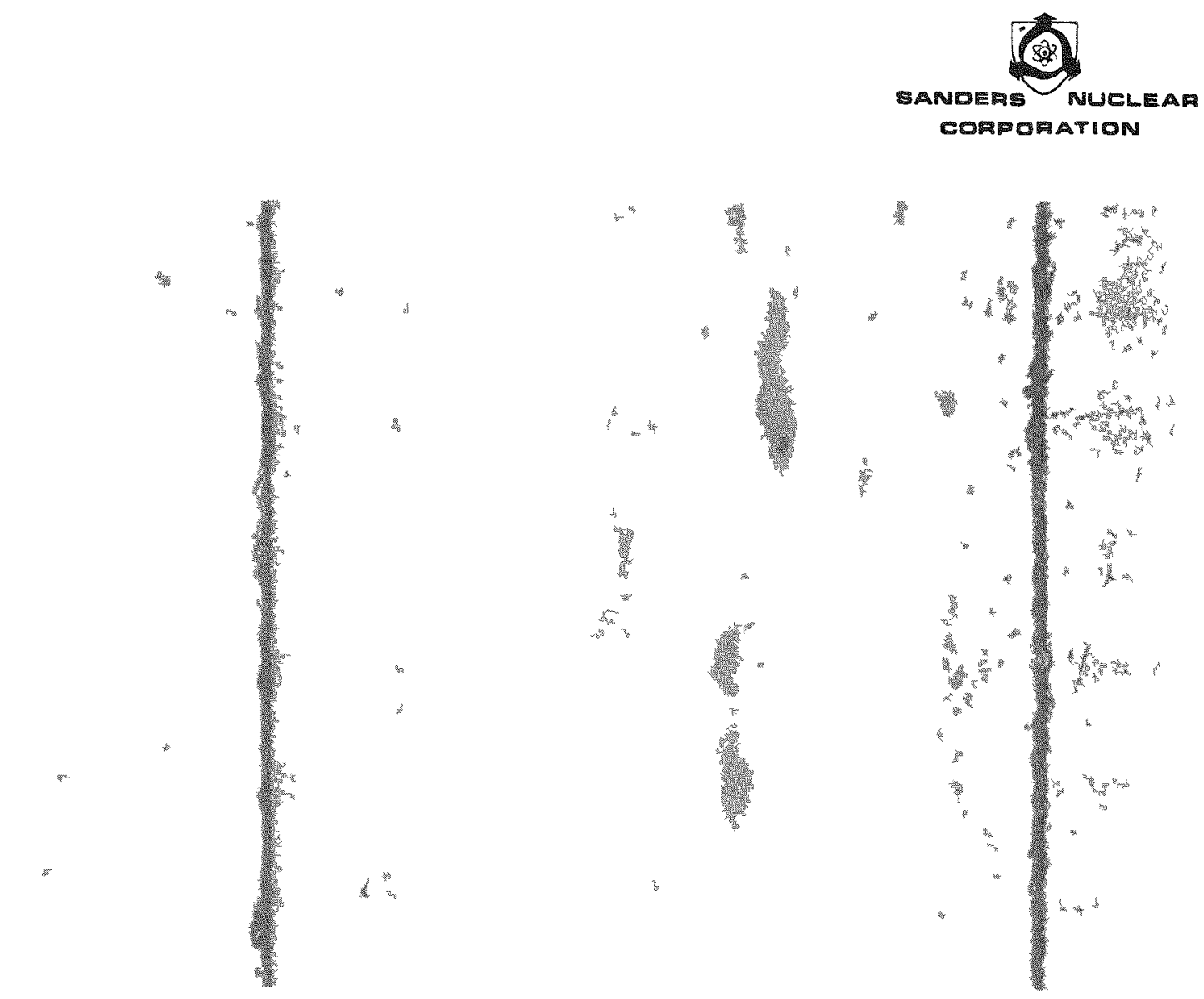

A. $100 \% \operatorname{Tm}_{2} \mathrm{O}_{3}$

B. $80 \% \operatorname{Tm}_{2} \mathrm{O}_{3} / 20 \% \mathrm{Yb}_{2} \mathrm{O}_{3}$

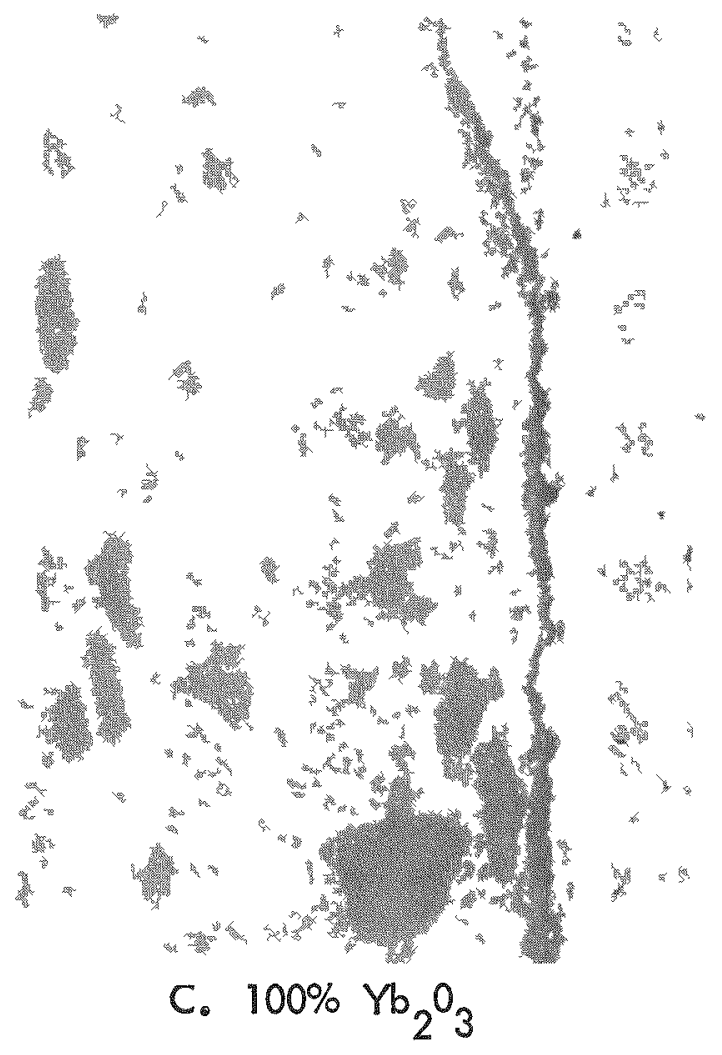

Figure 3-5 Dynamic Vacuum, $1750 \mathrm{C}, 100$ Hours (100X). 
in each specimen capsule at 100 hours increasing in quantity with ytterbium content. The $100 \% \mathrm{Yb}_{2} \mathrm{O}_{3}$ wafer gave up approximately $50 \%$ of its mass in this manner (Figure 3-6). Laminations were observed in a11 wafers, but were more severe for the $100 \% \mathrm{Yb}_{2} \mathrm{O}_{3}$.

Elemental levels of iron decreased with differences in loss being a function of increasing ytterbium content. Changes in levels of aluminum and magnesium were insensitive to environment. X-ray diffraction patterns obtained on wafers were typical of the controls. Lattice parameters calculated from the patterns were also in good agreement with control values. In the case of $100 \% \mathrm{Yb}_{2} \mathrm{O}_{3}$, the $\mathrm{x}-\mathrm{ray}$ pattern of the crystals deposited on the tungsten was not that of $\mathrm{Yb}_{2} \mathrm{O}_{3}$ and was not identified. X-ray patterns of crystals deposited in the $100 \% \mathrm{Tm}_{2} \mathrm{O}_{3}$ and $80 \% \mathrm{Tm}_{2} \mathrm{O}_{3} / 20 \% \mathrm{Yb}_{2} \mathrm{O}_{3}$ cases were not obtained because of insufficient material.

The microstructures of wafer specimens are shown in Figures 3-7 to 3Considerable increase in grain size was observed at $2000^{\circ} \mathrm{C}$ with some grain boundary definition appearing. Particularly, large growth was observed in the $80 \% \mathrm{Tm}_{2} \mathrm{O}_{3} / 20 \% \mathrm{Yb}_{2} \mathrm{O}_{3}$ wafer where some grains were 700 microns in size after 100 hours. Translucency was generally enhanced throughout, the bodies becoming transparent in many areas. The bodies appeared to be quite dense. No Ensoluble phases were observed. The surface of the $100 \% \mathrm{Yb}_{2} \mathrm{O}_{3}$ sample (Figure $3-9)$ shows the effect of selective vaporization.

\section{Dynamic Vacuum}

Wafers exposed to dynamic vacuum for 5, 24 and 100 hours did not change color. Laminations could be observed macroscopically particularly with the $100 \% \mathrm{Yb}_{2} \mathrm{O}_{3}$ wafers. The wafers were intact with the exception of the 100 hour $-100 \% \mathrm{Yb}_{2} \mathrm{O}_{3}$ wafex which had completely vaporized. The surfaces were irregular and swelling was again observed in wafers containing $\mathrm{Yb}_{2} \mathrm{O}_{3}$ at 5 and 24 hours. (See Table 3-3).

Iron levels were essentially the same as those reported for $1750^{\circ} \mathrm{C}$ dynamic vacuum and had the same behavioral pattern. The net changes for aluminum and magnesium were again without apparent 


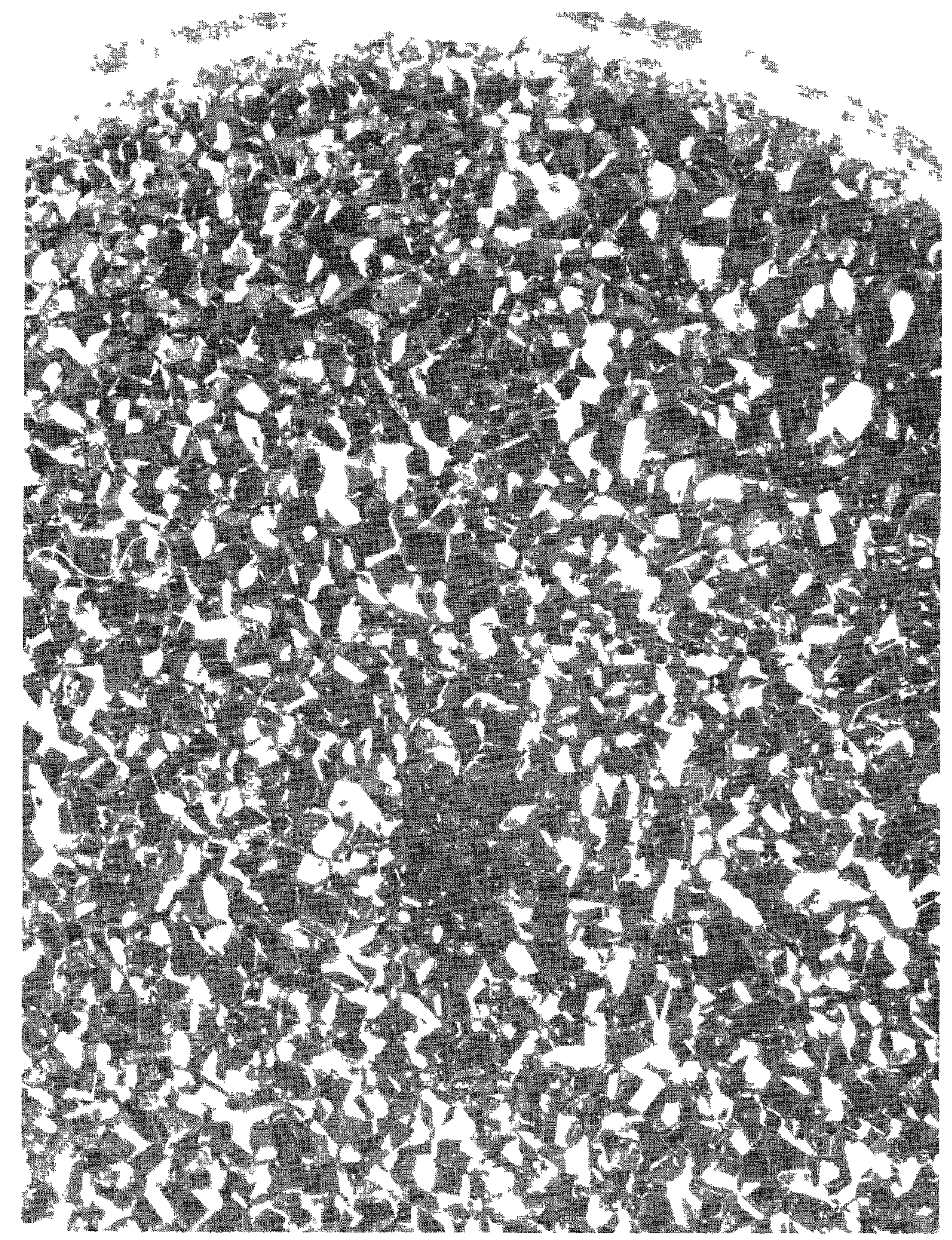

Figure 3-6 Vapor Deposited Crystals on Tungsten Capsules From $100 \% \mathrm{Tm}_{2} \mathrm{O}_{3}$ Wafer. 


\section{(8) \\ SAMDERS NUCLEAF COPIOAATION}

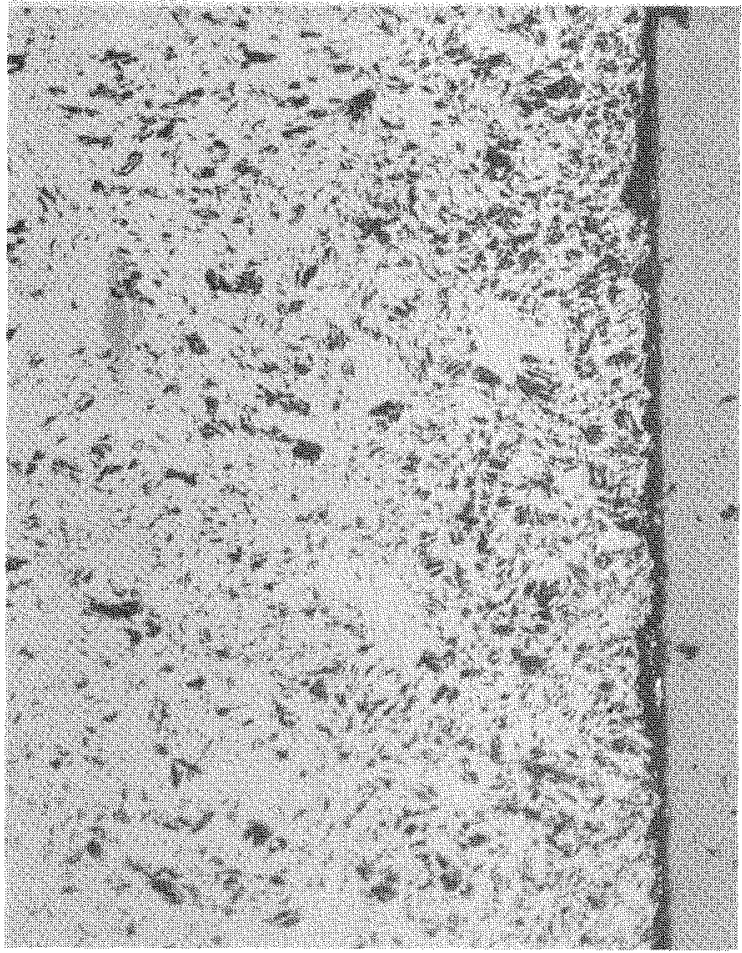

A. $100 \% \operatorname{Tm}_{2} \mathrm{O}_{3}$

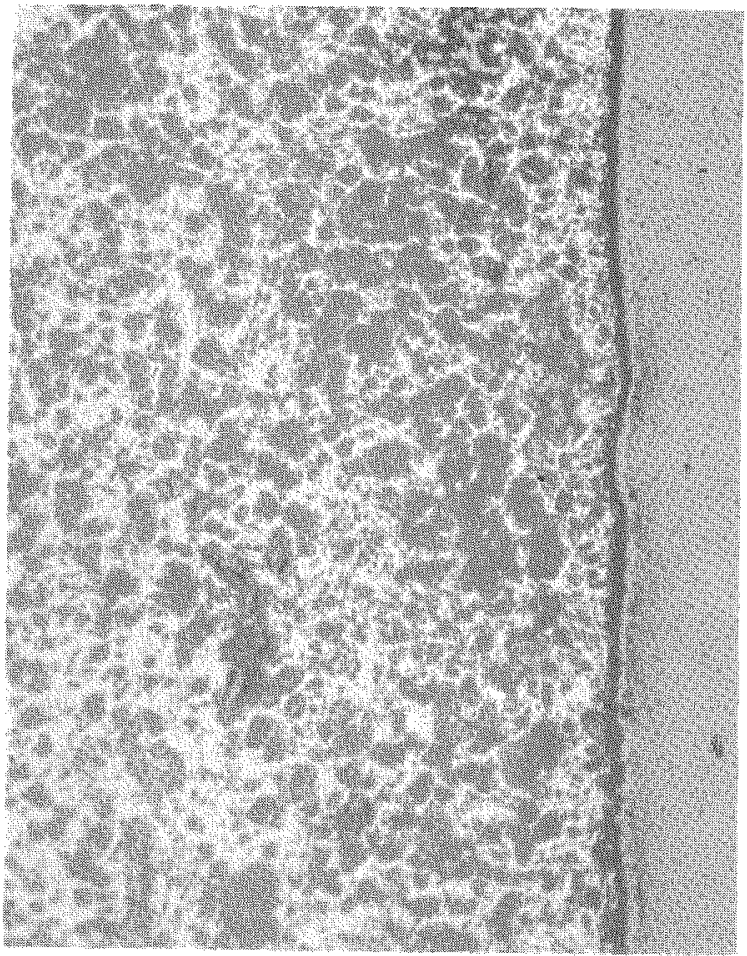

B. $80 \% \operatorname{Tm}_{2} \mathrm{O}_{3} / 20 \% \mathrm{Yb}_{2} \mathrm{O}_{3}$

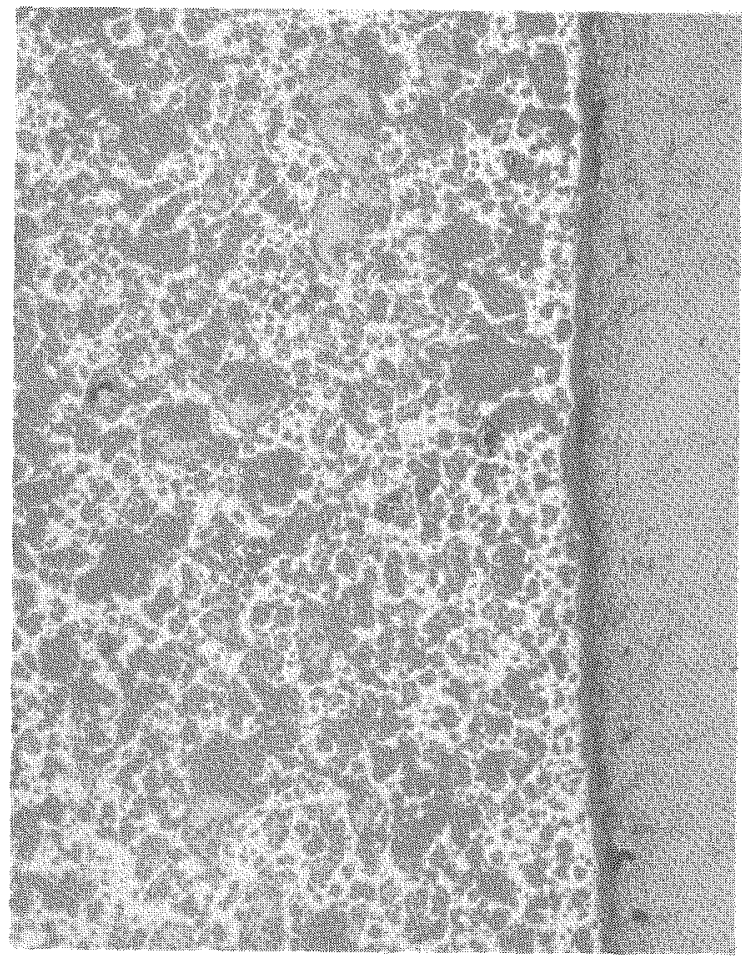

\section{C. $100 \% \mathrm{Yb}_{2} \mathrm{O}_{3}$}

Figure 3-7 Static Vacuum, $2000^{\circ} \mathrm{C}, 5$ Hours (100X). 

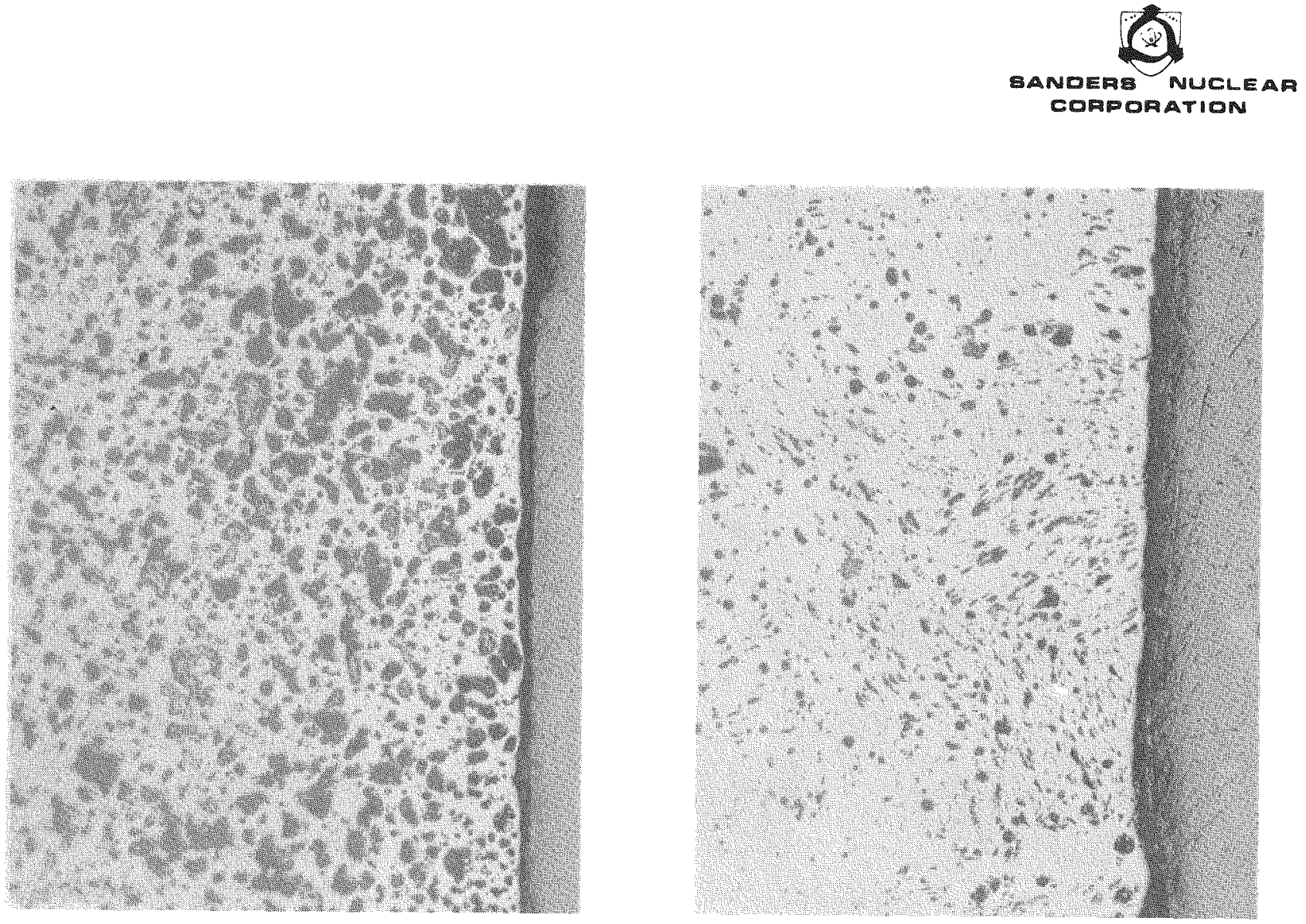

A. $100 \% \operatorname{Tm}_{2} \mathrm{O}_{3}$

B. $80 \% \operatorname{Tm}_{2} \mathrm{O}_{3} / 20 \% \mathrm{Yb}_{2} \mathrm{O}_{3}$

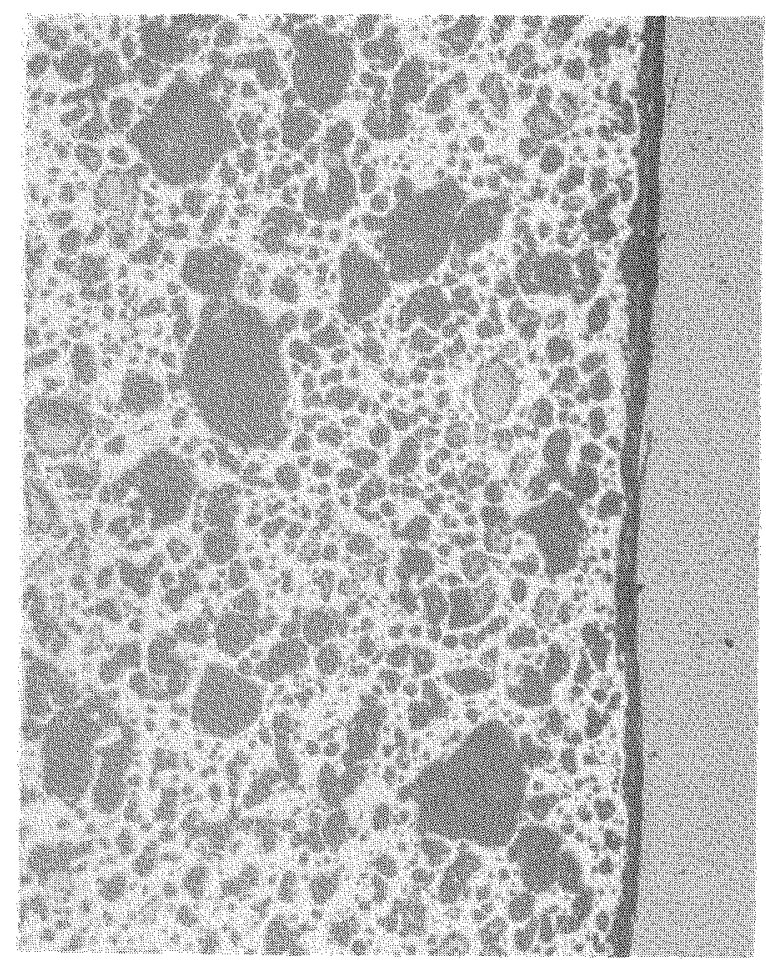

\section{C. $100 \% \mathrm{Yb}_{2} \mathrm{O}_{3}$}

Figure 3-8 Static Vacuum, $2000^{\circ} \mathrm{C}, 24$ Hours (100X). 


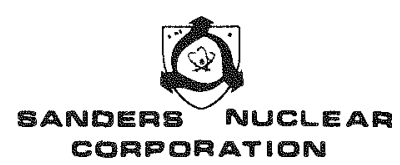

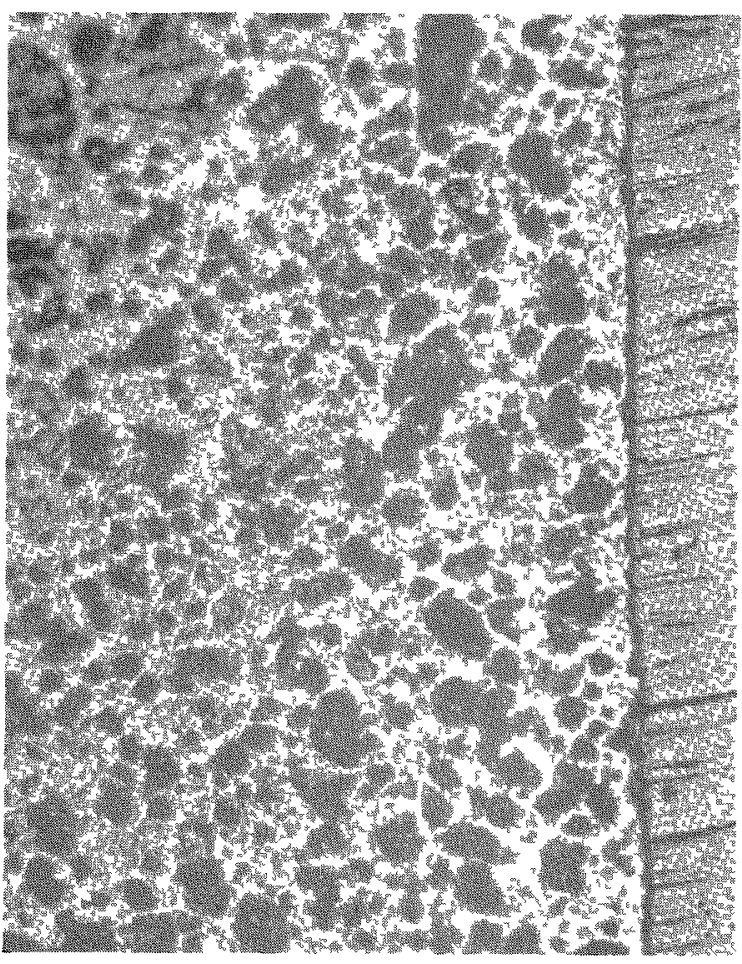

A. $100 \% \mathrm{Tm}_{2} \mathrm{O}_{3}$

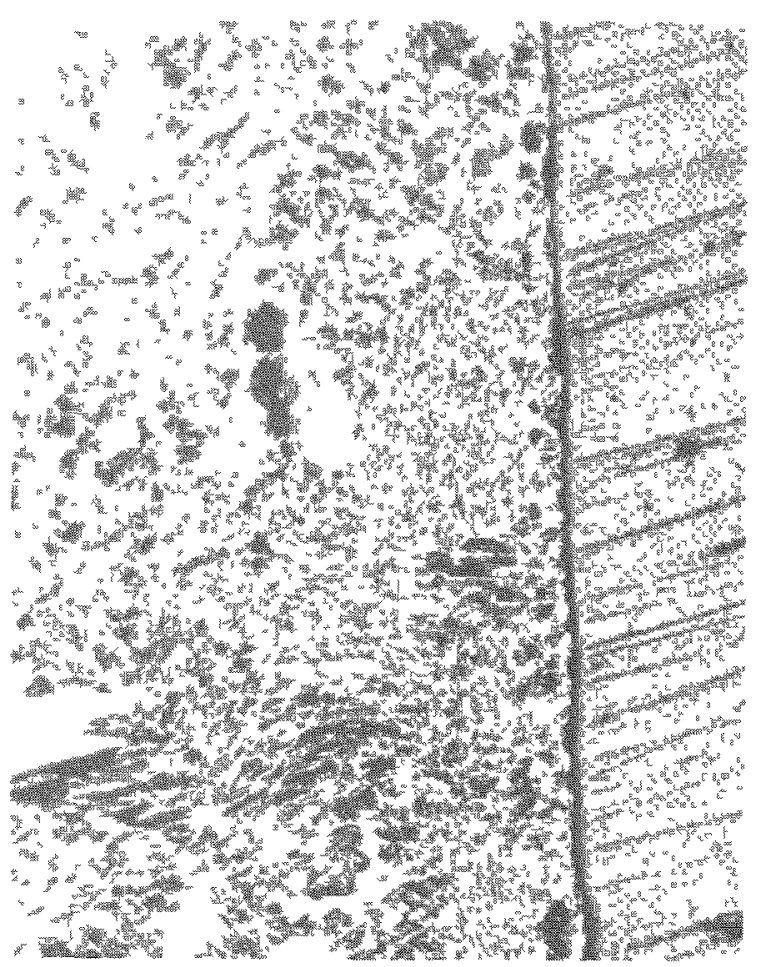

B. $80 \% \operatorname{Tm}_{2} \mathrm{O}_{3} / 20 \% \mathrm{Yb}_{2} \mathrm{O}_{3}$

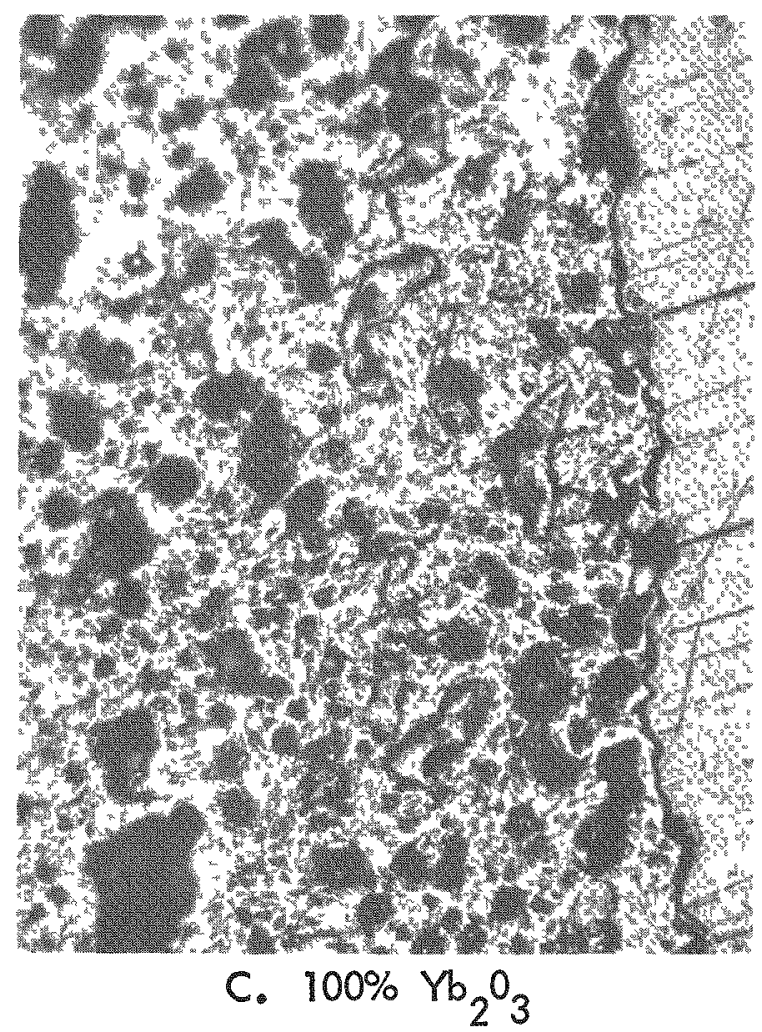

Figure 3-9 Static Vacuum, $2000^{\circ} \mathrm{C}, 100$ Hours (100X). 
pattern. X-ray diffraction patterns were obtained on all but the missing wafer. Patterns were typical of controls except for a new line appearing in the $100 \% \mathrm{Tm}_{2} \mathrm{O}_{3}$ samples exposed for 5 and 24 hours. No change in lattice parameter was found in those samples analyzed.

Microscopically, the grain sizes in these samples were smaller than those observed in static vacuum, but larger than their $1750^{\circ} \mathrm{C}$ analogs. No insoluble phases were observed. Again, clear evidence of vaporization can be seen from the surfaces of the wafers particularly at 5, 24 and 100 hours (Figures $3-10$ to 3-12). Samples are quite translucent overall, with some areas being quite transparent.

Conclusions

Initial powders were obtained by a homogeneous precipitation process that provides some purification of the "as received" $\operatorname{Tm}_{0} \mathrm{O}_{3}$ and $\mathrm{Yb}_{2} \mathrm{O}_{3}$. The changes in levels of the four principle elements were measured against control specimens sintered in air at $1450^{\circ} \mathrm{C}$ for 17 hours. Only iron changed with any degree of order. Increases in iron in $100 \% \mathrm{Tm}_{2} \mathrm{O}_{3}$ were seen in all but the $2000^{\circ} \mathrm{C}$ static vacuum exposure. In comparative time frames, the absolute iron level decreased as ytterbium concentration increased. The significance of this behavior and the possible implications that the presence of iron may have was not known. However, the $\mathrm{Tm}_{2} \mathrm{O}_{3}-\mathrm{Yb}_{2} \mathrm{O}_{3}$ cubic structure was stable where these levels of "impurity" were present.

The laninations frequently observed were also present in the control wafers and were due to the high pressure - cold pressing conditions used in preparing the test specimens. In several instances, particularly at the higher temperatures, these laminations had begun to heal.

X-ray diffraction patterns were typical of the controls except in the $100 \% \mathrm{Tm}_{2} \mathrm{O}_{3}$ wafers exposed to a static vacuum at $2000^{\circ} \mathrm{C}$ for 5 and 24 hours. A new line observed in the diffraction pattern of this sample suggested the presence of some other 


\section{(a) COPOATION}

SARDERS MUCLEAP

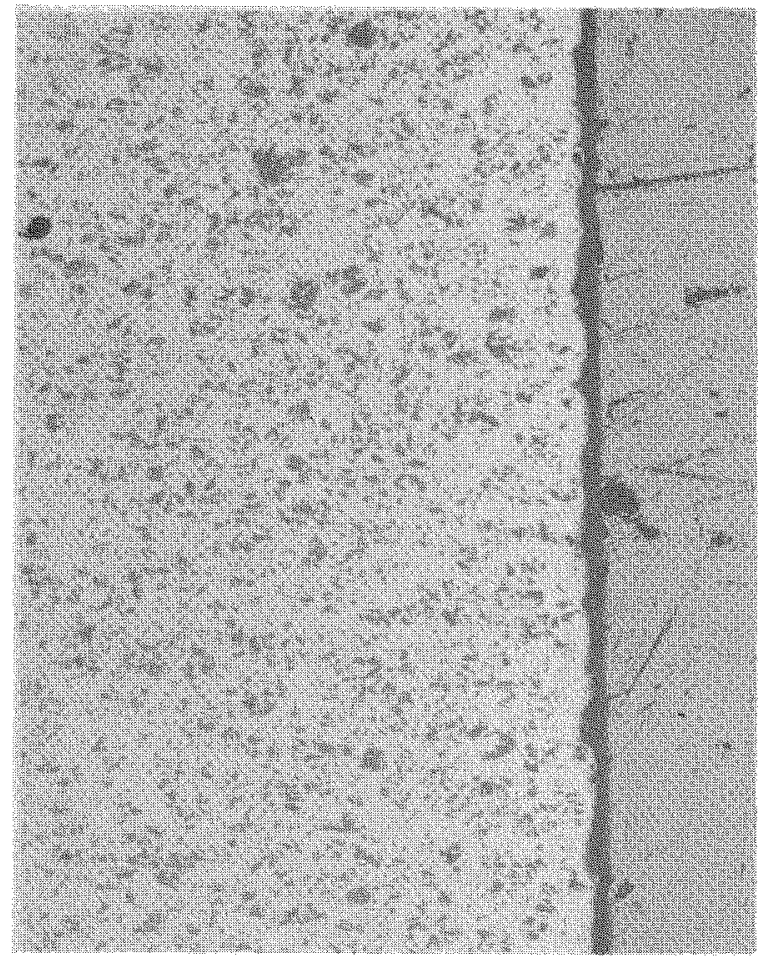

A. $\operatorname{Tm}_{2} \mathrm{O}_{3}$

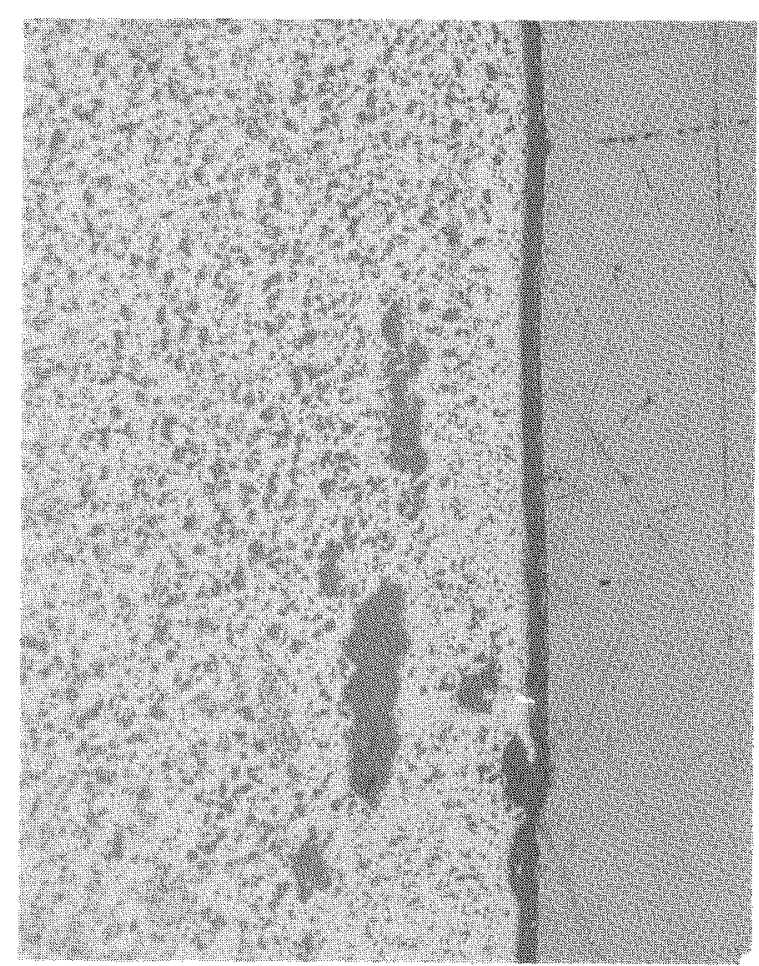

B. $80 \% \mathrm{Tm}_{2} \mathrm{O}_{3} / 20 \% \mathrm{Yb}_{2} \mathrm{O}_{3}$

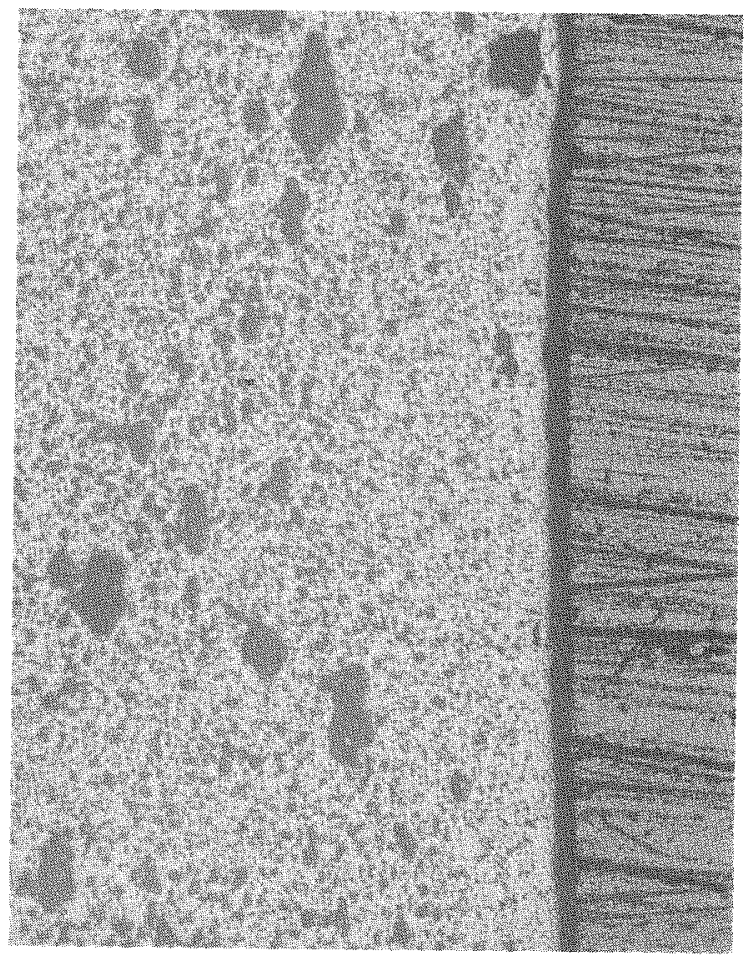

\section{C. $100 \% \mathrm{Yb}_{2} \mathrm{O}_{3}$}

Figure 3-10 Dynamic Vacuum, 2000 C, 5 Hours (100X). 


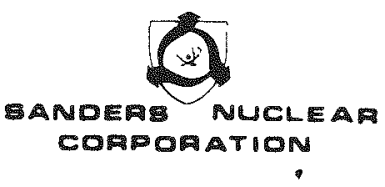

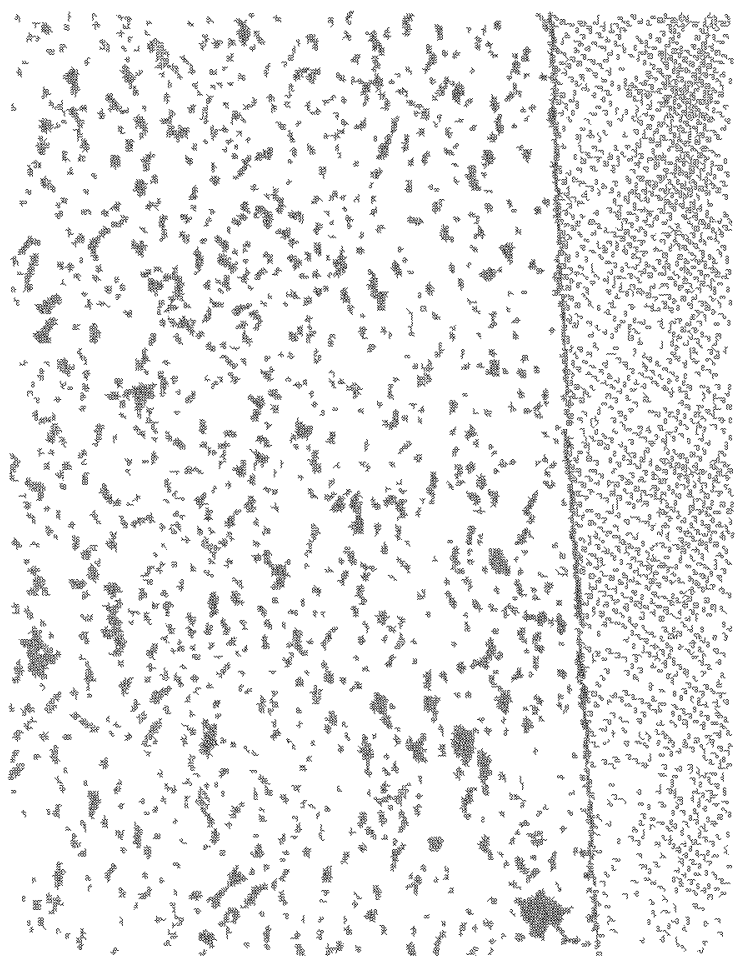

A. $100 \% \operatorname{Tm}_{2}{ }^{0}$

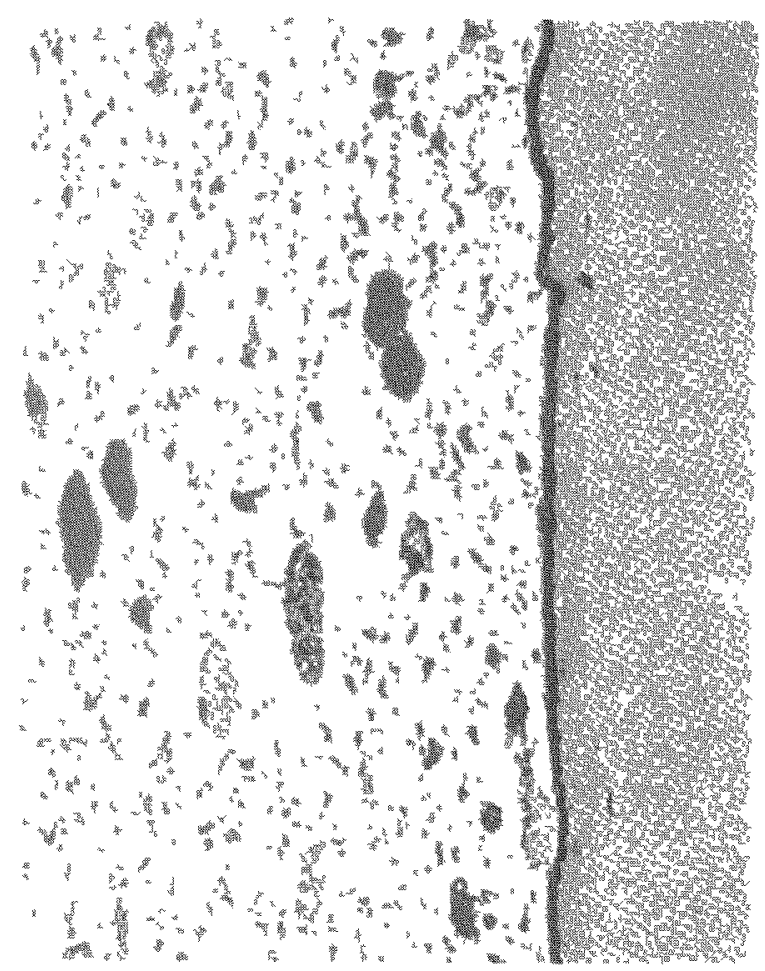

B. $80 \% \operatorname{Tm}_{2} \mathrm{O}_{3} / 20 \% \mathrm{Yb}_{2} \mathrm{O}_{3}$

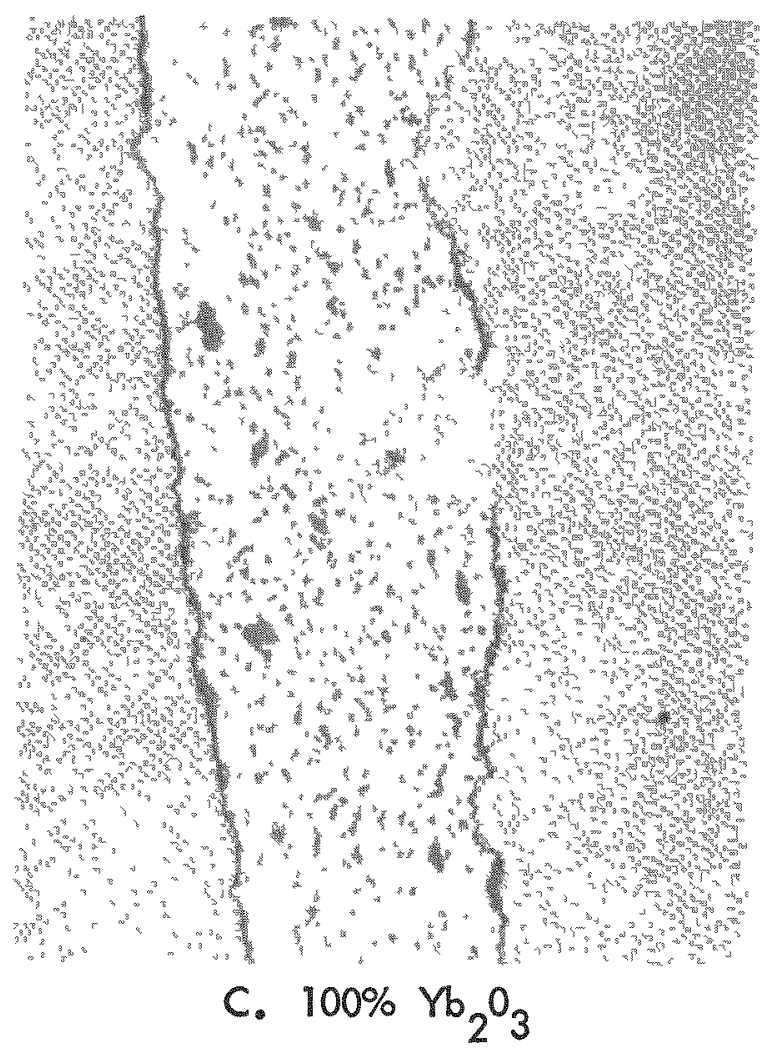

Figure 3-11 Dynamic Vacuum, $2000^{\circ} \mathrm{C}, 24$ Hours (100X). 

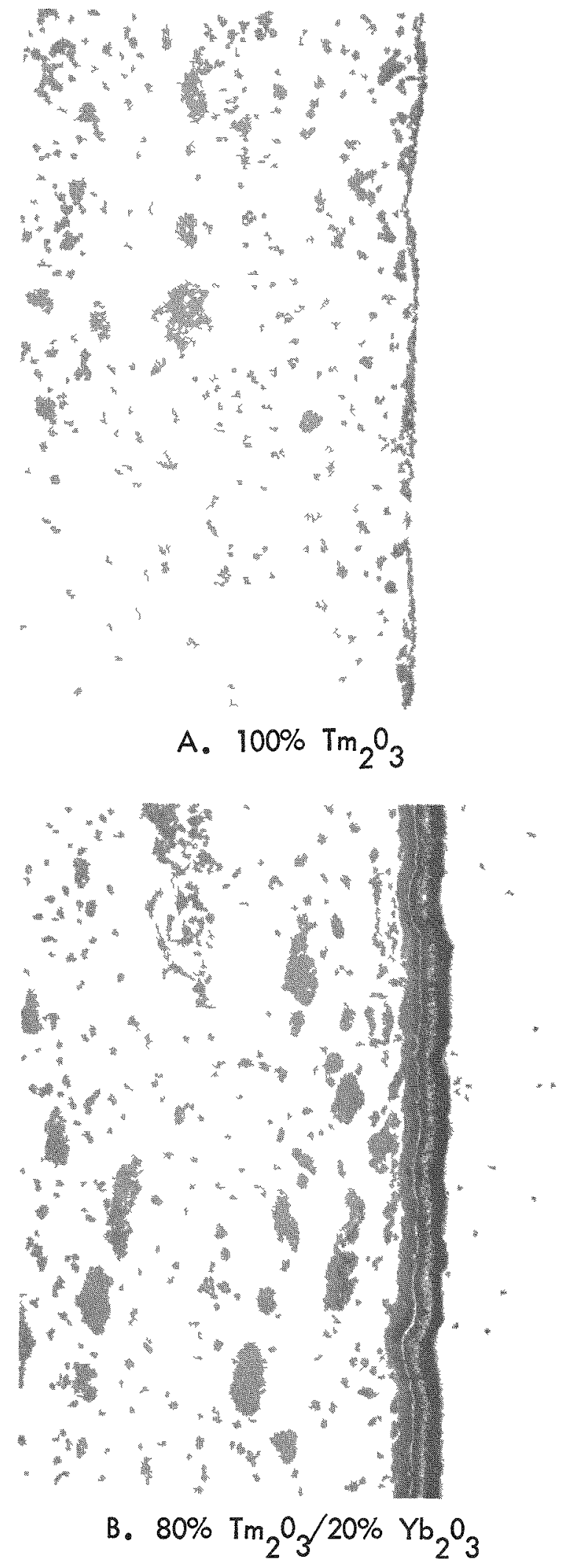

Figure 3-12 Dynamic Vacuum, $2000^{\circ} \mathrm{C}, 100$ Hours (100X). 
crystaline phase. A similar occurence was reported for the tungsten $-\operatorname{Tm}_{2}{ }_{3}$ compatibility couple after 500 hours at $2000^{\circ} \mathrm{C}^{(2)}$.

The $100 \% \mathrm{Yb}_{2} \mathrm{O}_{3}$ wafer exposed in a similar environment had a normal diffraction pattern but the pattern obtained from the vapor deposited crystals was not that of $\mathrm{Yb}_{2} \mathrm{O}_{3}$. The different behavior was not understood. It does suggest, however, that designers with applications requiring tungsten encapsulated $\operatorname{Tm}_{2} \mathrm{O}_{3}$ beyond 500 hours at $2000^{\circ} \mathrm{C}$ should conduct additional compatibility tests. Lattice parameters as calculated from the diffraction patterns obtained were all in good agreement with the control values.

Mass transport was evident in all samples encapsulated and exposed at $1750^{\circ} \mathrm{C}$ and above. The degree of transport was temperature, time and ytterbium concentration dependent, the latter probably having the greatest influence because of the higher vapor pressure of $\mathrm{Yb}_{2} \mathrm{O}_{3}$. Mass transport behavior would not be significant, capsule failure not withstanding, as containment has been demonstrated for times to 10,000 hours. In a dynamic vacuum, mass loss was observed to be primarily a function of temperature and time for a given composition.

Dimensional swelling was noted for several environmental conditions (Table 3-3). Swelling became more observable with increasing ytterbium concentration. Swelling increased with increasing temperature to $2000^{\circ} \mathrm{C}$. At $2000^{\circ} \mathrm{C}$, the dimensional thickness was observed to decrease; the decrease was greater as ytterbium concentration increased. The swelling behavior suggests some dedensification process, possible the formation of a lower density phase. The temperature at which this behavior might be initiated was not known nor could long time exposure effects be postulated from the sparse data available. The decrease in thickness at higher temperatures suggested that vapor pressure was the predominant factor operating. Attributing these effects to one or the other factor, however, was not possible within the confines of the experiment. In addition, the $\mathrm{Tm}_{2} \mathrm{O}_{3} / \mathrm{Yb}_{2} \mathrm{O}_{3}$ used herein was processed by one method and because no other process wafers had experienced this set of 
TABLE $\quad 3-3$

INCREASE/DECREASE (\%) IN THICKNESS OF $100 \% \mathrm{Tm}_{2} \mathrm{O}_{3}, 80 \% \quad \mathrm{Tm}_{2} \mathrm{O}_{3} / 20 \% \quad \mathrm{Yb} \mathrm{O}_{3}$ AND $100 \% \mathrm{Yb}_{2} \mathrm{O}_{3}$ AS A RESULT OF ENVIRONMENT EXPOSURE

\begin{tabular}{|c|c|c|c|c|c|c|}
\hline \multirow{3}{*}{$\begin{array}{l}\text { TEMPERATURE/ATMOSPHERE } \\
1450^{\circ} \mathrm{C} / \mathrm{air}\end{array}$} & & \multicolumn{5}{|c|}{ INCREASE/DECREASE (\%) } \\
\hline & TIME & \multirow[t]{2}{*}{$\mathrm{Tm}_{2} \mathrm{O}_{3}$} & \multirow[t]{2}{*}{$80 \%$} & \multirow{2}{*}{$\begin{array}{c}\operatorname{Tm}_{2} \mathrm{O}_{3} / 20 \% \\
14\end{array}$} & \multirow[t]{2}{*}{$\mathrm{Yb}_{2} \mathrm{O}_{3}$} & $100 \% \mathrm{Yb}_{2} \mathrm{O}_{3}$ \\
\hline & $100 \mathrm{hrs}$ & & & & & 23 to 32 \\
\hline $1450^{\circ} \mathrm{C} /$ dynamic vacuum & $100 \mathrm{hrs}$ & 0 & & 0 & & -6.5 \\
\hline $1750^{\circ} \mathrm{C} / \mathrm{static}$ vacuum & $100 \mathrm{hrs}$ & 7 & & 13 & & 26 \\
\hline $1750^{\circ} \mathrm{C} /$ dynamic vacuum & $100 \mathrm{hrs}$ & 0 & & to 10 & & 0 to 14 \\
\hline $2000^{\circ} \mathrm{C} / \mathrm{static}$ vacuum & 5 hrs & 0 & & 13 & & 23 \\
\hline $2000^{\circ} \mathrm{C} /$ dynamic vacuum & 5 hrs & 0 & & 7 & & 7 to 14 \\
\hline $2000^{\circ} \mathrm{C} / \mathrm{static}$ vacuum & $24 \mathrm{hrs}$ & 0 & & 10 & & 14 \\
\hline $2000^{\circ} \mathrm{C} /$ dynamic vacuum & 24 hrs & -7 & 10 & to 13 & & -90 \\
\hline $2000^{\circ} \mathrm{C} / \mathrm{static}$ vacuum & $100 \mathrm{hrs}$ & 10 & & -3 & & -25 to -35 \\
\hline $2000^{\circ} \mathrm{C} /$ dynamic vacuum & $100 \mathrm{hrs}$ & -58 & & -58 & & -100 \\
\hline
\end{tabular}


conditions, the possibility of a third factor, a process factor could not be eliminated.

The data obtained in this study indicate that the crystaline structure of $\mathrm{Tm}_{2} \mathrm{O}_{3}-\mathrm{Yb}_{2} \mathrm{O}_{3}$ is stable in air, dynamic vacuum and static vacuum for periods to 100 hours at $2000^{\circ} \mathrm{C}$.

\section{SUMMARY}

$100 \% \mathrm{Tm}_{2} \mathrm{O}_{3}, 80 \% \mathrm{Tm}_{2} \mathrm{O}_{3} / 20 \% \mathrm{Yb}_{2} \mathrm{O}_{3}$ and $100 \% \mathrm{Yb}_{2} \mathrm{O}_{3}$ wafers were exposed to air, dynamic vacuum and static vacum (tungsten capsules) at temperatures to $2000^{\circ} \mathrm{C}$ for times to 100 hours. The stability of the $\mathrm{Tm}_{2} \mathrm{O}_{3}-\mathrm{Yb}_{2} \mathrm{O}_{3}$ cubic structure was unaffected by the elemental levels of iron, aluminum, silicon and magnesium present in the wafers and unaffected by the environmental conditions imposed on the wafers. Dimensional swelling developed in several wafers including $100 \% \mathrm{Tm}_{2} \mathrm{O}_{3}$ and may be a potential problem because the behavioral pattern is not known. 


\section{SECTION 4 \\ MECHANICAL, THERMAL, CHEMICAL STABILITY ENHANCEMENT}

The goal of this task was to assess enhancement of mechanical, thermal, chemical stability of $\mathrm{Tm}_{2} \mathrm{O}_{3}$. Possible enhancement was to emerge as the end product of:

- Process Variable Optimization

- Selective Addition of Metal oxides

Enhancement was defined when properties of the end products of process variable optimization and selective addition of metal oxides were improved when compared to bench marks. Mechanical integrity was assessed from macroscopic, microscopic and impact - particle sizing analyses; thermal influences were determined from density measurements, grain size and $x$-ray diffraction analyses; chemical influence from changes in impurity levels of aluminum, silicon, magnesium and iron, lattice parameter data, macro-microscopic evaluation and electron microprobe analysis. It was understood that all of these major categories were heavily interrelated. The experimentation proceeded accoraing to the general format.

- Characterization of starting materials,

- Processing under controlled conditions into sintered product,

- Characterization of sintered product,

- Controlled aging,

- Characterization of aged product.

The sequence of accomplishment of the three task elements was: 
- Bench mark testing,

- Process variable optimization testing,

- Metal oxide additives testing.

\subsection{BENCH MARKS}

Starting powder was obtained by processing "as received" $\mathrm{Tm}_{2} \mathrm{O}_{3}$ and $\mathrm{Yb}_{2} \mathrm{O}_{3}(99.9 \%$ Michigan Chemical Co*) according to a caustic precipitation process reported in Phase I and Phase II of this study. Following calcining at $750^{\circ} \mathrm{C}$ for 1 hour in air, the $100 \% \mathrm{Tm}_{2} \mathrm{O}_{3}$ and $80 \% \mathrm{Tm}_{2} \mathrm{O}_{3} / 20 \% \mathrm{Yb}_{2} \mathrm{O}_{3}$ powders were cold pressed in stainless steel dies at 29 tsi subsequent to the addition of Carbowax 4000 as a binder ( $4 \%$ solution). The green wafers were sintered in air at $1450^{\circ} \mathrm{C}$ for 17 hours.

Density data were obtained by weighing on an analytical balance and computing the bulk volume from micrometer measurements of the thickness and diameter of the wafer. Chemical analysis for changes in impurity level were determined by atomic absorption spectrophotometric techniques; surface area measurements on pre and post calcined powder were run on an Aminco "SorBet*" using the BET technique with helium preconditioning at $150^{\circ} \mathrm{C}$. For impact-fines analysis, wafers were impacted with a falling steel weight and resultant particles collected and fractionated through a series of sieves by a solution method ( 3$)$. Details of all procedures may be found elsewhere in this report ${ }^{(4)}$ ).

\section{$\underline{\text { RESULTS }}$}

The experimental data is summarized in Table 4-1. Processing of "as received" $\mathrm{Tm}_{2} \mathrm{O}_{3}$ and $\mathrm{Yb}_{2} \mathrm{O}_{3}$ through the calcining stage produce a fine particulate white powder having several times the volume of the original "as received" oxide. Conversion efficiencies (oxide to oxide) were greater than $90 \%$.

\footnotetext{
* All material used in this program was obtained from Michigan Chemical Co., Kalamazoo, Michigan.

* American Instrument Co., Silver springs, Maryland.
} 
SUMMARY OF BENCH MARK EXPERIMENTAL DATA

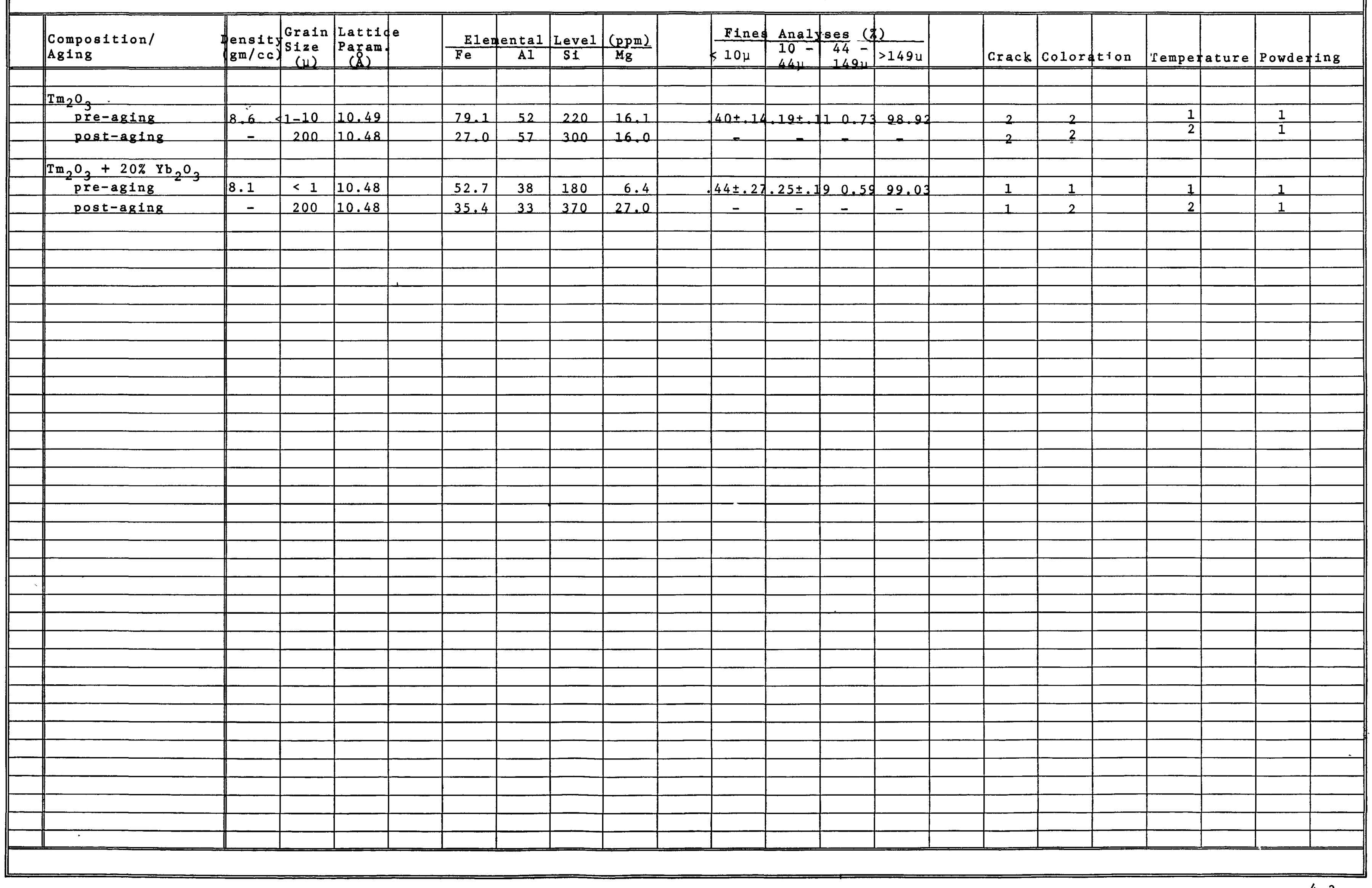


The "as sintered" $100 \% \mathrm{Tm}_{2} \mathrm{O}_{3}$ and $80 \% \mathrm{Tm}_{2} \mathrm{O}_{3} / 20 \% \mathrm{Yb}_{2} \mathrm{O}_{3}$ wafers were whole with no visible laminations. The $100 \% \mathrm{Tm}_{2} \mathrm{O}_{3}$ wafers exhibited slight radial cracking and had a mottled appearance throughout the subsurface.

$\mathrm{X}$-ray diffraction analyses identified only crystalline $\mathrm{Tm}_{2} \mathrm{O}_{3}$ or $\mathrm{Yb}_{2} \mathrm{O}_{3}$. Lattice parameters were in good agreement with values calculated from the d spacing data report by Bommer $(5)$.

Metallographically, samples of both compositions exhibited slight laminar cracking but no other evidence of cracking was observed. The porosity patterns were different only in the greater population of smallex pores in the mixed oxide wafers (Figure 4-1). A rather large percentage of the wafer volume in both the $100 \% \operatorname{Tm}_{2} \mathrm{O}_{3}$ and the mixed oxide was transparent. Grain size for $100 \% \mathrm{Tm}_{2} \mathrm{O}_{3}$ wafers as determined from fractographs was < 1-10 microns, while for the mixed oxide, the grain size could not be determined by optical microscopy and was therefore assumed to be less than one micron.

Wafers that received an aging treatment were pale green in color. The aging treatment consisted of exposing a stack of wafers encapsulated in tungsten to temperatures of $1600^{\circ} \mathrm{C}$ for periods of 500 hours. A11 wafers of both compositon had bonded together but no metal to wafer bonding was observed. Vapor deposited crystals were found on the bottom side of the capsule and suggested that a temperature gradient was present within the capsule during test. Thicknesses of aged individual wafers measured macroscopically were unchanged from the "as sintered" thickness despite the bonding. Wafers of both compositions had a glazed appearance after 500 hours in tungsten.

Metallographically, some large voids had appeared as a result of aging. Numerous small pores were also observed that were conservatively estimated to be about 10 volume percent. A grain boundary network was present at the surfaces of the wafers and at the bonded interfaces that extended into the wafers. At least three phases were identifiable by both optical microscopy and 


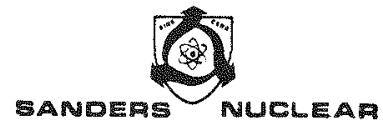

CORPORATION

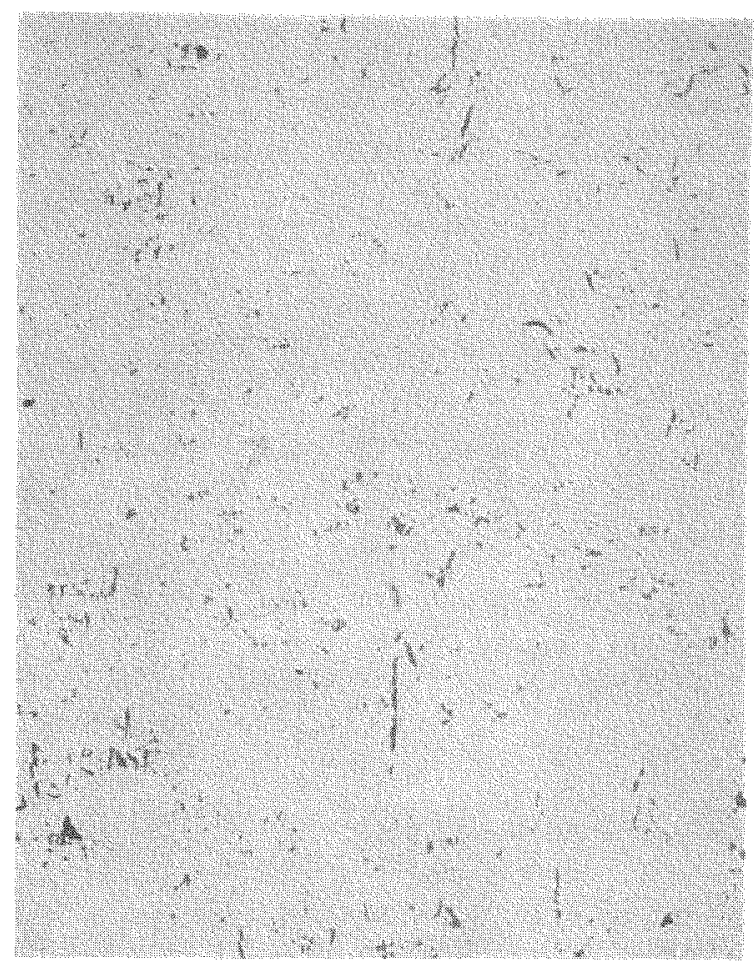

A. $100 \% \operatorname{Tm}_{2} \mathrm{O}_{3}$

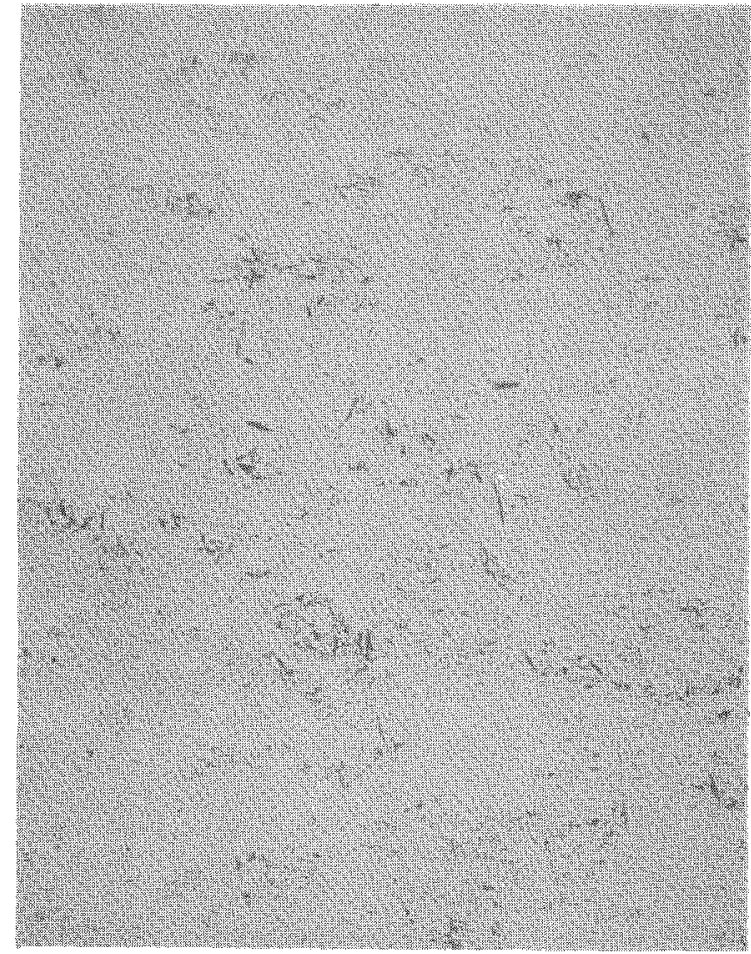

B. $80 \% \operatorname{Tm}_{2} \mathrm{O}_{3} / 20 \% \mathrm{Yb}_{2} \mathrm{O}_{3}$

Figure 4-1 Bench Mark Wafers Sintered $1450^{\circ} \mathrm{C}$ in Air for 17 Hours (as Polished - 200X). 


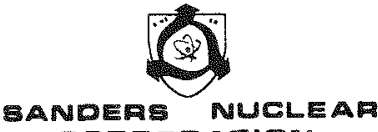

CORPOATION

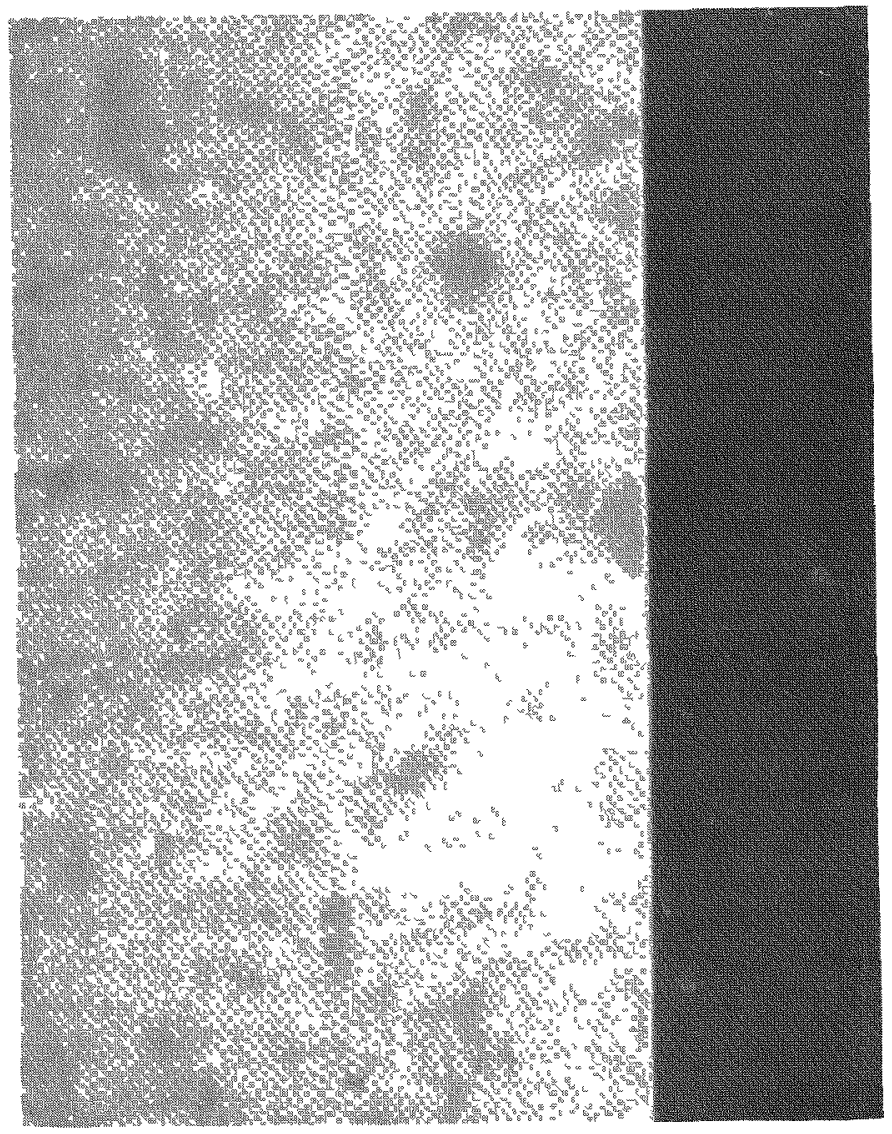

Figure 4-2 $100 \% \mathrm{Tm}_{2} \mathrm{O}_{3}$ Wafer Sintered $1450^{\circ} \mathrm{C}$ in Air for 17 Hours (as Polished - 100X). 


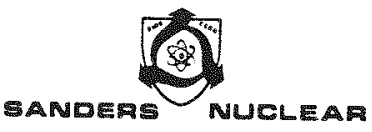

COAPOAATION

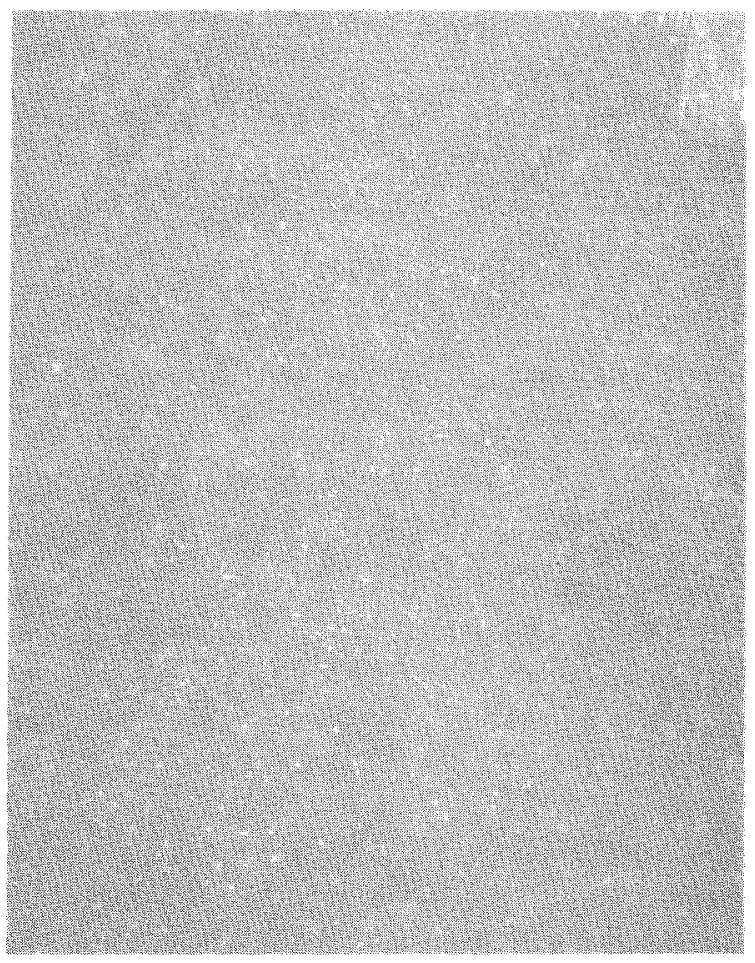

A. $100 \% \mathrm{Tm}_{2} \mathrm{O}_{3}$

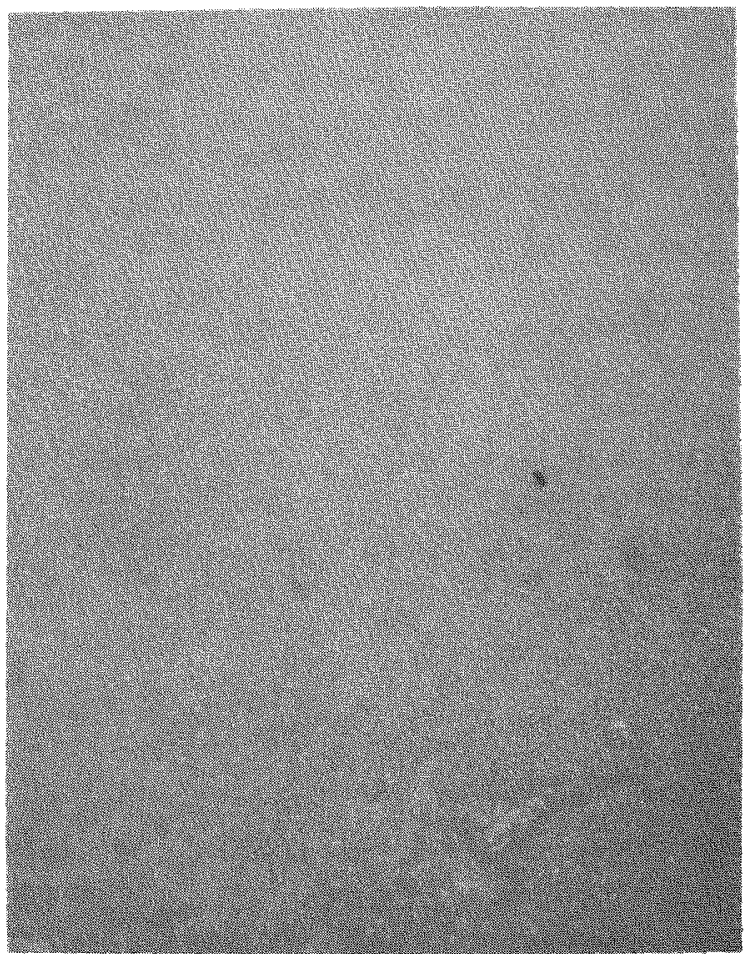

B. $80 \% \operatorname{Tm}_{2} \mathrm{O}_{3} / 20 \% \mathrm{Yb}_{2} \mathrm{O}_{3}$

Figure 4-3 Bench Mark Wafers Sintered in Air $1450^{\circ} \mathrm{C}$ for 17 Hours $=$ Fractured Surface (100X). 


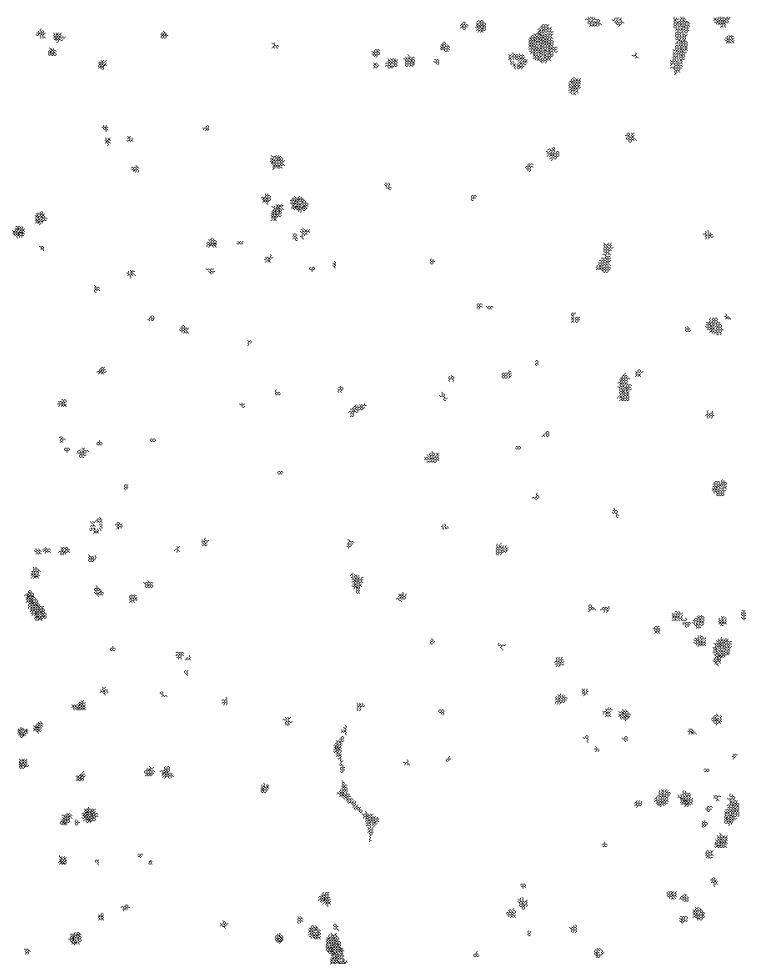

A. $100 \% \operatorname{Tm}_{2}{ }^{0} 3$

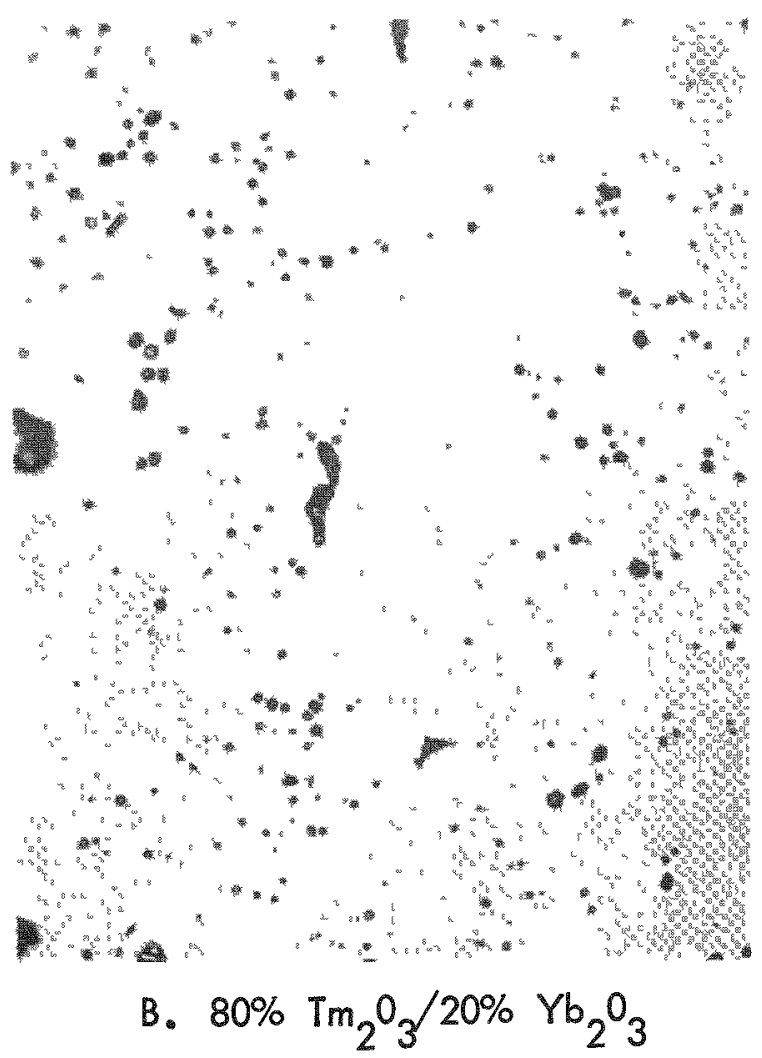

Figure 4-4 Bench Mark Wafers Aged 500 Hours at $1600^{\circ} \mathrm{C}$, Then 20 Minute Rise to $2000^{\circ} \mathrm{C}$ and Shut Down (as Polished - 200X). 
electron microprobe analysis. The microprobe showed calcium and silicon to be present in the phases in addition to rare earth; the amounts of calcium \& silicon varied between phases. Figure 4-5 is an x-ray composition micrograph of the network. The darkest areas are the in calcium. In these areas, that element was 10 fold more abundant than silicon and about equal with respect to rare earth. The shape of the phase indicated melting had taken place. The eutectic point was somewhere below $2000^{\circ} \mathrm{C}$, the maximum temperature of the final thermal spike.

The grain size of the aged bench mark wafers as determined by fractography ranged to $200 \mu$, a marked contrast to the "as sintered" grain size. Figure $4-6$ is a fractograph of the aged wafer. The grain size was typical of that observed throughout the aged bench mark wafers.

\section{DISCUSSION}

The surface area obtained for a randomly selected powder sample of $100 \% \operatorname{Tm}_{2} \mathrm{O}_{3}$ was $\sim 12 \mathrm{~m}^{2} / \mathrm{gm}$ while that of $80 \% \mathrm{Tm}_{2} \mathrm{O}_{3} / 20 \%$ $\mathrm{Yb}_{2} \mathrm{O}_{3}$ was $\sim 5 \mathrm{~m}^{2} / \mathrm{gm}$. Since no difference in behavior during chemical processing was observed between the $100 \% \mathrm{Tm}_{2} \mathrm{O}_{3}$ and mixed oxide powder, the difference is likely in manual grinding of calcined powders.

The bulk sintered density of $100 \% \mathrm{Tm}_{2} \mathrm{O}_{3}$ wafers averaged $\sim 8.6 \mathrm{gm} / \mathrm{cm}^{3}$ while that for the mixed oxide was $8.1 \mathrm{gm} / \mathrm{cc}$. With all other conditions essentially equal, the smaller surface area of the mixed oxide powder did not provide quite the degree of sintering and therefore, slightly less bulk sintered density. Bulk density of the aged wafers was estimated from porosity to be somewhat less, conservatively about $90 \%$ of theoretical density. Many pores were trapped within the large grains indicative of rapid grain growth. The large grain size observed may have been influenced in part by calcium and silicon. The mechanism whereby these elements concentrate at grain boundaries is not understood. However, because it is surface initiated, it may well involve the encapsulant material. In those regions where the grain boundary network was observed, the 

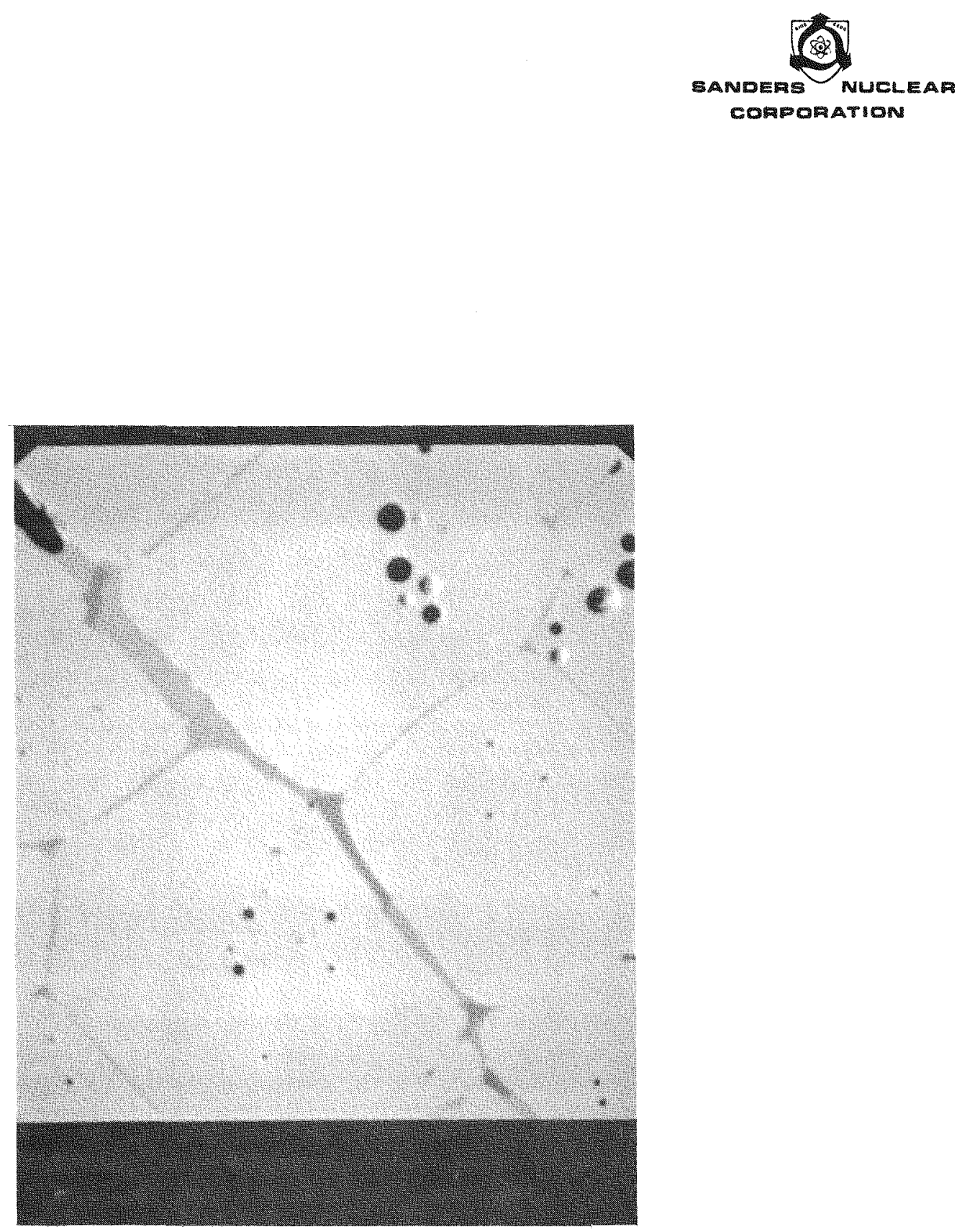

Figure 4-5 X-Ray Composition and Scan of $80 \% \quad \mathrm{Tm}_{2} \mathrm{O}_{3} / 20 \% \quad \mathrm{Yb}_{2} \mathrm{O}_{3}$ Wafers Aged at $1600^{\circ} \mathrm{C}$ for 500 Hours $(600 \mathrm{X})$. 

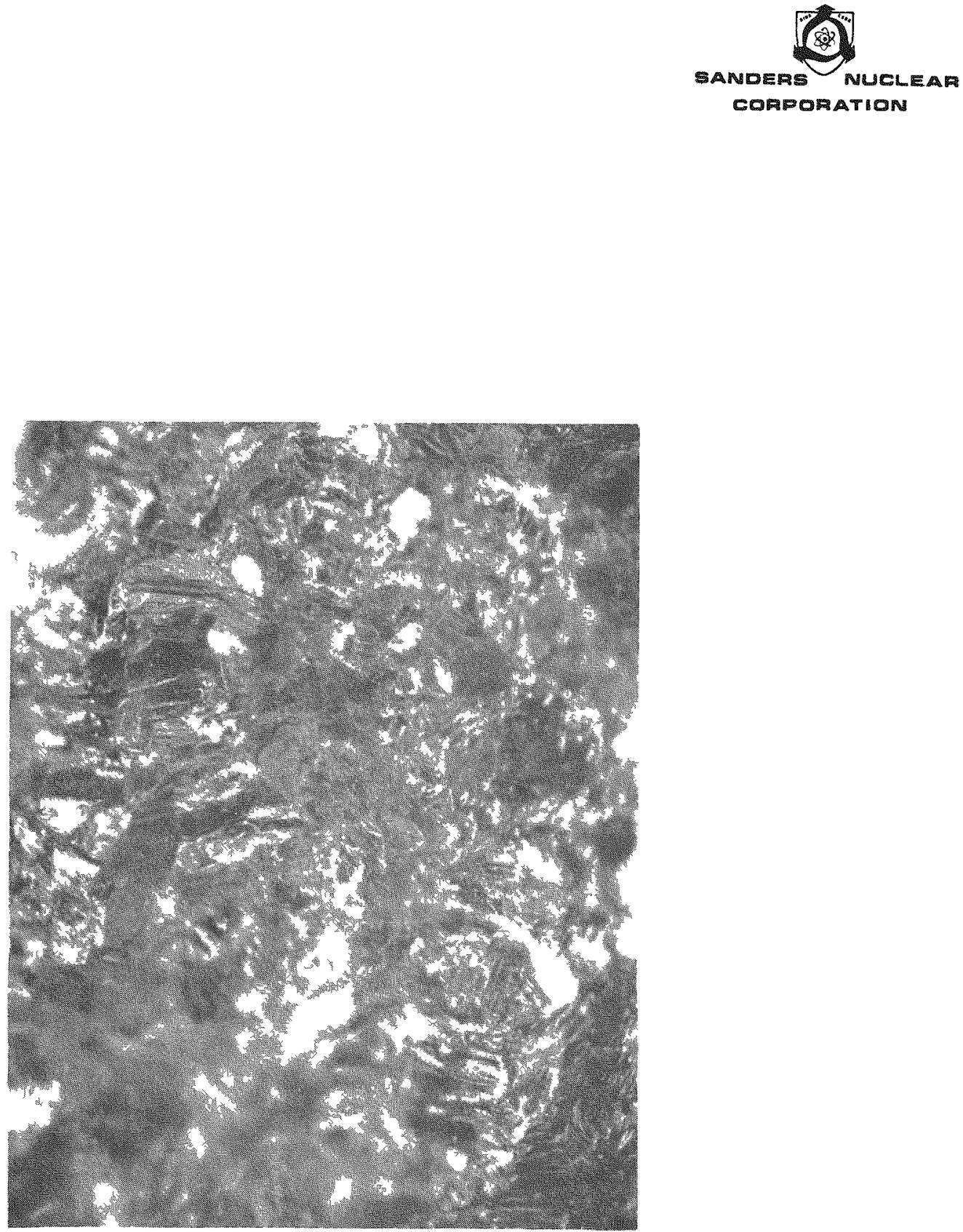

Figure 4-6 $100 \% \mathrm{Tm}_{2} \mathrm{O}_{3}$ Wafer Aged $1600^{\circ} \mathrm{C}$ for 500 Hours Fractured Surface (100X). 
average volume of the phase was estimated to be approximately 5-6\% of the bulk volume. In some cases, where surface grains had been completely enveloped, (Figure 4-7), the percentage was higher. The presence of calcium and silicon in the initial wafers was not surprising because it "Nas present in the "as received" powder and reprecipitation by caustic addition was ideal for coprecipitation of these impurities. What the eventual disposition of this phase on further exposure would be, is not known. However, these observations strongly point to the need for close quality control of product prior to fuel form fabrication. There was no observable influence in the aged wafers of the presence of $\mathrm{Yb}_{2} \mathrm{O}_{3}$.

The interwafer bonding precluded a determination of fines generation after aging. Therefore, comparisons with other aged products were limited mainly to microstructure.

\subsection{PROCESS VARIABLE OPTIMIZATION}

As stated earlier, the goal of this task was to assess the enhancement of mechanical, thermal, chemical stability of $\mathrm{Tm}_{2} \mathrm{O}_{3}$ through optimization of process variables. The variables included the following:

- Conditions for chemical reprocessing of "as received" $\mathrm{Tm}_{2} \mathrm{O}_{3}$

- Calcining conditions.

- Method of binder addition.

- Pressing pressure.

- Sintering time/temperature/atmosphere.

- Aging at $1600^{\circ} \mathrm{C}$ for 500 hours.

The investigation was divided into three (3) subtasks for logical sequence of study.

- Effects of varying chemical reprocessing of "as received" $\mathrm{Tm}_{2} \mathrm{O}_{3}$

- Effects of sintering - time/temperature/atmosphere.

- Effects of aging ( $T-111$, TZM and tungsten capsules).

One set of process conditions that had emerged as the best, 

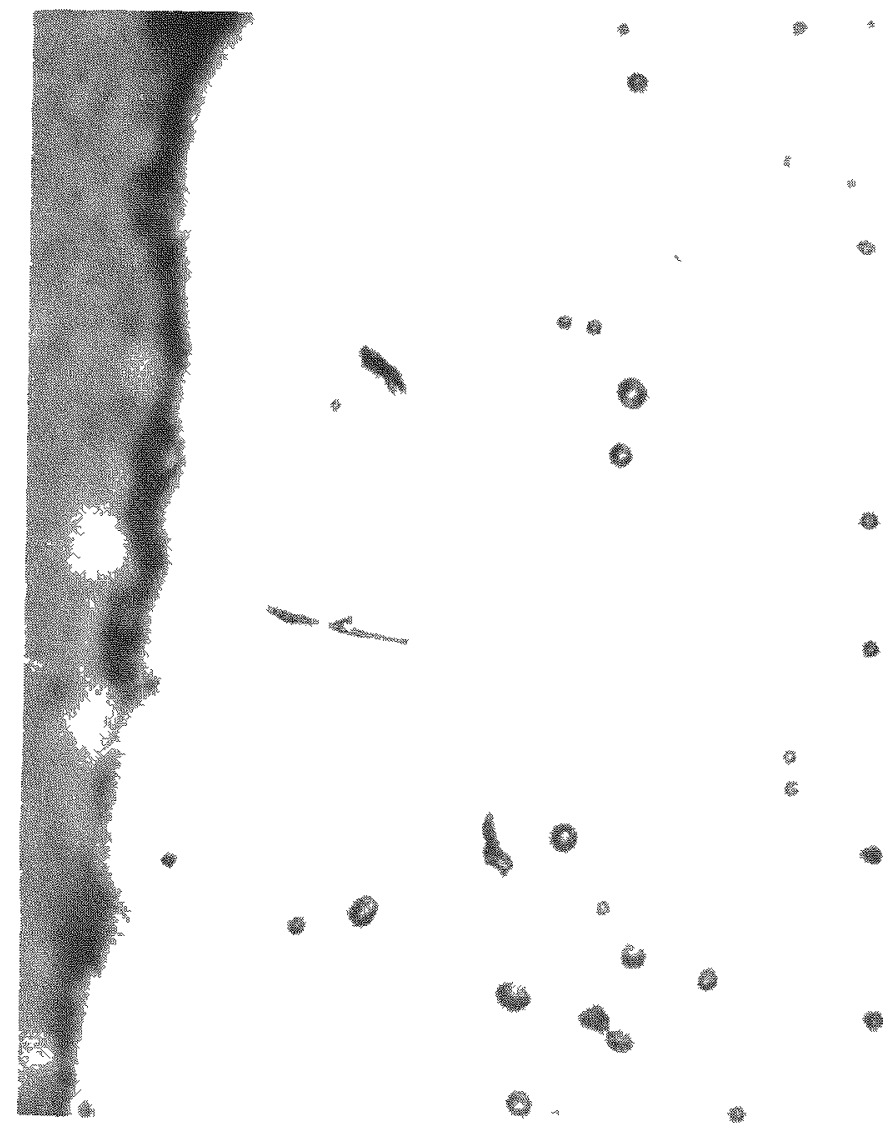

Figure 4-7 100\% $\mathrm{Tm}_{2} \mathrm{O}_{3}$ Bench Mark Aged 500 Hours at $1600^{\circ} \mathrm{C}$ (as Polished - 500X). 
based on inter-comparison of product properties was selected to produce 30 wafers for further testing by AEC.

4.2.I EFFECTS OF VARYING CHEMICAL REPROCESSING OF "AS RECEIVED" $\mathrm{Tm}_{2} \mathrm{O}_{3}$

Experimentation utilized four different methods for reprocessing "as received" $\mathrm{Tm}_{2} \mathrm{O}_{3}$. Two were homogeneous precipitations and two were heterogeneousiprecipitations. The homogeneous techniques utilized urea and methyl oxalate as primary reagent; the second technique used ammonium oxalate and oxalic acid. In three cases, thulium oxalate was the product obtained prior to calcining. The fourth (urea) formed thulium carbonate/oxycarbonate. Table 4-2 summarizes the conditions of reprocessing. Full details may be found in Part III of this report.

TABLE 4-2

SUMMARY OF CONDITIONS FOR REPROCESSING "AS RECEIVED" $\operatorname{Tm}_{2} \mathrm{O}_{3}$

\begin{tabular}{|c|c|c|c|c|}
\hline $\begin{array}{l}\text { Precipitating } \\
\text { Agent }\end{array}$ & $\begin{array}{c}\text { Thulium Concentration } \\
\text { (Moles/liter) }\end{array}$ & $\begin{array}{c}\text { Excess } \\
\text { Reagent } \\
\text { Thulium }\end{array}$ & $\mathrm{pH}$ & Temperature \\
\hline $\begin{array}{c}\text { Ammonlum } \\
\text { oxalate }\end{array}$ & 0.185 & $3.8: 1$ & 5.0 & Ambient \\
\hline $\begin{array}{l}\text { Oxalic } \\
\text { Acid }\end{array}$ & 0.185 & $3.8: 1$ & 1 & $93^{\circ} \mathrm{C}$ \\
\hline Urea & 0.185 & $73: 1$ & 5.0 & $95^{\circ} \mathrm{C}$ \\
\hline $\begin{array}{l}\text { Methy } 1 \\
\text { Oxalate }\end{array}$ & 0.185 & $2.0: 1$ & 3.0 & $95^{\circ} \mathrm{C}$ \\
\hline
\end{tabular}

EXPERIMENTAL

"As received" $\mathrm{Tm}_{2} \mathrm{O}_{3}$ was converted to the nitrate and made $0.555 \mathrm{~N}$ in strength. Following pH adjustment (where required), paccipitation was initiated, the precipitate collected, filtered and washed to neutrality with distilled water and dried in a vacuum oven at $100^{\circ} \mathrm{C}$ overnight. Optimum calcining temperature was determined by heating samples of the dried powder for 1 hour at 1 atmosphere in a silicon globar furnace. Infrared spectra of calcined powders were obtained using the KBr disc technique in conjunction with a Beckman IR-12 
Spectrophometer. The portion of the spectrum was $2.5-50$ microns $\left(400-200 \mathrm{~cm}^{-1}\right)$. Surface area measurements on calcined powders, chemical purity and densities were obtained in the manner described previously. Thermal gravimetric analysis of Carbowax 4000 solution was obtained on a Pexkin Elmer Thermal Gravimetric system in both air and nitrogen. Sample weight was 8 - 10 milligrams.

Two methods of binder addition were compared. One, the method described in the modified Savannah River Laboratory process as employed in the preparation of the bench marks, and two, a spray drying technique whereby the binder was atomized and then dried on the particles with a stream of hot air.

All wafers prepared were cold pressed in steel dies at 29 tsi end sintered in air at $1450^{\circ} \mathrm{C}$ for 17 hours.

\section{RESULTS}

The procedures developed allowed the preparation of these thulium compounds with little difficulty. The precipitates in contrast to standardized SRL process material were easy to work with and processing through the calcining stage was straightforward. The thulium oxalate preparations were all white, crystalline solids that varied from fine powder (ammonium oxalate, methyl oxalate) to a granual texture (oxalic acid). Thulium carbonate was also a white crystalline solid of powdery texture. The yields obtained are 1 isted in Table $4-3$.

\section{TABLE 4-3}

CONVERSION EFFICIENCY OF CHEMICAL REPROCESSING - $\operatorname{Tm}_{2} \mathrm{O}_{3} \rightarrow \mathrm{Tm}_{2} \mathrm{O}_{3}$

Percent

Oxalic Acid

Ammonium oxalate

Urea

Methyl oxalate

$$
\begin{aligned}
& 74.8-92.1 \\
& 59.7-75.0 \\
& 37.8-99.5 \\
& 33.8-70.8
\end{aligned}
$$


The low yield listed for urea preparations was a first attempt and subsequent preparations were at least $88 \%$ efficient.

Several investigators ${ }^{6-10}$ have studied the conditions necessary for obtaining optimum yields of rare earth oxalates and their conclusions are somewhat contradictory. The work of Broadhead and Heady 11 however, was a more systematic analysis of the parameters involved and showed the important factors to be mineral acid concentration ( $\mathrm{pH}$ should be greater than 2) and rare earth concentrations greater than 0.01M. Al1 the precipitations performed in our laboratories were carried out at conditions that were in agreement with these criteria with the exception of the pH for the oxalic acid ${ }^{12}$ (Table 4-2). In addition, the following experimental conditions were observed: a $2-5$ fold excess of oxalate ion: a stirring time of several minutes and the absence of complexing agents.

The selection of a calcining temperature was based on laboratory experimentation and review of other work $(13,14,15,16)$. The calcining temperature used in other laboratories varied from $750^{\circ} \mathrm{C}$ (generally for hydroxides and carbonates) to $900^{\circ} \mathrm{C}$ (oxalate). $950^{\circ} \mathrm{C}$ was selected as a standard calcining temperature to ensure complete compound conversion and to minimize levels of residual carbon and other elemental impurities. Once calcined at this temperature, the powders easily passed through a 100 mesh sieve with little grinding. Infrared spectra obtained on each product gave no evidence of residual reagent and were comparable with respect to pattern.

The results of the chemical impurity analyses are found in $\operatorname{Tab} 1 \mathrm{e} 4-4$.

Processing reduced impurity levels by an order of magnitude. Powders calcined at $750^{\circ} \mathrm{C}$ had higher levels of impurity than precalcined powders. The source of these impurities is not known, however, calcining at $950^{\circ} \mathrm{C}$ had virtually returned these increases to precalcined levels. 
TABLE $4-4$

IMPURITY LEVELS (ppm) OF IRON, MAGNESIUM, ALUMINUM AND SILICON IN "AS RECEIVED", PRECALCINED, CALCINED $750^{\circ} \mathrm{C}$ AND CALCINED $950^{\circ} \mathrm{C}$ POWDERS

Impurity Levels (ppm) As Received Powders

$\begin{array}{lcccc} & \text { Iron } & \text { Magnesium } & \text { Silicon } & \text { Aluminum } \\ \mathrm{S} / \mathrm{N} & 120 & 13 & 246 & 34 \\ \mathrm{UNH} & 100 & 10 & 200 & 30\end{array}$

Impurity Levels (ppm) Precalcined Powders

\begin{tabular}{|c|c|c|c|c|}
\hline Agent & Iron & Magnesium & Silicon & Aluminum \\
\hline Ammonium & & & & \\
\hline oxalate & 25 & 2.5 & $<40$ & $<25$ \\
\hline Oxalic acid & 17 & 1.0 & $<40$ & $<19$ \\
\hline Urea & 18 & 0.5 & $<40$ & $<17$ \\
\hline Methy 1 & & & & \\
\hline oxalate & 21 & 2.9 & $<40$ & $<17$ \\
\hline
\end{tabular}

Impurity Levels (ppm) Powders Calcined at $750^{\circ} \mathrm{C}$

$\begin{array}{lllll}\text { Agent } & \text { Iron } & \text { Magnesium } & \text { Silicon } & \text { Aluminum } \\ \begin{array}{l}\text { Ammonium } \\ \quad \text { Oxalate }\end{array} & 20-40 & 0.9-12.1<40-125 & <17-30 \\ \text { Oxalic acid } & 11-40 & 0.7-6.4<40-70 & <17-40 \\ \text { Urea } & 21-50 & 0.9-4.4<40-270 & <17-50 \\ \begin{array}{l}\text { Methyl } \\ \text { oxalate }\end{array} & 11-26 & 1.2-1.5<40 & <17\end{array}$

Impurity Leve1s (ppm) Powders Calcined at $950^{\circ} \mathrm{C}$

$\begin{array}{lcccc}\text { Agent } & \text { Iron } & \text { Magnesium } & \text { Silicon } & \text { Aluminum } \\ \begin{array}{l}\text { Ammonium } \\ \text { oxalate }\end{array} & 26 & 3.6 & <40 & <17 \\ \begin{array}{l}\text { Oxalic acid } \\ \text { Urea }\end{array} & 12 & 0.9 & <40 & <17 \\ \begin{array}{l}\text { Methyl } \\ \text { oxalate }\end{array} & 23 & 1.9 & <40 & <17 \\ & 10-21 & 1.1-1.3 & <40 & <17\end{array}$


Carbowax 4000 was also analysed for impurities by emission spectroscopy. The binder contained only copper as a cationic impurity. The level present was $0.001 \%$ or 1 ess, an amount considered to be ineffectual.

Surface area measurements were attempted on pre and post calcined powders. Precalcined powders gave highly erratic results due mainly to outgassing of the powder during the test even though preconditioned at $150^{\circ} \mathrm{C}$. The results presented in Table $4-5$ are for powders calcined at $950^{\circ} \mathrm{C}$.

TABLE $\quad 4-5$

SURFACE AREA OF $\operatorname{Tm}_{2} \mathrm{O}_{3}$ POWDERS CALCINED AT $950^{\circ} \mathrm{C}$ DETERMINED BY BET NITROGEN ABSORPTION METHOD

\section{Process}

Ammonium oxalate

Oxalic acid

Urea

Methyl oxalate
Surface Area $\left(\mathrm{m}^{2} / \mathrm{gm}\right)$

3.8

0.9

6.2

2.1

The surface area data for ammonium oxalate and methyl oxalate appears to be higher than that expected from the pictorial representation of these powders (Figure 4-8). The remainder were in reasonabie agreement; the nature of these discrepancies was not understood. Correlation of surface area to bulk sintered density (Table 4-6) was not observed. Generally, the bulk densities were within $15 \%$ of theoretical density ( $8.8 \mathrm{gm} / \mathrm{cc})$; $1 \mathrm{ack}$ of correlation with density was attributed to the overriding effect of pressing pressure of 29 tsi.

TABLE $\quad 4-6$

$$
\text { BULK - SINTERED DENSITIES ( } \mathrm{gm} / \mathrm{cc} \text { ) }
$$

Bulk Densities

\begin{tabular}{|c|c|}
\hline$(\mathrm{gm} / \mathrm{cc})$ & $\%$ Theo. \\
\hline $7.6-8.4$ & $86-95$ \\
\hline $6.7-7.5$ & $76-84$ \\
\hline
\end{tabular}




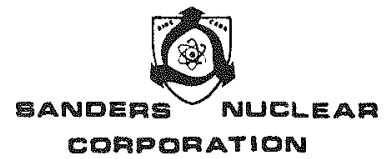

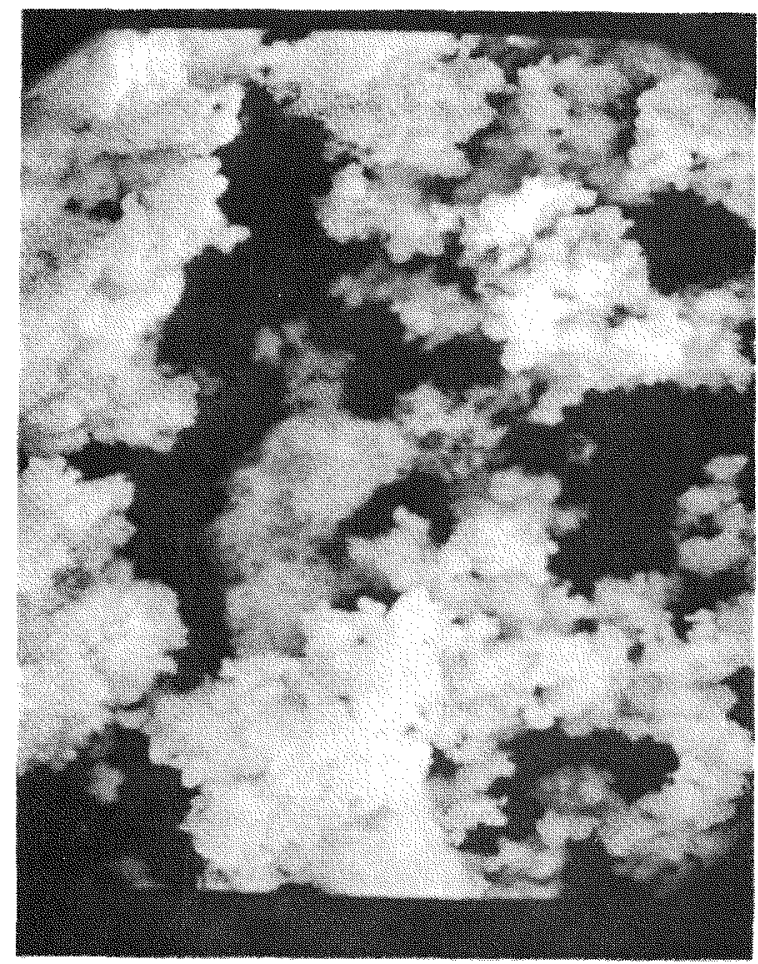

A. UREA PROCESS (3000X)

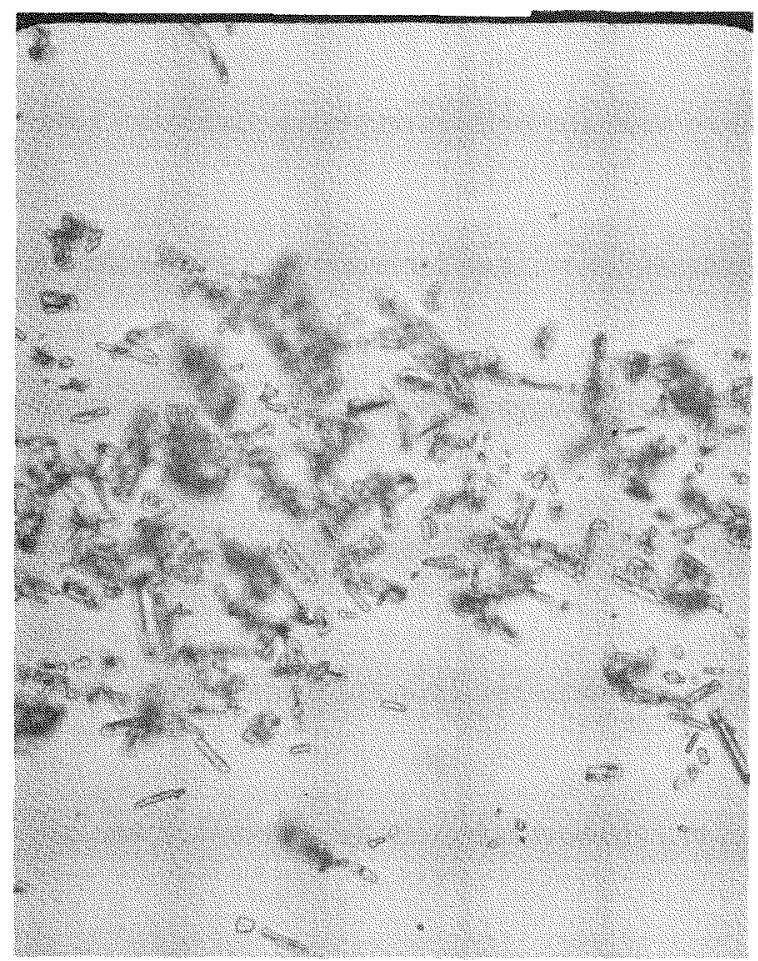

C. METHYL OXALATE

PROCESS (1000X)

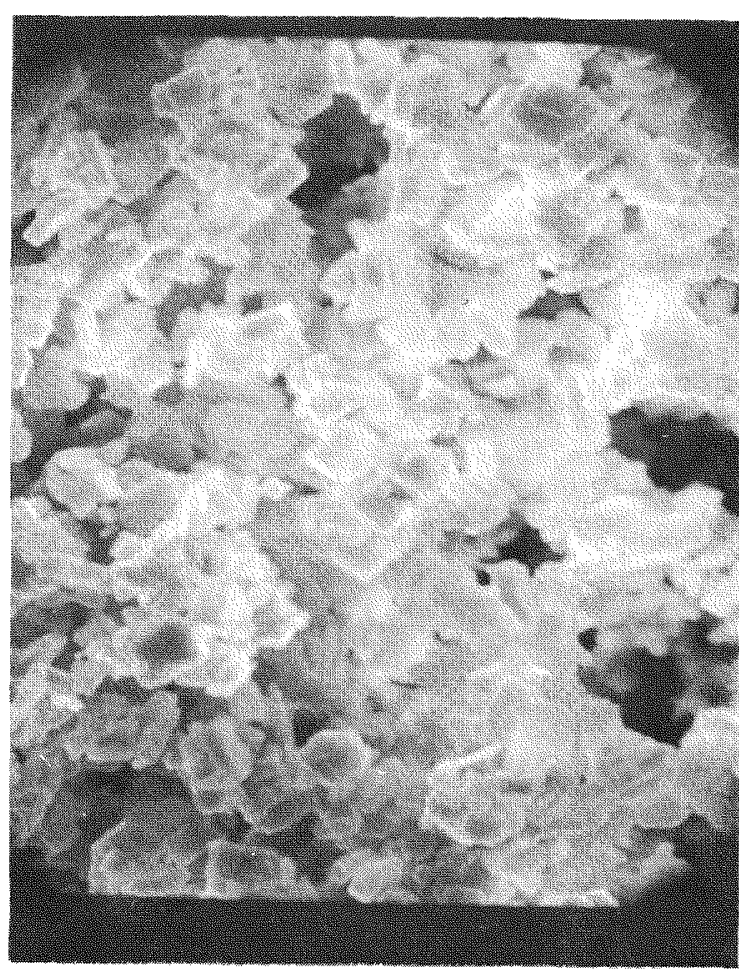

B. AMMONIUM OXALATE PROCESS (3000X)

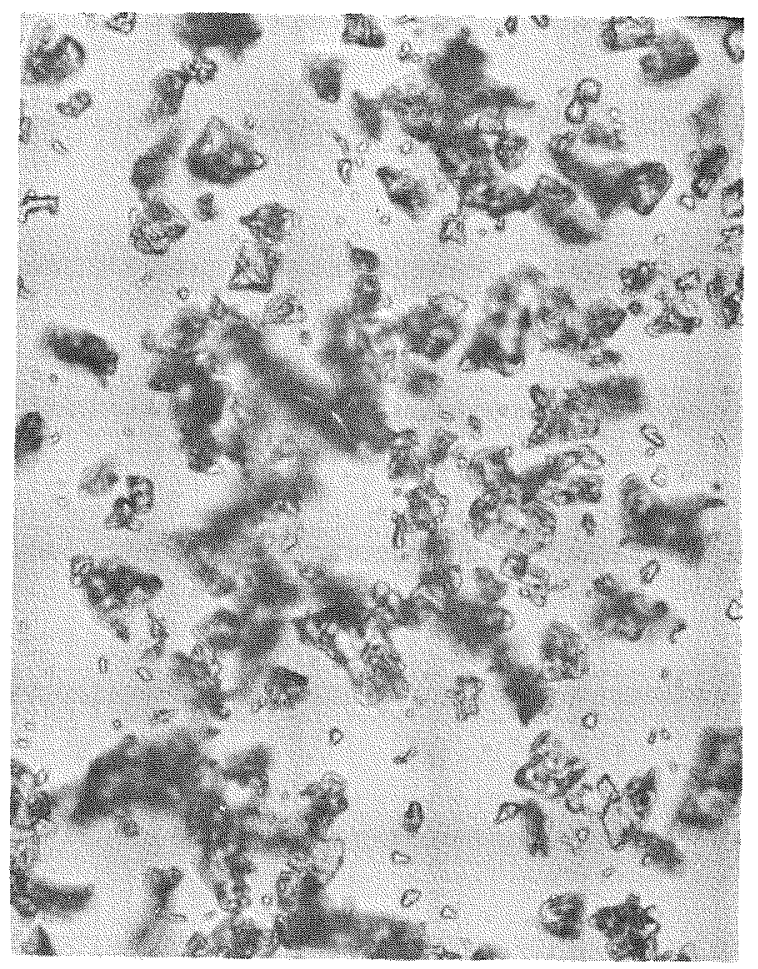

D. OXALIC ACID PROCESS (1000X)

Figure 4-8 $\operatorname{Tm}_{2} \mathrm{O}_{3}$ Powders Calcined at $950^{\circ} \mathrm{C}$. 
TABLE $\quad 4-6$

$$
\text { BULK - SINTERED DENSITIES ( } \mathrm{gm} / \mathrm{cc} \text { ) (Cont) }
$$

Urea

Methyl oxalate
Bulk Densities

$(\mathrm{gm} / \mathrm{cc})$

$8.2-8.5$

$7.5-7.9$
$\%$ Theo.

$92-95$

$84-89$

Thase wafers prepared by precipitation with ammonium oxalate had superior sintered bulk density than those prepared by oxalic acid. Wafers fabricated from thulia prepared by the urea route had a higher sintered bulk density than those prepared from powders obtained by methyl oxalate precipitation and had the highest sintered density of the four processes.

Substantial differences in appearance of wafer products were observed. The thulia wafers produced from urea and ammonium oxalate exhibited more shrinkage than those prepared from methyl oxalate and oxalic acid and were more translucent. All had some surface coloration and some wafers had a speckled appearance that extended into the subsurface. This phenomena did not appear with any consistancy in a given type of preparation. Some of the wafers fabricated with thulia prepared from oxalic acid were severely laminated and disintegrated when handled in routine fashion. On the basis of sintered density and conversion efficiency, the urea and ammonium oxalate processes were selected.

\subsubsection{EFFECTS OF SINTERING - TIME/TEMPERATURE/ATMOSPHERE ON Tm $2_{3} \mathrm{O}_{3}$}

The objective of this task was to (1) determine the effects of varying pressing pressure and sintering time/temperature/ atmosphere on $\mathrm{Tm}_{2} \mathrm{O}_{3}$ bodies made from powders reprocessed from "as received" $\mathrm{Tm}_{2} \mathrm{O}_{3}$ by two different chemical processes and (2) following this determination to select 5 processes that represented the optimum in process conditions with respect to mechanical, thermal and chemical stability. The pressing pressure investigated were 4, 15 and 29 tsi; air, vacuum and hydrogen atmospheres were employed for sintering wafers at temperatures to $1750^{\circ} \mathrm{C}$ for times to 32 hours. Evaluation was performed according to the same format used in evaluating the bench marks. 
EXPERIMENTAL

The two process selected for preparing $\mathrm{Tm}_{2} \mathrm{O}_{3}$ for this evaluation were the urea and ammonum oxalate precipitation processes (13). Both of these were scaled up 10 fold for these experiments $(20 \mathrm{gm}$ to ح $200 \mathrm{gm}$ ) with improved efficiency realized for the ammonium oxalate method ( $90 \%$ ). No change in surface area of the powder nor impurity level of the four elements occurred as a consequence of scale up.

The wafers were cold pressed in steel dies as described previously at 4,15 and 29 tsi subsequent to binder addition and sintered on tungsten or aluminum oxide setters covered with $\mathrm{Tm}_{2} \mathrm{O}_{3}$ powder. Sintering was carried out according to the matrix outlined in Table 4-7. Density, chemical analysis and "mechnical strength" test were performed as previously described. The mechanical strength test was identical to the fines analysis test except one screening at $149 \mu$ was used instead of three different sizings. A summary of experimental data is given in Table 4-8.

\section{RESULTS AND DISCUSSION}

The wafers analysed in this group of work were representative of 54 different sets of processing conditions. The broad matrix had no effect however, on the $\mathrm{Tm}_{2} \mathrm{O}_{3}$ structure as determined from $x$-ray diffaction nor was any change in lattice parameter observed. EFEECTS OF SINTERING IN AIR AT $1450^{\circ} \mathrm{C}$

$\operatorname{Tm}_{2}{ }_{3}$ wafers were sintered in air for times to 32 hours, were off white in color and were in one piece at the end of the maximum time period. Sintered densities of wafers from both processes increased with increasing pressure to a maximum of 8.1 $\mathrm{gm} / \mathrm{cc}$ of for the urea process and $7.4 \mathrm{gm} / \mathrm{cc}$ for the oxalate method. Elemental levels of iron were slightly higher in urea process wafers. The remaining three elements were either constant or changed erratical1y. The particle population in the sub 149 micron range for all wafers was essentially the same considering the statistical error band. 
TABLE 4-7 TEST MATRIX TO OPTIMIZE PRODUCTION PROCESS VARIABLES

AS MEANS TO $\mathrm{Tm}_{2} \mathrm{O}_{3}$ FUEL FORM STABILITY ENHANCEMENT

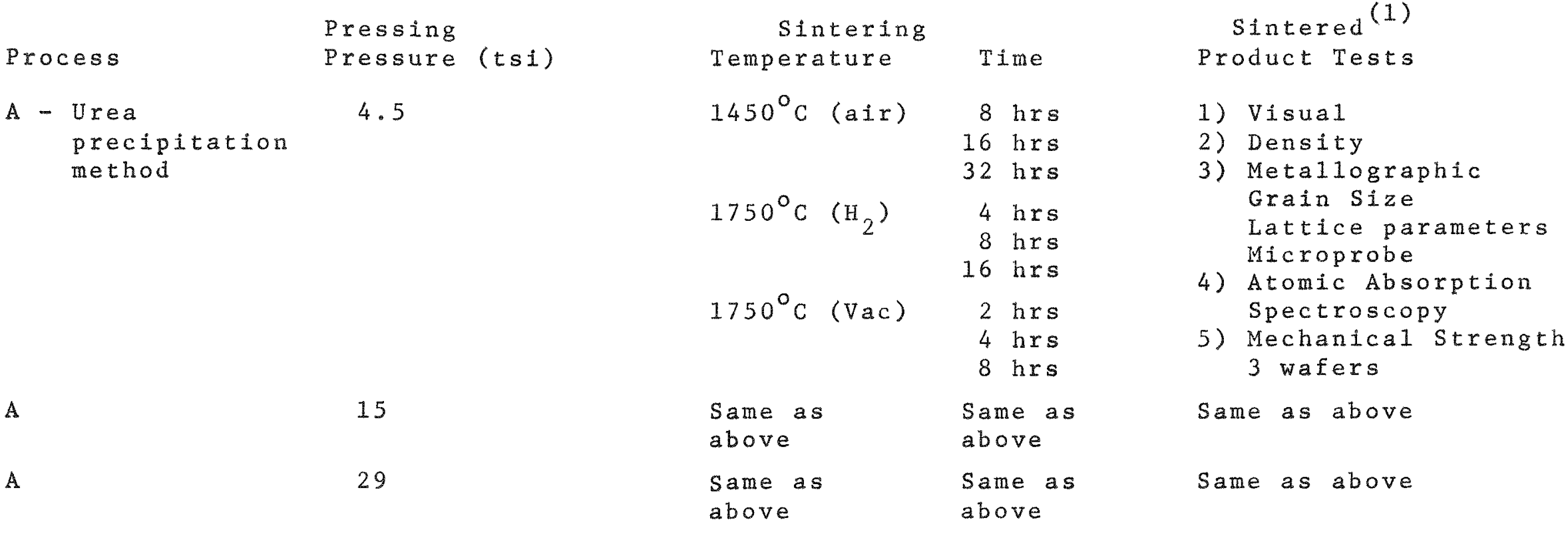

$B$ - Ammonium Oxalate

SAME AS ABOVE FOR PROCESS A

precipitation

method

(1) 54 production processes are evaluated using 270 wafers; five processes are selected for evaluation in Phase III on the bases of sintered product tests. 
TABLE 4-8

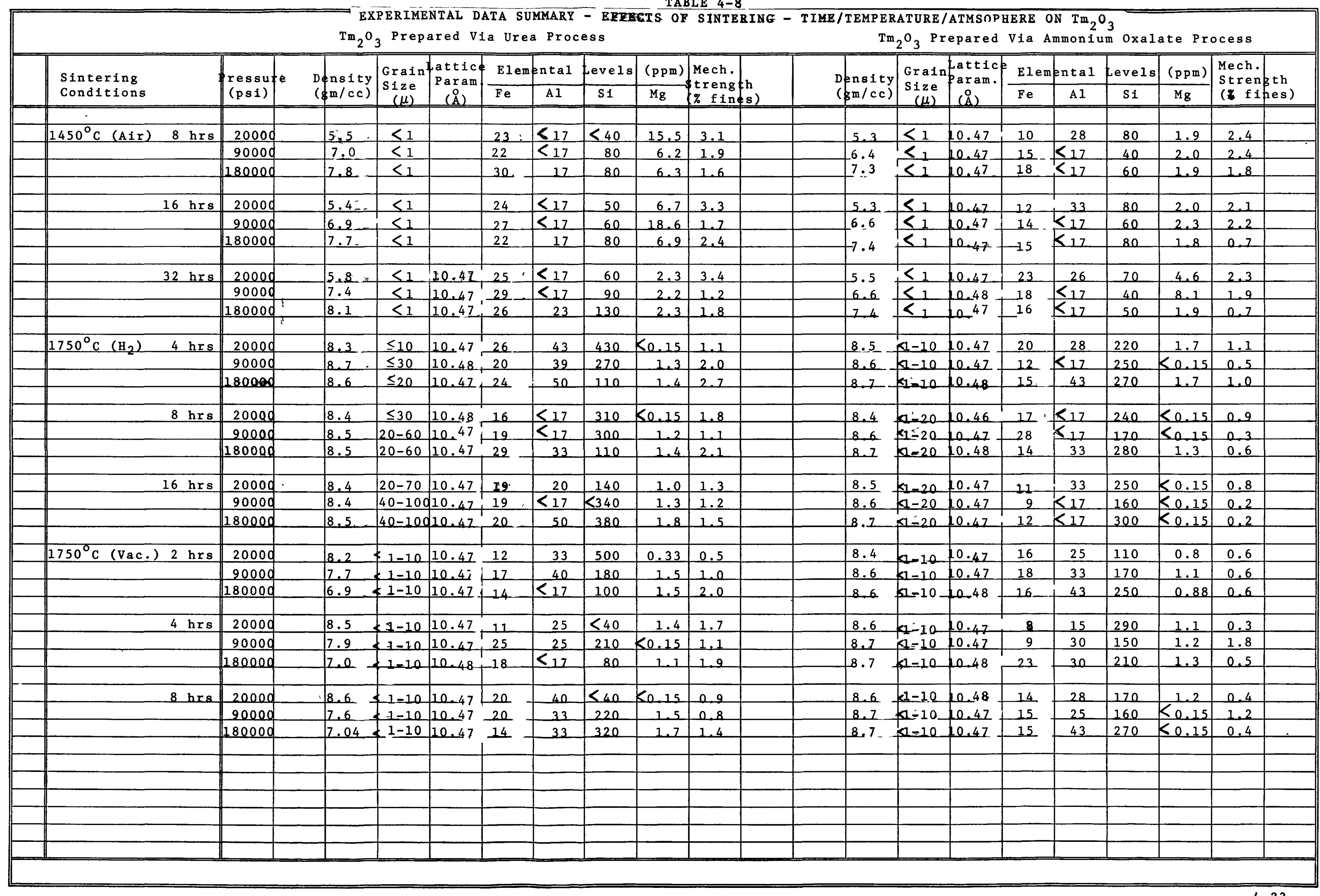


In cross section, the wafers were observed to have different colorations. Laminations were present in some instances, particularly at low pressing pressure that nearly split the wafer in two. These laminations were due to non-uniform die pressure, the magnitude thereof suggested that more binder might have been used particularly for the low pressing pressure. Microprobe analysis of these areas confirmed that both contained only thulium.

The wafers from both processes were very soft and difficult to polish. Fractographs of these wafers indicated a grain size below the resolving power of a light microscope, i.e., less than 1 micron. Metallographically, the porosity appeared to be very fine and uniformly distributed. No other phases were observed.

No differences in microstructure were observed that might explain the two textures present in both of the types of processes. The degree to which fines production was attributable to pressure or some other set of factors was difficult to determine because of poor statistics. No major differences attributable to processing were observed.

EFFECTS OF SINTERING IN VACUUM AT $1750^{\circ} \mathrm{C}$

Wafers were sintered in vacuum of $\sim 10^{-6}$ torr for times to 8 hours, were pale green in color and were visually free of cracks. The surfaces were smooth and glossy with well defined edges. Sintered densities of urea process wafers increased with increasing pressure for a 4.5 tsi pressure to a maximum of $8.6 \mathrm{gm} / \mathrm{cc}$. Increasing pressures produced little or no improvement in density for this material. Wafers of the oxalate material attained densities to $8.7 \mathrm{gm} / \mathrm{cc}$. Densities in this group were comparably higher for all conditions. Also, densities were generally higher under these conditions than for air sintering, at $1450^{\circ} \mathrm{C}$, the major reason being the increased temperature.

Levels of the 4 elements checked were essentially the same process for process, but slightly lower in magnesium when compared to air sintering. This effect was also primarily attributed to increased temperature. 
Fractographs showed an increase in grain growth to a maximum of 10 microns in both cases and a slight reduction in particles of less than 149 micrors. Comparing process for process, the fines fractions again fell within the statistical error band.

Attempts to chemically etch samples to enhance grain structure were ineffective throughout this entire nvestigation. Sintered wafers could be dissolved only after lengthy grinding and strong nitric acid treatment at elevated temperatures. No better testimony of the chemical resistance of $\operatorname{Tm}_{2} \mathrm{O}_{3}$ was required to rate the chemical stability of this ceramic extremely high. Because of this resistance to etching, fractured surfaces were used to assess grain size.

No other phases were observed metallographically. The void pattern observed supported the higher sintered density measured. In both cases, there was evidence of lamination to a much lesser extent than the prior observations. Crack healing was observed and adjacent to crack areas, the oxide had developed transparency. The wafers were also less opaque than air sintered wafers. Sma11, transparent grains were observed randomly in the wafers produced from urea process materials.

A small difference in sintered density was observed to be the distinguishing feature between processes under these conditions. There were, however, many improvements in specific properties over air sintered wafers, particularly in sintered density.

EFFECTS OF SINTERING IN HYDROGEN AT $1750^{\circ} \mathrm{C}$

$\mathrm{Tm}_{2} \mathrm{O}_{3}$ wafers were sintered in hydrogen at $1750^{\circ} \mathrm{C}$ for times to 16 hours. The wafers were black, were visually free from cracks, and smooth like the wafers sintexed in vacuum. Sintered densities of wafers made from urea process material increased with time when originally pressed at 4.5 tsi. Although increased pressure produced a slight increase in density for the same sintering time, a longer sintering time induced a decrease in density. This effect may have been true for oxalate method wafers also, but the 
data were too close to define a pattern. Sintered densities ranged from $8.3-8.7 \mathrm{gm} / \mathrm{cc}$, the highest spread of densities achieved in this phase of study.

Elemental levels of iron were slightly higher in this series for urea process wafers, but about the same as those found in air sintered product. Levels of the remaining elements were essentially unchanged. The particle population in the sub 149 micron range for oxalate method wafers was the 1 owest observed throughout. This reduction was accompanied by corresponding increase in grain size to 20 microns, about twice that for wafers sintered in vacuum. Urea process product however, maintained the same particle population in the sub 149 micron range even though grain size increased up to 100 microns. Grain growth was both pressing pressure and time dependent for this product. The increased grain size observed in urea method wafers and the behavior observed in the oxalate product would lead to a first prediction that sub 149 particles in urea process product would be lower than what was actually found. Since this was not observed, it suggests that fracturing was dependent on parameters not identified. Figures 4-9 to 4-31 contrast these two product types.

Metallographically, wafers from both processes were highly translucent to transparent and colored throughout suggesting that in situ reduction of some impurity had occurred or deposition of impurity on the surface during processing or sintering and then subsequent diffusion. Some lamination was observed in both types of wafers. The urea process wafers were studded with transparent grains that were particularly dense along crack surfaces exposed to environment (Figure 4-14). This grain phenomenon was observed in oxalate method wafers, but to a much lesser degree. Microprobe analysis of these grains showed equal concentration of thulium with respect to surrounding, areas. It was concluded that the population of these grains was a function of the hydrogen atmosphere and that some subtle process dependent factor was either responsible 
for the grain growth observed in the urea process product or was acting as a controlling agent in the oxalate method wafers.

\section{CONCLUSIONS}

54 sets of processing conditions were used to prepare $\mathrm{Tm}_{2} \mathrm{O}_{3}$ wafers. Processing conditions included chemical processing, pressing paessure, atmosphere, temperature and time. The product properties used as indicators of process condition influence were crystaline structure, wafer integrity, chemical purity sintered density, grain size and fines generation.

The cubic crystalline structure of $\mathrm{Tm}_{2} \mathrm{O}_{3}$ was insensitive to any of the test matrix conditions. All wafers were whole following sintering, but some degree of lamination could be observed in most samples. The laminating was attributed to the cold pressing techniques used for product preparation.

Although chemical processing, pressing pressure, ptmosphere and time were observed to influence levels of impurity, sintered density, grain size and fines generation, temperature was the major influence on these properties. Sintering at $1750^{\circ} \mathrm{C}$, clearly improved density and lowered fines generation when compared with products sintered at $1450^{\circ} \mathrm{C}$. At $1750^{\circ} \mathrm{C}$, relatively low percentages of particles of less than 149 microns were observed and bulk sintered densities approaching theoretical density $(8.9 \mathrm{gm} / \mathrm{cc})$ were prevalent.

It was concluded from these results that pressing pressure, time, atmosphere and chemical processing were secondary to temperature in influencing process conditions and that $1750^{\circ} \mathrm{C}$ was the optimum temperature for sintering $\mathrm{Tm}_{2} \mathrm{O}_{3}$ wafers. The insensitivity of $\mathrm{Tm}_{2} \mathrm{O}_{3}$ properties to such a wide range of process variables at $1750^{\circ} \mathrm{C}$ provided great flexibility in the selection sf conditions for the 5 process required for further study.

The resultant five sets of process conditions selected are given in Table $4-9$. 


\section{TABLE $\quad 4-9$ \\ PROCESS CONDITIONS SELECTED FOR PRERARING WAFERS FOR STUDYING "EFFECTS OF AGING ON $\operatorname{Tm}_{2} \mathrm{O}_{3}$ "}

METHOD

Ammonium oxalate Ammonium oxalate Ammonium oxalate Ammonium oxalate Urea
SINTERING CONDITIONS (TEMPERATURE, PRESSING PRESSURE, TIME, ATMOSPHERE)

$* 1750^{\circ} \mathrm{C}, 29 \mathrm{tsi}, 6$ hours, hydrogen

$1750^{\circ} \mathrm{C}, 29 \mathrm{tsi}, 8$ hours, vacuum

$1750^{\circ} \mathrm{C}, 15 \mathrm{tsi}, 6$ hours, hydrogen

$1750^{\circ} \mathrm{C}, 4.5 \mathrm{tsi}, 4$ hours, vacuum $* 1750^{\circ} \mathrm{C}, 4.5$ tsi, 8 hours, vacuum

* Selected for preparing $80 \% \mathrm{Tm}_{2} \mathrm{O}_{3} / 20 \% \quad \mathrm{Yb}_{2} \mathrm{O}_{3}$ wafers.

4.2.3 EFFECTS OF AGING ON MECHANICAL, CHEMICAL AND THERMAL STABILITY

The object of this task was to expose test samples to an environment that represented nominal operation mission conditions and to determine the degree of mechanical, chemical and thermal stability enhancement realized from this environment. Susceptibility or resistance of encapsulated $100 \% \operatorname{Tm}_{2} \mathrm{O}_{3}$ or $80 \% \mathrm{Tm}_{2} \mathrm{O}_{3} / 20 \% \mathrm{Yb}_{2} \mathrm{O}_{3}$ to these artificially imposed conditions was assessed from metallographic, $x$-ray diffraction and impact-fines generation analyses. The three encapsulants selected, tungsten, TZM and T-111 were from a group of seven candidate encapsulant materials that had been tested for compatibility with $\operatorname{Tm}_{2} \mathrm{O}_{3}$ in a previous study ( 1 ). Aging consisted of heat treating encapsulated wafers for 500 hours at $1600^{\circ} \mathrm{C}$ followed by a thermal spike at $2000^{\circ} \mathrm{C}$. Enhancement of mechanical, thermal and chemical stability was determined by comparison with bench marks that had been'similarly treated.

\section{EXPERIMENTAL}

5 sets of $100 \% \mathrm{Tm}_{2} \mathrm{O}_{3}$ wafers were prepared according to the five processes identified previously. 2 sets of $80 \% \mathrm{Tm}_{2} \mathrm{O}_{3} / 20 \% \mathrm{Yb}_{2} \mathrm{O}_{3}$ were also fabricated. Seven wafers with the same process history 


\section{(1)}

SANDEAS NUCLEAR CORPOAATION

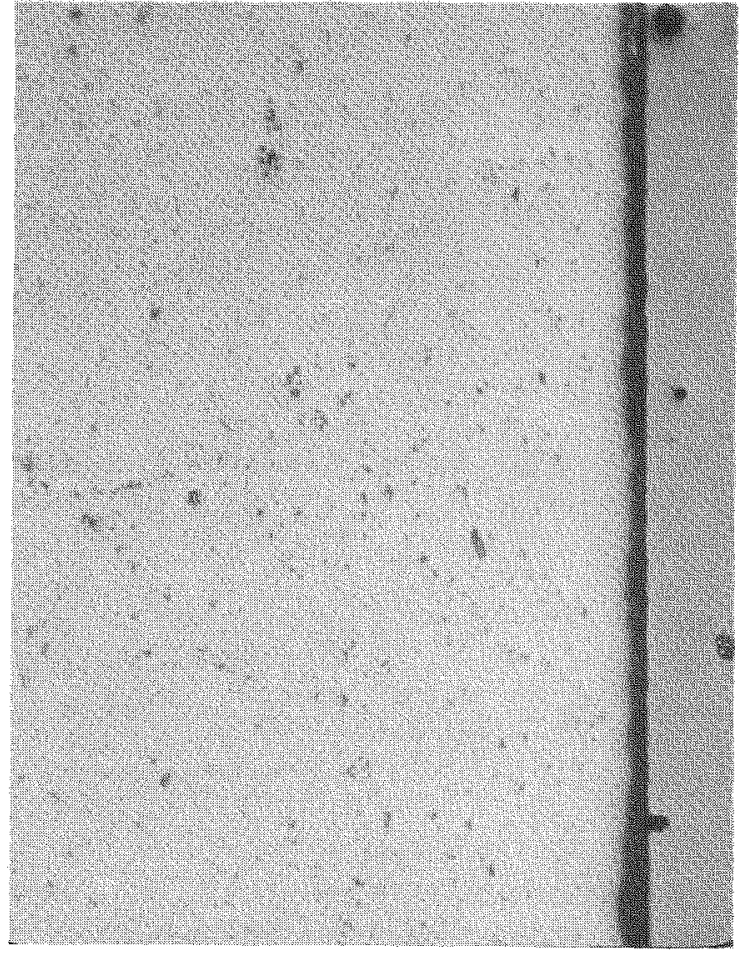

A. 2 HOURS

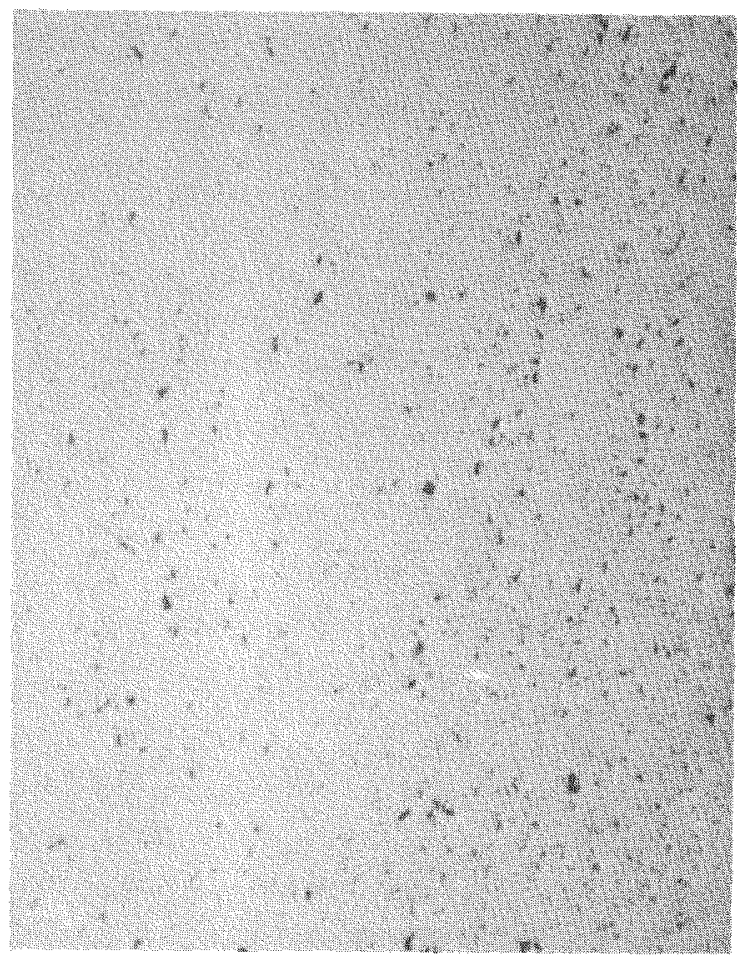

B. 4 HOURS

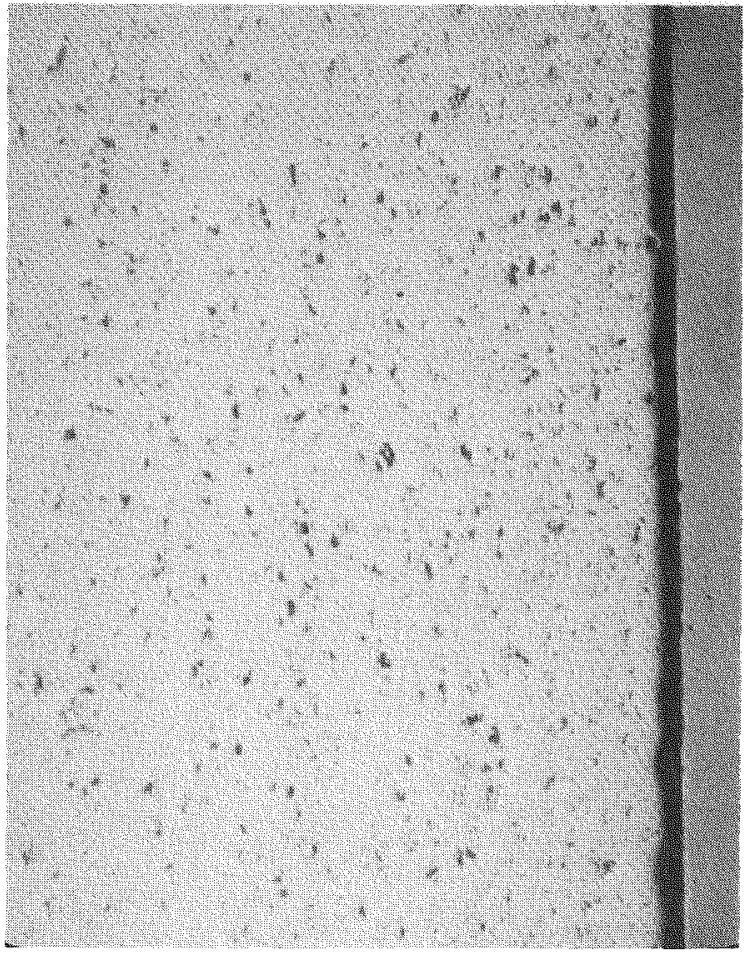

\section{8 HOURS}

Figure 4-9 Urea Process $\operatorname{Tm}_{2} \mathrm{O}_{3}$ Wafers, Pressed at 4.5 tsi, Sintered $1750^{\circ} \mathrm{C}$, Vacuum (as Polished - 70X). 

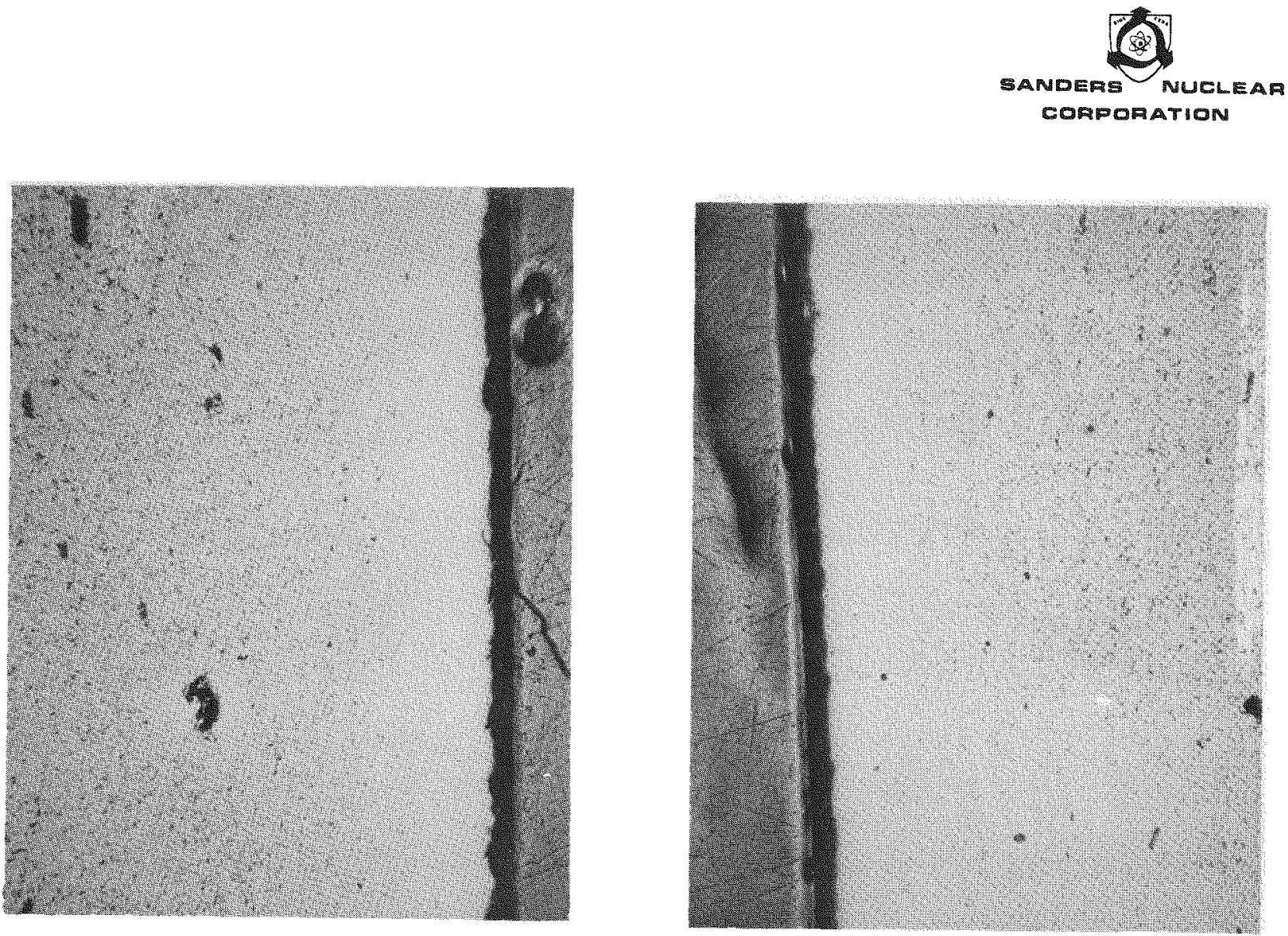

A. 2 HOURS

B. 4 HOURS

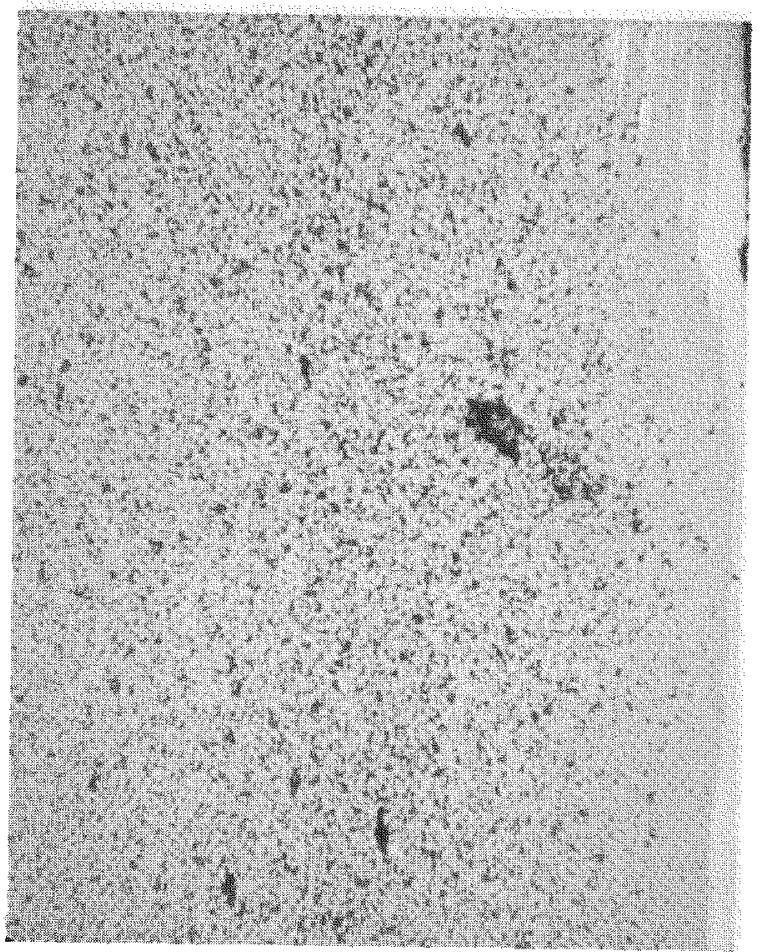

\section{8 HOURS}

Figure 4-10 Urea Process $\mathrm{Tm}_{2} \mathrm{O}_{3}$ Wafers, Pressed at 15 tsi, Sintered $1750^{\circ} \mathrm{C}$, Vacuum (as Polished - 70X). 


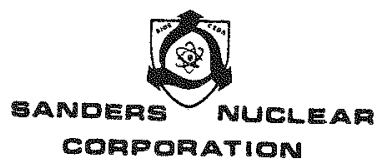

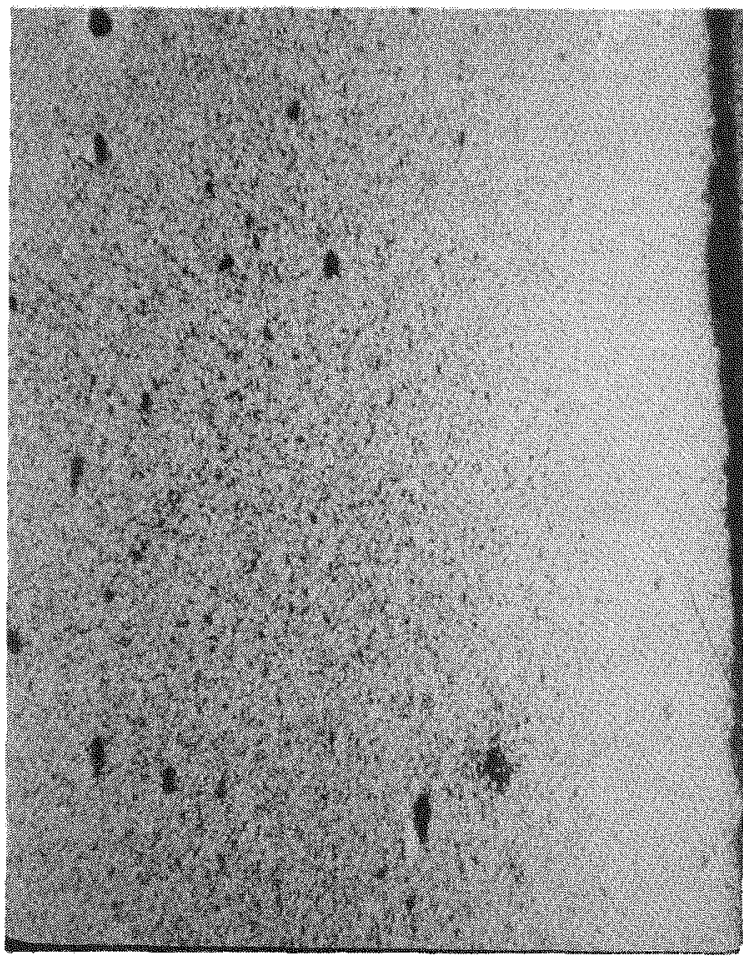

A. 2 HOURS

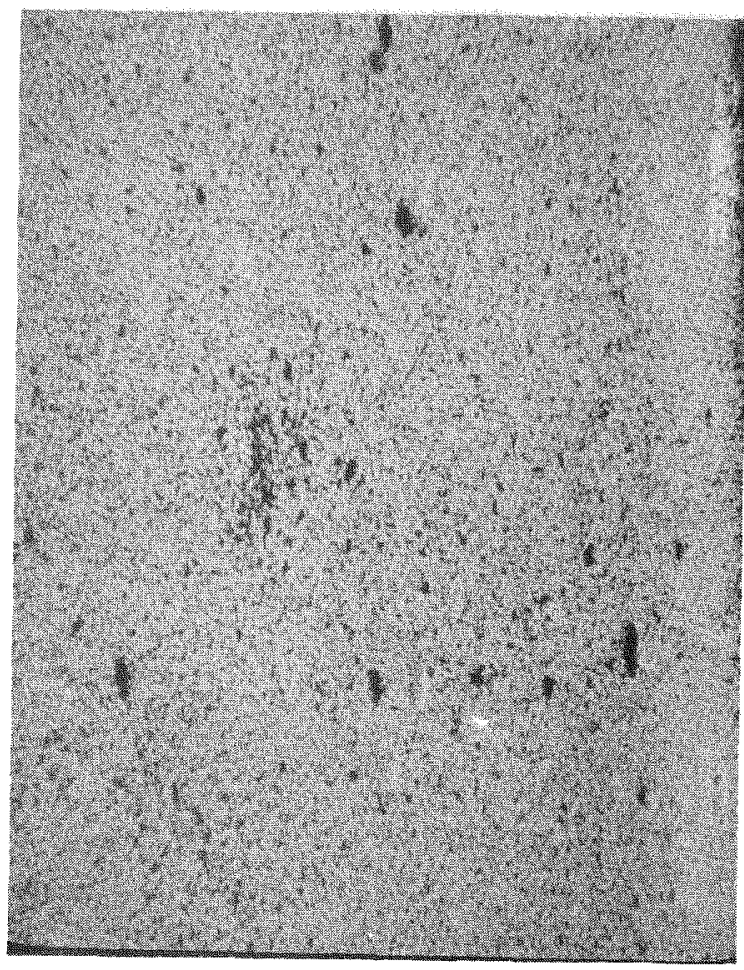

B. 4 HOURS

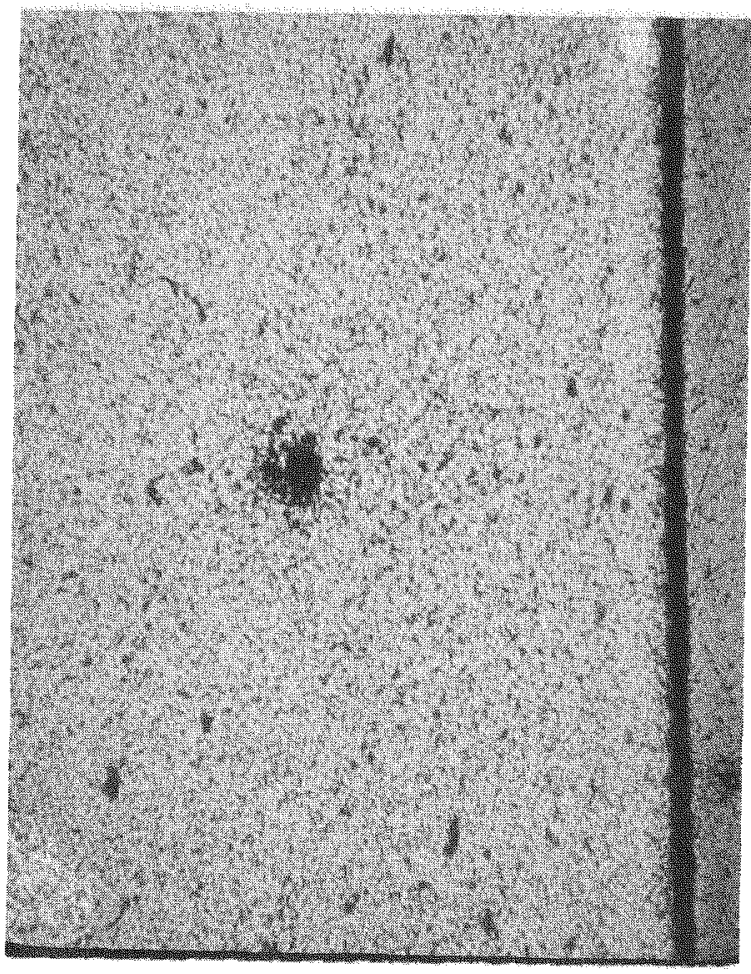

\section{8 HOURS}

Figure 4-11 Urea Process $\mathrm{Tm}_{2} \mathrm{O}_{3}$ Wafers, Pressed at 29 tsi, Sintered $1750^{\circ} \mathrm{C}$, Vacuum (as Polished - 70X). 

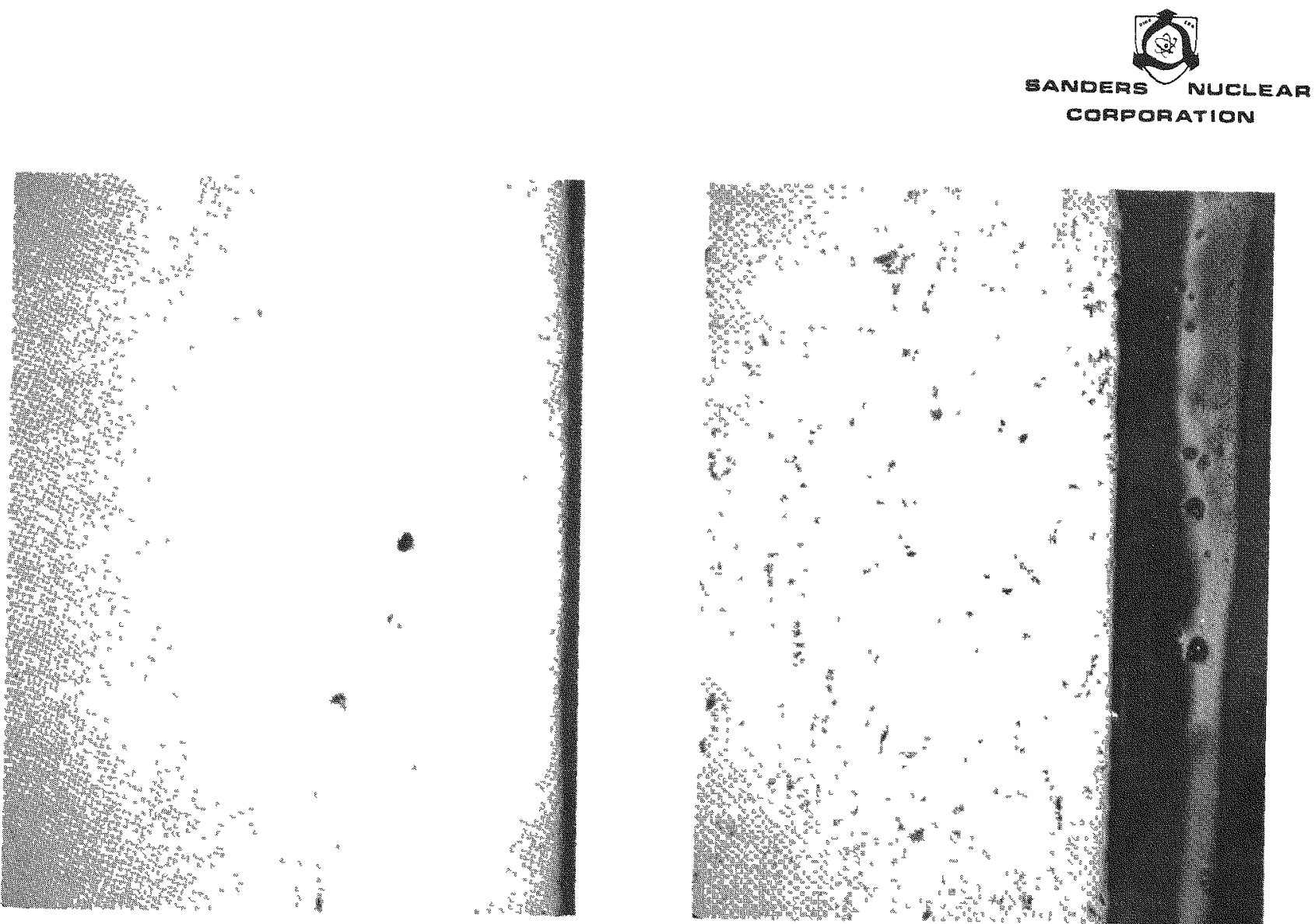

A. 4 HOURS

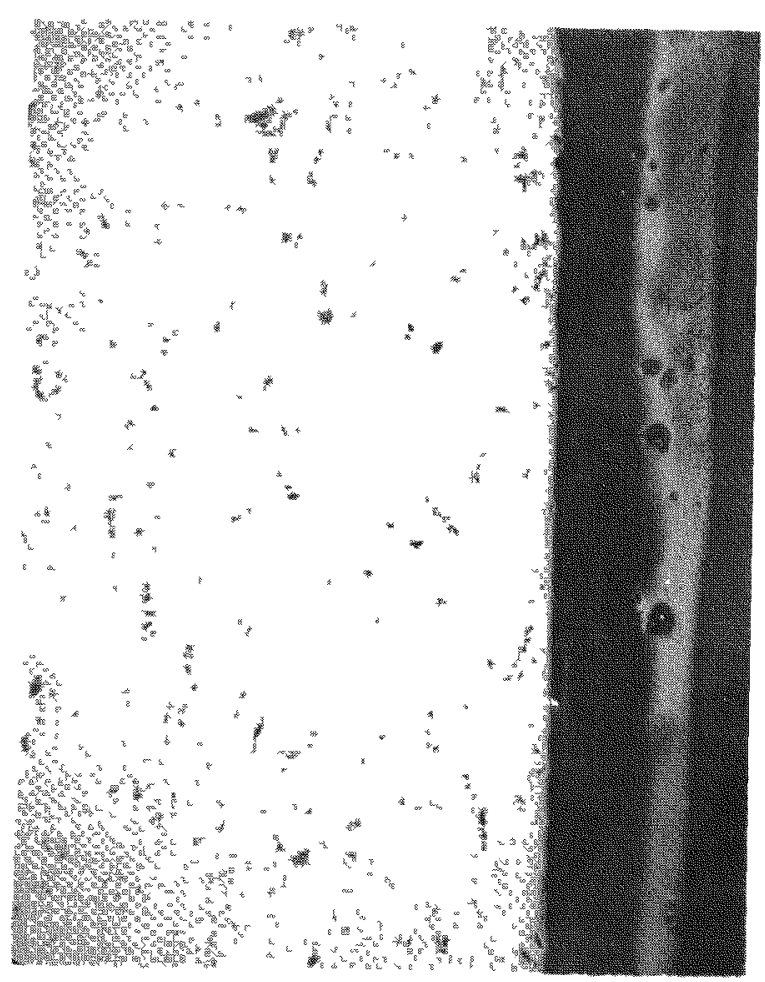

B. 8 HOURS

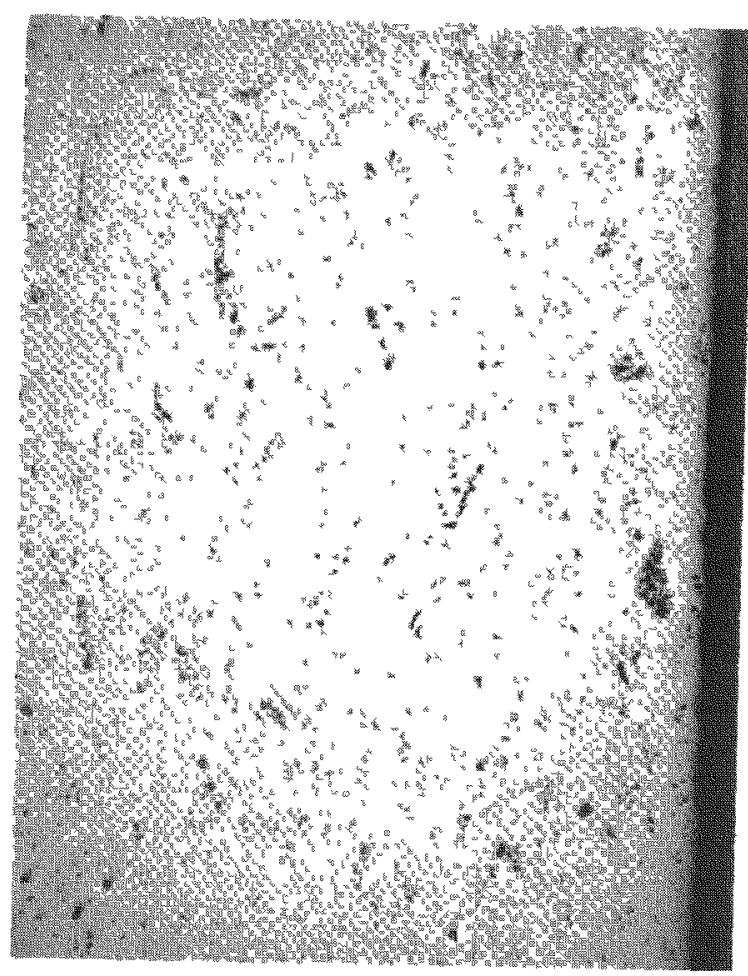

C. 16 HOURS

Figure 4-12 Urea Process $\mathrm{Tm}_{2} \mathrm{O}_{3}$ Wafers, Pressed at 4.5 tsi, Sintered $1750^{\circ} \mathrm{C}$, Hydrogen (as Polished - 70X). 


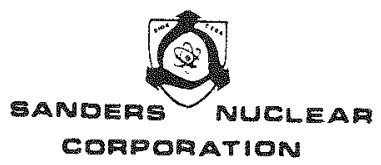

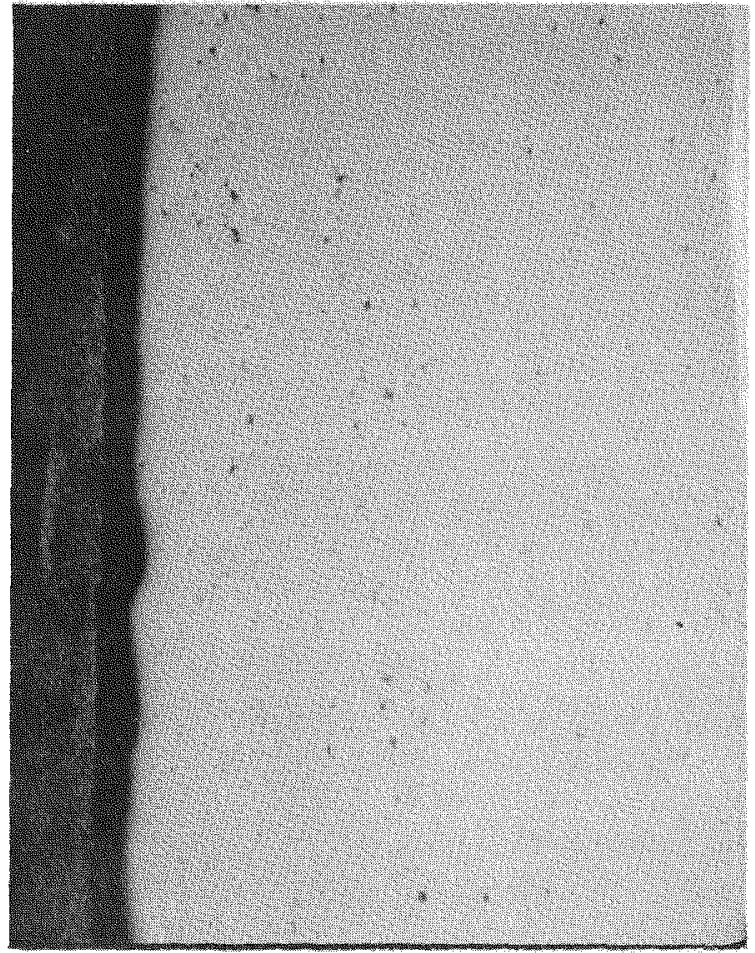

A. 4 HOURS

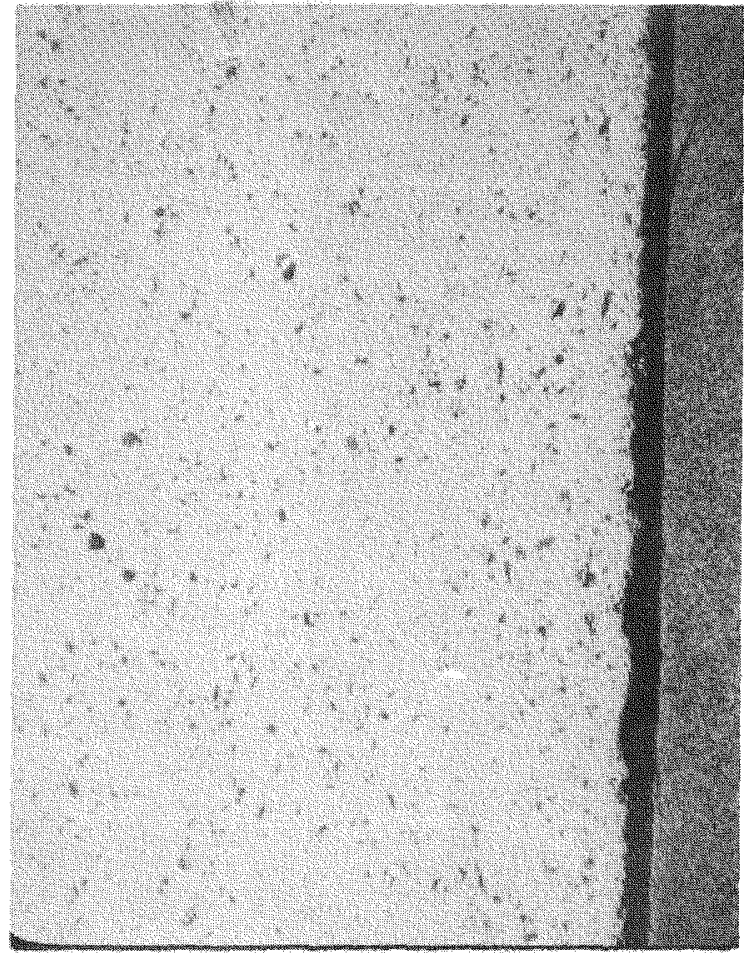

B. 8 HOURS

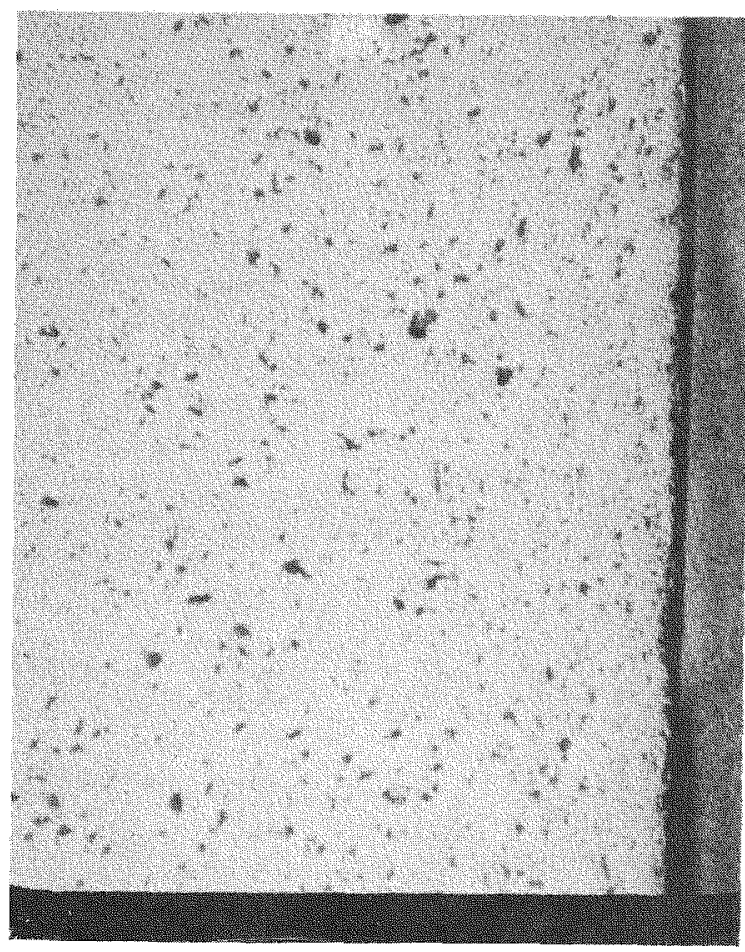

\section{16 HOURS}

Figure 4-13 Urea Process $\operatorname{Tm}_{2} \mathrm{O}_{3}$ Wafers, Pressed at 15 tsi, Sintered $1750^{\circ} \mathrm{C}$, Hydrogen (as Polished - 70X) 


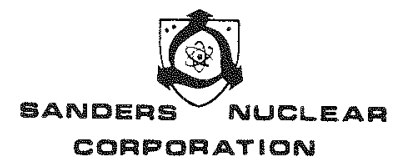

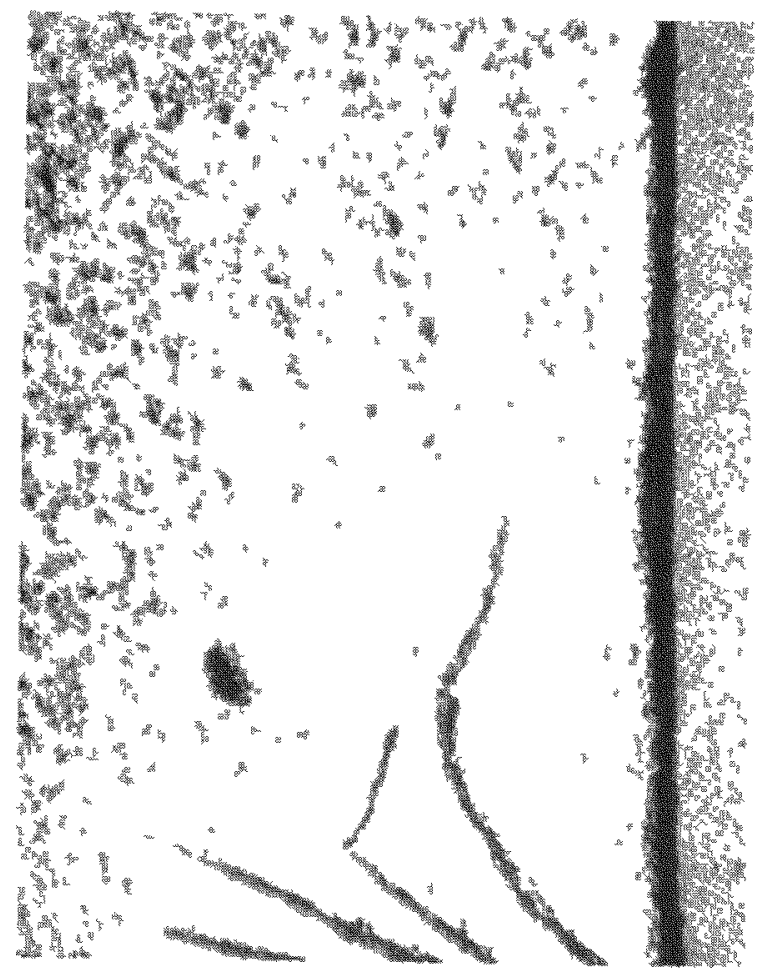

A. 4 HOURS

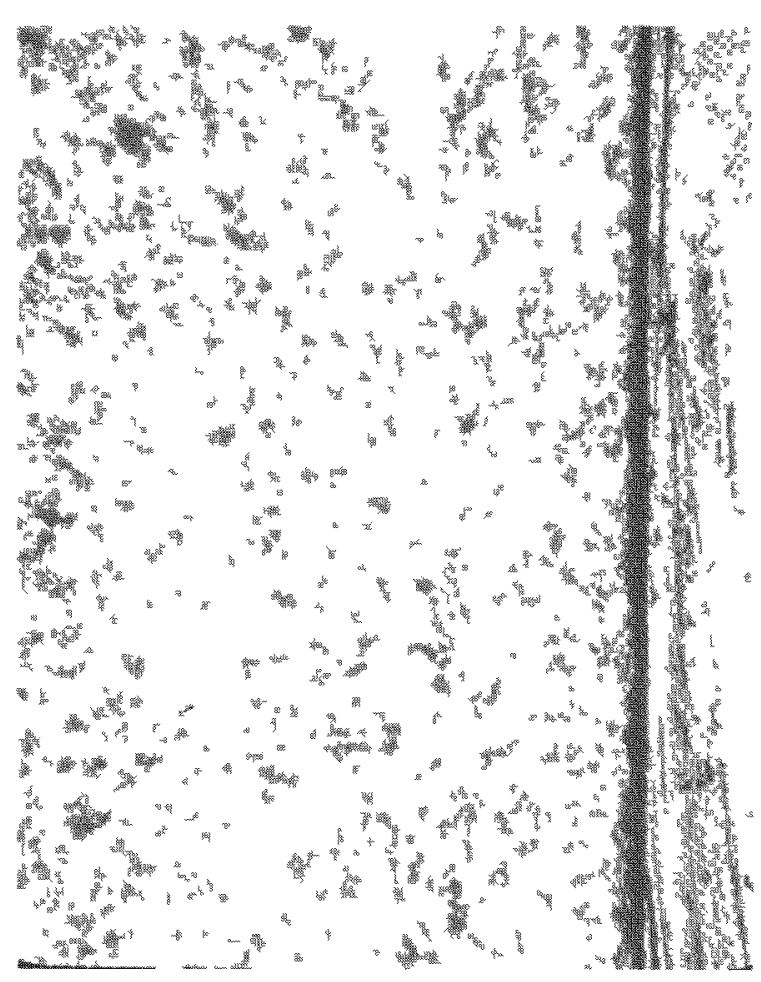

B. 8 HOURS

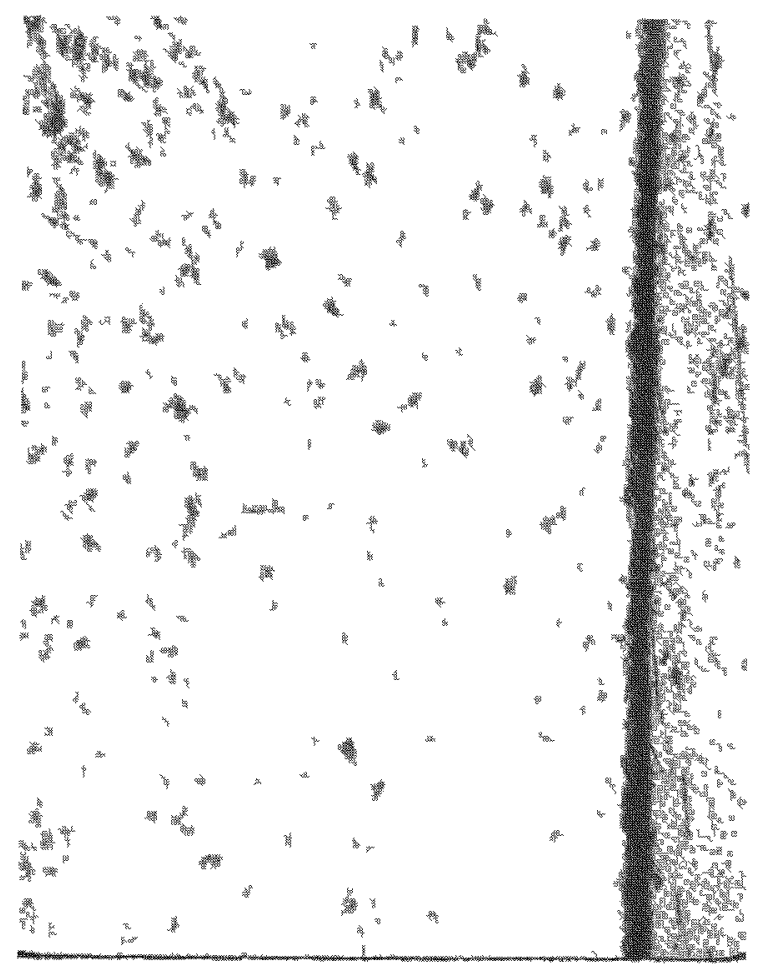

\section{16 HOURS}

Figure 4-14 Urea Process $\mathrm{Tm}_{2} \mathrm{O}_{3}$ Wafers, Pressed at $29 \mathrm{tsi}$, Sintered $1750^{\circ} \mathrm{C}$, Hydrogen (as Polished - 70X). 


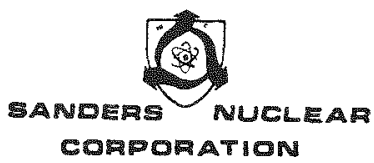

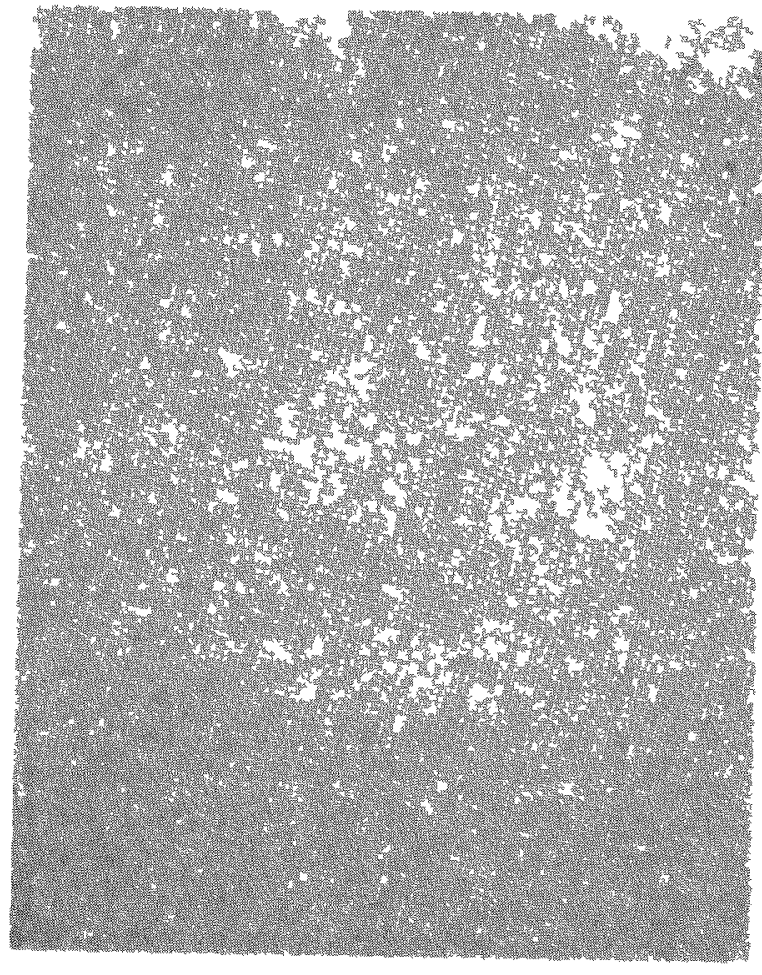

A. 2 HOURS

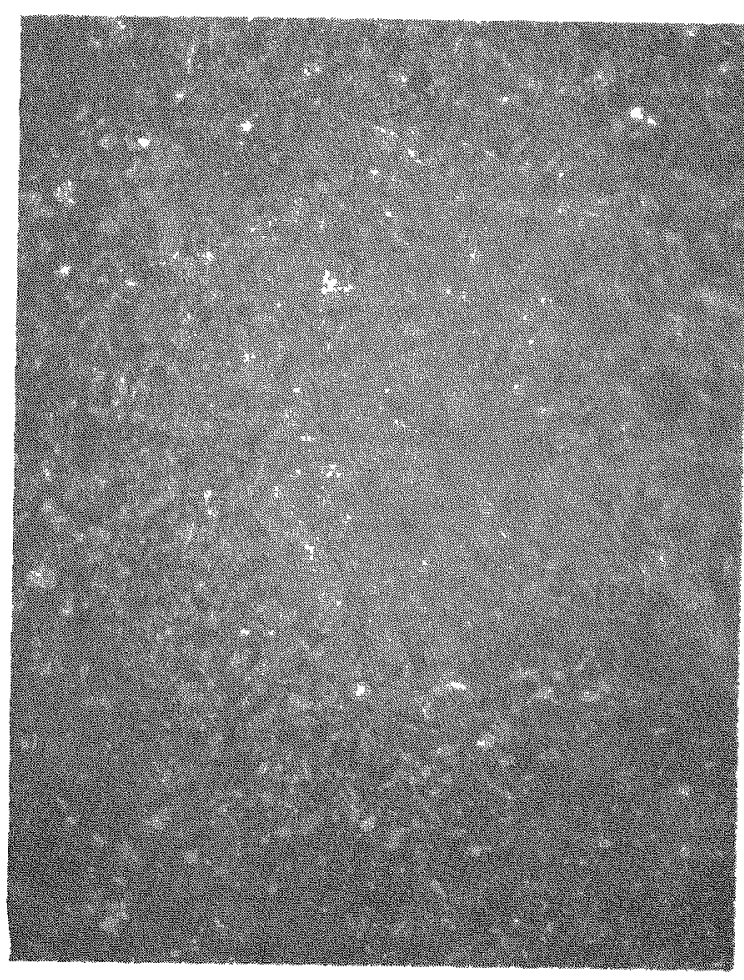

B. 4 HOURS

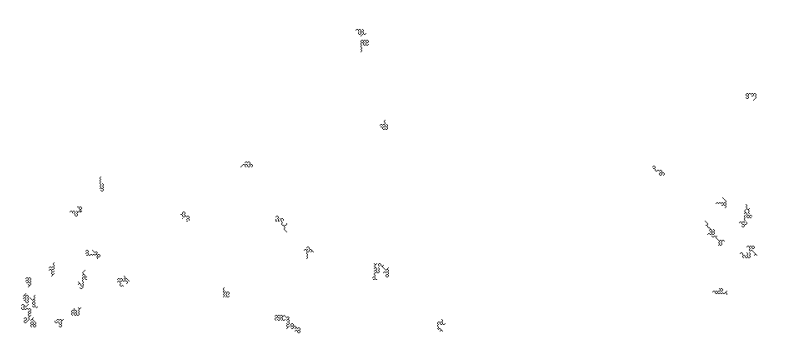

\section{8 HOURS}

Figure 4-15 Urea Process $\operatorname{Tm}_{2} \mathrm{O}_{3}$ Wafers, Pressed at $4.5 \mathrm{tsi}$, Sintered $1750^{\circ} \mathrm{C}$, Vacuum (Fractograph 100X). 

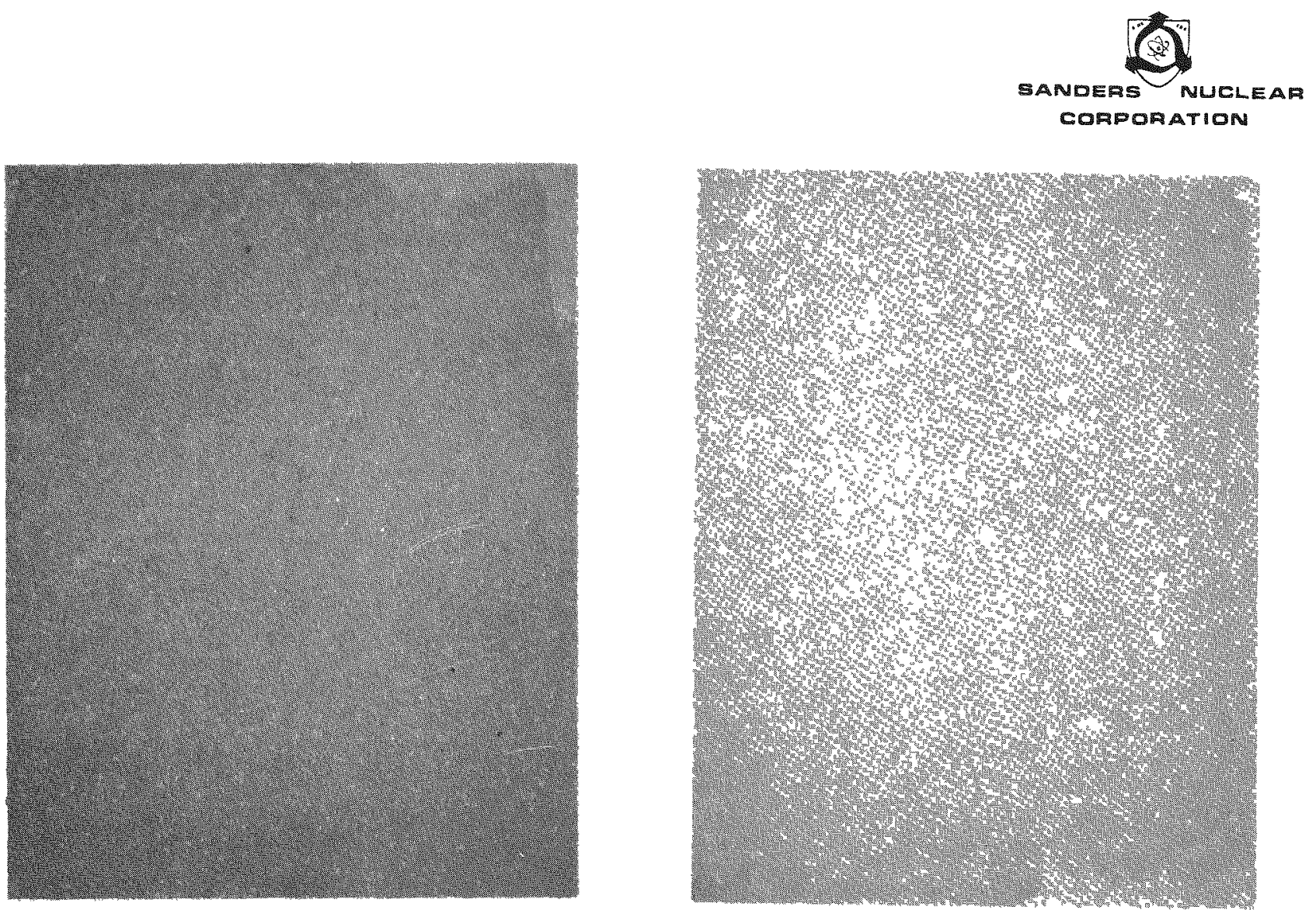

A. 2 HOURS

B. 4 HOURS

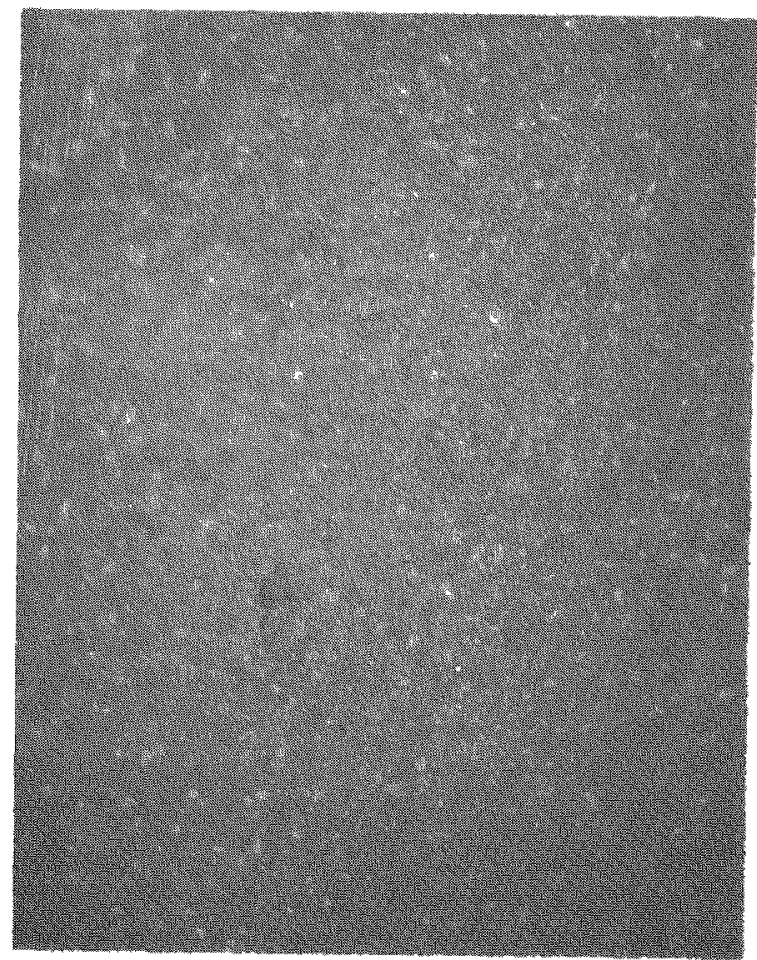

C. 8 HOURS

Figure 4-16 Urea Process $\mathrm{Tm}_{2} \mathrm{O}_{3}$ Wafers, Pressed at 15 tsi, Sintered $1750^{\circ} \mathrm{C}$, Vacuum (Fractograph 100X). 


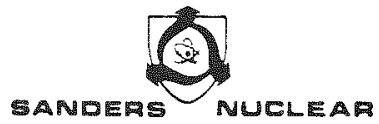

conPOAATION

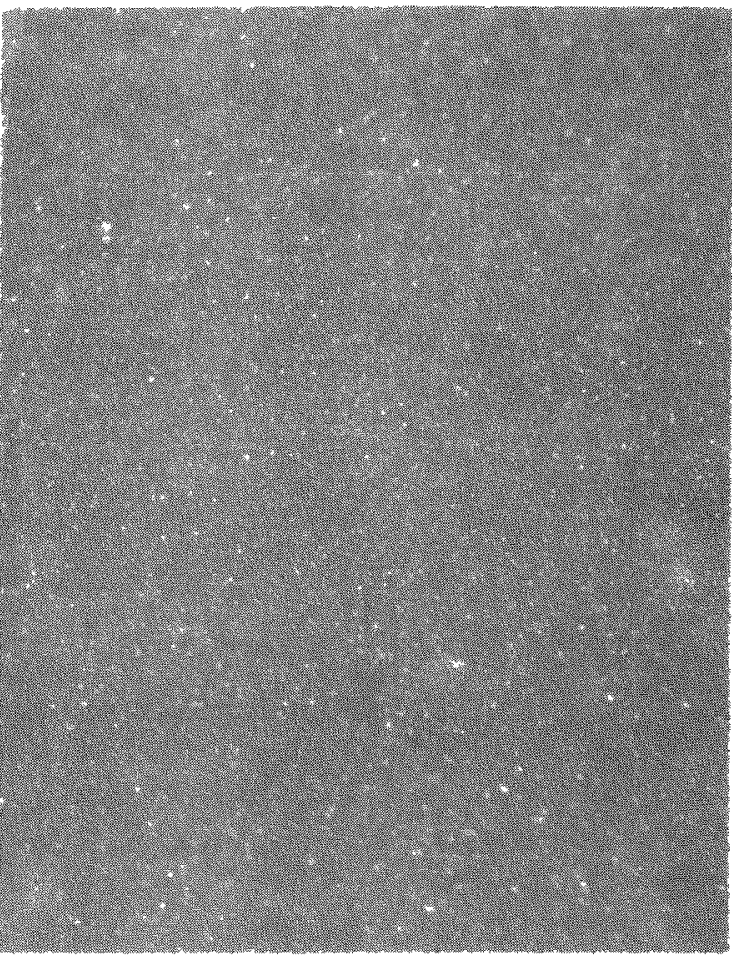

A. 2 HOURS

B. 4 HOURS

\section{8 HOURS}

Figure 4-17 Urea Process $\operatorname{Tm}_{2} \mathrm{O}_{3}$ Wafers, Pressed at 29 tsi, Sintered $1750^{\circ} \mathrm{C}$, Vacuum (Fractograph 100X). 


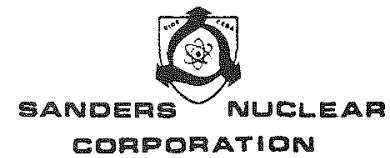

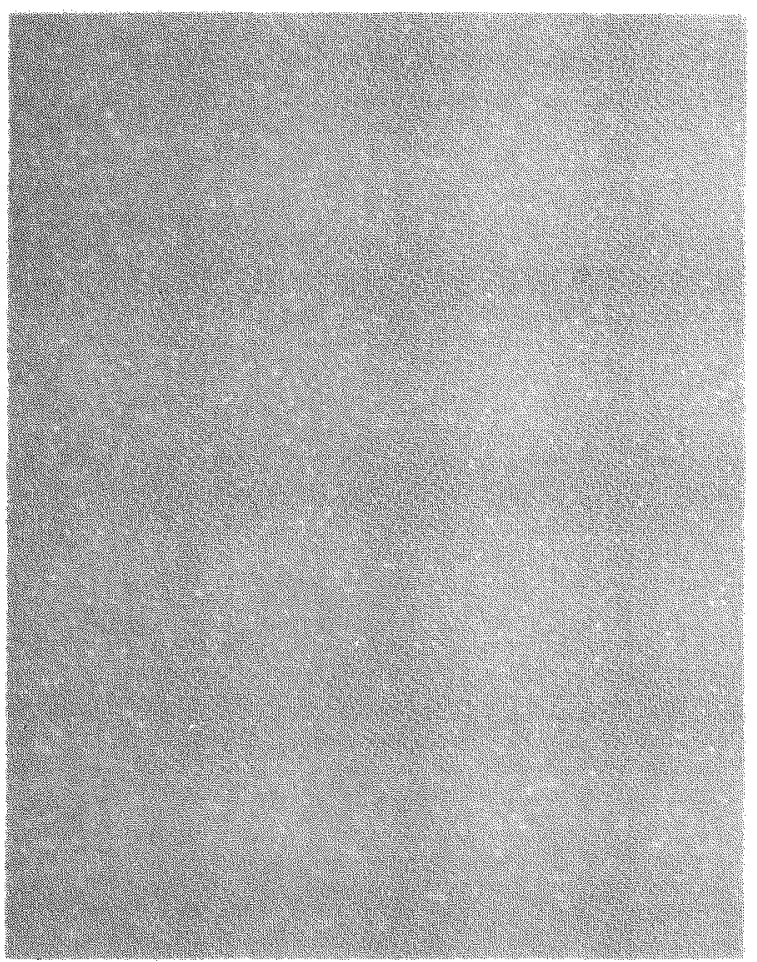

A. 4 HOURS

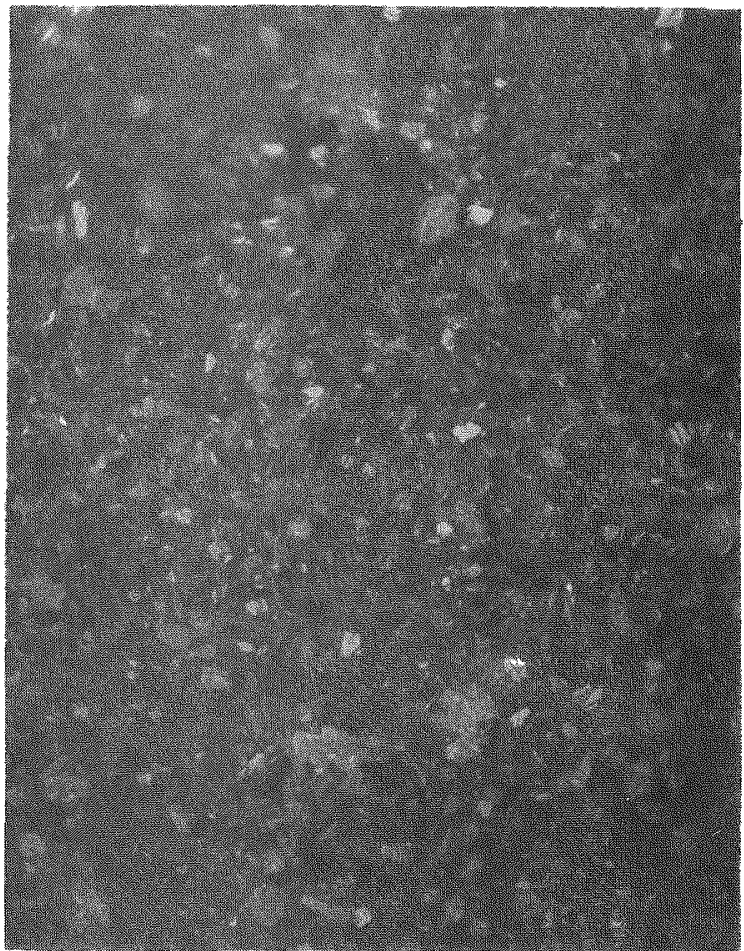

B. 8 HOURS

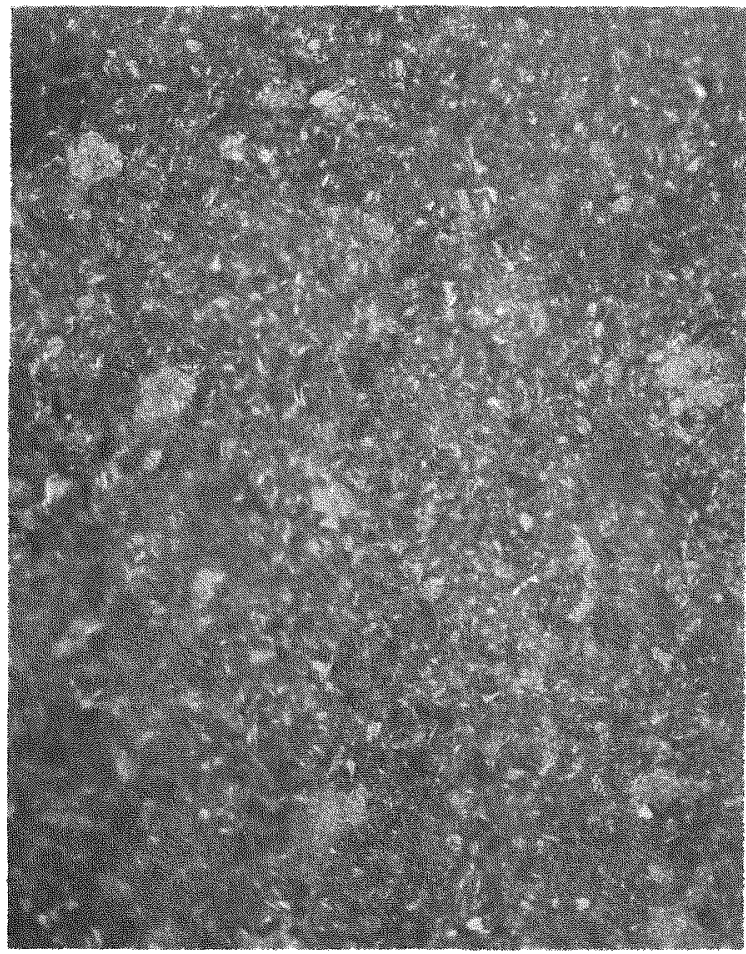

C. 16 HOURS

Figure 4-18 Urea Process $\operatorname{Tm}_{2} \mathrm{O}_{3}$ Wafers, Pressed at 4.5 tsi, Sintered $1750^{\circ} \mathrm{C}$, Hydrogen (Fractograph 100X). 


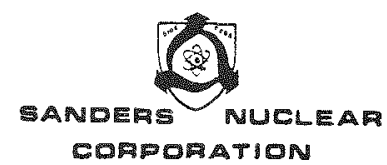

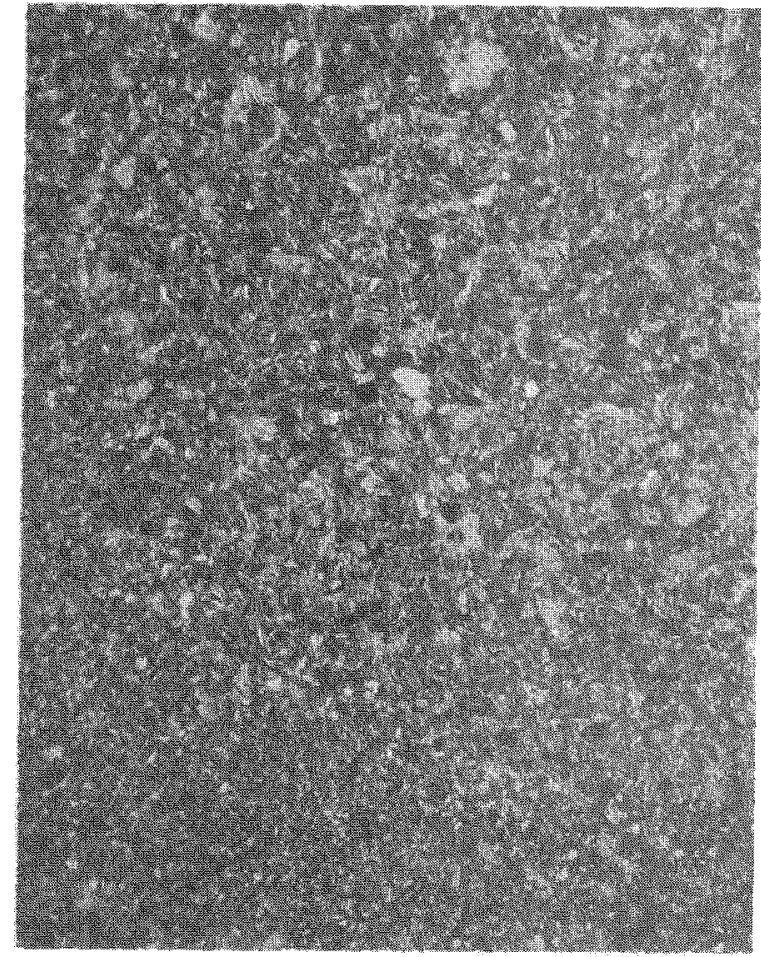

A. 4 HOURS

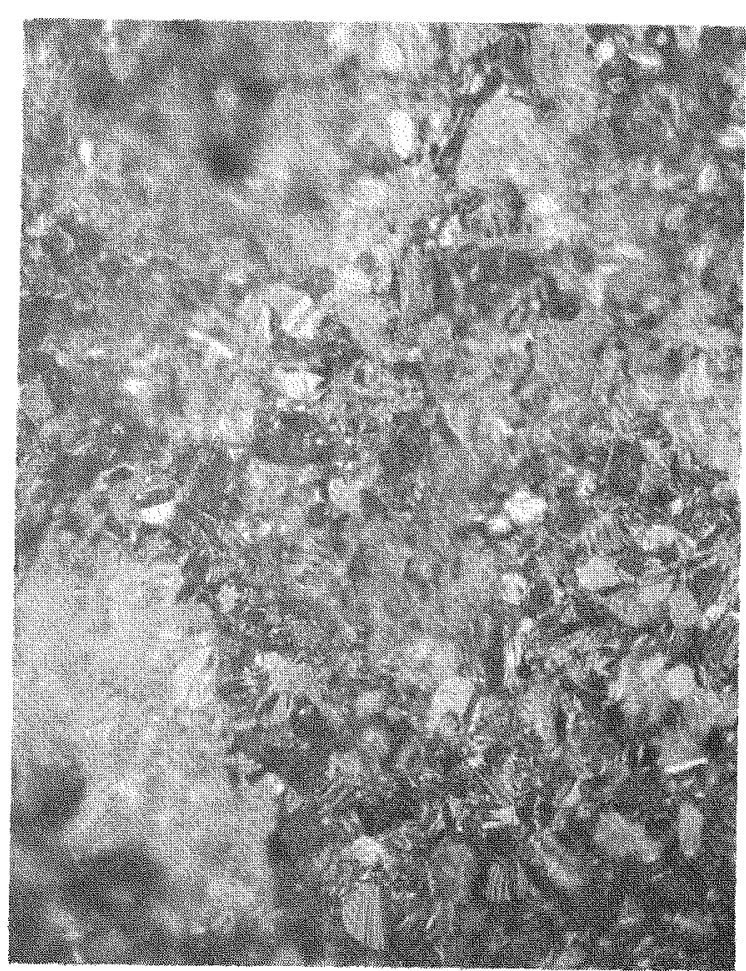

B. 8 HOURS

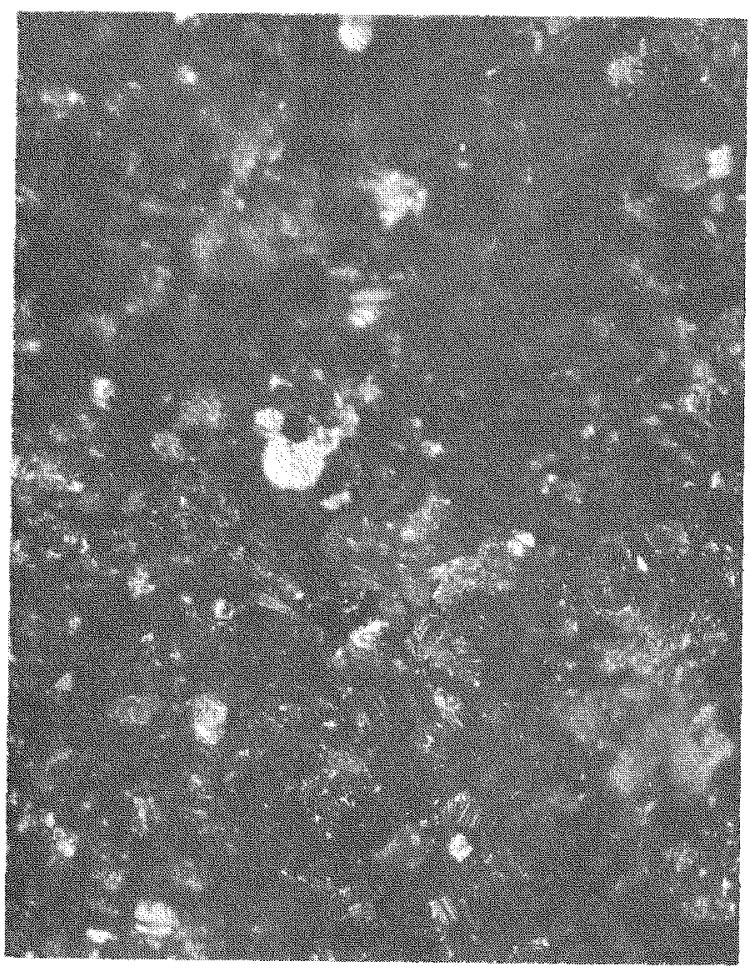

C. 16 HOURS

Figure 4-19 Urea Process $\mathrm{Tm}_{2} \mathrm{O}_{3}$ Wafers, Pressed at 15 tsi, Sintered $1750^{\circ} \mathrm{C}$, Hydrogen (Fractograph 100X). 


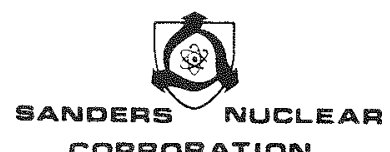

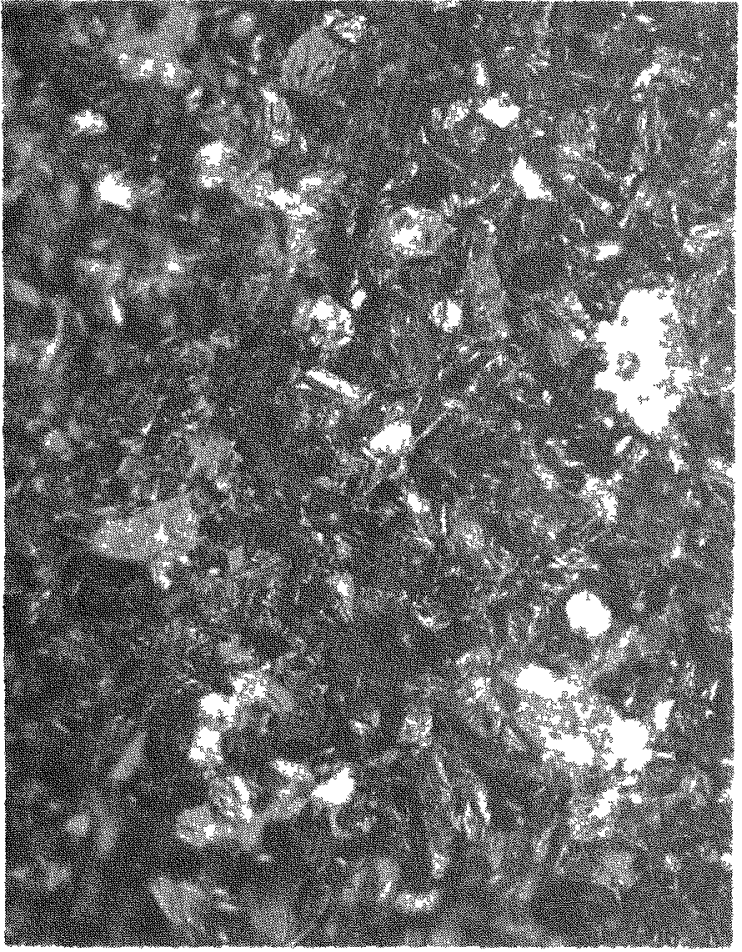

A. 4 HOURS

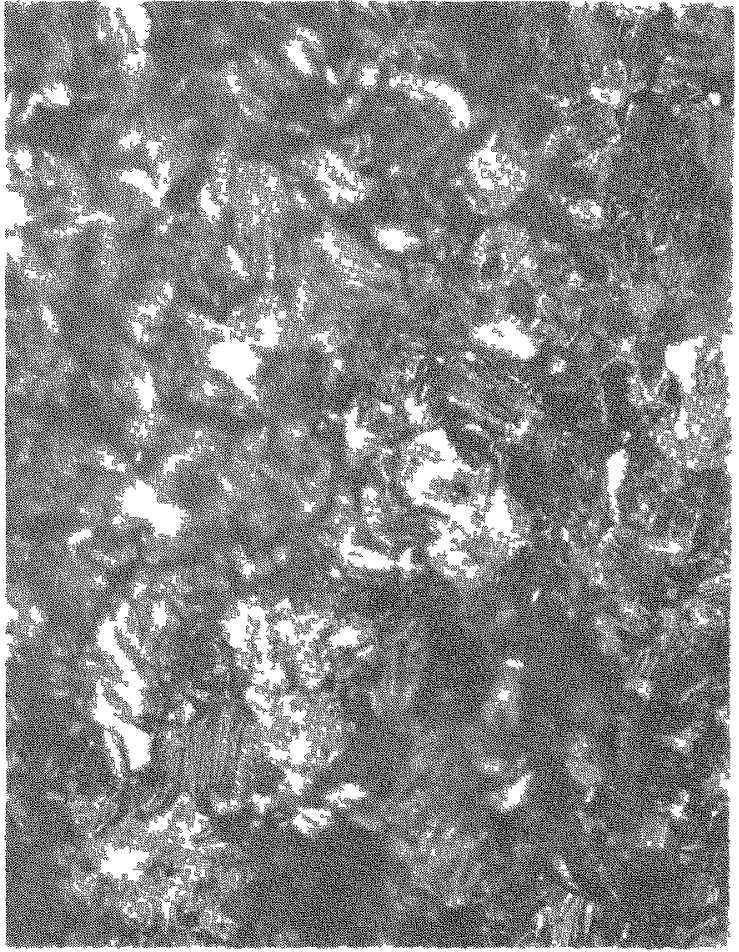

B. 8 HOURS

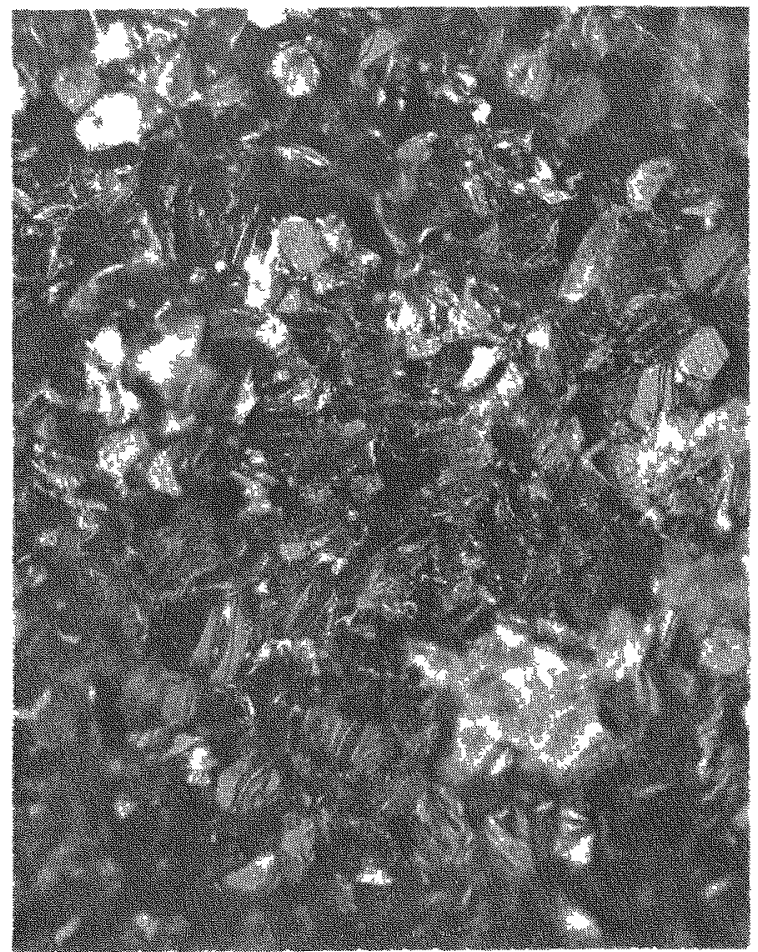

C. 16 HOURS

Figure 4-20 Urea Process $\mathrm{Tm}_{2} \mathrm{O}_{3}$ Wafers, Pressed at 29 tsi, Sintered $1750^{\circ} \mathrm{C}$, Hydrogen (Fractograph 100X). 


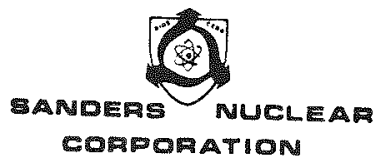

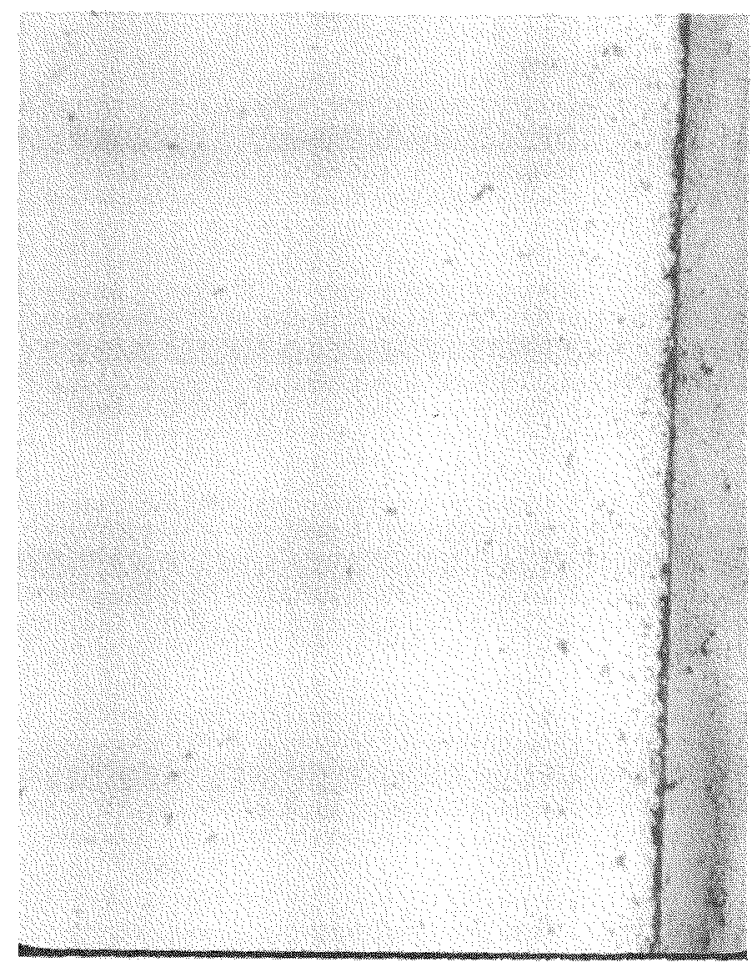

A. 4 HOURS

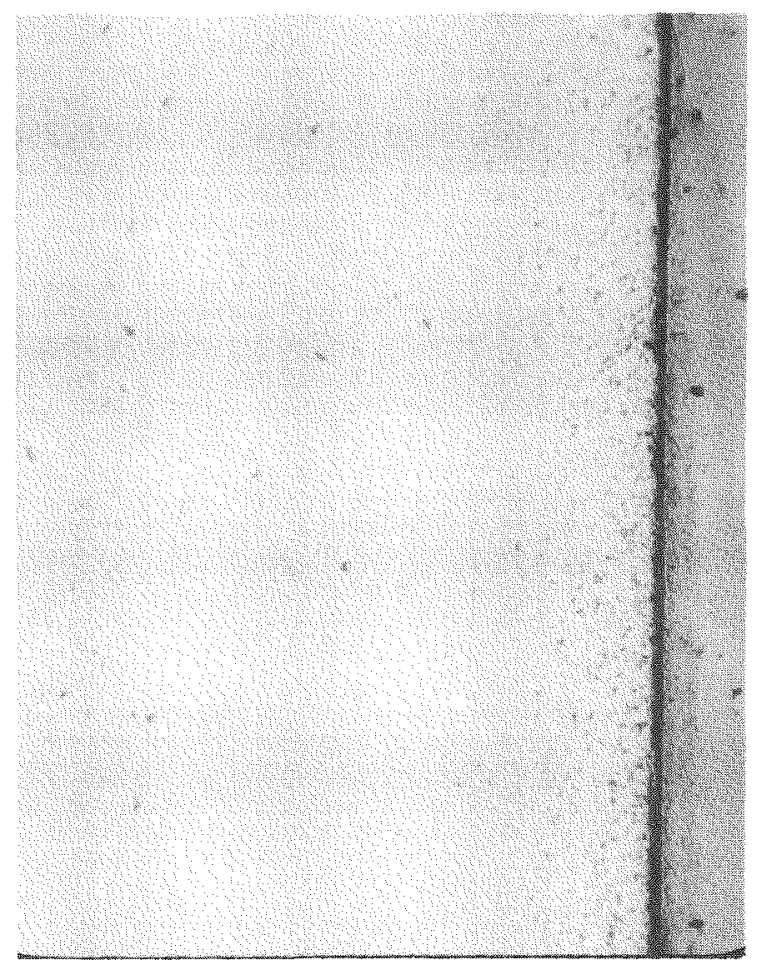

B. 8 HOURS

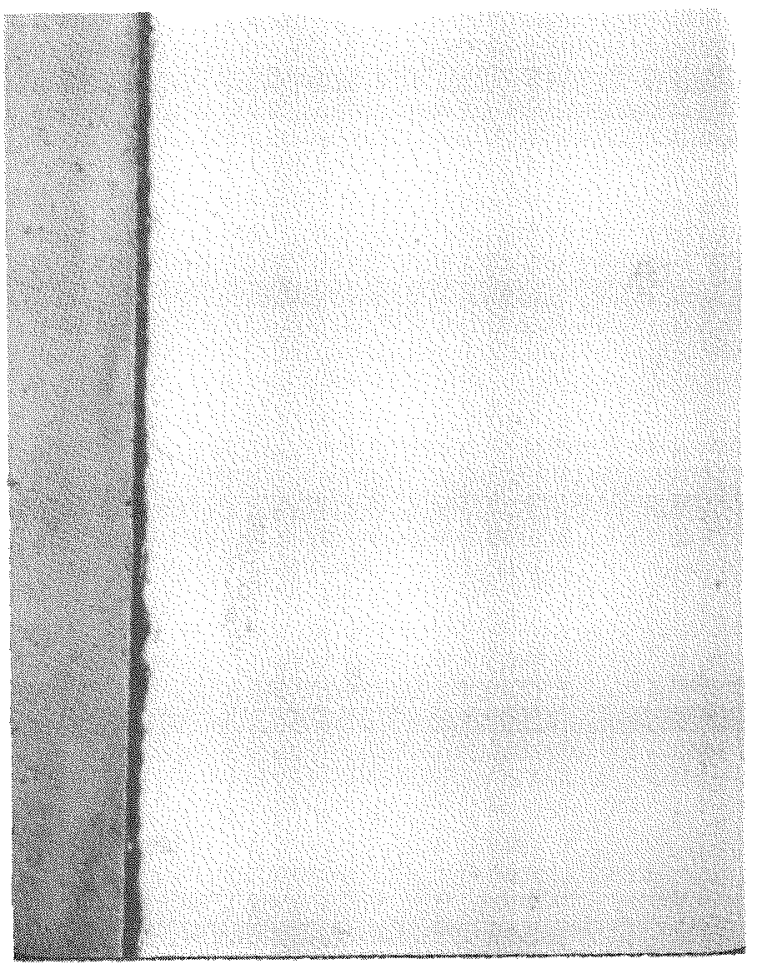

C. 16 HOURS

Figure 4-21 Ammonium Oxalate Process $\mathrm{Tm}_{2} \mathrm{O}_{3}$ Wafer, Pressed at 4.5 tsi, Sintered $1750^{\circ} \mathrm{C}$, Hydrogen (as Polished - 70X). 


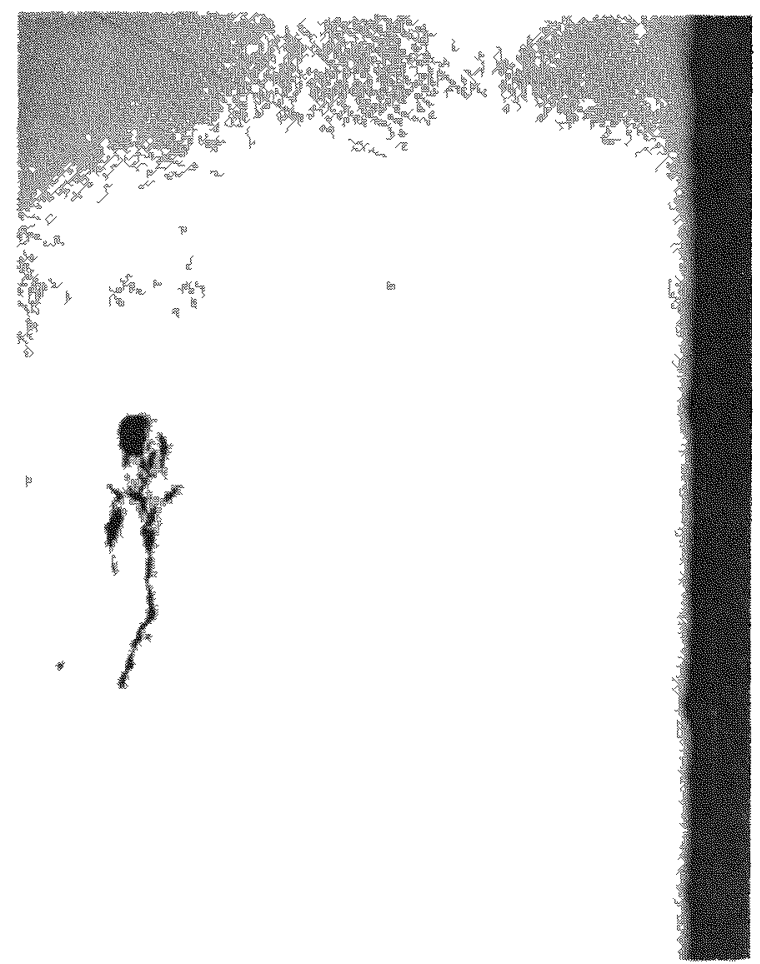

B. 8 HOURS

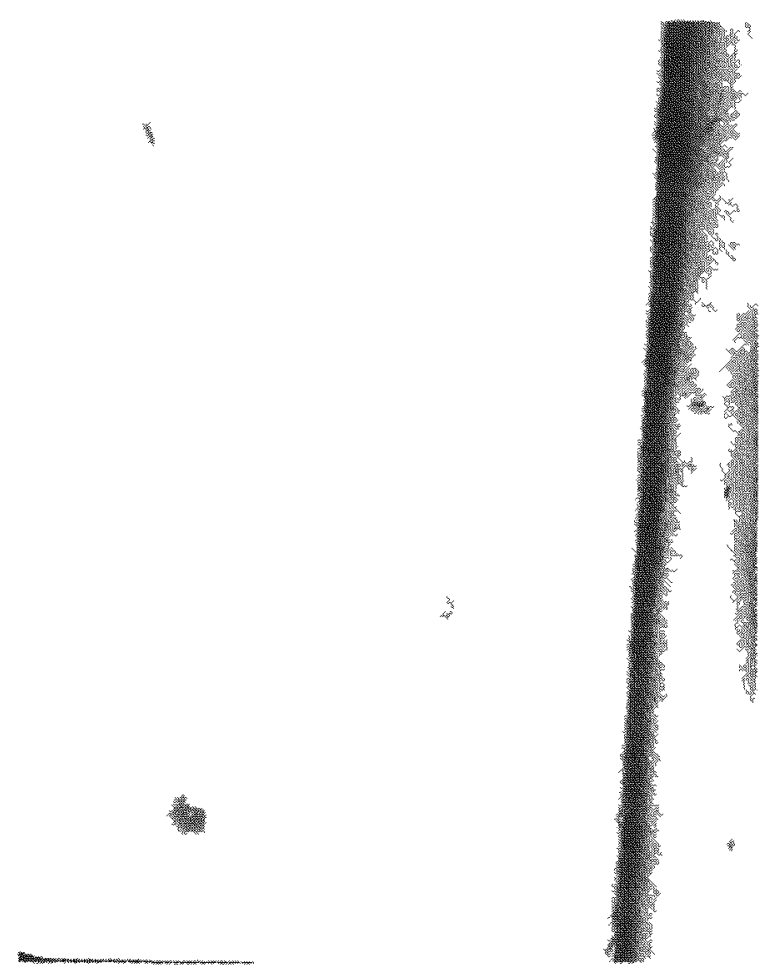

C. 16 HOURS

Figure 4-22 Ammonium Oxalate Process $\mathrm{Tm}_{2} \mathrm{O}_{3}$ Wafers, Pressed at 15 tsi, Sintered $1750^{\circ} \mathrm{C}$, Hydrogen (as Polished - 70X). 

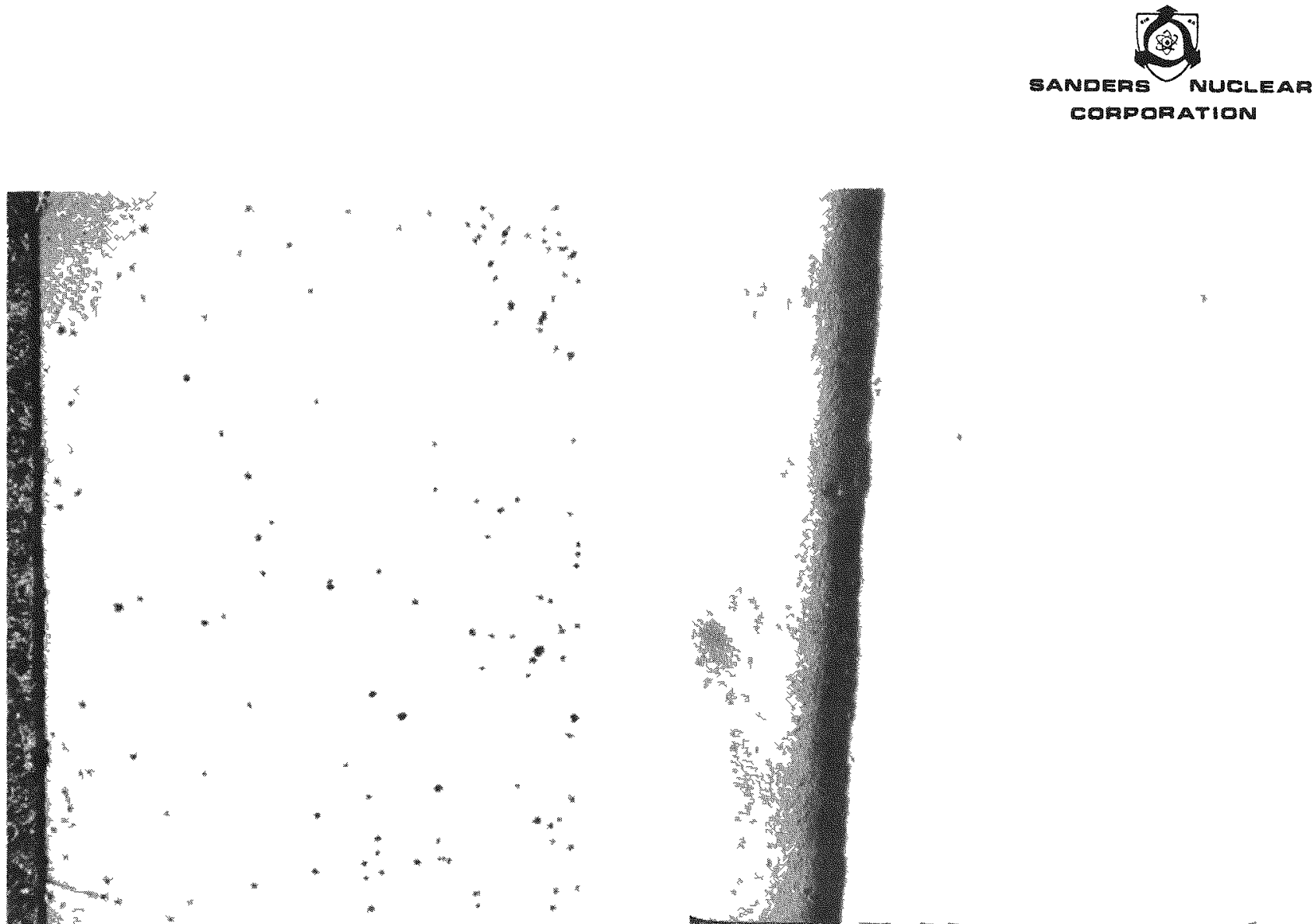

A. 4 HOURS

B. 8 HOURS
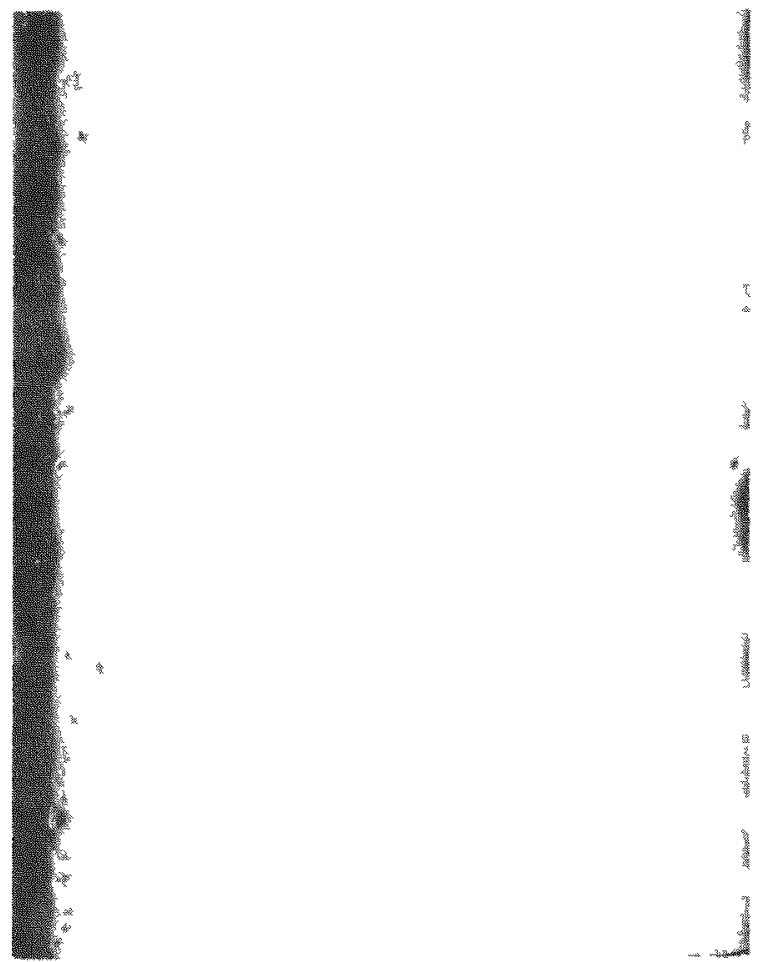

C. 16 HOURS

Figure 4-23 Ammonium Oxalate Process $\mathrm{Tm}_{2} \mathrm{O}_{3}$ Wafers, Pressed at 29 tsi, Sintered $1750^{\circ} \mathrm{C}$, Hydrogen (as Polished - 70X). 

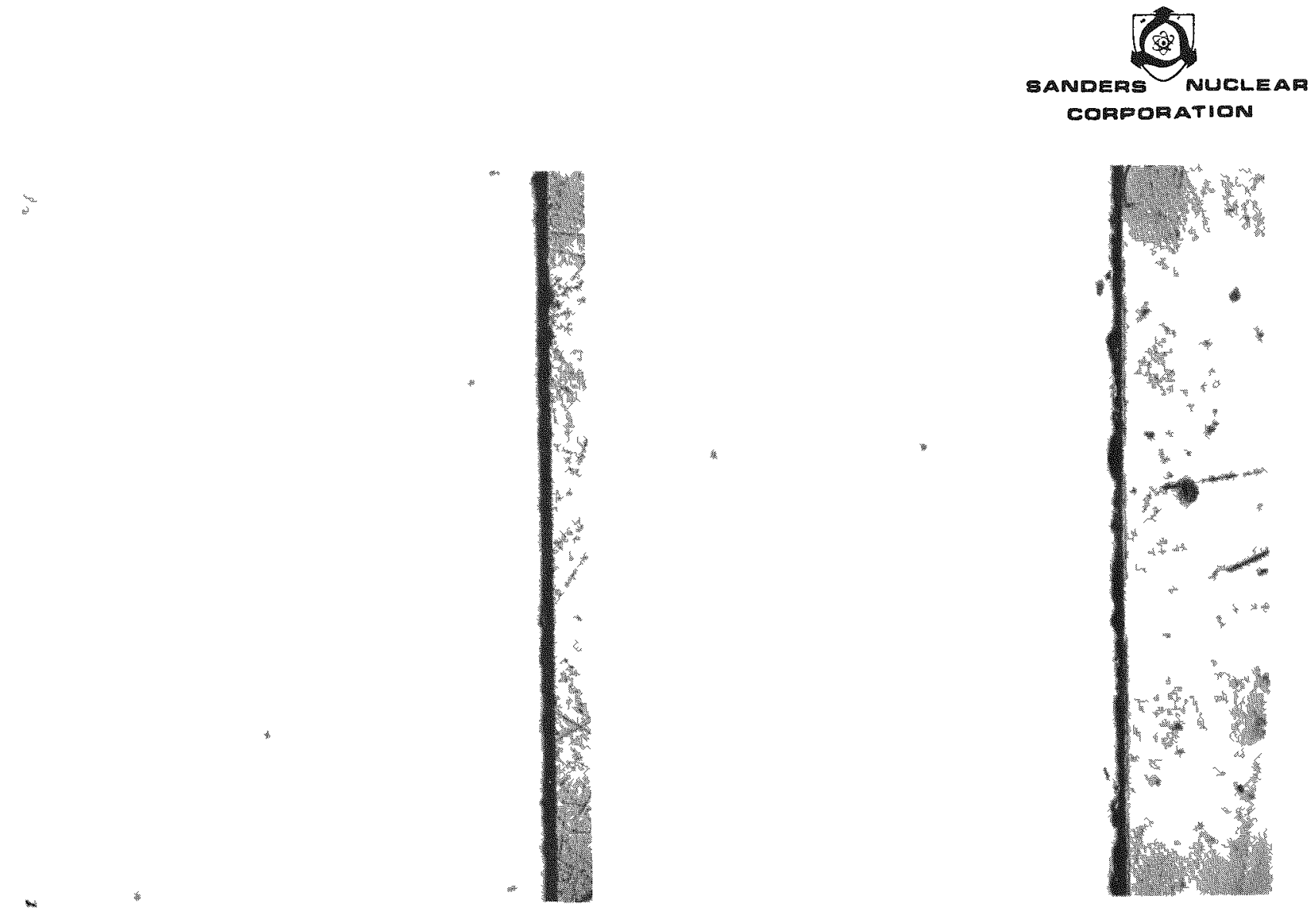

\section{A. 2 HOURS}

\section{B. 4 HOURS}
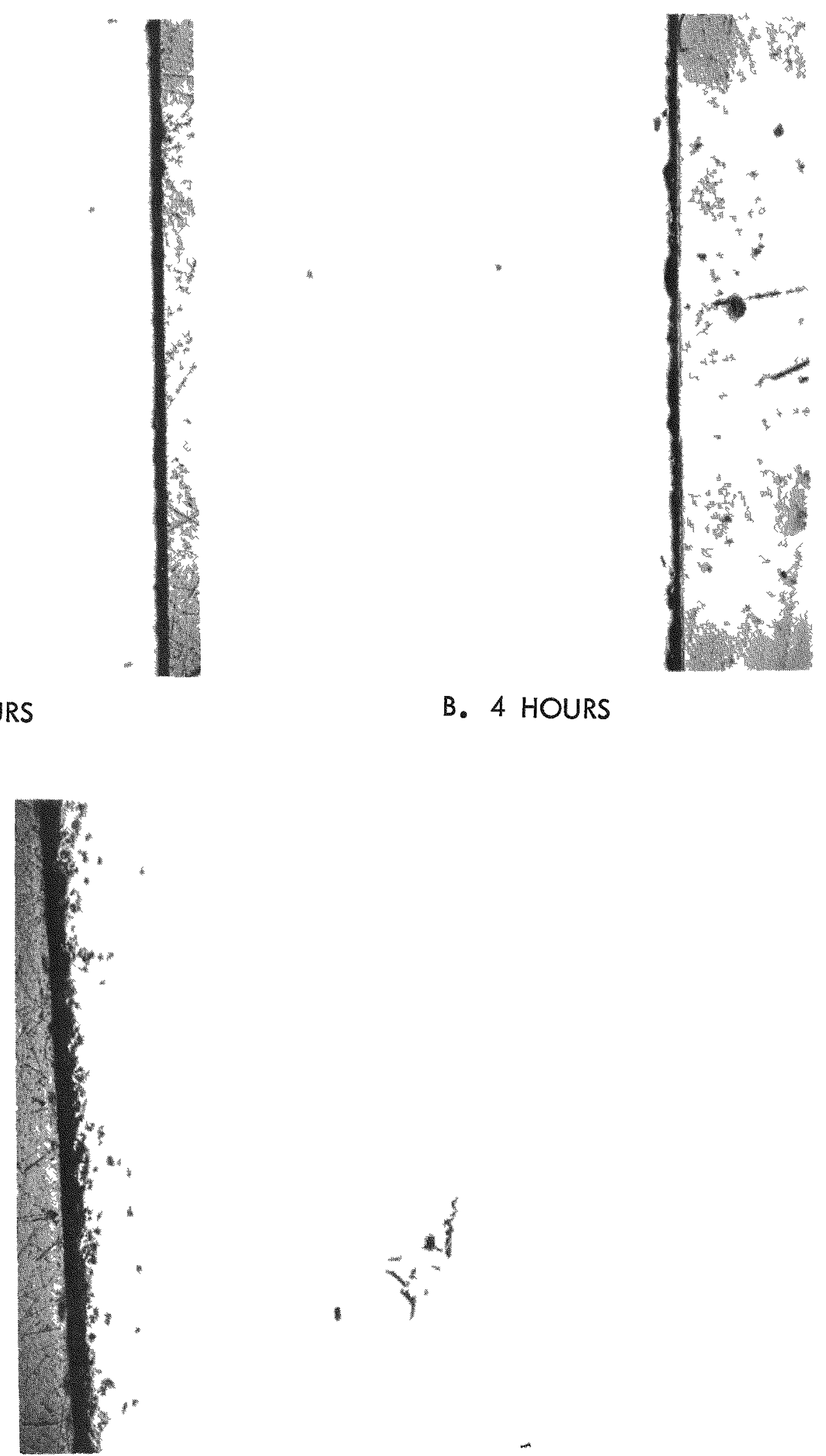

\section{8 HOURS}

Figure 4-24 Ammonium Oxalate Process $\mathrm{Tm}_{2} \mathrm{O}_{3}$ Wafers, Pressed at 15 tsi, Sintered $1750^{\circ} \mathrm{C}$, Vacuum (as Pllished - 70X). 


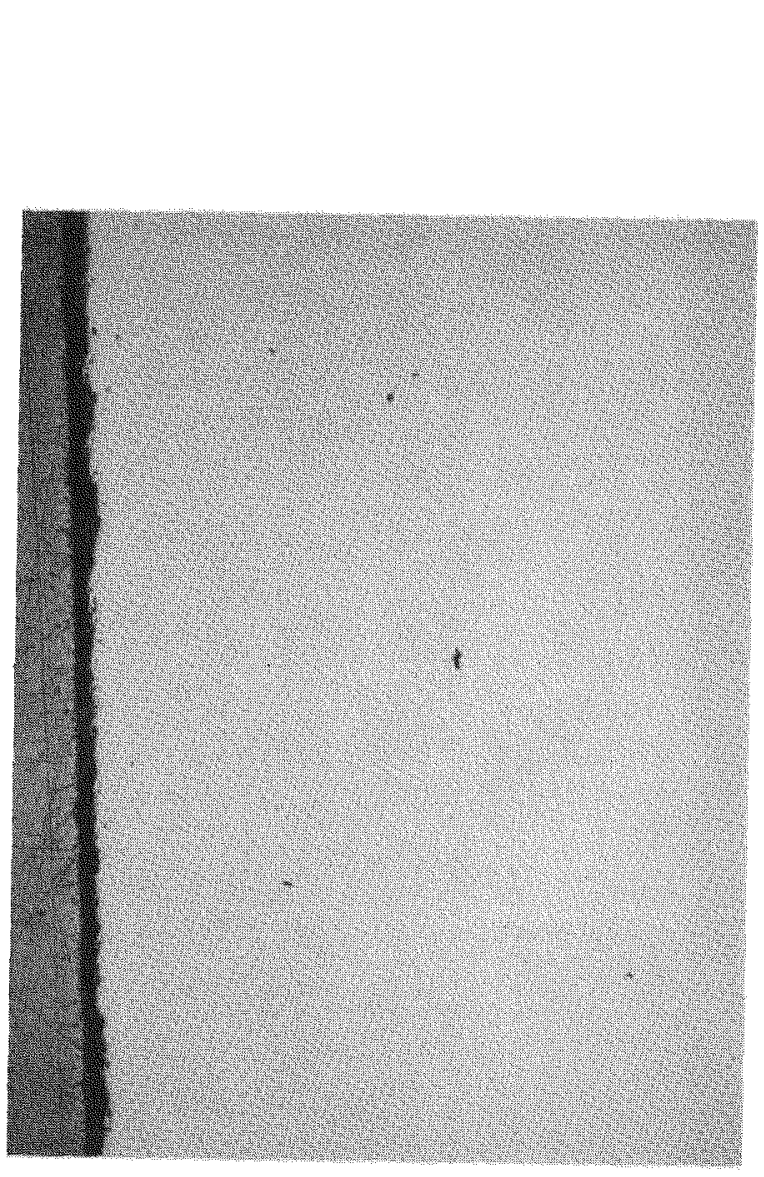

A. 2 HOURS
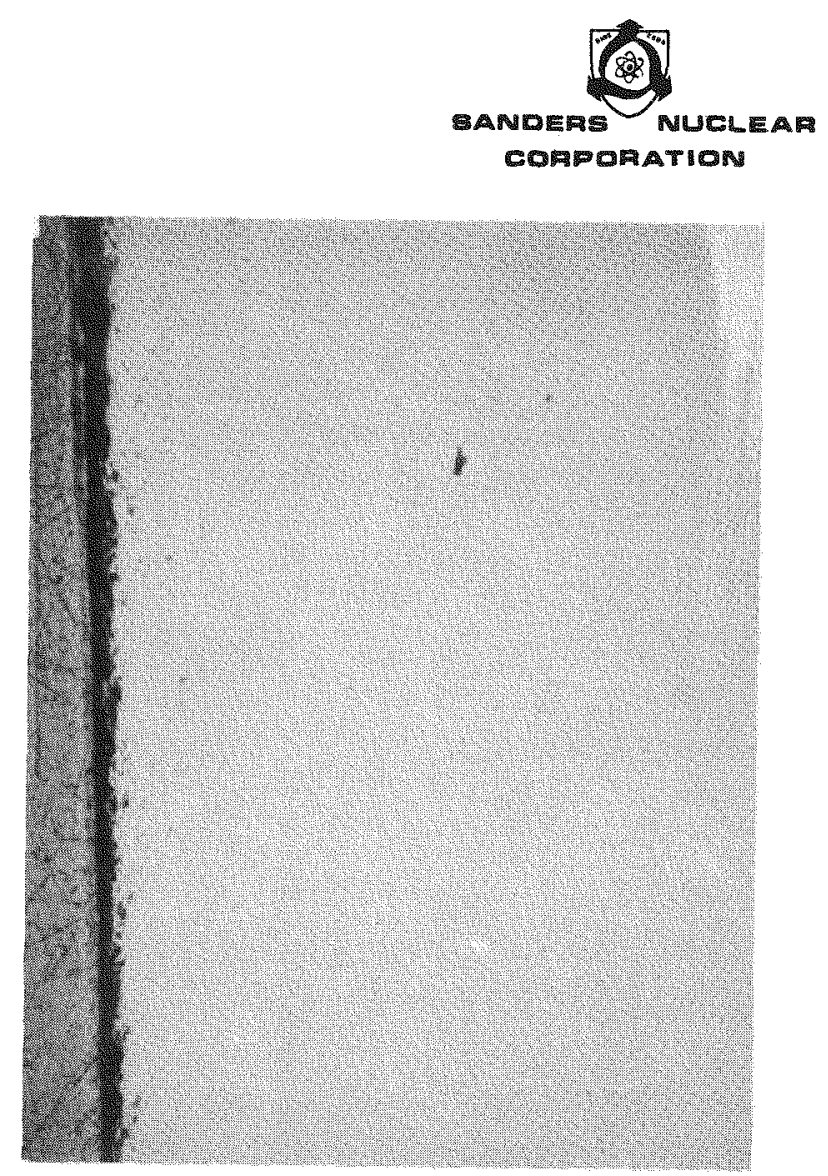

B. 4 HOURS

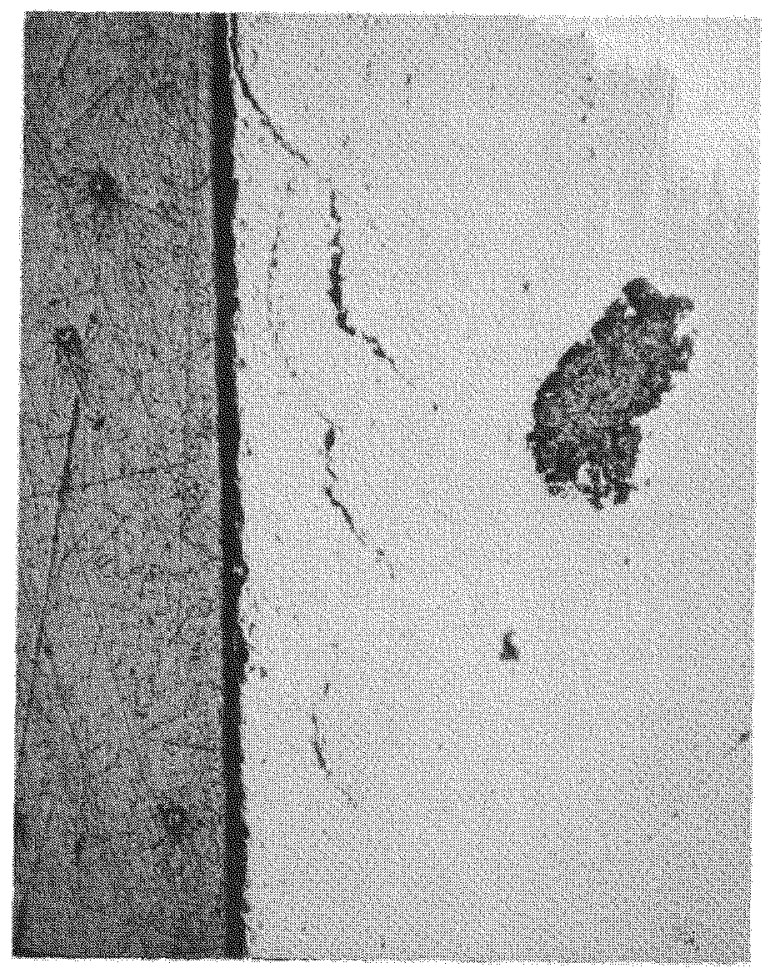

C. 8 HOURS

Figure 4-25 Ammonium Oxalate Process $\mathrm{Tm}_{2} \mathrm{O}_{3}$ Wafers, Pressed at 29 tsi, Sintered $1750^{\circ} \mathrm{C}$, Vacuum (as Polished - 70X). 

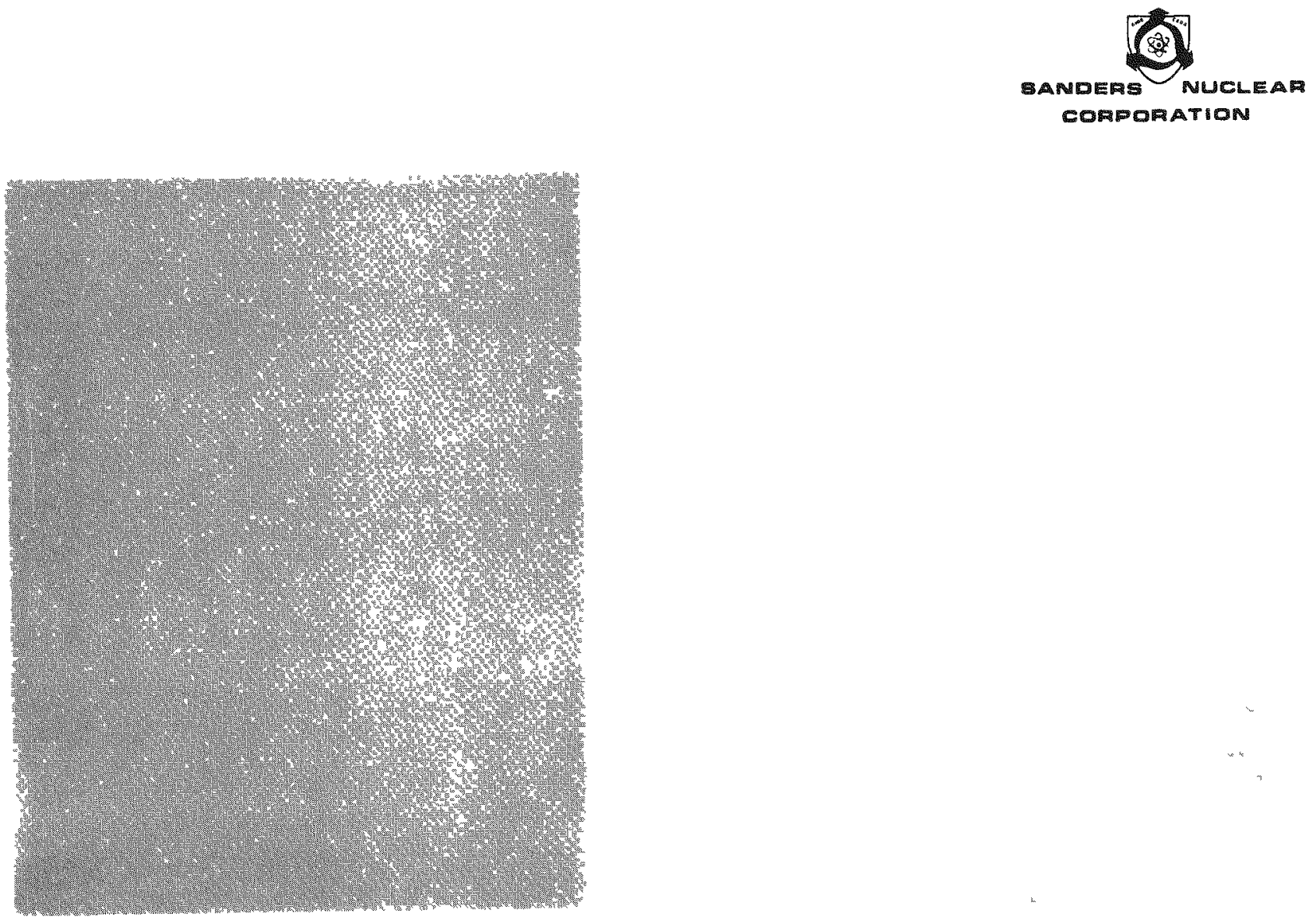

A. 2 HOURS

B. 4 HOURS

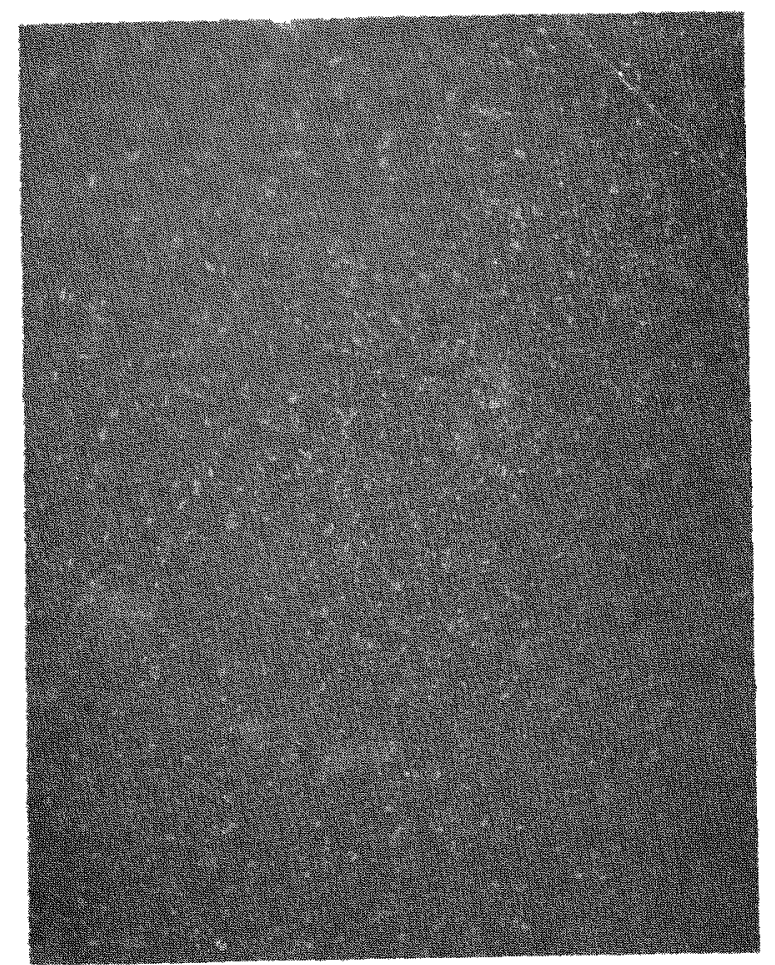

C. 8 HOURS

Figure 4-26 Ammonium Oxalate Process $\mathrm{Tm}_{2} \mathrm{O}_{3}$ Wafers, Pressed at 4.5 tsi, Sintered $1750^{\circ} \mathrm{C}$, Vacuum (Fractograph $-100 \mathrm{X}$ ). 


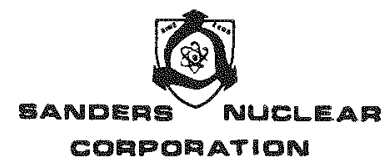

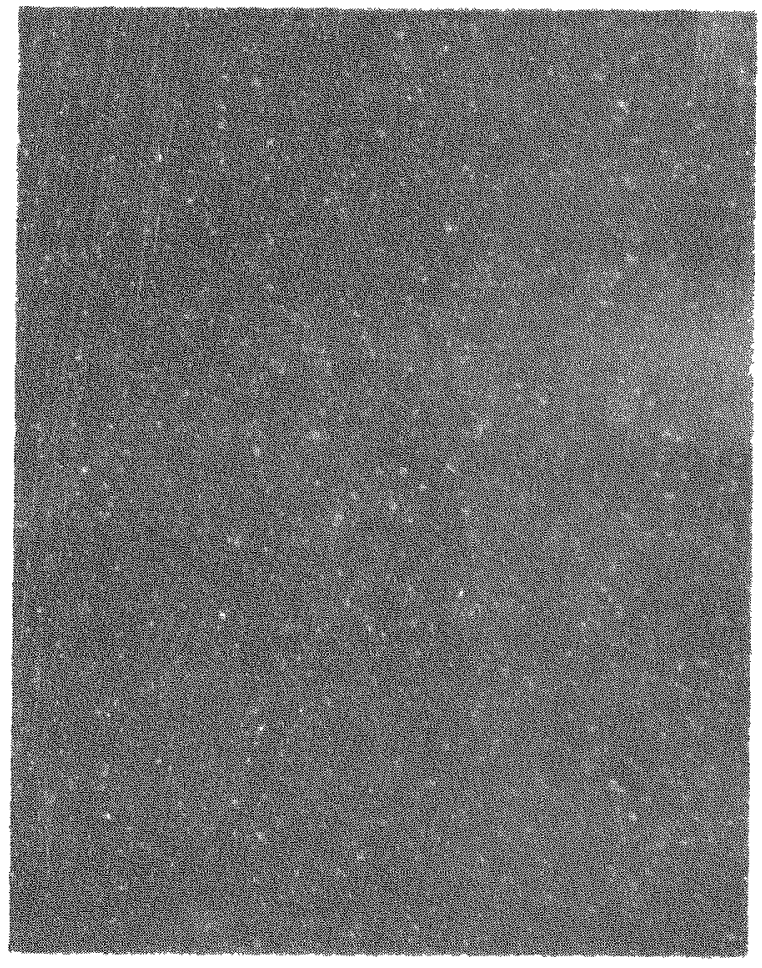

A. 2 HOURS

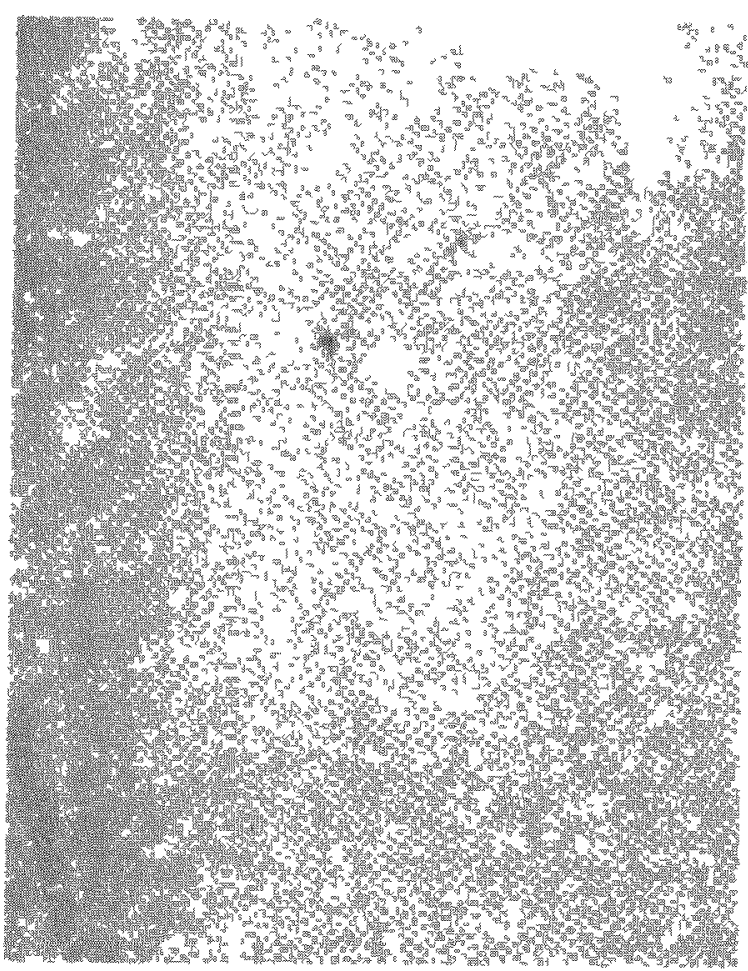

B. 4 HOURS

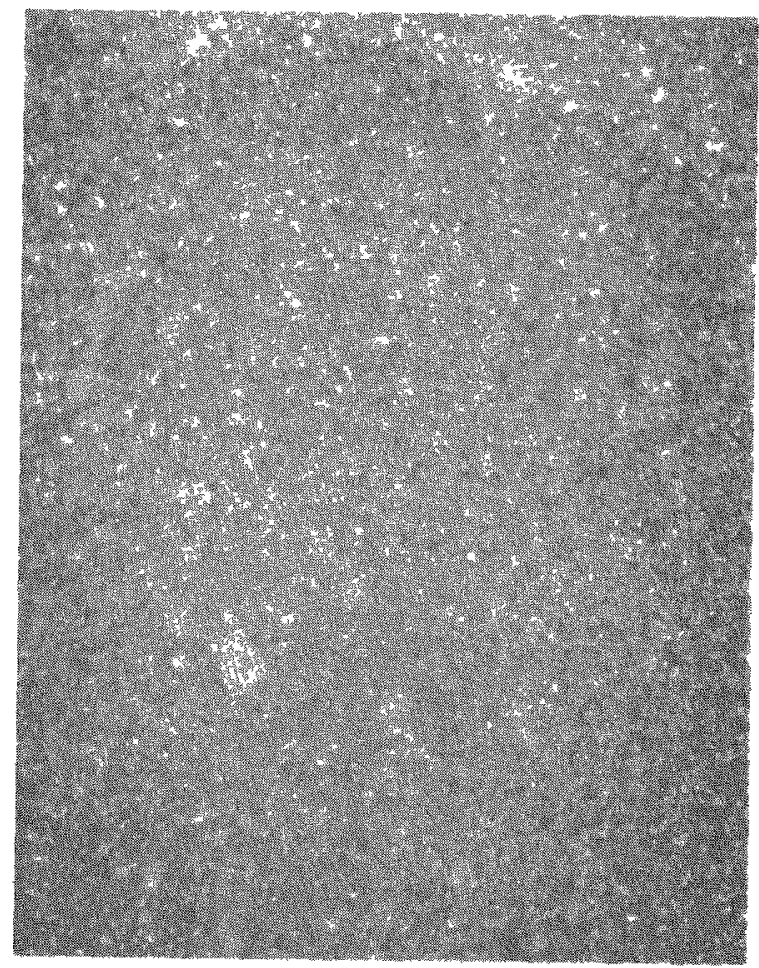

\section{8 HOURS}

Figure 4-27 Ammonium Oxalate Process $\operatorname{Tm}_{2} \mathrm{O}_{3}$ Wafers, Pressed at 15 tsi, Sintered $1750^{\circ} \mathrm{C}$, Vacuum (Fractograph - 100X). 


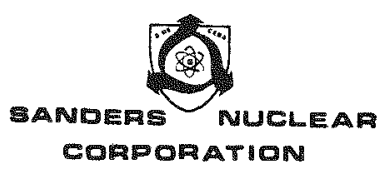

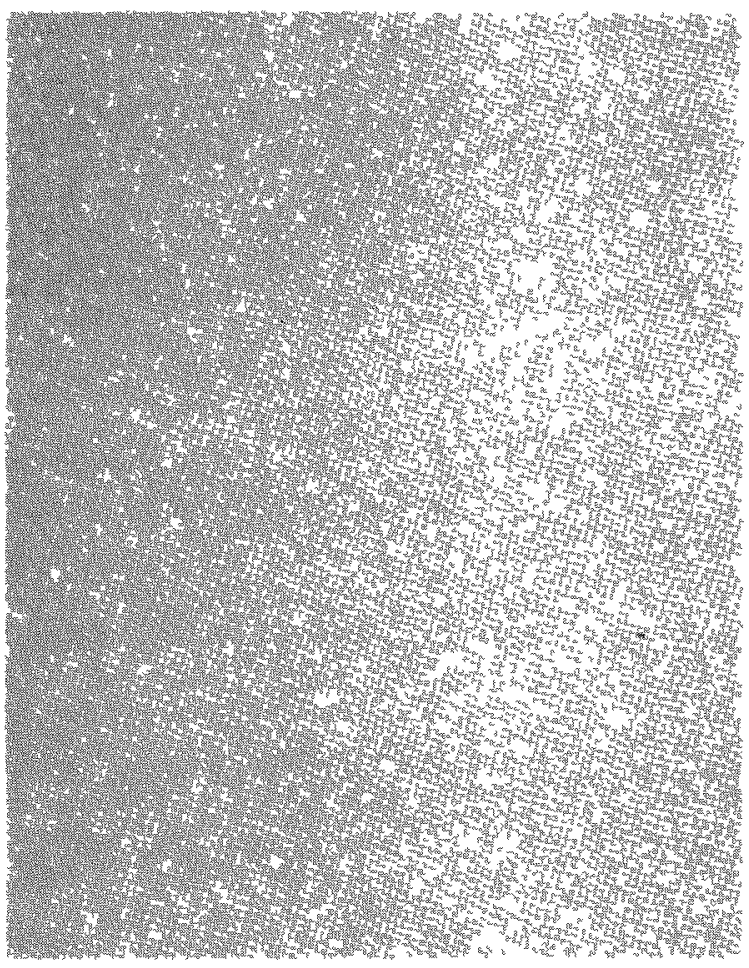

A. 2 HOURS

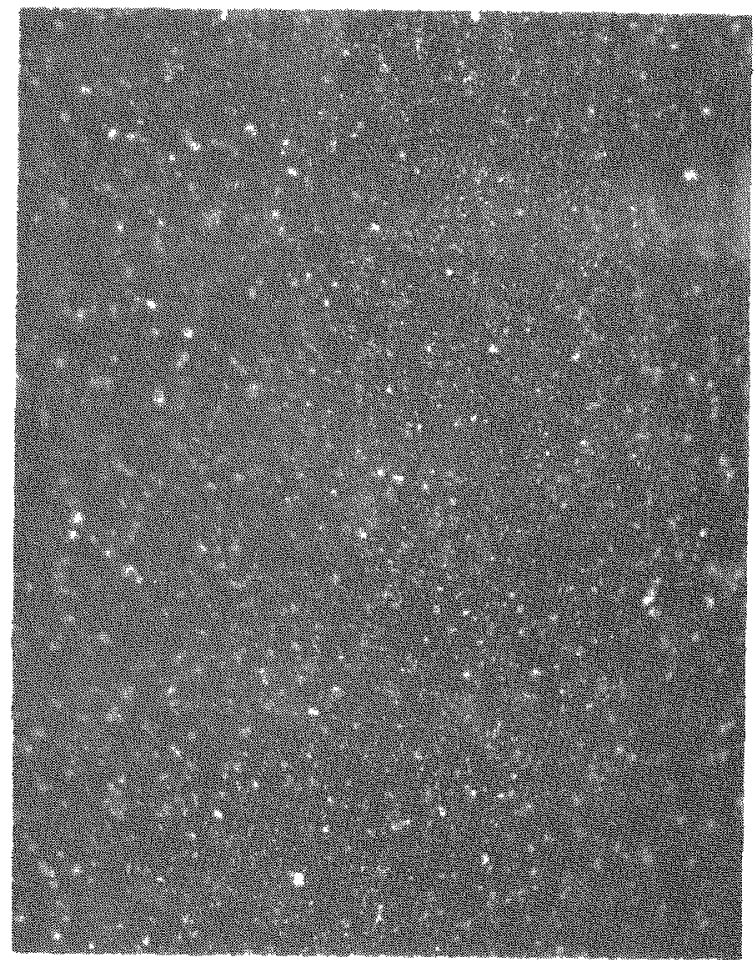

B. 4 HOURS

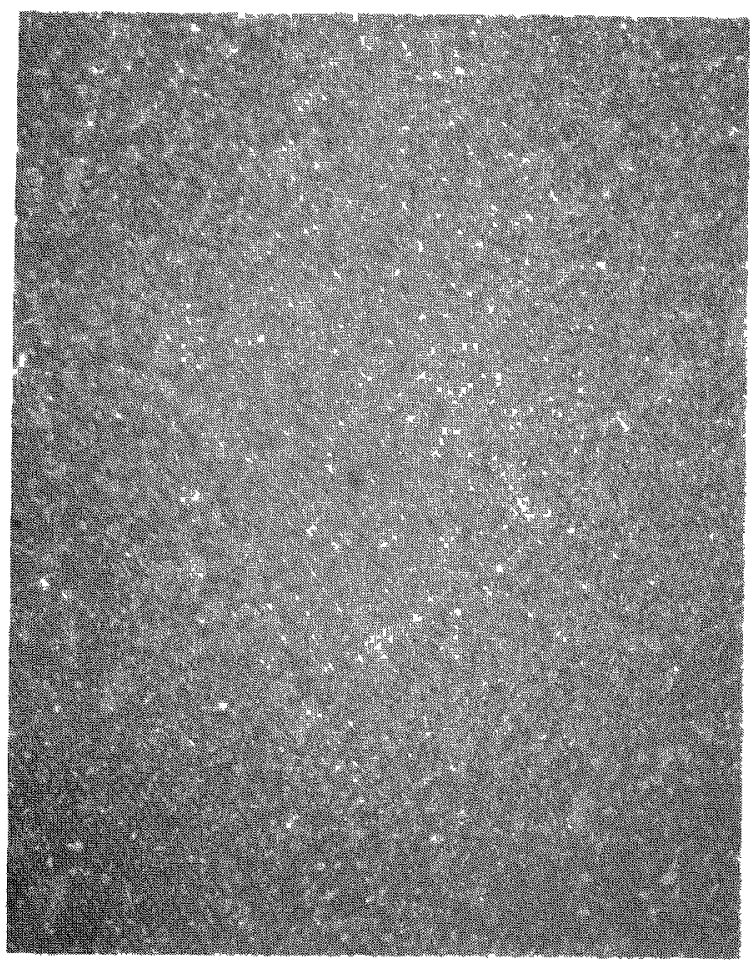

C. 8 HOURS

Figure 4-28 Ammonium Oxalate Process $\mathrm{Tm}_{2} \mathrm{O}_{3}$ Wafers, Pressed at 29 tsi, Sintered $1750^{\circ} \mathrm{C}$, Vacuum (Fractograph - 100X). 


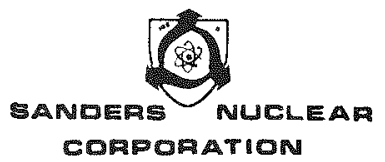

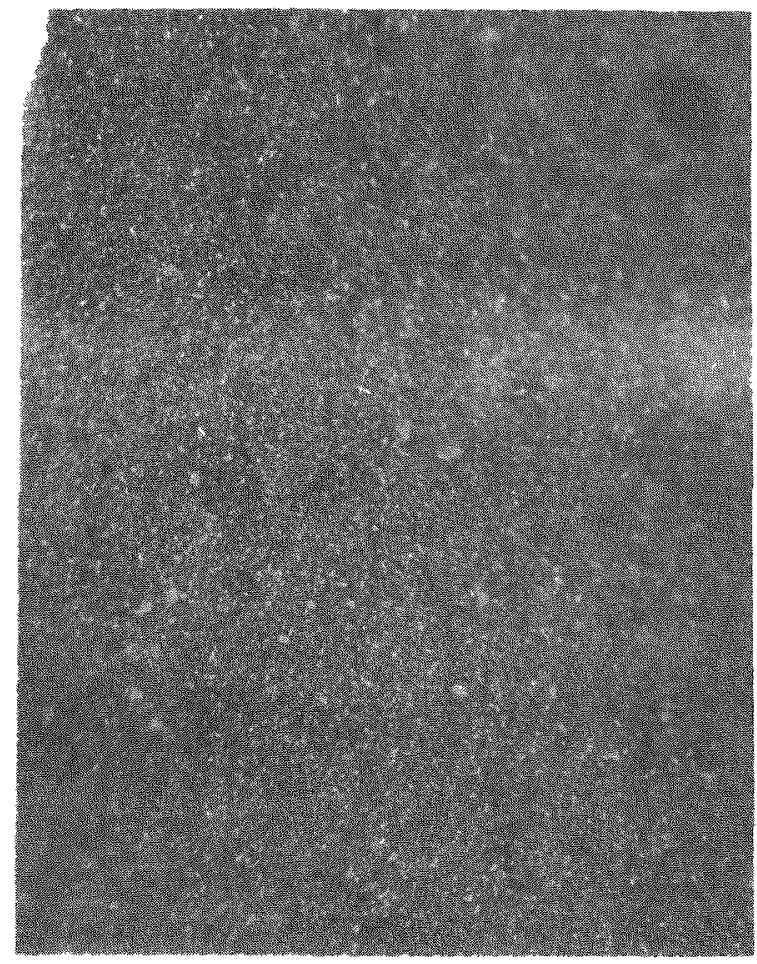

A. 4 HOURS

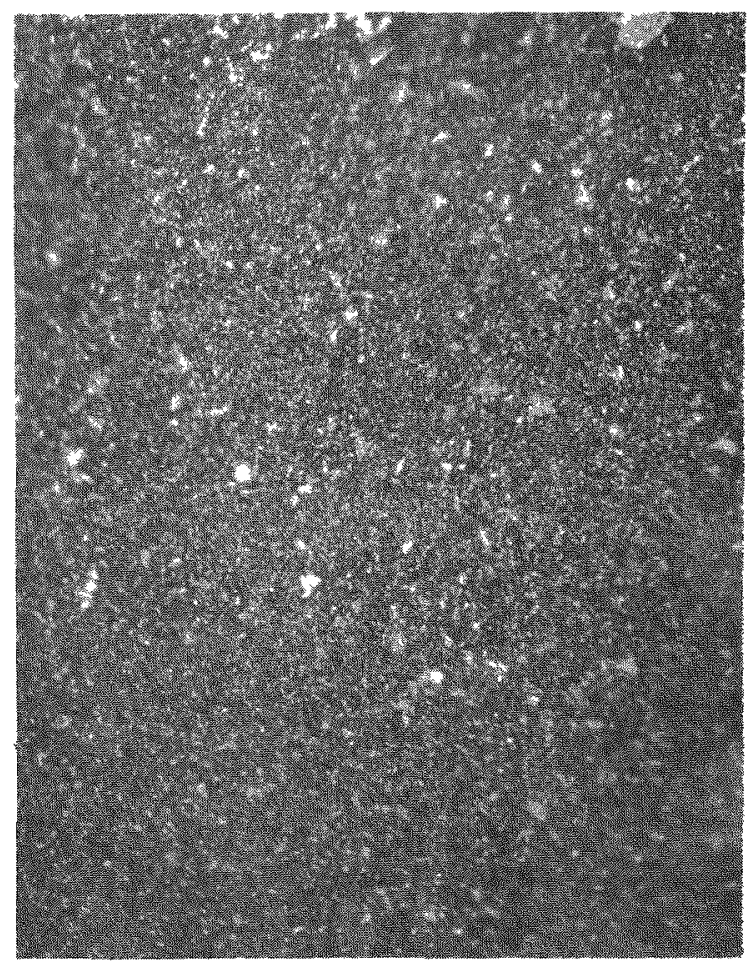

B. 8 HOURS

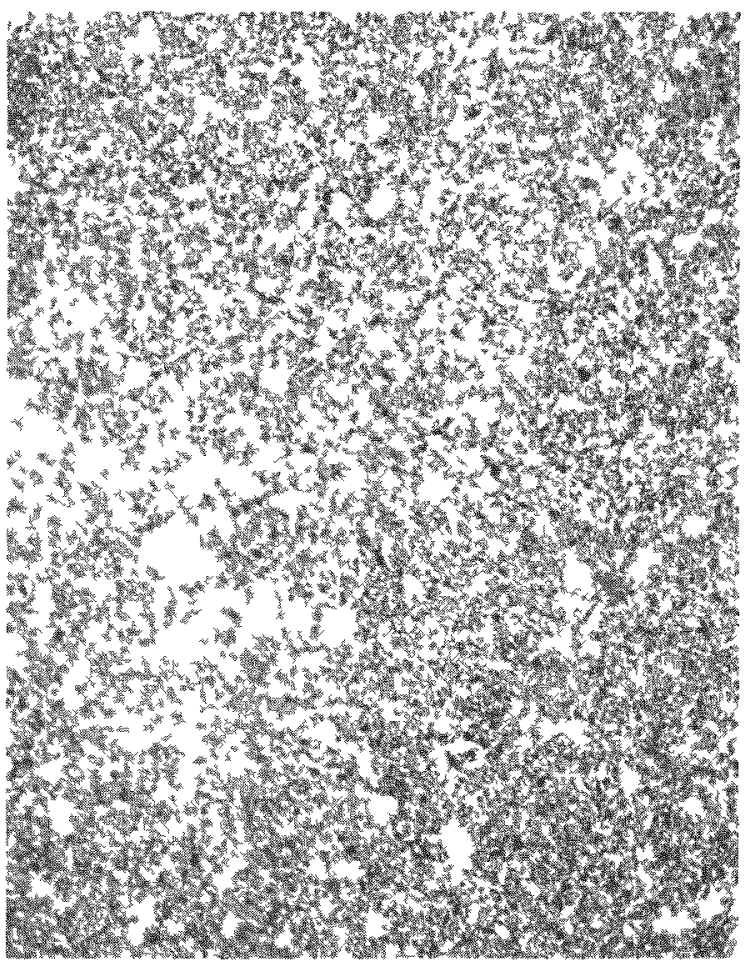

\section{16 HOURS}

Figure 4-29 Ammonium Oxalate Process $\operatorname{Tm}_{2} \mathrm{O}_{3}$ Wafers, Pressed at 4.5 tsi, Sintered $1750^{\circ} \mathrm{C}$, Hydrogen (Fractograph - 100X). 


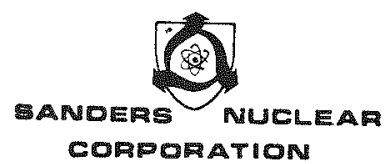

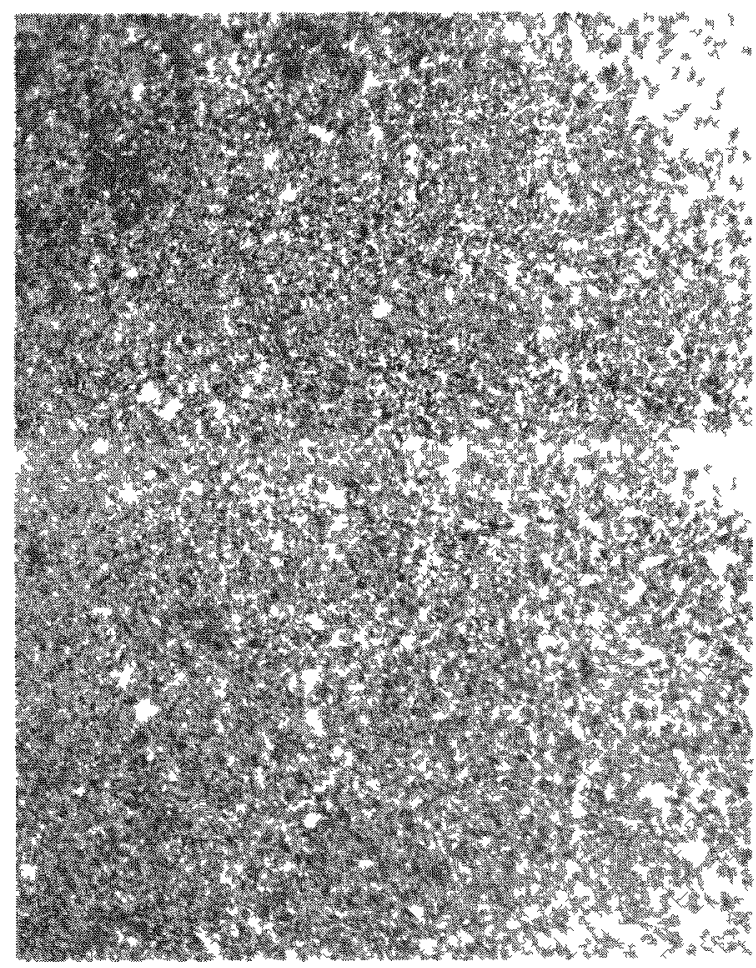

A. 4 HOURS

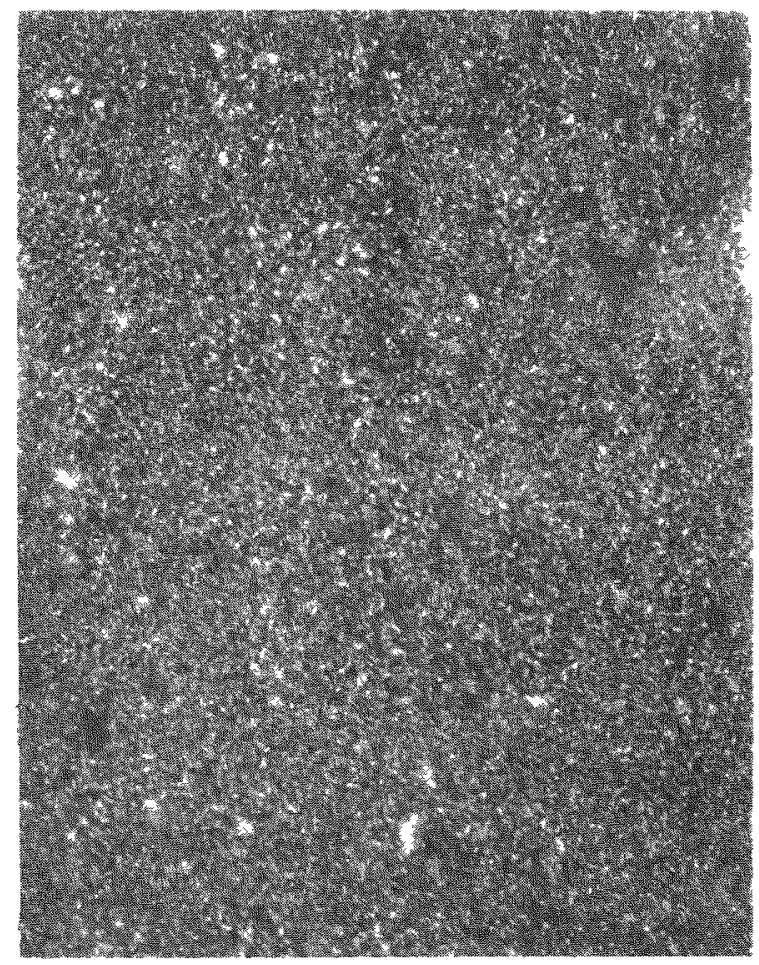

B. 8 HOURS

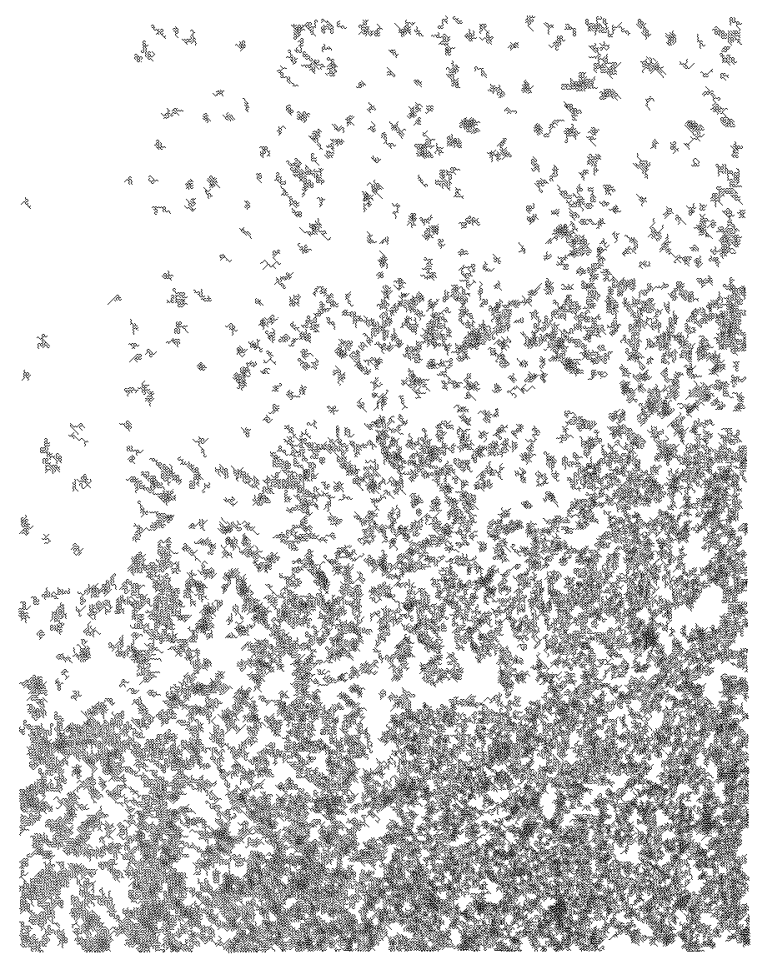

C. 16 HOURS

Figure 4-30 Ammonium Oxalate Process $\mathrm{Tm}_{2} \mathrm{O}_{3}$ Wafers, Pressed at 15 tsi, Sintered $1750^{\circ} \mathrm{C}$, Hydrogen (Fractograph - 100X). 


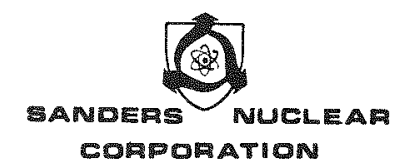

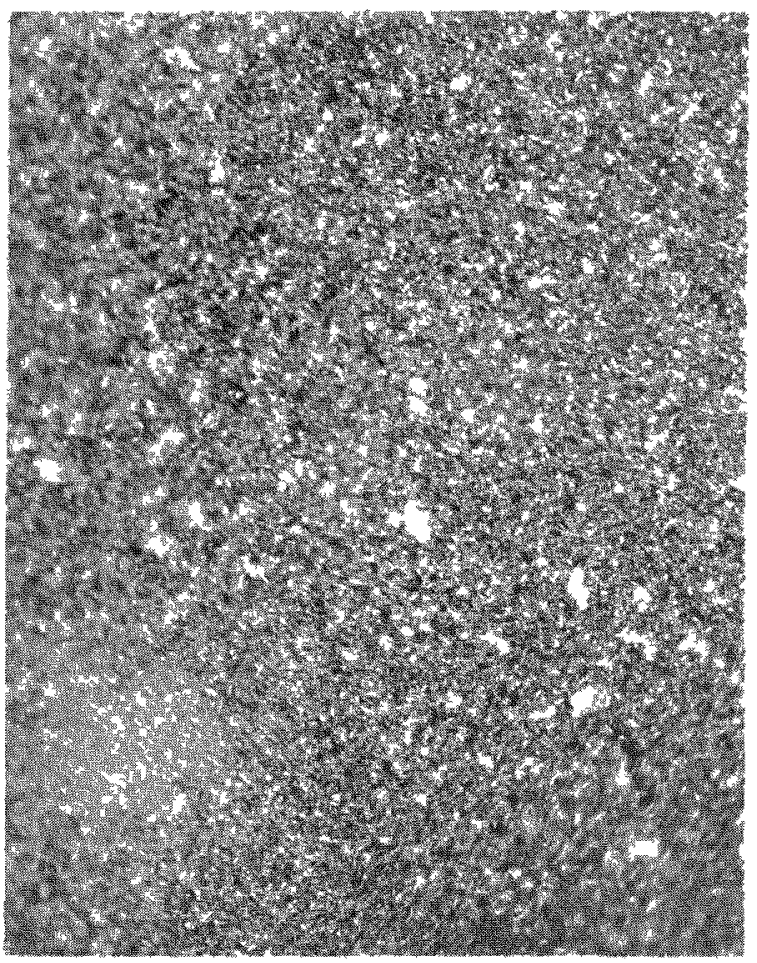

A. 4 HOURS

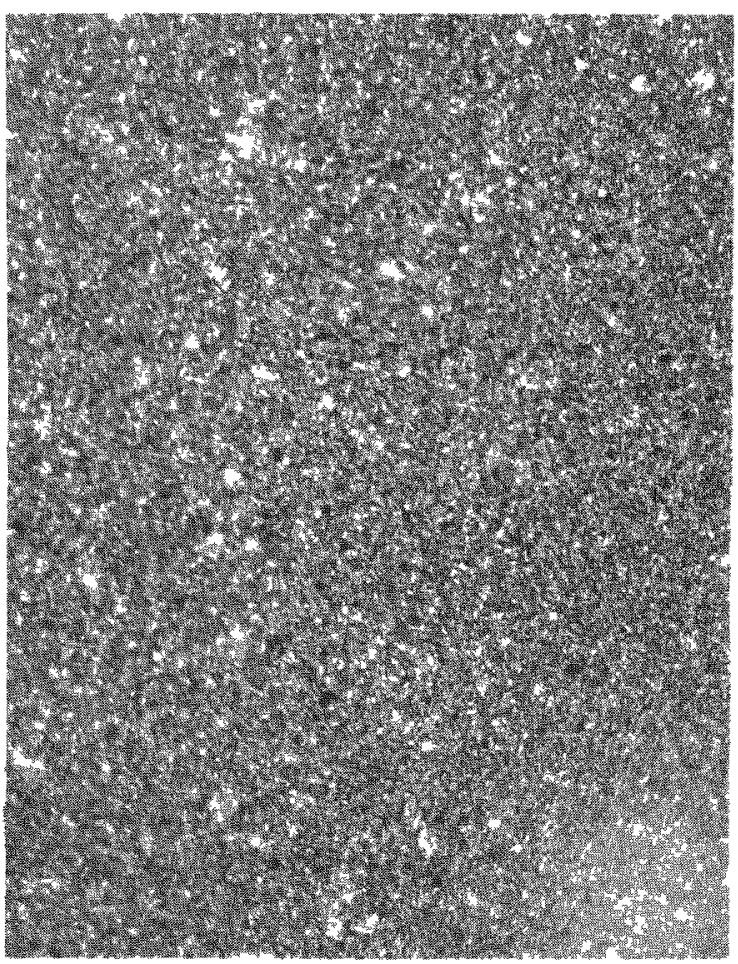

B. 8 HOURS

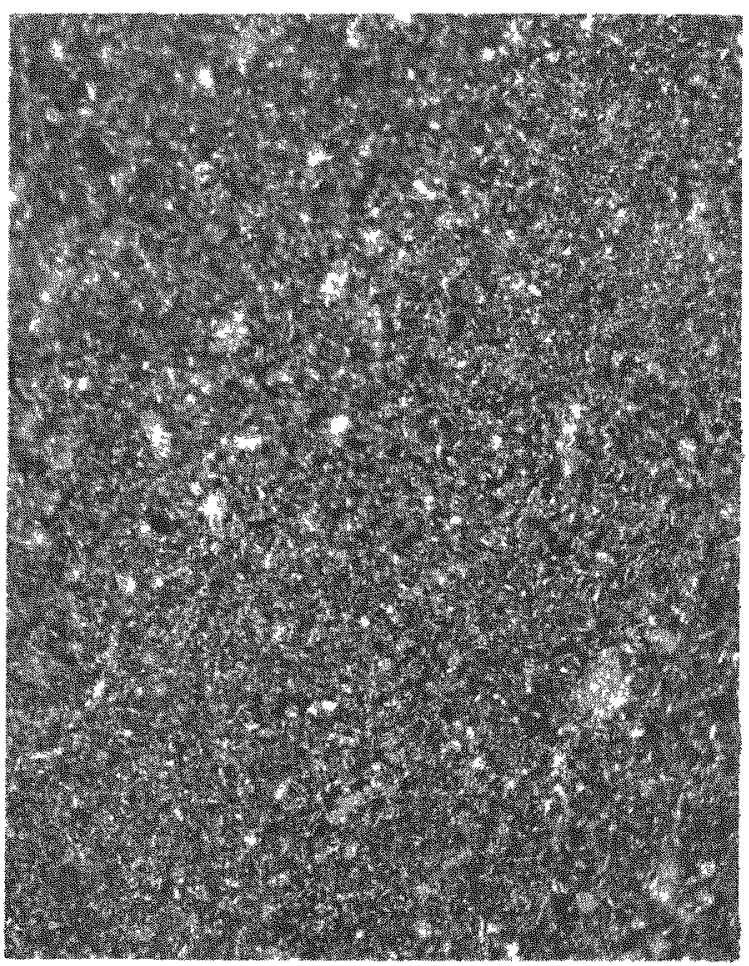

C. 16 HOURS

Figure 4-31 Ammonium Oxalate Process $\mathrm{Tm}_{2} \mathrm{O}_{3}$ Wafers, Pressed at 29 tsi, Sintered $1750^{\circ} \mathrm{C}$, Hydrogen (Fractograph - 100X). 
were placed in each capsule and aged for 500 hours at $1600^{\circ} \mathrm{C}$ in a static vacuum. Because interceramic bonding had been observed in the bench mark wafers, a 2-3 mil metal foil was placed between each wafer in the capsule to prevent interceramic bonding. Tantalum foil was used in $T-111$, molybdenum foil in TZM and tungsten foil in tungsten. Following 500 hours at $1600^{\circ} \mathrm{C}$, all but two of the capsules were given a $2000^{\circ} \mathrm{C}$ thermal spike (a 20 minute rise to $2000^{\circ} \mathrm{C}$ and then shut down).

The T-111 capsule removed prior to thermal spike contained wafers made from $100 \% \mathrm{Tm}_{2} \mathrm{O}_{3}$ in one and $80 \% \quad \mathrm{Tm}_{2} \mathrm{O}_{3} / 20 \% \mathrm{Yb}_{2} \mathrm{O}_{3}$ in the other. These controls were to give indication of annealing effects due to the thermal spike. All capsules were leak tested before and after aging to ensure capsule integrity.

A summary of experimental data is presented in Table 4-10.

\section{RESULTS AND DISCUSSION}

All wafers removed from encapsulants were in one piece. Wafers that were black in color from sintering in hydrogen were unchanged after aging. Other wafer colorations were also unchanged as a result of aging. Vapor deposited crystals were observed in the bottom of all capsules for both $100 \% \mathrm{Tm}_{2} \mathrm{O}_{3}$ and $80 \% \mathrm{Tm}_{2} \mathrm{O}_{3} / 20 \%$ $\mathrm{Yb}_{2} \mathrm{O}_{3}$ wafers.

X-ray diffraction patterns obtained on wafers representative of each process were typical of crystalline $\mathrm{Tm}_{2} \mathrm{O}_{3}$ or $\mathrm{Yb}_{2} \mathrm{O}_{3}$. Lattice parameters calculated from these $x-r a y$ patterns were in good agreement with bench mark lattice parameters.

In most cases, iron, magnesium, and aluminum levels decreased as a result of aging. Level of iron, however, increased markedly in two wafers aged in $T Z M$ (see data - Table 4-11). Changes in levels with respect to process conditions and encapsulant were random. Correlation of impurity level with grain size was difficult because of the irregular behavior of both these properties.

Grain size was obtained by fractography (see Figures 4-32 
Grain Lattice

Pressure Size Param.

Sintering Conditions Compostion $1750^{\circ} \mathrm{C}$ (Vac) $8 \mathrm{hrs}$ $1750^{\circ} \mathrm{C}$ ( Vac) $4 \mathrm{hrs}$ $1750^{\circ} \mathrm{C}$ (Vac) $8 \mathrm{hrs}$ $1750^{\circ} \mathrm{C}\left(\mathrm{H}_{2}\right) \quad 6 \mathrm{hrs}$ $1750^{\circ} \mathrm{C}\left(\mathrm{H}_{2}\right) \quad 6 \mathrm{hrs}$

$1750^{\circ} \mathrm{C}$ (vac) $8 \mathrm{hrs}$ $1750^{\circ} \mathrm{C}\left(\mathrm{H}_{2}\right) 6 \mathrm{hrs}$

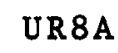

CD6A

$\operatorname{CD} 6 \mathrm{~A}$

$\mathrm{Cd} 6 \mathrm{~A}$

CD6A

UR8A/UR2K

$\mathrm{CD} 6 \mathrm{~A} / \mathrm{CD} 1 \mathrm{~K}$
4.5

4.5

29

15

29

4.5

29 El Elemental Level (ppm)

$(\mu)$

\section{$\begin{array}{ll}40 & 10.47\end{array}$}

$\begin{array}{ll}20 & 10.47\end{array}$

$20-60 \quad 10.47$

$10-40 \quad 10.47$

$20 \quad 10.47$

10.46

$20 \quad 10.46$

$5-20 \quad 10.45$

$17 \quad 230$

$\begin{array}{lll}20 & 220 & 1.0 \\ 17 & 320 & 1.8\end{array}$

$17 \quad 330 \quad 2.5$

$\begin{array}{lll}17 & 150 & 1.7 \\ 48 & 430 & 13.6\end{array}$

$\begin{array}{lll}48 & 430 & 13.6 \\ 20 & 320 & 1.1\end{array}$

$17 \quad 260 \quad 56$
Aged $\mathrm{T}-111$

$$
\text { Aged TZM }
$$

Grain Lattice Elemental Level (ppm) \begin{tabular}{ll} 
Size & Param. \\
$(\mu)$ & $(\AA)$ \\
\hline
\end{tabular}

20

$\begin{array}{lll}17 & 330 & 2.5 \\ 17 & 150 & 1.7\end{array}$ $\begin{array}{lll}-100 & 10.47 \quad 121\end{array}$

$\begin{array}{lll}30 & 10.47 & 18 \\ 10.47 & 26\end{array}$

$\begin{array}{lll}30 & 10.47 \quad 38\end{array}$

$40-100 \quad 10.45 \quad 35$

$5-40 \quad 10.46 \quad 36$
$10-50 \quad 10.47 \quad 84$

$\begin{array}{cll}\underline{\mathrm{A}} \mathrm{f} & \underline{\mathrm{Si}} & \underline{\mathrm{Mg}} \\ 17 & 230 & 1.1 \\ 20 & 190 & 1.1 \mathrm{q} \\ 17 & 330 & 6.9 \\ 17 & 180 & 1.3 \\ 17 & 230 & 1.9 \\ & & \\ 55 & 330 & 360 \\ 17 & 180 & 2.9\end{array}$

Grain Size $\frac{(\mu)}{30-80}$

20

20

30

$5-30$

$5-60$

$20-100$

MECHANICAL STRENGTH ( $\%$ fines)

Sintering Conditions $1750^{\circ} \mathrm{C}$ (Vac) $8 \mathrm{hrs}$ $1750^{\circ} \mathrm{C}$ (Vac) $4 \mathrm{hrs}$ $1750^{\circ} \mathrm{C}(\mathrm{Vac}) 8 \mathrm{hrs}$ $1750^{\circ} \mathrm{C}\left(\mathrm{H}_{2}^{\circ}\right) 6 \mathrm{hrs}$ $1750^{\circ} \mathrm{C}\left(\mathrm{H}_{2}\right) \quad 6 \mathrm{hrs}$ $1750^{\circ} \mathrm{C}$ (Vac) $8 \mathrm{hrs}$ $1750^{\circ} \mathrm{C}\left(\mathrm{H}_{2}\right) 6 \mathrm{hrs}$
Composition

Pressure
(tons)

\section{UR8A}

CD6A

CD6A

CD6A

CD6A

UR8A/UR2K

$\mathrm{CD} 6 \mathrm{~A} / \mathrm{CD} 1 \mathrm{~K}$

29

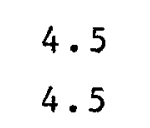

$\frac{<10 \mu}{\text { Pre-aged Aged-T1II Aged-TZM Aged-W }}$

$0.30 \pm 0.09 \quad 0.175 \pm 0.066 \quad 0.219 \pm .078 \quad 0.376 \pm .113$

$\begin{array}{llllll}4.5 & 0.28+0.08 & 0.235+0.063 & 0.209+.025 & 0.198+.047\end{array}$

$29 \quad 0.26 \pm 0.09 \quad 0.044 \pm 0.039 \quad 0.072 \pm .020 \quad 0.085 \pm .064$

$15 \quad 0.33+0.13 \quad 0.151+0.041 \quad 0.134 \pm .085 \quad 0.094+.042$

$29 \quad 0.37 \pm 0.20 \quad 0.075 \pm 0.051 \quad 0.071 \pm .051 \quad 0.070 \pm .036$

$\begin{array}{llllll}4.5 & 0.35 \pm 0.14 & 0.279 \pm 0.035 & 0.345 \pm .131 & 0.332 \pm .078\end{array}$

$0.31+0.17 \quad 0.067+0.027 \quad 0.094 \pm .048$

$0.135+.139$
Sintering Conditions $1750^{\circ} \mathrm{C}$ (Vac) $8 \mathrm{hrs}$
$1750^{\circ} \mathrm{C}$ (Vac) $4 \mathrm{hrs}$ $1750^{\circ} \mathrm{C}(\mathrm{Vac}) \quad 8 \mathrm{hrs}$ $1750^{\circ} \mathrm{C}\left(\mathrm{H}_{2}\right) \quad 6 \mathrm{hrs}$ $1750^{\circ} \mathrm{C}\left(\mathrm{H}_{2}\right) \quad 6 \mathrm{hrs}$ $1750^{\circ} \mathrm{C} \mathrm{(VaC)} 8 \mathrm{hrs}$ $1750^{\circ} \mathrm{C}\left(\mathrm{H}_{2}\right) \quad 6 \mathrm{hrs}$

\begin{tabular}{|c|c|c|c|c|c|}
\hline \multirow[b]{2}{*}{ Composition } & \multirow{2}{*}{$\begin{array}{l}\text { Pressure } \\
\text { (tons) }\end{array}$} & \multicolumn{3}{|c|}{$44-149 \mu$} & \multirow[b]{2}{*}{ Aged-W } \\
\hline & & Pre-aged & Aged-T111 & Aged-TZM & \\
\hline UR8A & 4.5 & 1.182 & 1.131 & 1.426 & 2.292 \\
\hline $\mathrm{CD} 6 \mathrm{~A}$ & 4.5 & 1.077 & 1.012 & 1.057 & 1.024 \\
\hline $\mathrm{CD} 6 \mathrm{~A}$ & 29 & 1.163 & 0.135 & 0.250 & 0.231 \\
\hline CD6A & 15 & 1.019 & 0.975 & 0.730 & 0.218 \\
\hline CD6A & 29 & 0.203 & 0.460 & 0.326 & 0.348 \\
\hline UR8A/UR $2 \mathrm{~K}$ & 4.5 & 1.467 & 0.997 & 2.078 & 1.936 \\
\hline $\mathrm{CD} 6 \mathrm{~A} / \mathrm{CD} 1 \mathrm{~K}$ & 29 & 1.098 & 0.142 & 0.372 & 0.322 \\
\hline
\end{tabular}

\begin{tabular}{llll}
\multicolumn{4}{c}{$10-44 \mu$} \\
\hline$\underline{\text { Pre-aged }}$ & Aged-T111 & $\underline{\text { Aged-TZM }}$ & $\underline{\text { Aged-W }}$ \\
$0.21 \pm 0.02$ & $0.284 \pm .064$ & $0.458 \pm .126$ & $0.810 \pm .136$ \\
$0.17 \pm 0.03$ & $0.215 \pm .026$ & $0.272 \pm .051$ & $0.301 \pm .046$ \\
$0.22 \pm 0.08$ & $0.040 \pm .025$ & $0.058 \pm .030$ & $0.038 \pm .011$ \\
$0.22 \pm 0.03$ & $0.373 \pm .054$ & $0.274 \pm .162$ & $0.065 \pm .039$ \\
$0.16 \pm 0.03$ & $0.125 \pm .034$ & $0.095 \pm .027$ & $0.094 \pm .036$ \\
$0.30 \pm 0.09$ & $0.354 \pm .062$ & $0.553 \pm .106$ & $0.642 \pm .049$ \\
$0.22+0.08$ & $0.101 \pm .033$ & $0.131 \pm .027$ & $0.105+.043$
\end{tabular}

Lattice Elemental Level (ppm) (\&) $\mathrm{Fe} \quad \mathrm{Al} \quad \mathrm{Si} \quad \mathrm{Mg}$

10.47

10.47

10.47

10.47

10.46

10.46

$\begin{array}{llll}\underline{\text { Fe }} & \underline{\mathrm{A}} & \underline{\mathrm{Si}} & \underline{\mathrm{Mg}} \\ 19 & 20 & 310 & 1.4 \\ 23 & 20 & 230 & 1.0 \\ 18 & 18 & 190 & 0.9 \\ 55 & 17 & 330 & 5.3 \\ 52 & 17 & 260 & 1.9 \\ & & & \\ 71 & 17 & 120 & 9.3 \\ 27 & 17 & 220 & 1.9\end{array}$

$\mathrm{CD} 6 \mathrm{~A} / \mathrm{CD} 1 \mathrm{~K}$

0.142

0.372

0.322

\begin{tabular}{|c|c|c|c|}
\hline \multicolumn{4}{|c|}{$>149 \mu$} \\
\hline Pre-aged & Aged-TIII & Aged-TZM & Aged-W \\
\hline 98.268 & 98.514 & 97.940 & 96.316 \\
\hline 98.444 & 98.449 & 98.532 & 98.553 \\
\hline 98.333 & 99.871 & 98.715 & 99.755 \\
\hline 98.526 & 98.524 & 98.876 & 99.759 \\
\hline 98.522 & 99.480 & 99.640 & 99.568 \\
\hline 97.788 & 98.388 & 96.785 & 96.984 \\
\hline 98.299 & 99.800 & 99.484 & 99.459 \\
\hline
\end{tabular}




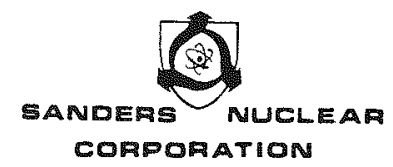

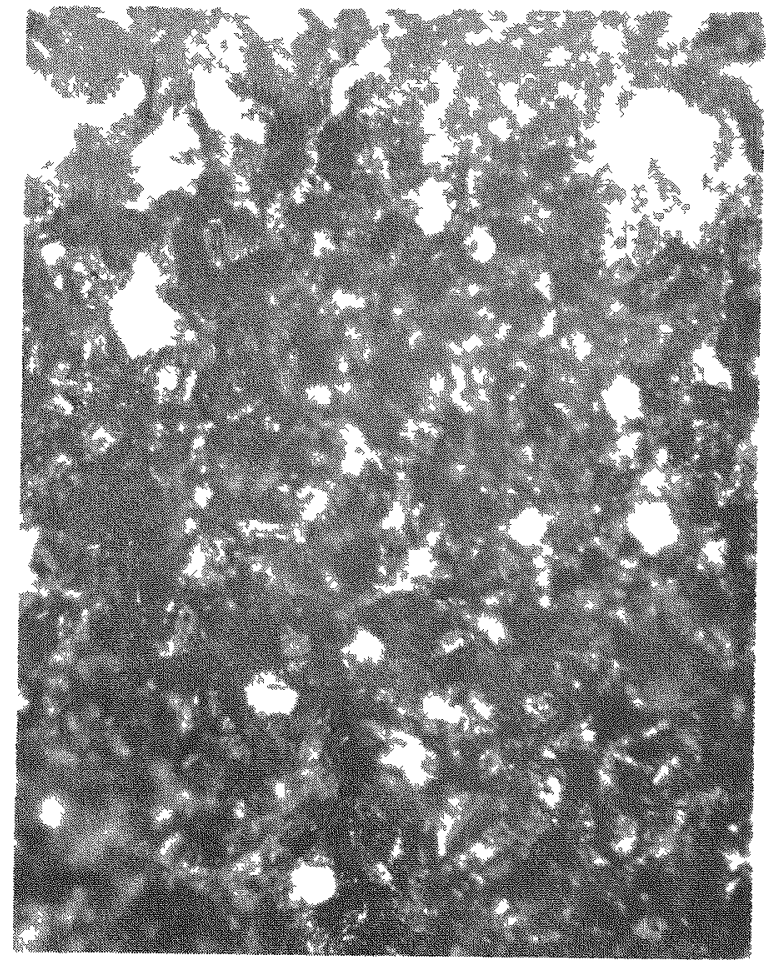

A. $T-111$

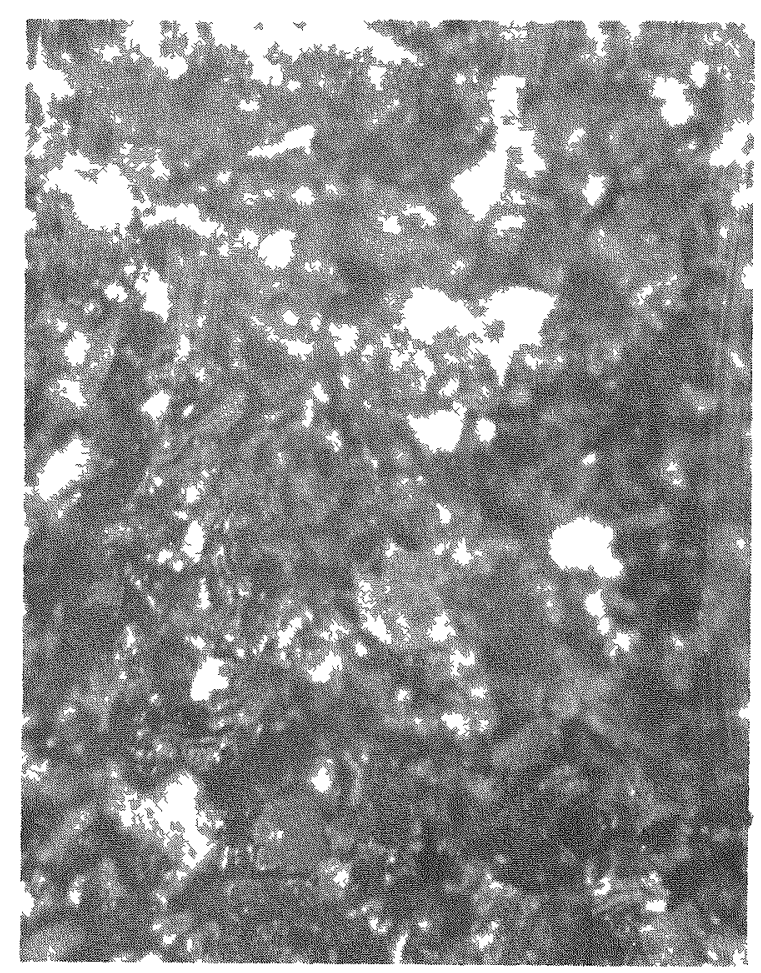

B. TZM

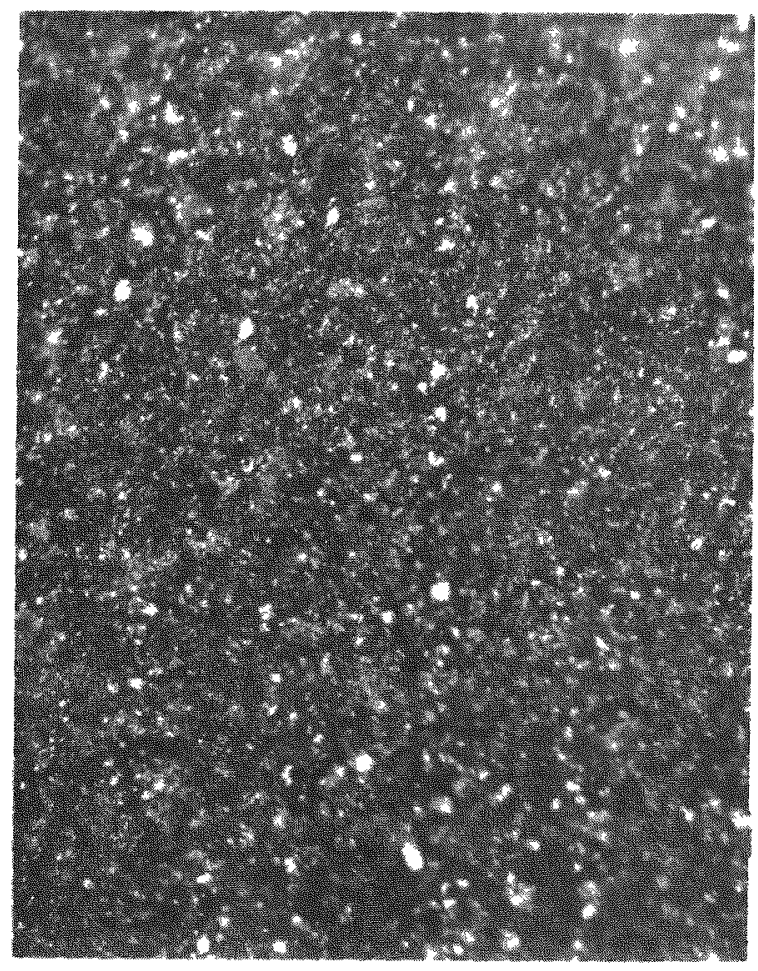

C. TUNGSTEN

Figure $4-32100 \% \operatorname{Tm}_{2} 0_{3}$, Pressed at 4.5 tsi, Sintered $1750^{\circ} \mathrm{C}, 8$ Hours

Vacuum, Aged 500 Hours, $1600^{\circ} \mathrm{C}(100 \mathrm{X})$. 


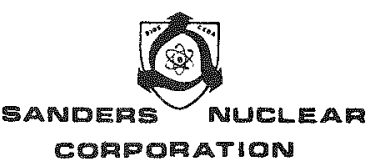

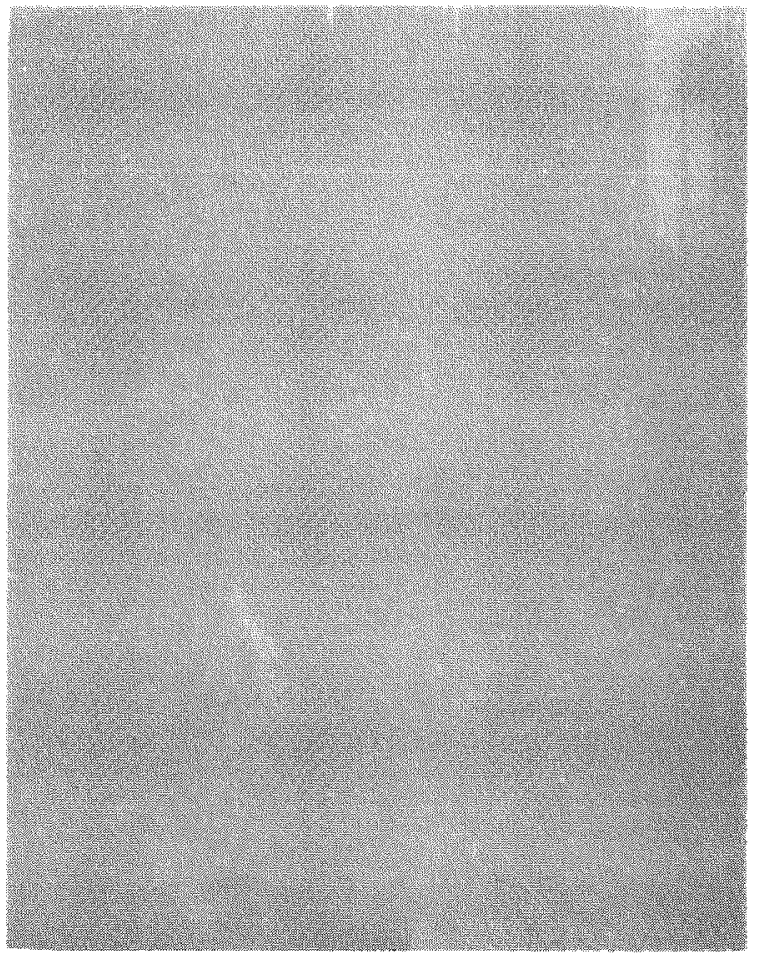

A. CONTROL-NO AGE

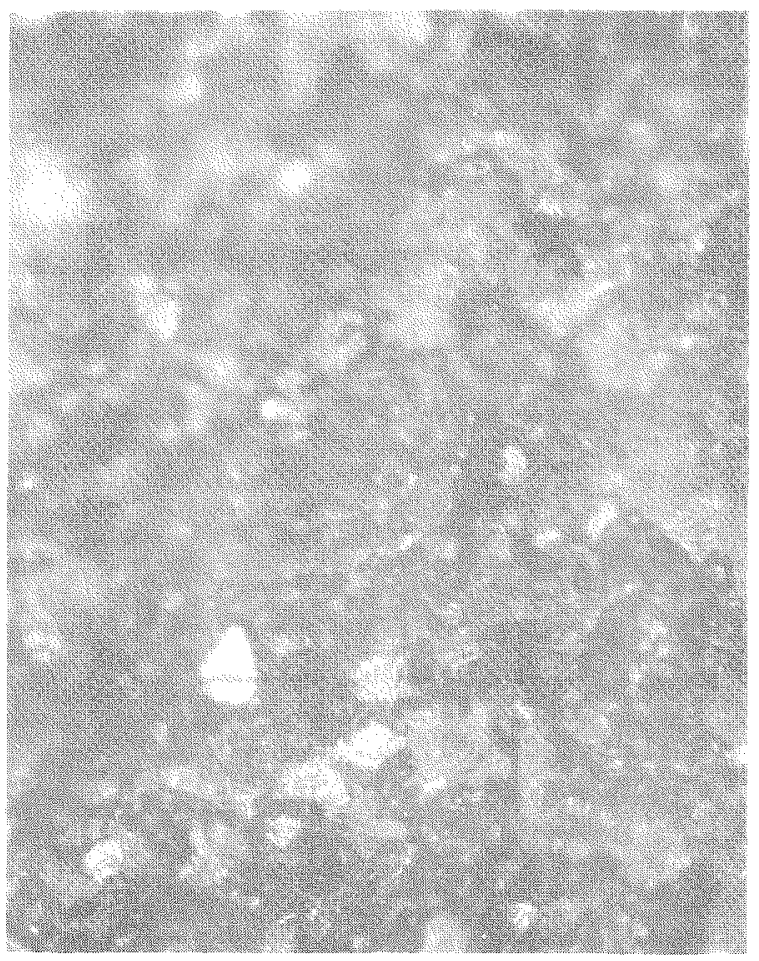

C. TZM

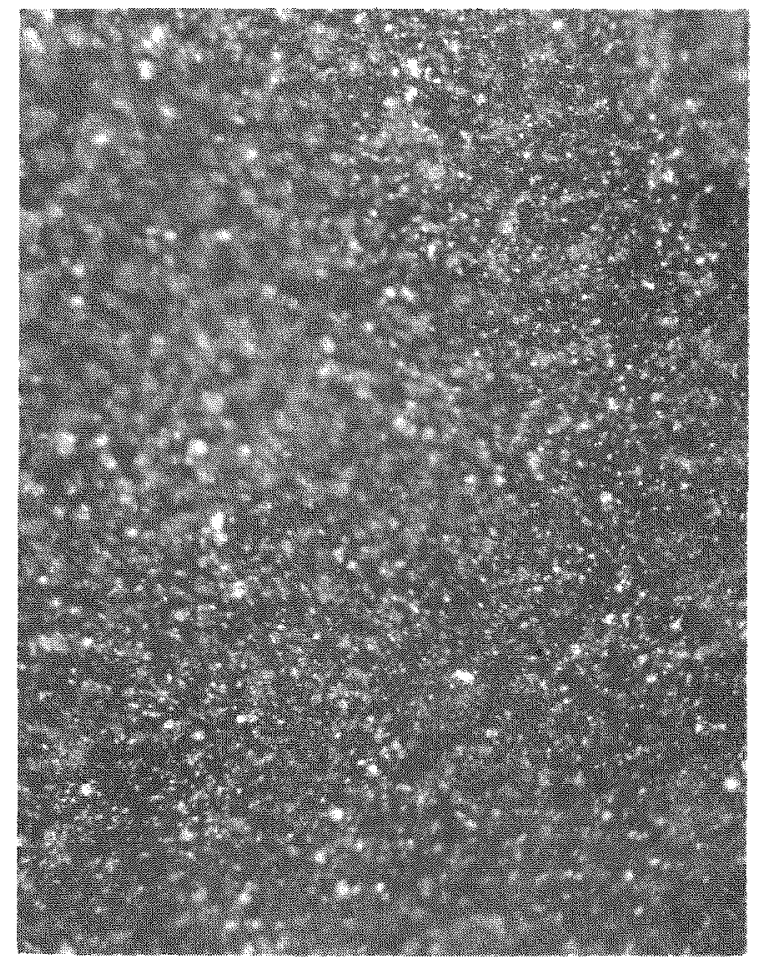

B. $T-111$

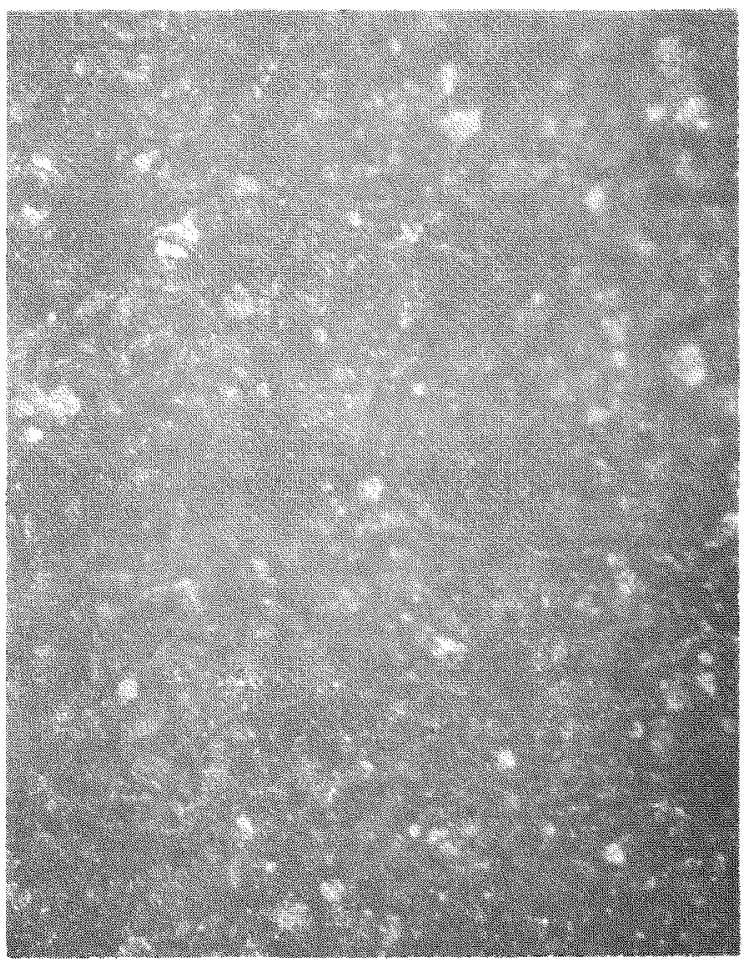

D. TUNGSTEN

Figure 4-33 80\% $\mathrm{Tm}_{2} \mathrm{O}_{3} / 20 \% \mathrm{Yb}_{2} \mathrm{O}_{3}$, Pressed at $4.5 \mathrm{tsi}$, Sintered $1750^{\circ} \mathrm{C}$, 8 Hours Vacuum, Aged 500 Hours, $1600^{\circ} \mathrm{C}(100 \mathrm{X})$. 


\section{(1) \\ SANDERS NUCLEA \\ COAPORATION}

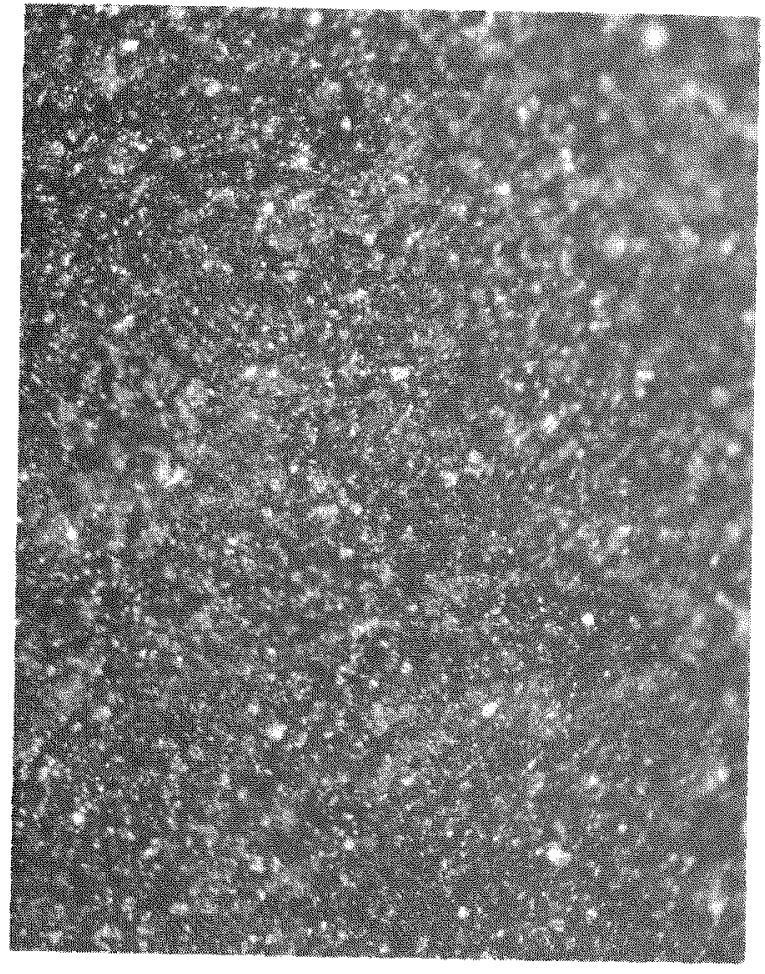

A. T-111

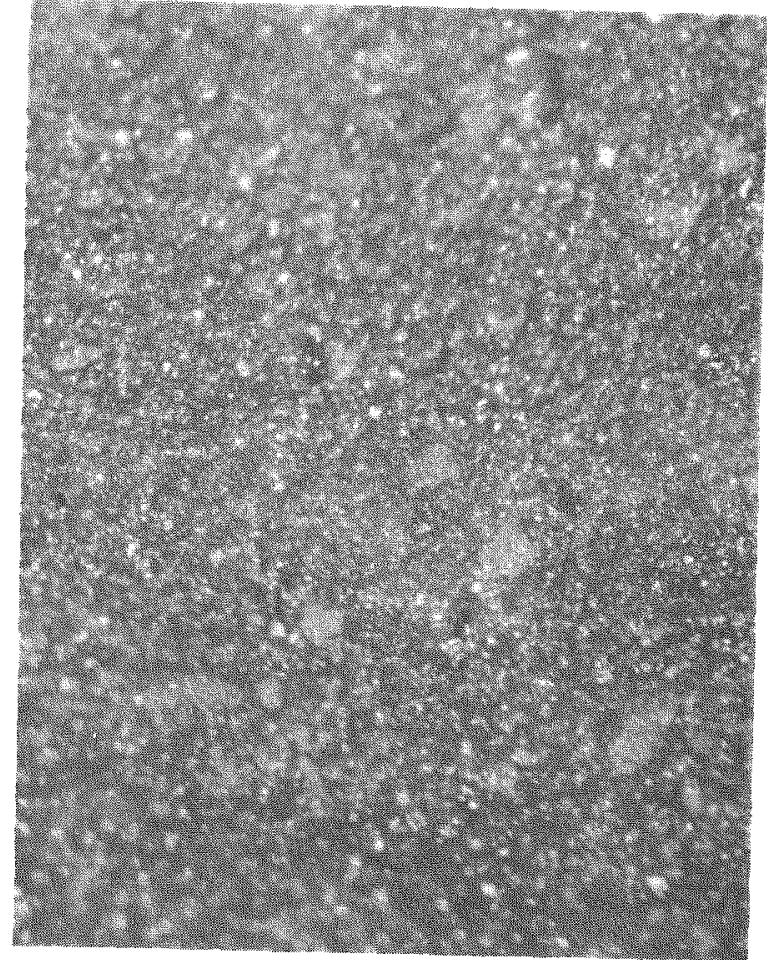

B. $T Z M$

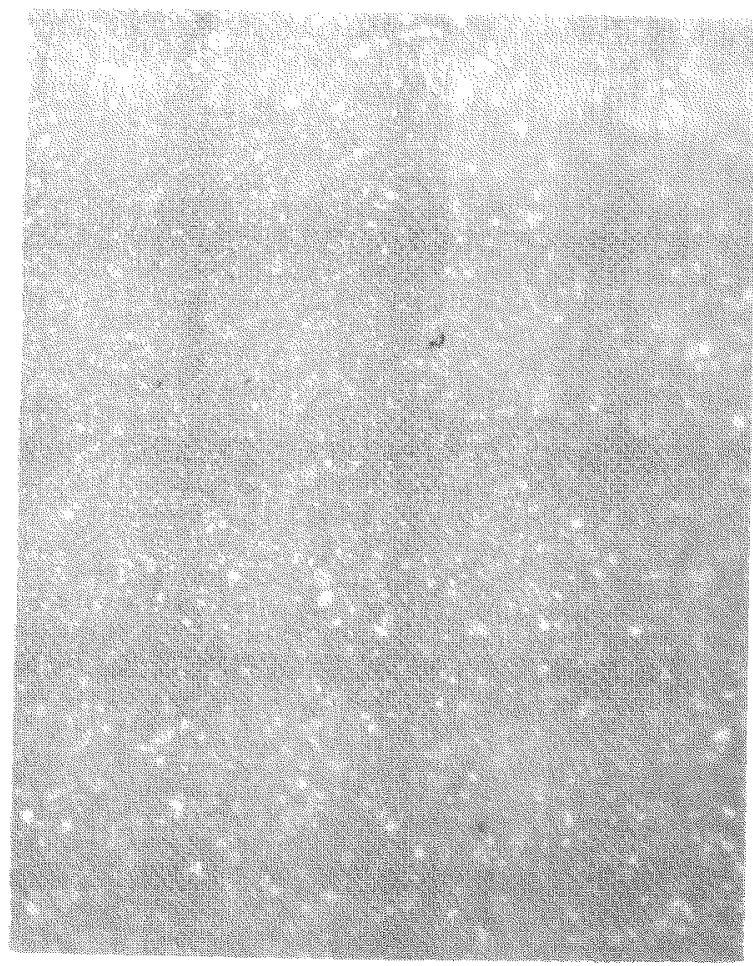

C. TUNGSTEN

Figure 4-34 100\% $\mathrm{Tm}_{2} \mathrm{O}_{3}$, Pressed at $4.5 \mathrm{tsi}$, Sintered $1750^{\circ} \mathrm{C}, 4$ Hours

Vacuum, Aged 500 Hours, $1600^{\circ} \mathrm{C}(100 \mathrm{X})$. 


\section{(2) \\ BANDEAS NUELEAT \\ COMPONATION}

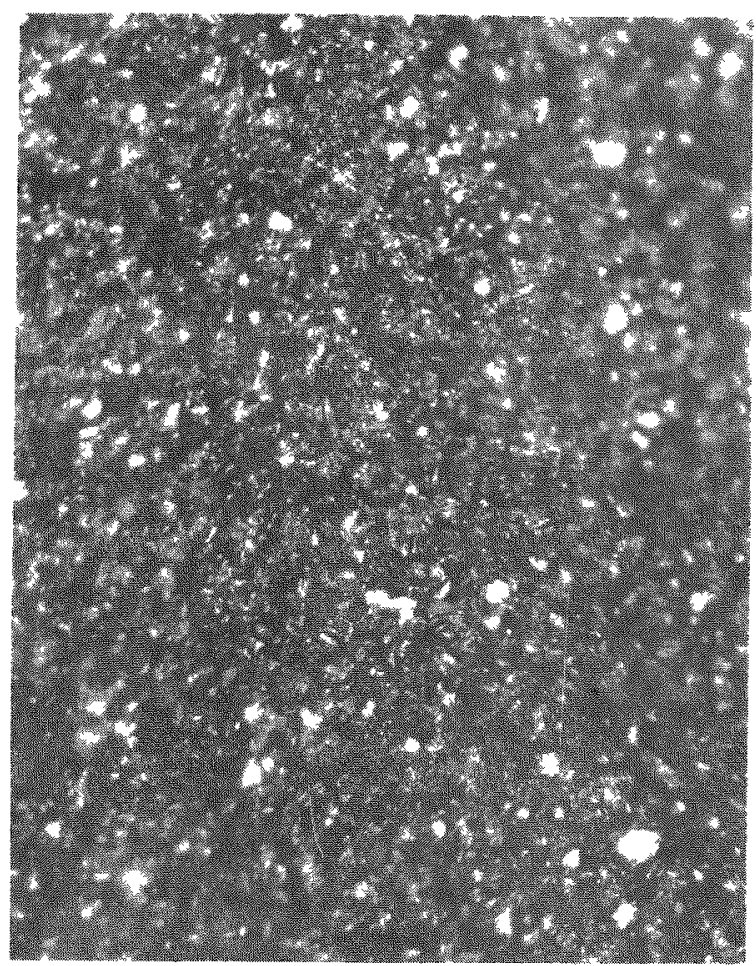

A. $T-111$

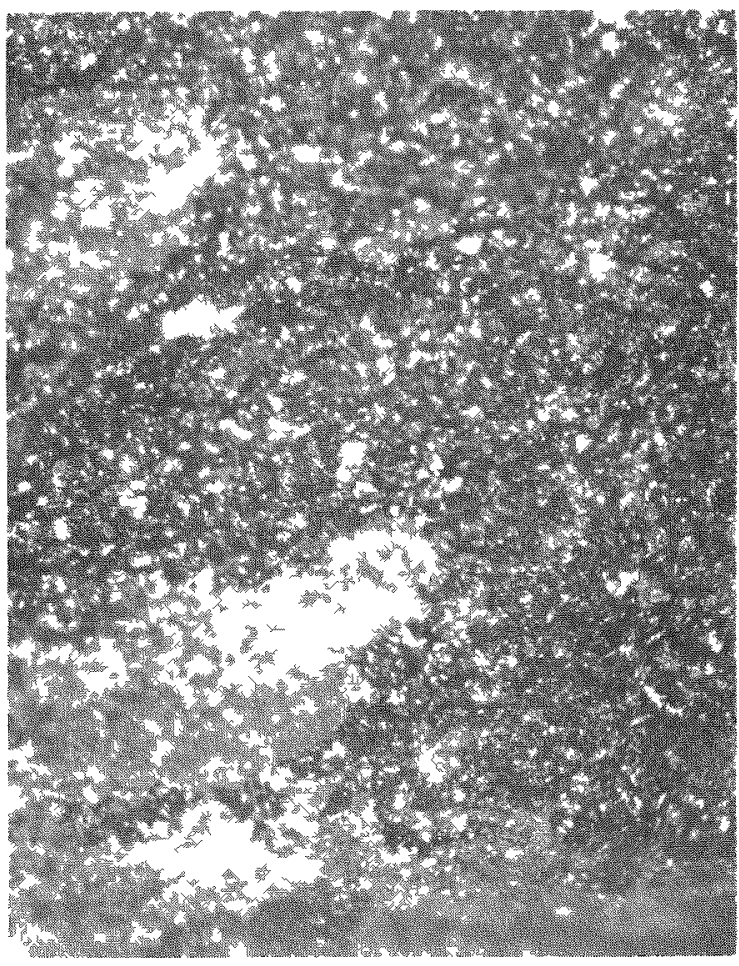

B. $T Z M$

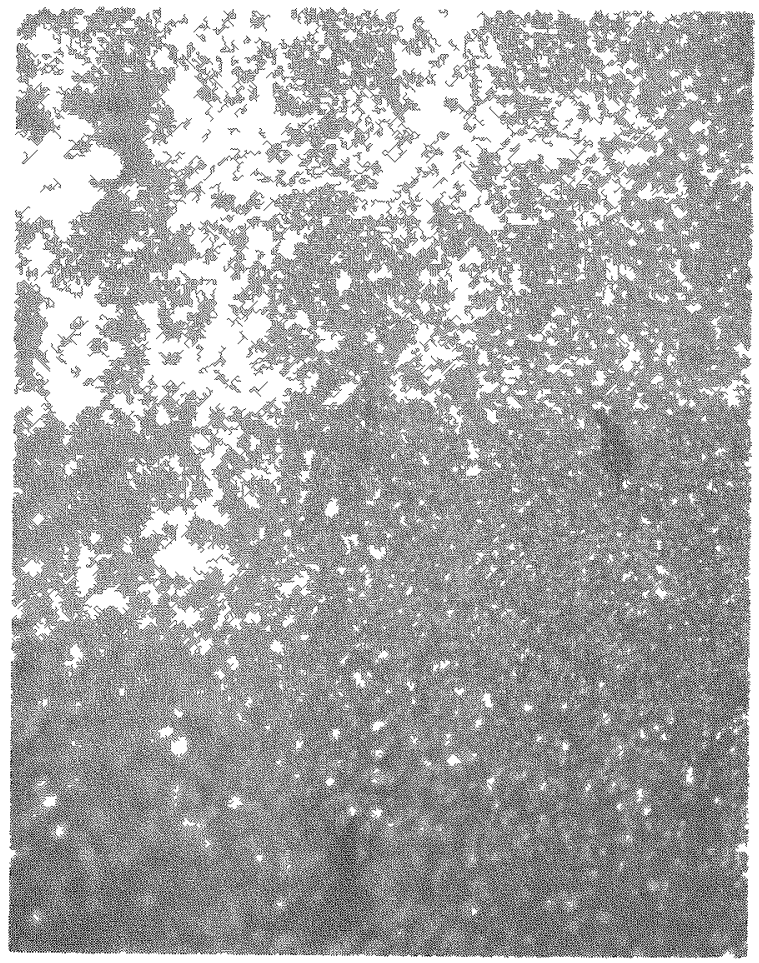

C. TUNGSTEN

Figure 4-35 100\% $\mathrm{Tm}_{2} \mathrm{O}_{3}$, Pressed at $29 \mathrm{tsi}$, Sintered $1750^{\circ} \mathrm{C}, 8$ Hours Vacuum, Aged 500 Hours $1600^{\circ} \mathrm{C}(100 \mathrm{X})$. 


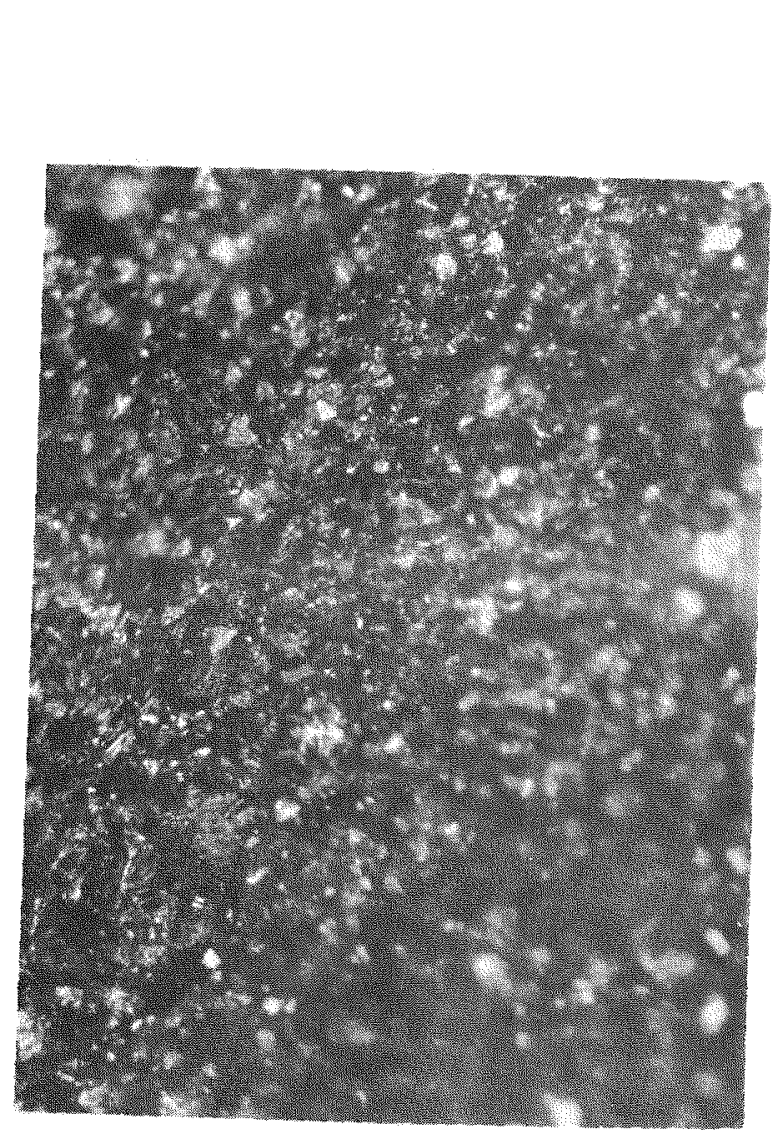

A. $T-111$
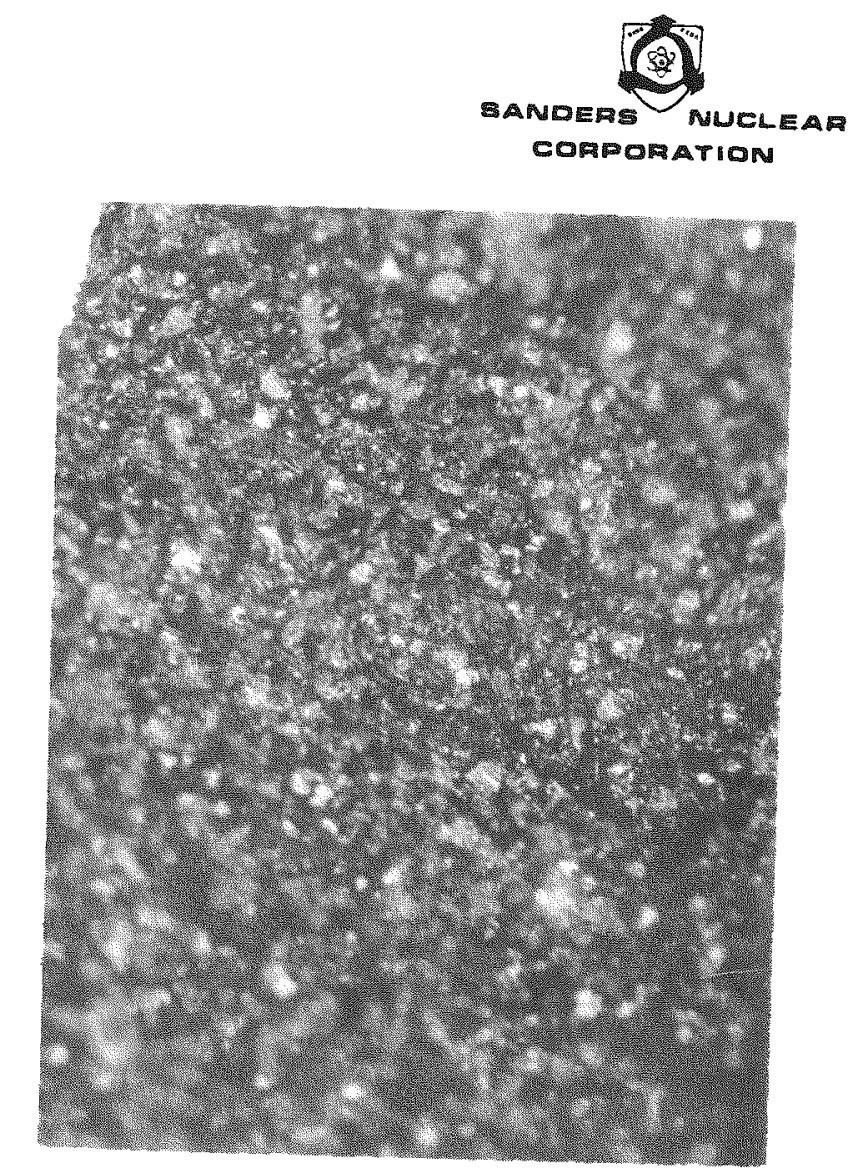

B. TZM

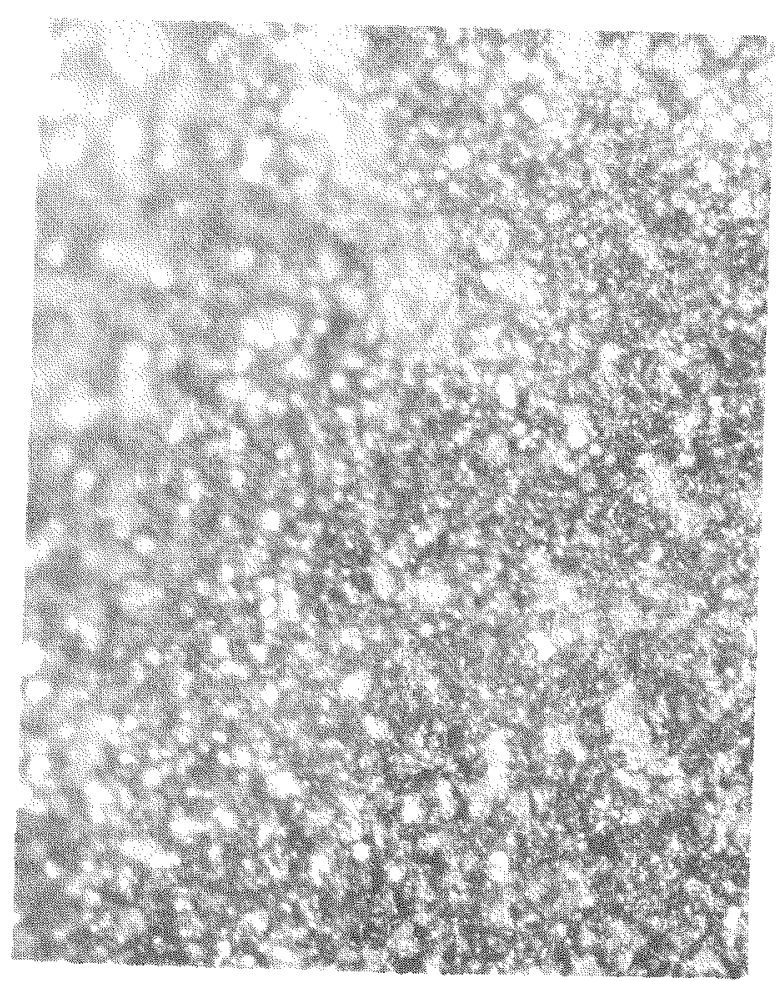

\section{TUNGSTEN}

Figure 4-36 100\% $\operatorname{Tm}_{2} \mathrm{O}_{3}$, Pressed at 15 tsi, Sintered $1750^{\circ} \mathrm{C}$, 6 Hours Hydrogen, Aged 500 Hours, $1600^{\circ} \mathrm{C}$ (100X). 


\section{(8) \\ SANDERE NUELERA \\ CORPOAATION}

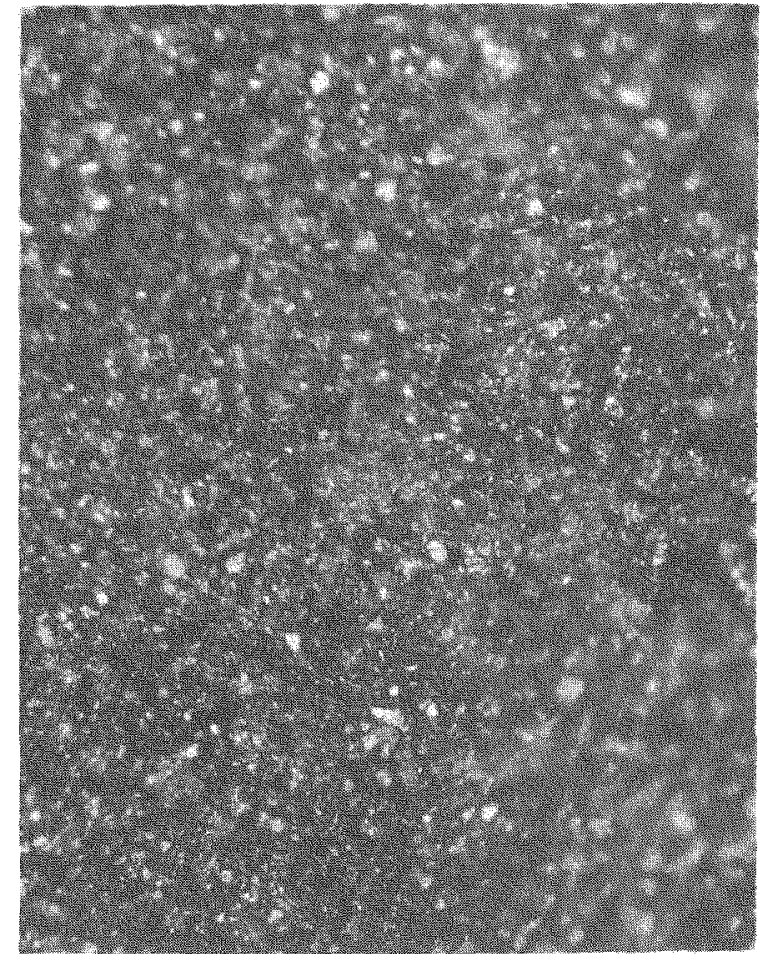

A. $T-111$

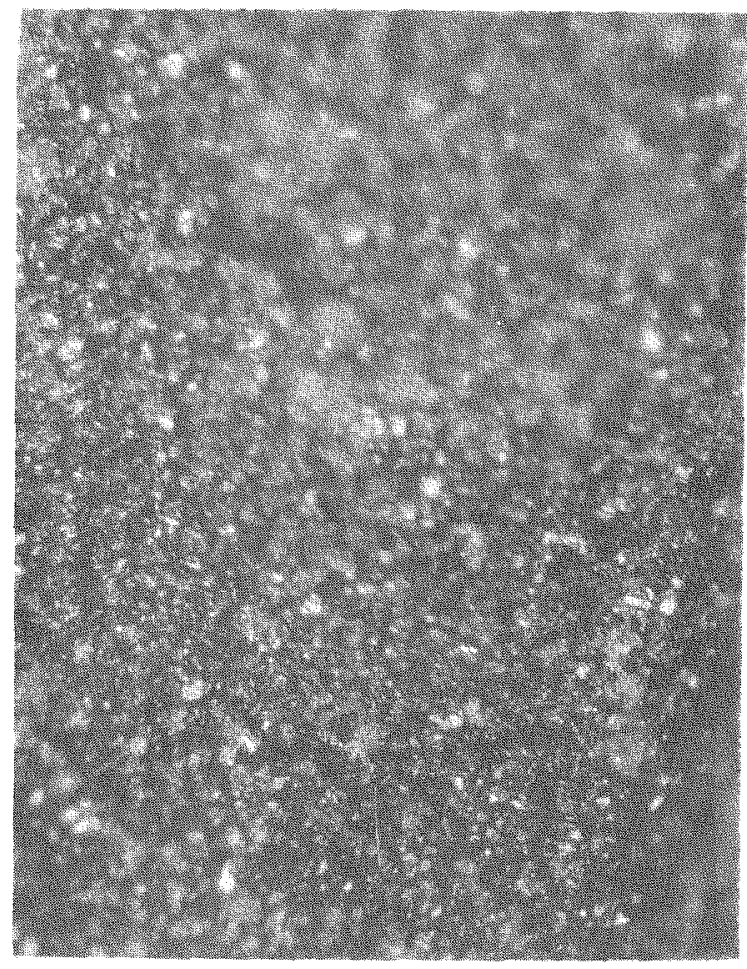

B. $T Z M$

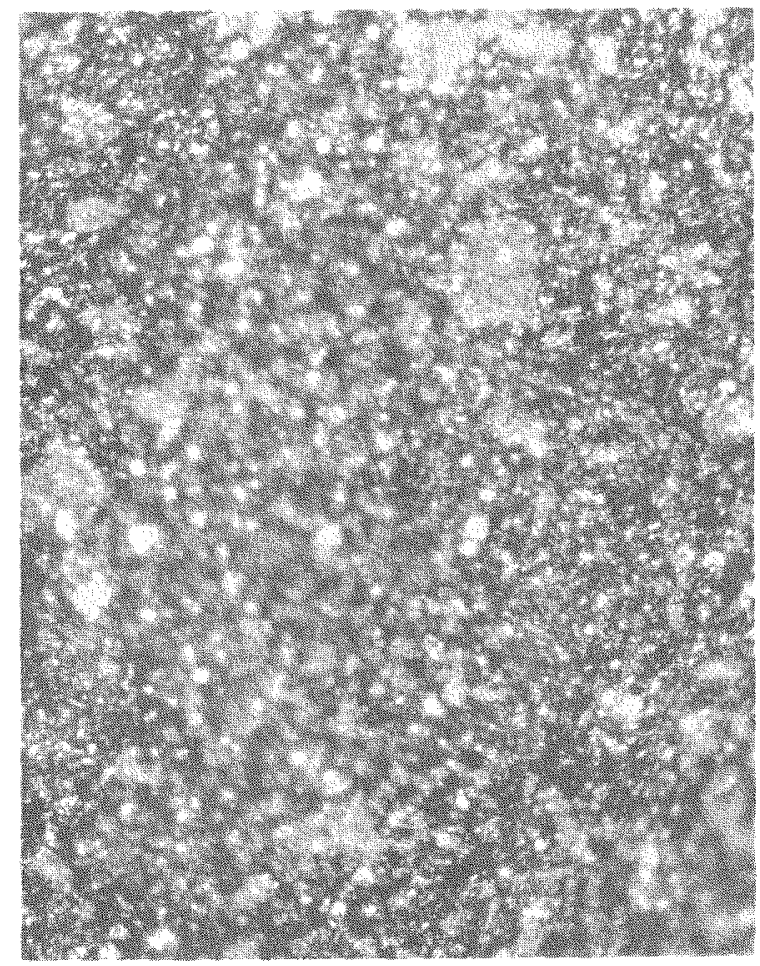

\section{TUNGSTEN}

Figure 4-37 100\% $\operatorname{Tm}_{2} \mathrm{O}_{3}$, Pressed at $29 \mathrm{tsi}$, Sintered $1750^{\circ} \mathrm{C}, 6$ Hours Hydrogen, Aged 500 Hours, $1600^{\circ} \mathrm{C}(100 \mathrm{X})$. 


\section{1. \\ SANDES NUCLEAT CORPOAATION}

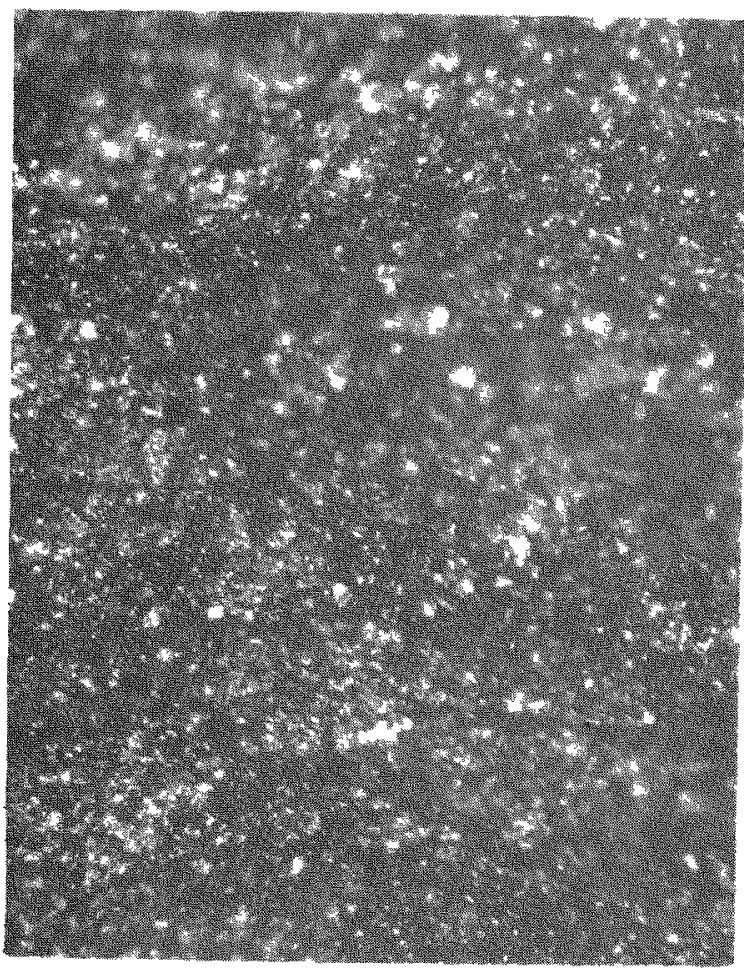

A. $T-\Pi 11$

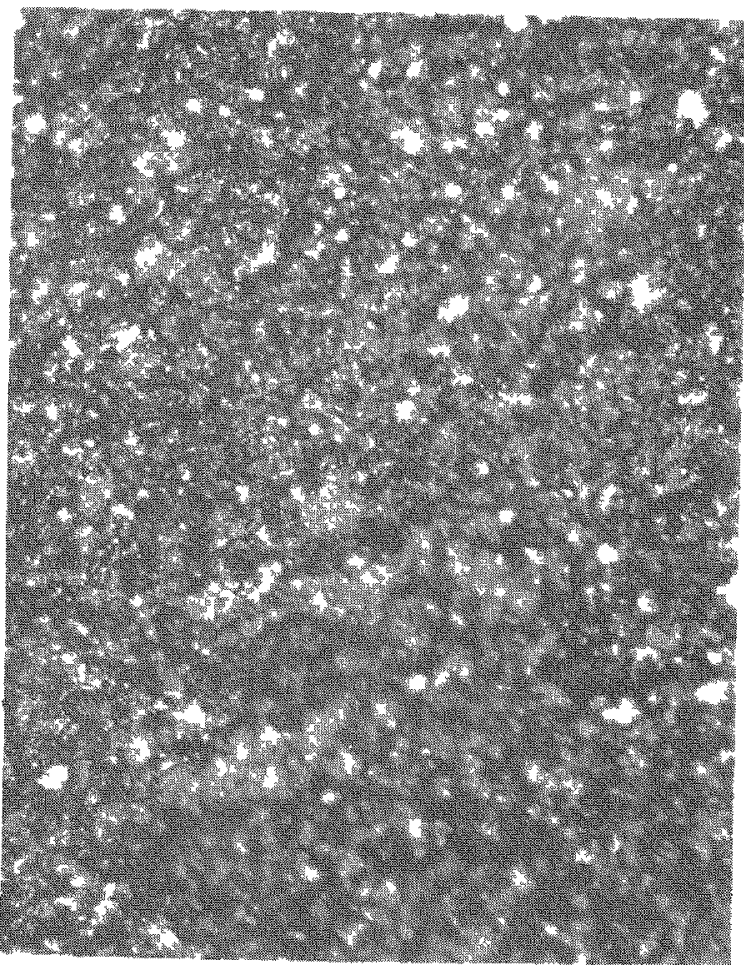

B. $T Z M$

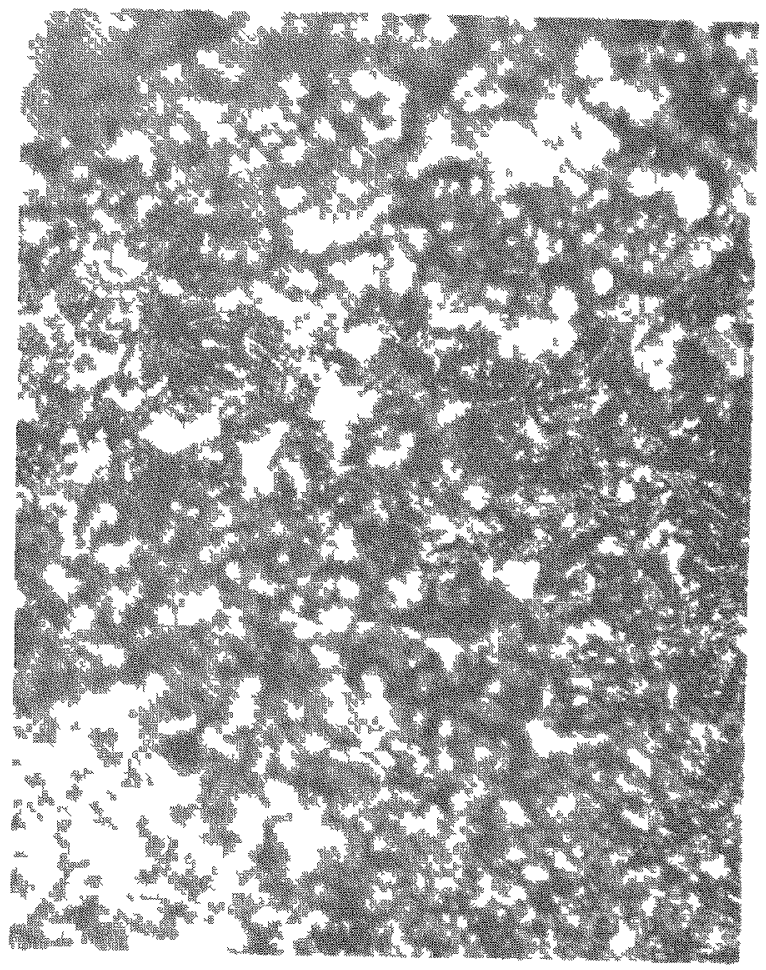

\section{TUNGSTEN}

Figure 4-38 80\% $\operatorname{Tm}_{2} \mathrm{O}_{3} / 20 \% \mathrm{Yb}_{2} \mathrm{O}_{3}$, Pressed at $29 \mathrm{tsi}$, Sintered $1750^{\circ} \mathrm{C}$, 6 Hours Hydrogen, Aged 500 Hours, $1600^{\circ} \mathrm{C}(100 \mathrm{X})$. 
to 4-38). Grain sizes measured in these wafers were related to chemical procese and capsule material. The data are presented in Table $4-11$.

Grain size of wafers made by urea process $100 \% \mathrm{Tm}_{2} \mathrm{O}_{3}$ and $80 \% \mathrm{Tm}_{2} \mathrm{O}_{3} / 20 \% \mathrm{Yb}_{2} \mathrm{O}_{3}$ were enhanced when encapsulated but particularly when encapsulated in TZM and tungsten. Grain size of wafers made by ammonium oxalate process were also enhanced by encapsulation, but particularly the $80 \% \mathrm{Tm}_{2} \mathrm{O}_{3} / 20 \% \mathrm{Yb}_{2} \mathrm{O}_{3}$ wafer encapsulated in tungsten. The 10 micron enhancement observed in grain size of al1 wafers beyond that of preaged wafers was attributed primarily to the extended time at temperature. Increases in grain size beyond the 10 micron base level were interpreted as being a function of the encapsulant.

Metallographic analysis was performed on cross sectioned wafers in the as polished condition. Wafers sintered in hydrogen prior to aging were black throughout and highly translucent to transparent. Vacuum sintered samples were green to grey following aging and also highly translucent. Laminar cracking was observed in wafers pressed at 4.5, 15 and 29 tsi. Crack healing was observed in all these wafers.

Figures $4-39$ to 4-45 are micrographs of the as-polished surfaces. The microstructure of the $80 \% \mathrm{Tm}_{2} \mathrm{O}_{3} / 20 \% \mathrm{Yb}_{2} \mathrm{O}_{3}$ wafers prepared from urea processed materials contained areas of clustered porosity whereas the porosity in $100 \% \mathrm{Tm}_{2} \mathrm{O}_{3}$ wafers was uniformly distributed. $\quad \mathrm{A} \mathrm{Yb}_{2} \mathrm{O}_{3}$ effect was also observed in wafers prepared from ammonium oxalate process (see Figures 4-39, 4-40 and 4-45). A brittle phas had formed in the mixed oxide samples that was most prevalent in wafers encapsulated in $\mathrm{T}-111$. Large voids were also observed in the mixed oxide wafers. $100 \% \mathrm{Tm}_{2} \mathrm{O}_{3}$ wafers were free of both these effects.

All wafers regardless of pre-aging history contained areas that were eliptically shaped and were integral part of the matrix. In $100 \% \operatorname{Tm}_{2} \mathrm{O}_{3}$, these wafers were quite clear and relatively void 
TABLE $\quad 4-11$

GRAIN SIZE OF $100 \% \mathrm{Tm}_{2} \mathrm{O}_{3}-80 \% \mathrm{Tm}_{2} \mathrm{O}_{3} / 20 \% \mathrm{Yb}_{2} \mathrm{O}_{3}$ WAFERS AGED IN T-111, TZM AND TUNGSTEN FOR 500 HOURS AT $1600^{\circ} \mathrm{C}$ FOLLOWED BY MINUTE RISE TO $2000^{\circ} \mathrm{C}$ AND SHUT DOWN

PROCESS
$1750^{\circ} \mathrm{C}(\mathrm{VaC}) 8 \mathrm{hrs}$
$1750^{\circ} \mathrm{C}(\mathrm{VaC}) 4 \mathrm{hrs}$
$1750^{\circ} \mathrm{C}(\mathrm{VaC}) 8 \mathrm{hrs}$
$1750^{\circ} \mathrm{C}\left(\mathrm{H}_{2}\right) 6 \mathrm{hrs}$
$1750^{\circ} \mathrm{C}\left(\mathrm{H}_{2}\right) 6 \mathrm{hrs}$
$1750^{\circ} \mathrm{C}(\mathrm{VaC}) 8 \mathrm{hrs}$
$1750^{\circ} \mathrm{C}\left(\mathrm{H}_{2}\right) 6 \mathrm{hrs}$

PREAGED
$<1-10$
$<1-10$
$<1-10$
$<1-20$
$<1-20$
$<1-10$
$<1-10$

AGED T-111

$<40$

$<20$

$20-60$

$10-40$

$<20$

$<20$

$5-20$
AGED TZM

20-100

$<10$

30

$10-50$

$<30$

$40-100$

$5-40$
AGED W $30-80$

$<20$

20

30

$5-20$

$5-60$

20-100 


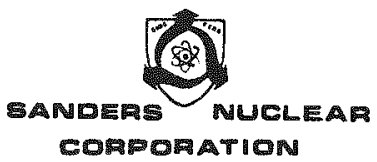

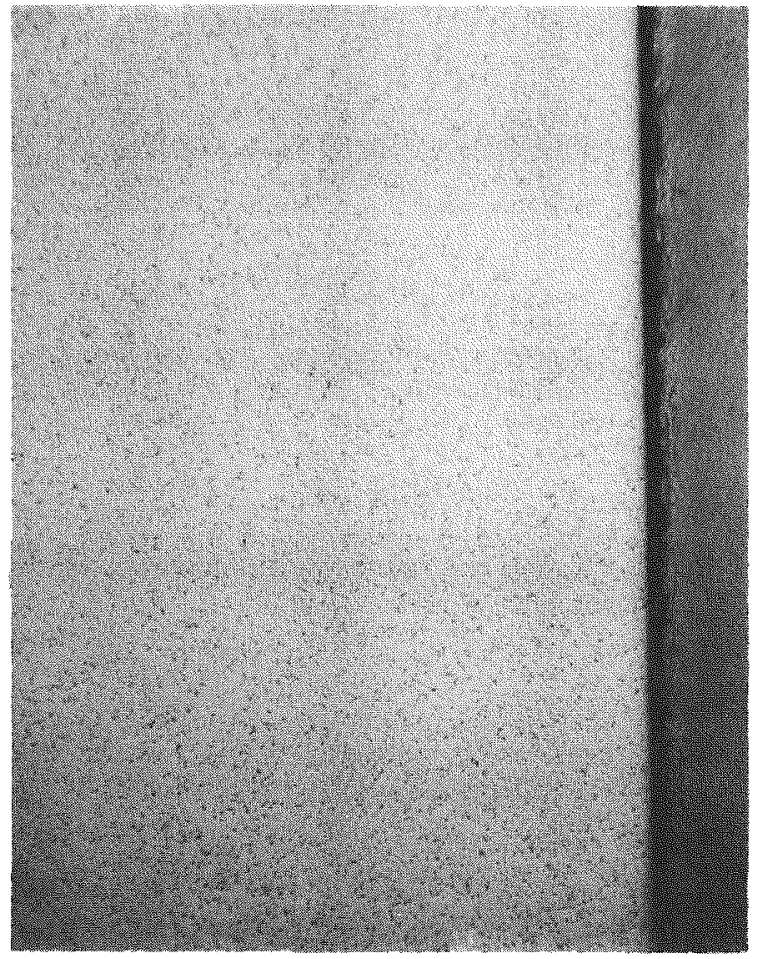

A. T-111

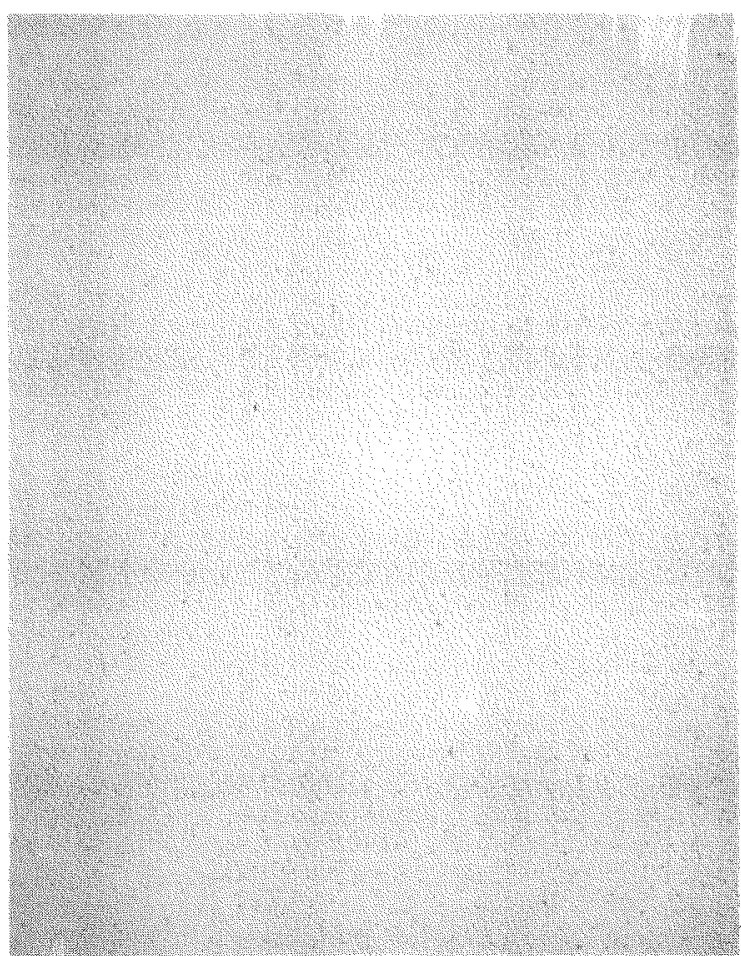

B. TZM

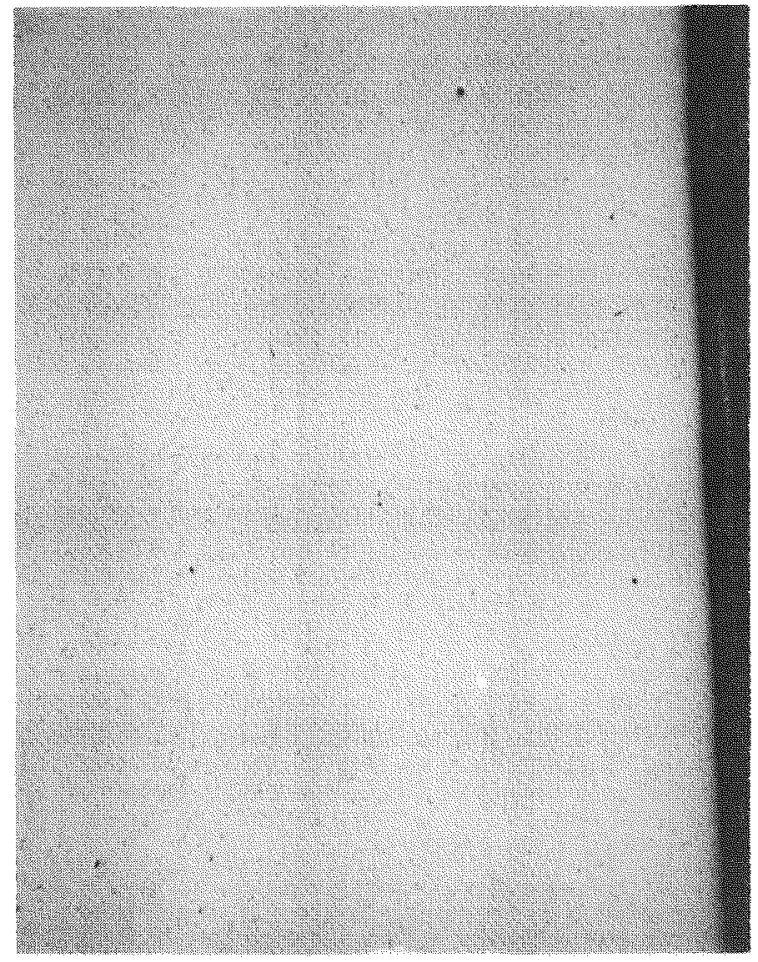

\section{TUNGSTEN}

Figure 4-39 100\% $\mathrm{Tm}_{2} \mathrm{O}_{3}$. Pressed at $4.5 \mathrm{tsi}$, Sintered $1750^{\circ} \mathrm{C}$ Vacuum 8 Hours, Aged 500 Hours, $1600^{\circ} \mathrm{C}(70 \mathrm{X})$. 


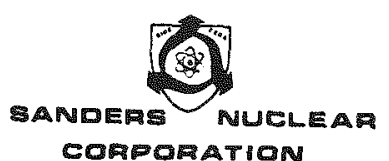

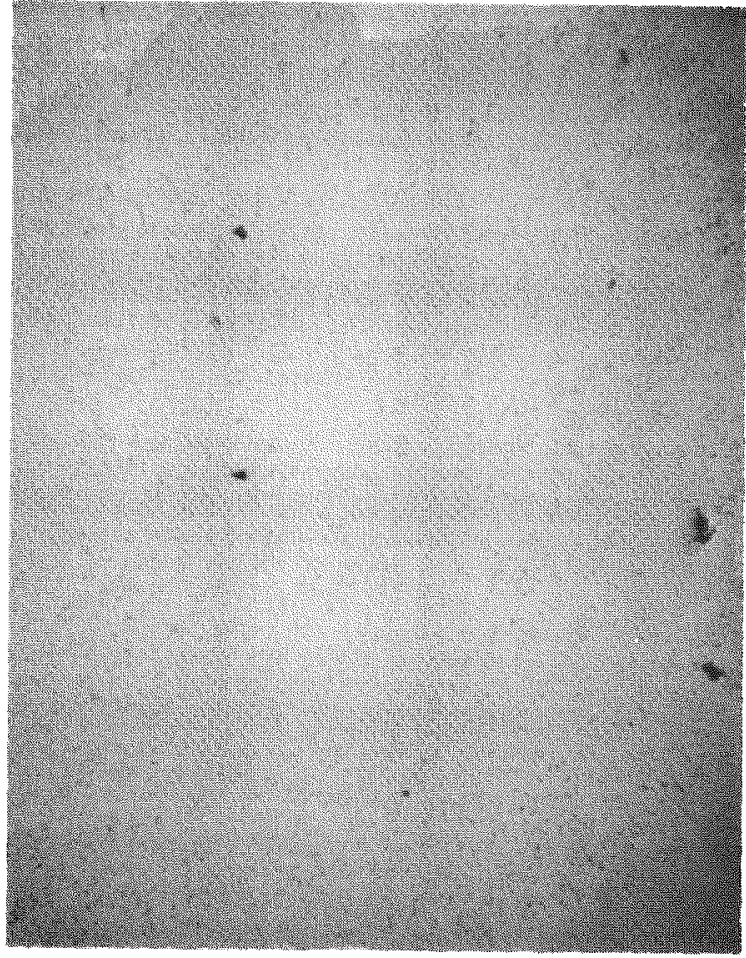

A. T-111

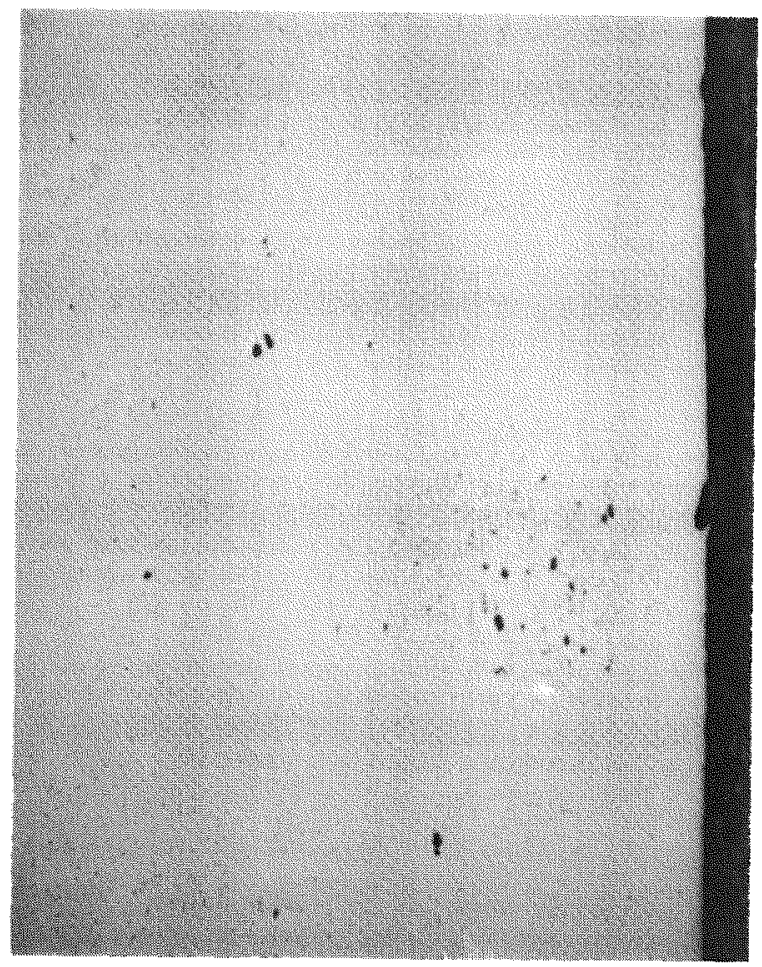

B. $T Z M$

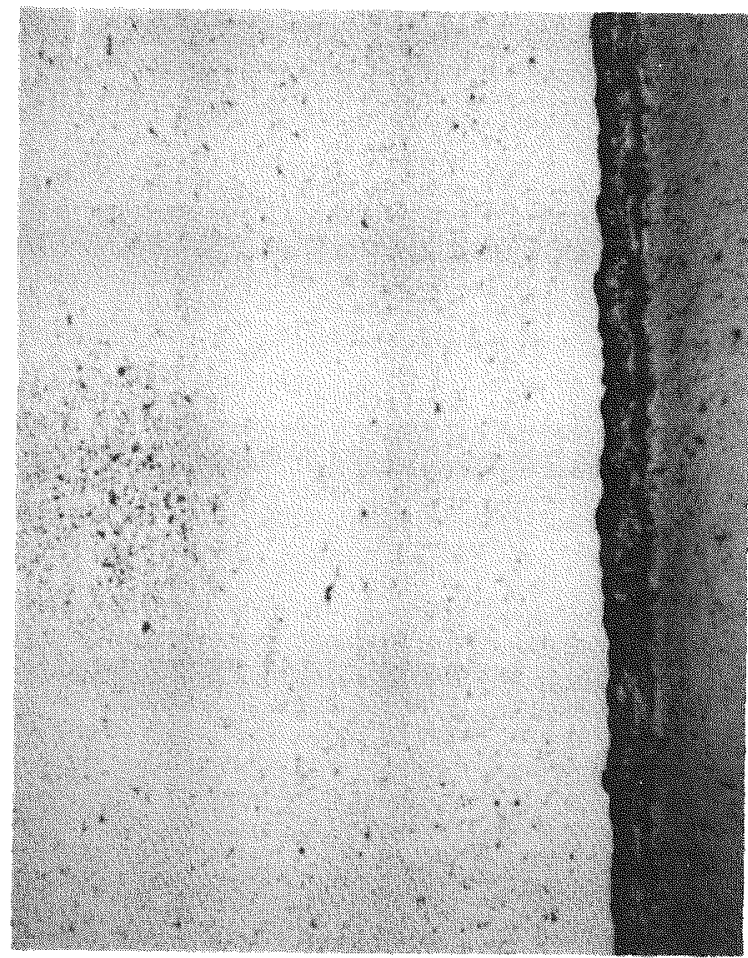

C. TUNGSTEN

Figure $4-40 \quad 80 \% \mathrm{Tm}_{2} \mathrm{O}_{3} / 20 \% \mathrm{Yb}_{2} \mathrm{O}_{3}$ Wafers, Pressed at 4.5 tsi, Sintered $1750^{\circ} \mathrm{C}, 8$ Hours Vacuum, Aged 500 Hours, $1600^{\circ} \mathrm{C}(70 \mathrm{X})$. 


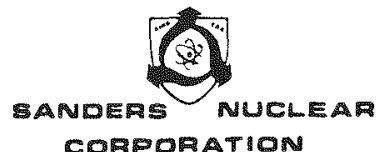

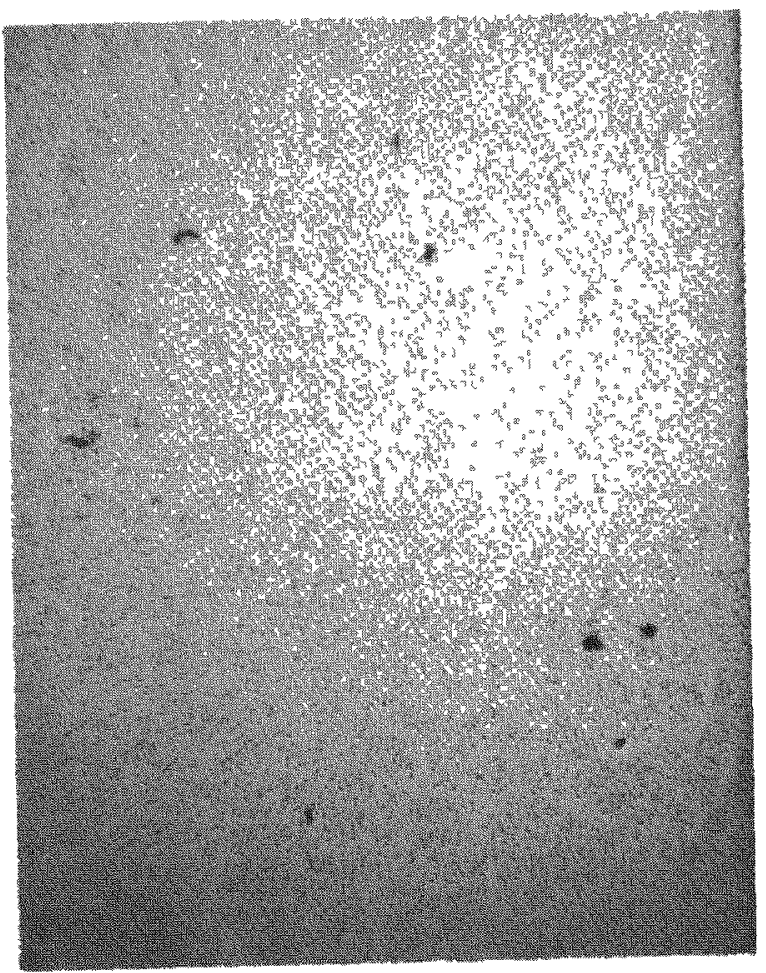

A. T-111

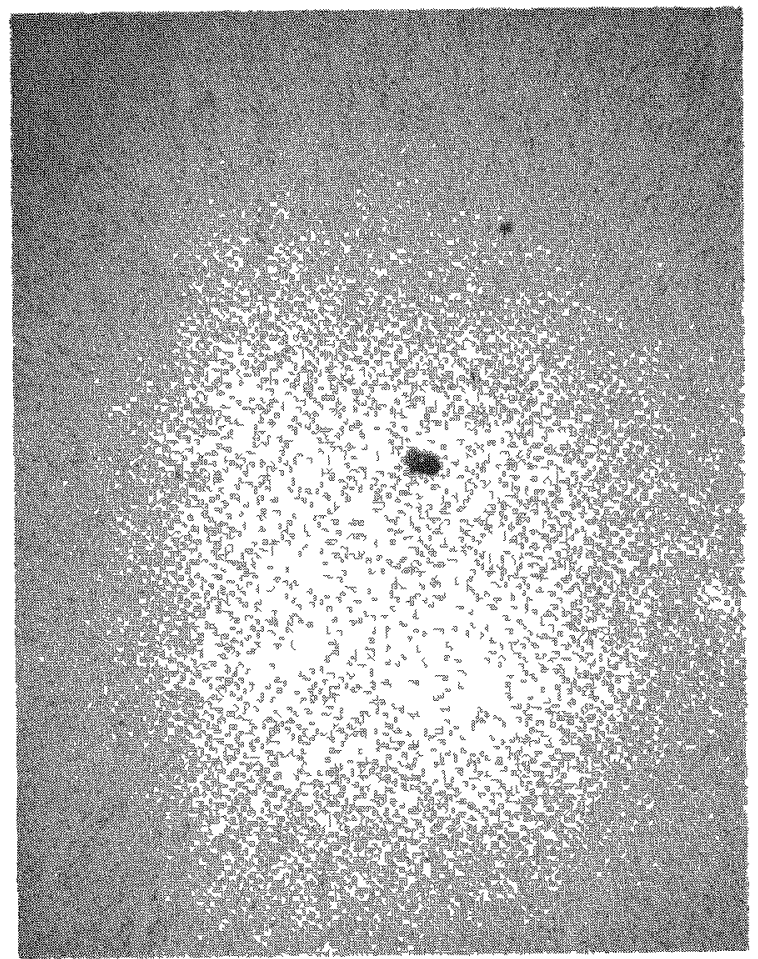

B. TZM

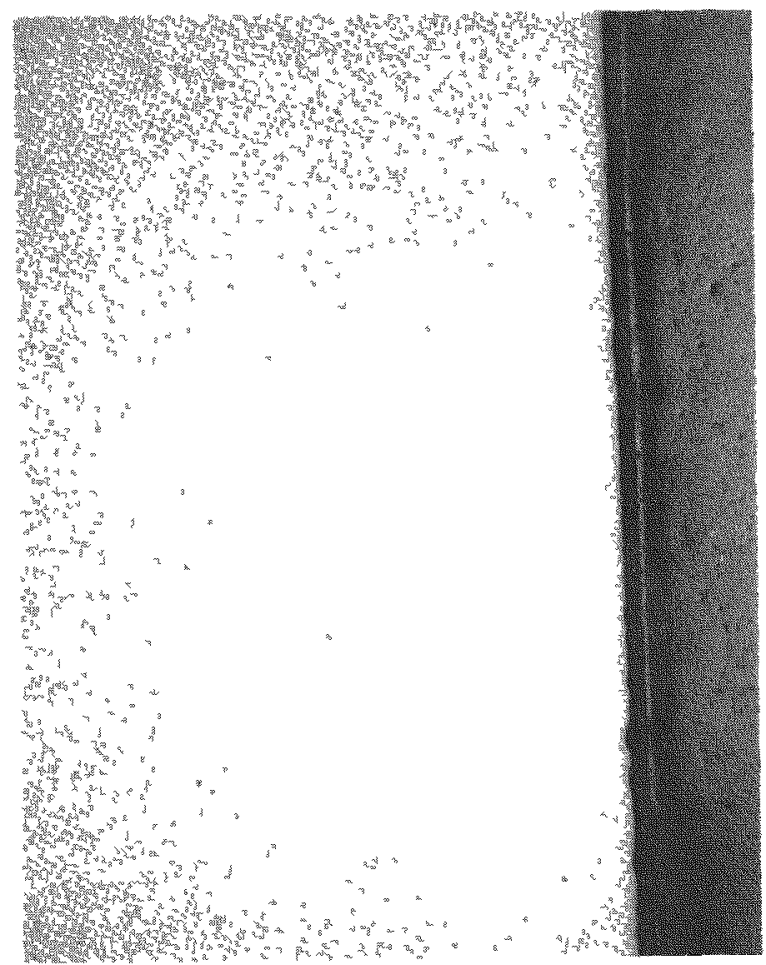

\section{TUNGSTEN}

Figure 4-41 100\% $\operatorname{Tm}_{2} \mathrm{O}_{3}$, Pressed at $4.5 \mathrm{tsi}$, Sintered at $1750^{\circ} \mathrm{C}, 4$ Hours Vacuum, Aged 500 Hours, $1600^{\circ} \mathrm{C}(70 \mathrm{X})$. 


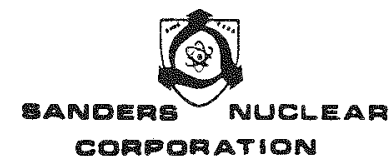

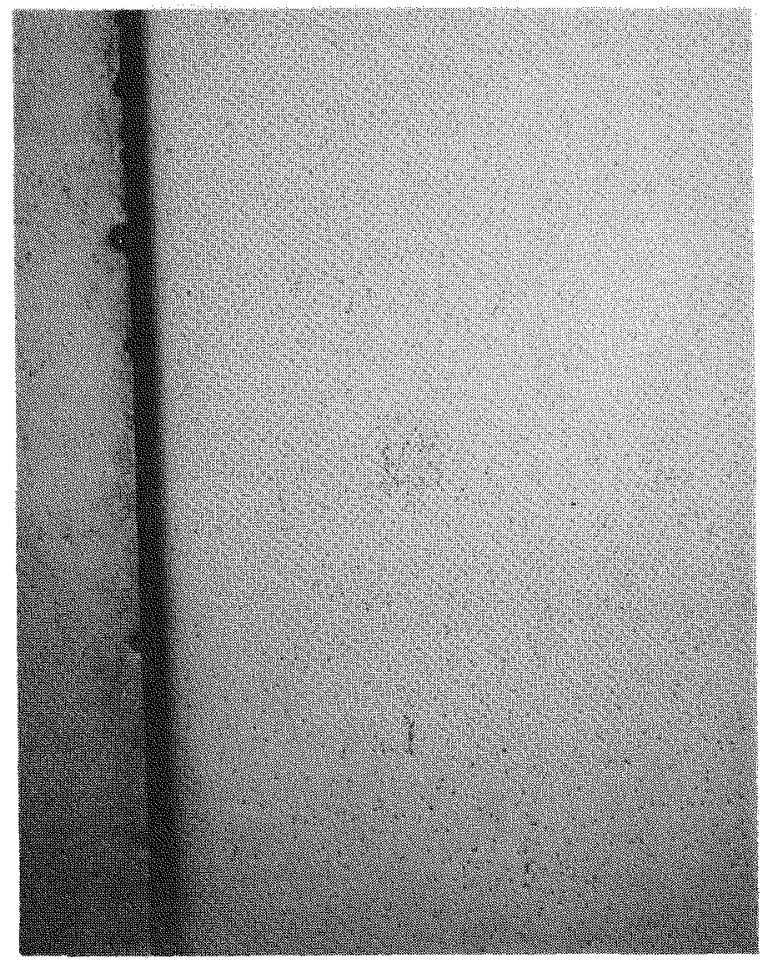

A. T-111

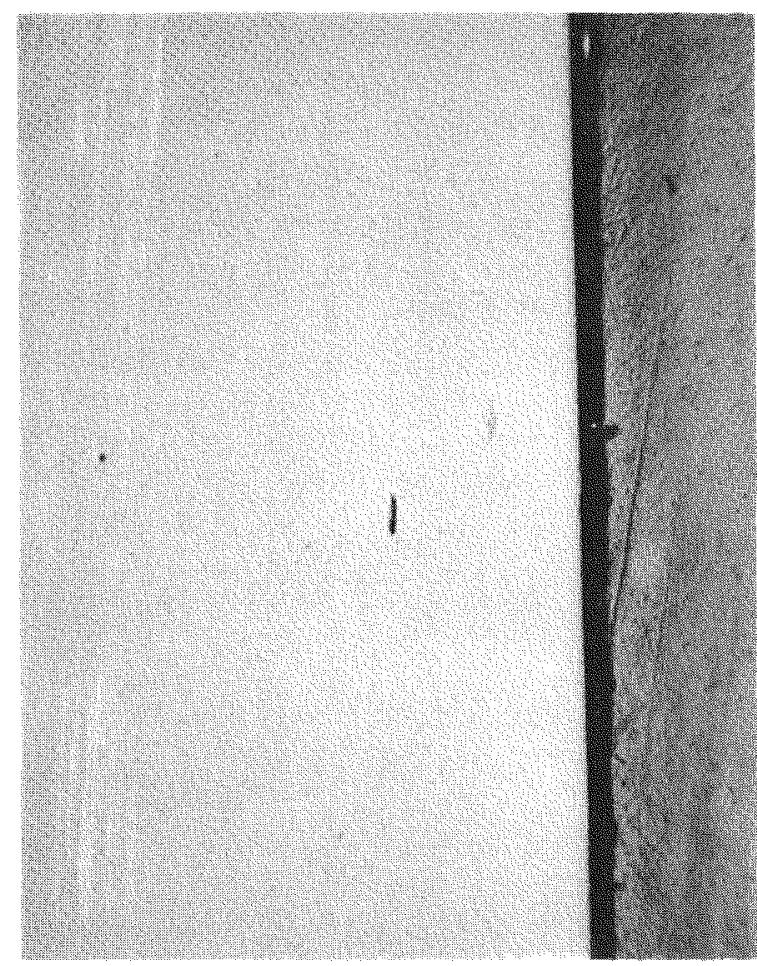

B. $T Z M$

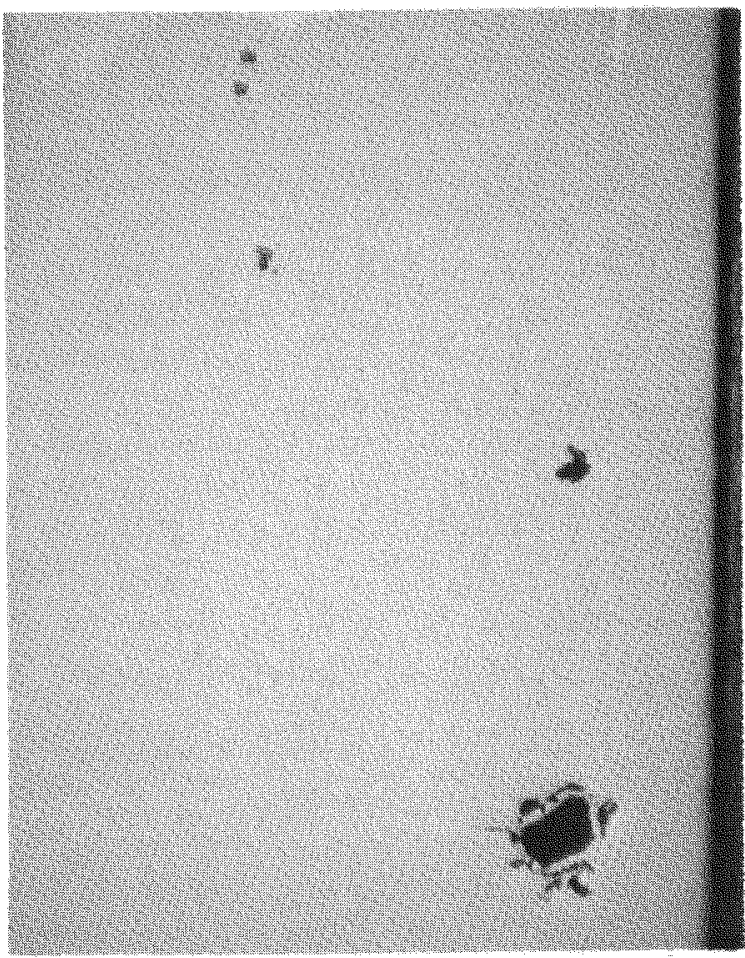

C. TUNGSTEN

Figure 4-42 100\% $\mathrm{Tm}_{2} \mathrm{O}_{3}$, Pressed at 29 tsi, Sintered $1750^{\circ} \mathrm{C}, 8$ Hours Vacuum, Aged 500 Hours, $1600^{\circ} \mathrm{C}(70 \mathrm{X})$. 


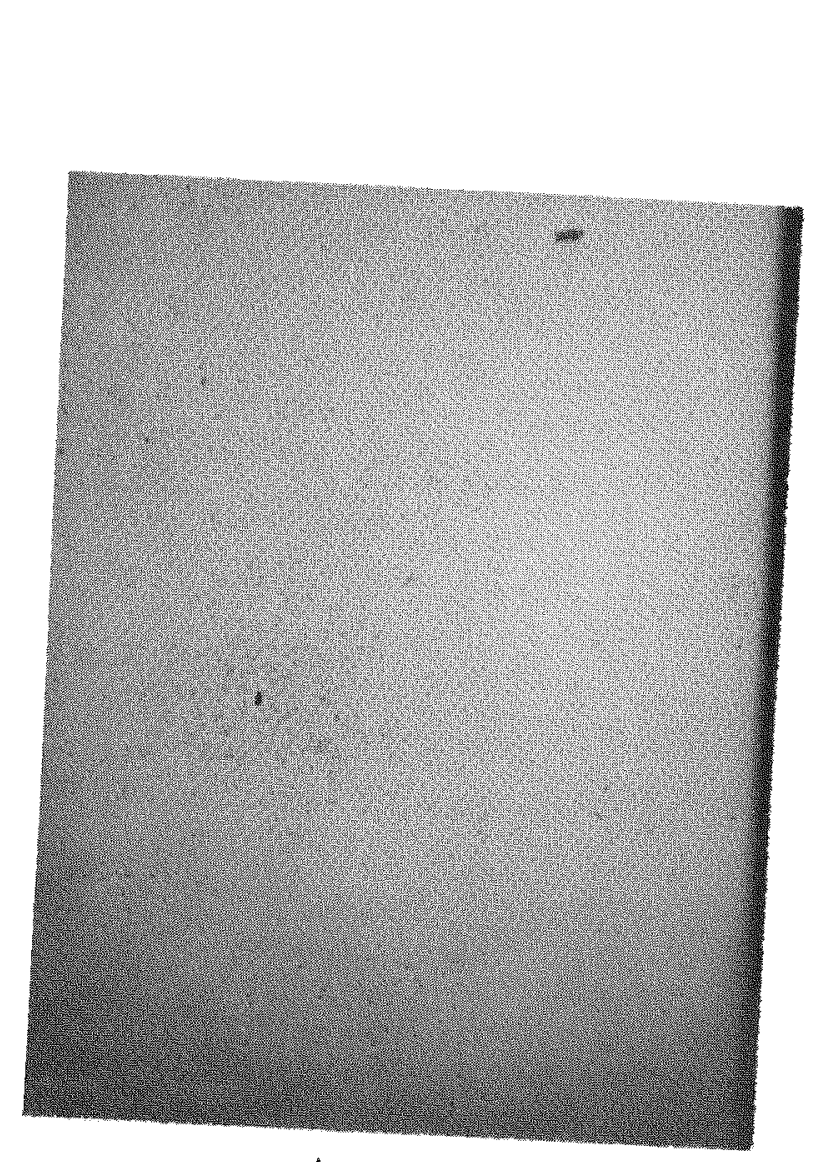

A. $T-111$
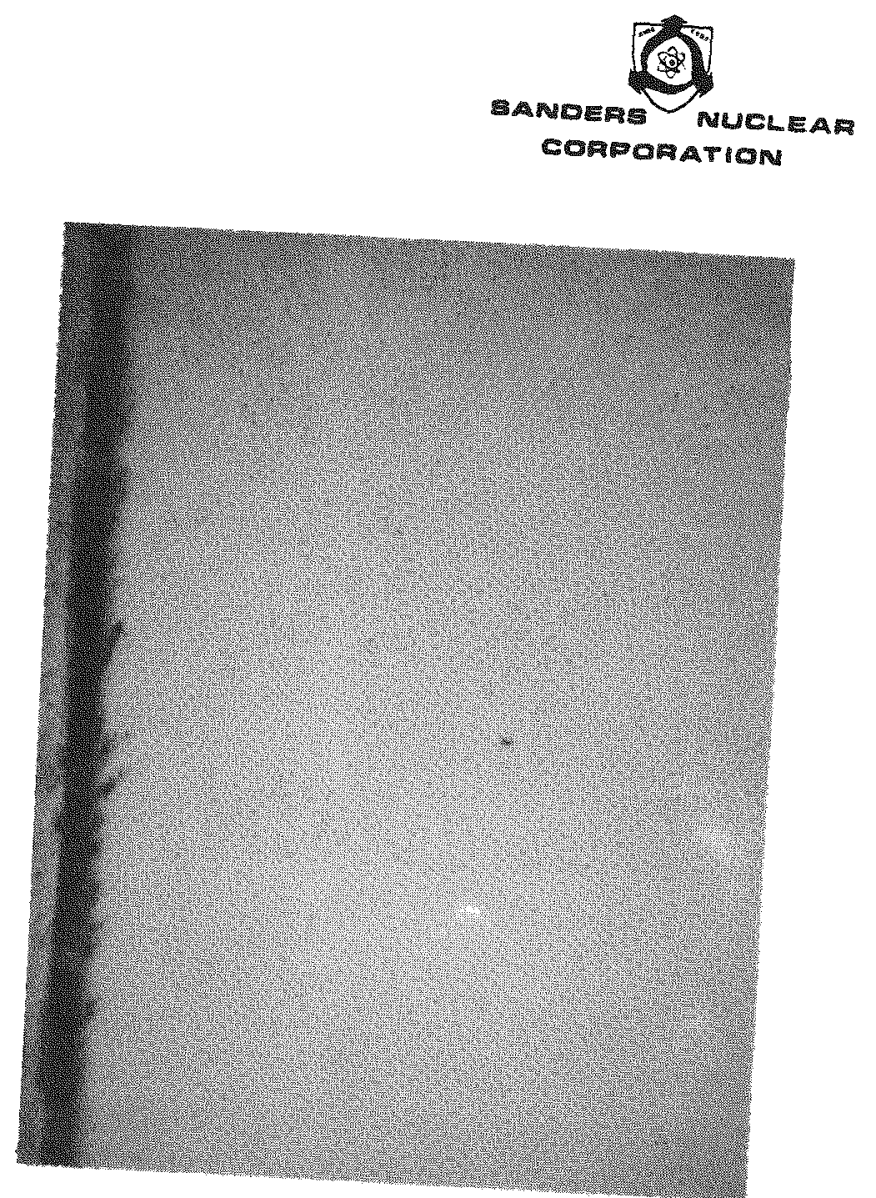

B. TZM

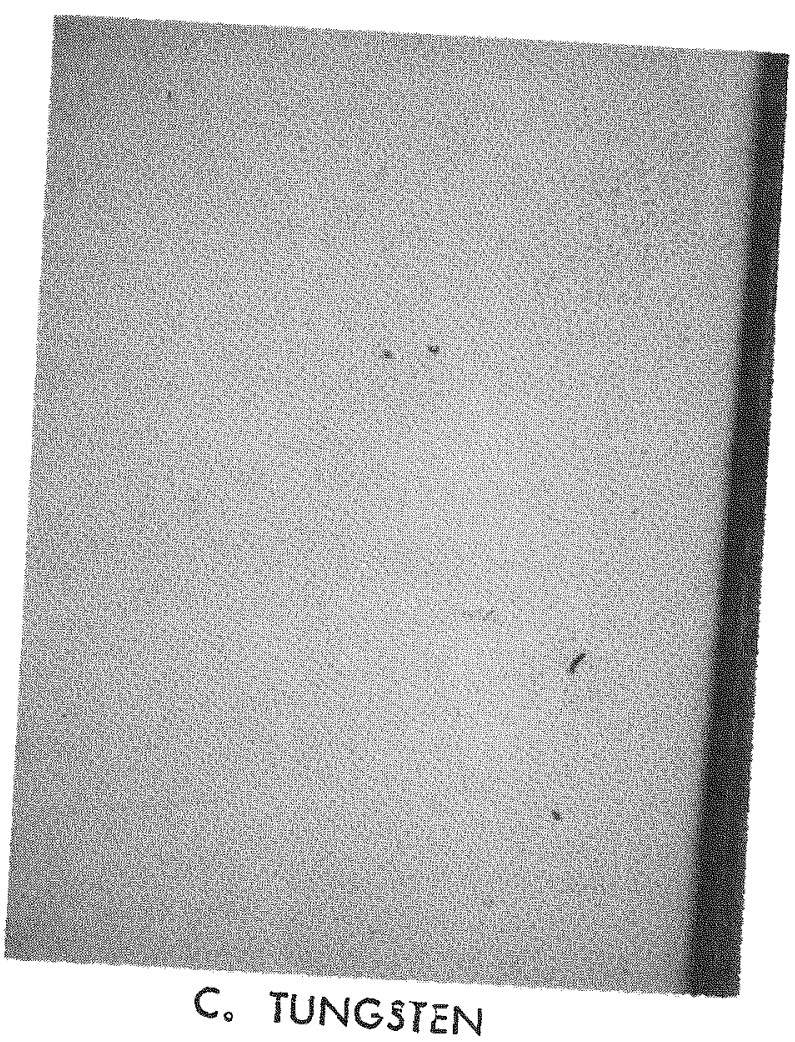

Figure $4-43 \quad 100 \% \operatorname{Tm}_{2} \mathrm{O}_{3}$, Co TUNGSTEN

Hydrogen, Aged $500^{2}$ Hours, $1600^{\circ} \mathrm{C} 15 \mathrm{tsi}$. Sintered at $1750^{\circ} \mathrm{C}, 6$ Hours (20 Min) Rise to $2000^{\circ} \mathrm{C}(70 \mathrm{X})$. 

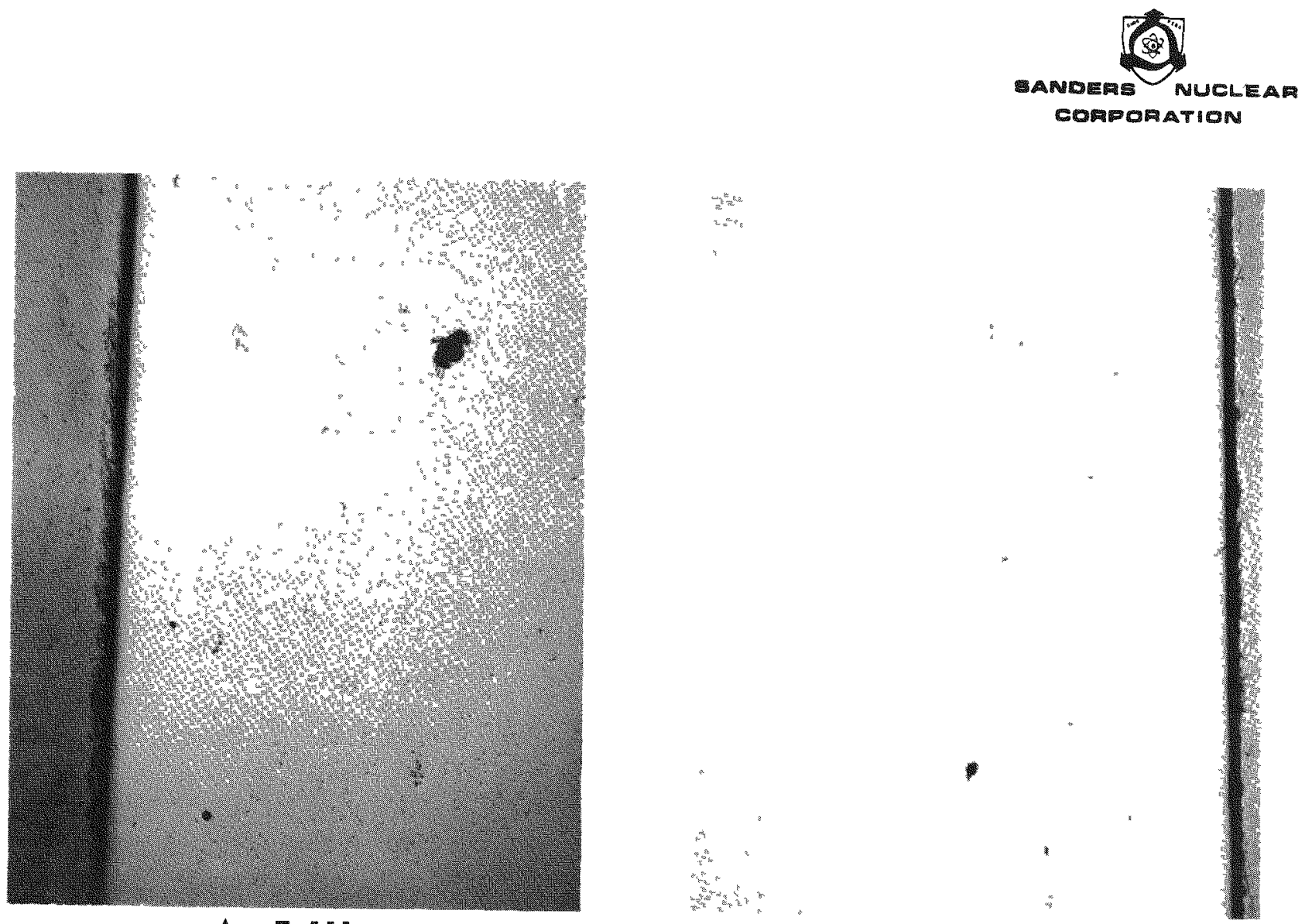

A. $T-111$

B. $T Z M$

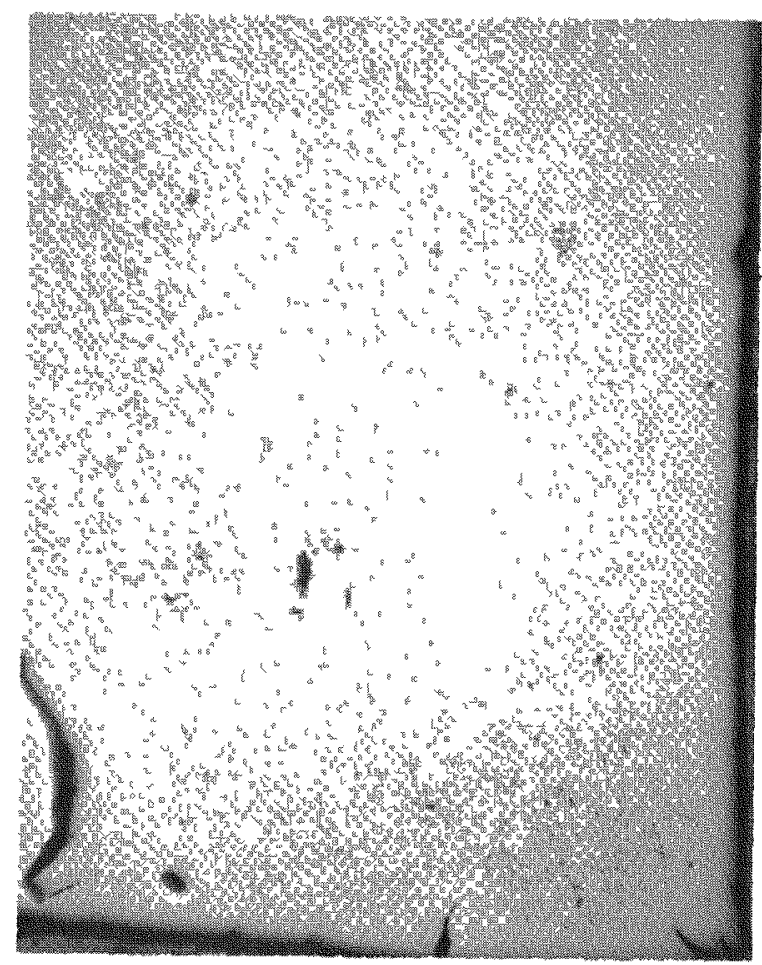

C. TUNGSTEN

Figure 4-44 100\% $\mathrm{Tm}_{2} \mathrm{O}_{3}$, Pressed at 29 tsi, Sintered $1750^{\circ} \mathrm{C}, 6$ Hours Hydrogen, Aged 500 Hours, $1600^{\circ} \mathrm{C}(70 \mathrm{X})$. 


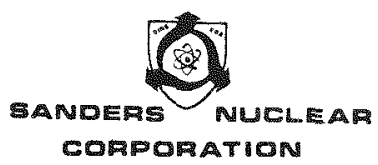

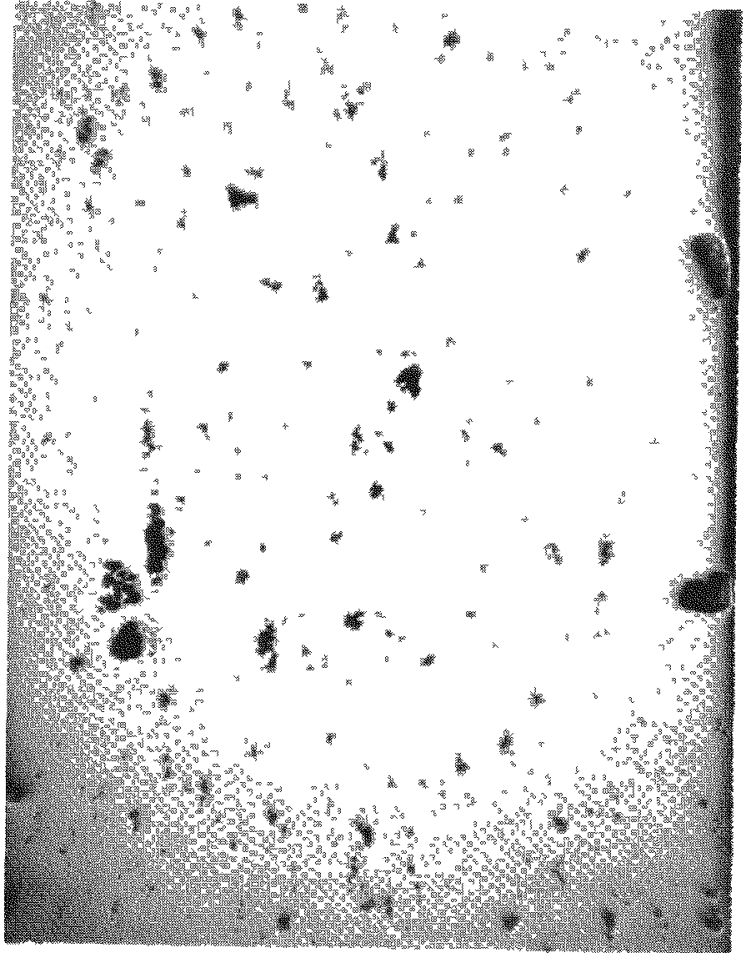

A. CONTROL

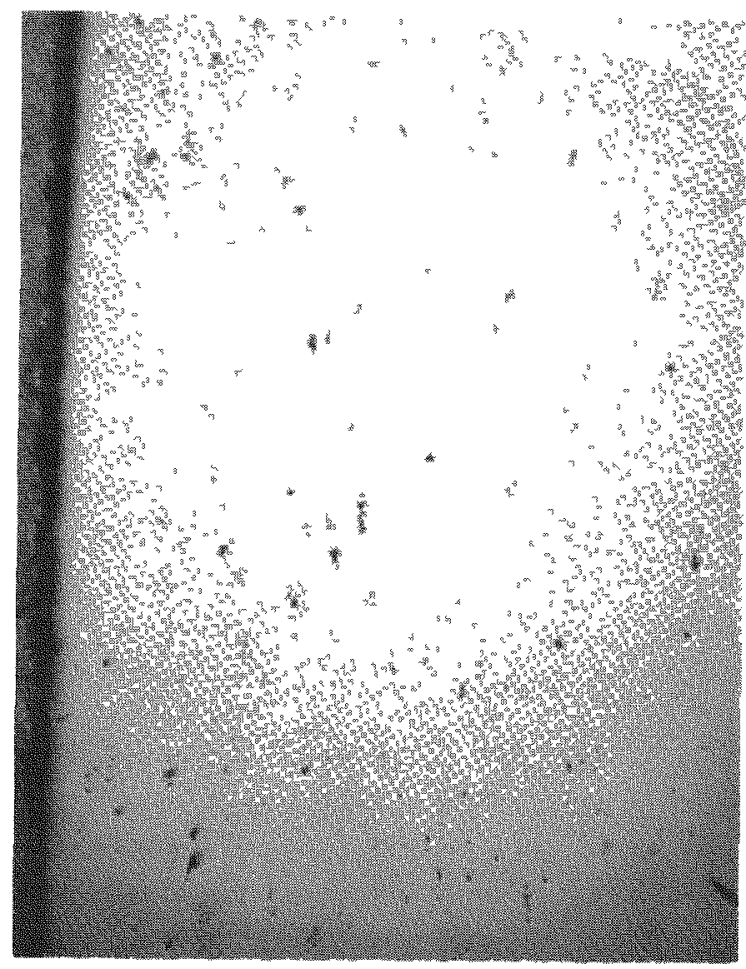

C. TZM

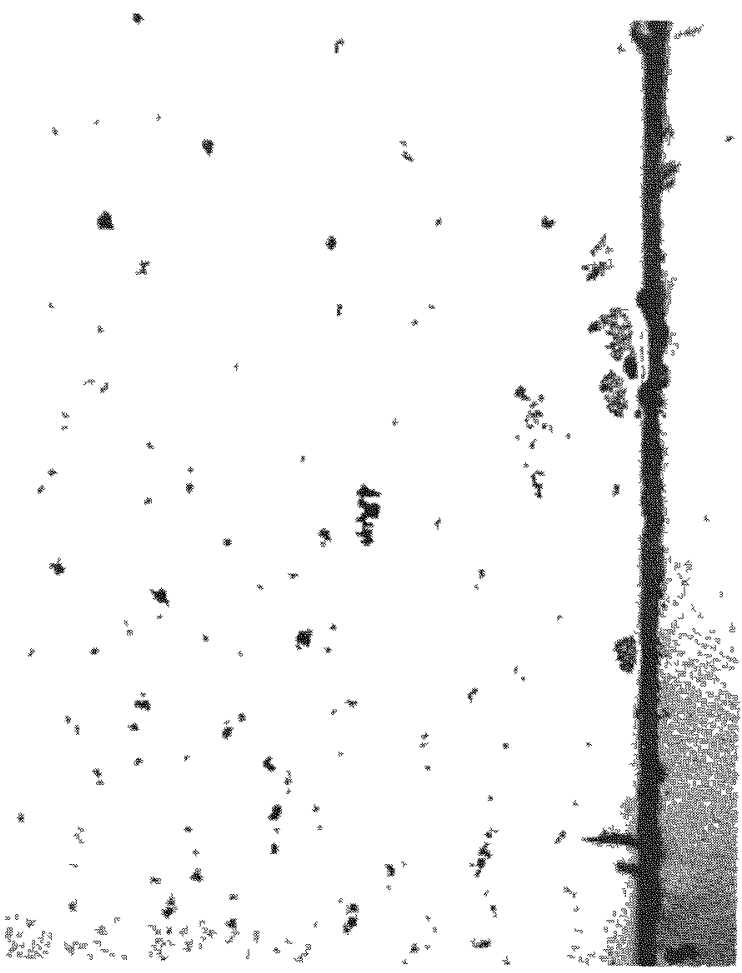

B. $T-111$

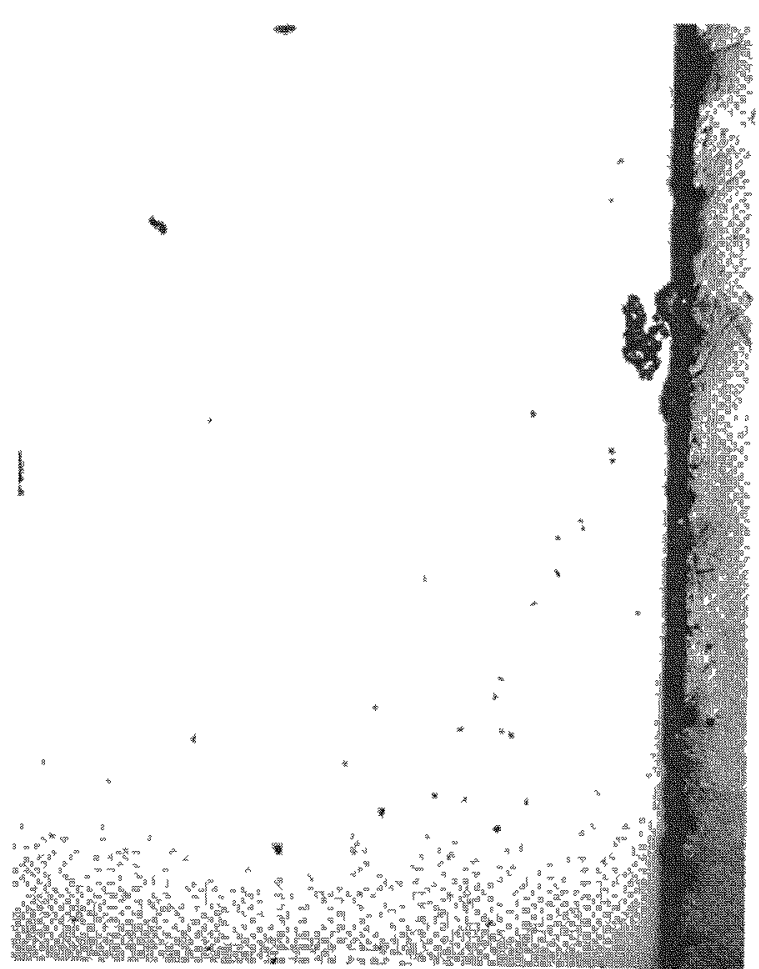

D。 TUNGSTEN

Figure 4-45 $80 \% \mathrm{Tm}_{2} \mathrm{O}_{3} / 20 \% \mathrm{Yb}_{2} \mathrm{O}_{3}$ Wafers, Pressed at $29 \mathrm{tsi}$, Sintered $1750^{\circ} \mathrm{C}$, 6 Hours Hydrogen, Aged 500 Hours, $1600^{\circ} \mathrm{C}(70 \mathrm{X})$. 
free under electron microprobe, these areas were free of structure. In the mixed oxide samples, microprobe showed considerable structure not only in the elliptical areas but throughout the wafers (Figure 4-46). Microprobe analyses for elements related to the metal matrix proved the wafers to be free of any of these elements. However, evidence of ytterbium segregation in the eliiptical areas was found. Figure 4-46b was a sweep scan for ytterbium and clearly showed the segregation pattern. This pattern was typical of that found in all wafers and therefore, seemed to be insensitive to the encapsulant materials. The long axis of the elliptical areas was generally perpendicular to the pressing direction. This pattern suggested the source of this phenomena to lie with the calcined powder and may be due to agglomerates or groups of agglomerates that formed during calcining and when cold pressed assumed these shapes.

The major data points in determining stability enhancement in this task were the fines generated from impacting wafers. Although the calculated final velocity at impact was only $10 \mathrm{ft} / \mathrm{sec}$, far lower than the operational $325 \mathrm{ft} / \mathrm{sec}$, the test did serve to distinguish among process conditions. Of particular interest was the fraction of particles in the sub 10 micron range as these particles may become airborne on impact and present a potential source of radiological contamination. Fines (10 micron particles) ranges from $0.04 \%$ to $0.38 \%$ of total mass for the products analyzed. Fines data were random with respect to all process and/or aging parameters except for pressing pressure. Figure 4-47 depicts the relationship between particles of less than 10 microns and pressing pressure for all conditions. Bulk sintered density was also included for reference. The data showed that increasing pressing pressure proportionally produced fewer fines. A preview of this behavior would have been expected from preaged wafers, however, as shown in the graph, fines generated from these wafers were essentially constant for all pressing pressures. How aging developed this relationship was unknown but the potential of predicting and possible influencing \% fines generated on impact 


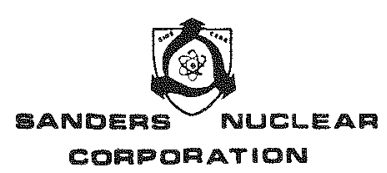

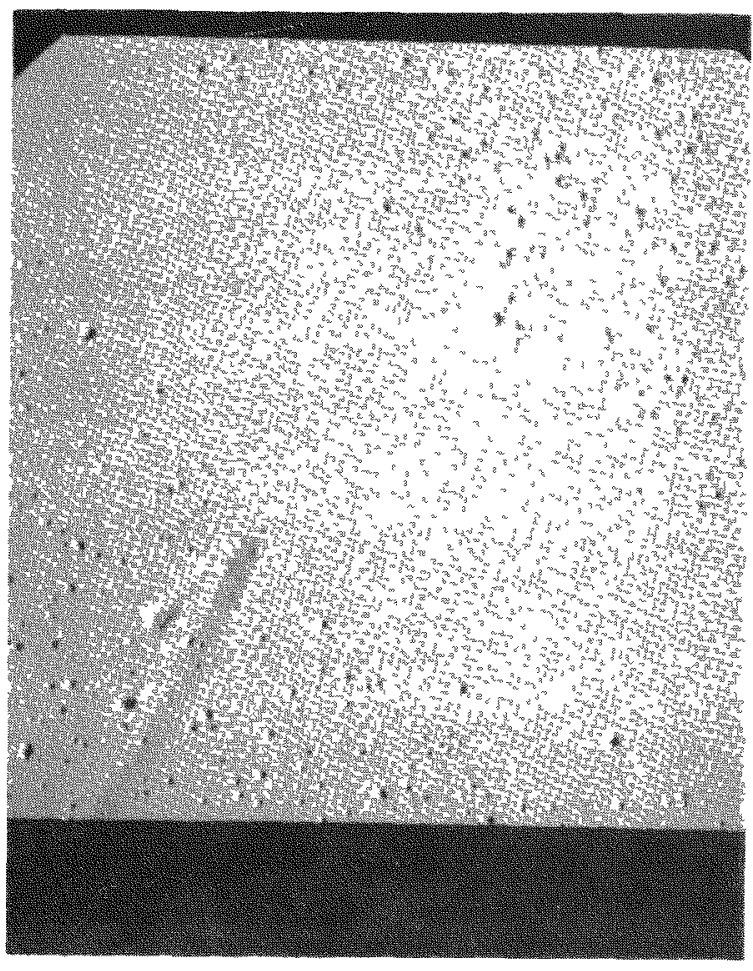

A. TOPOGRAPHICAL REPRESENTATION

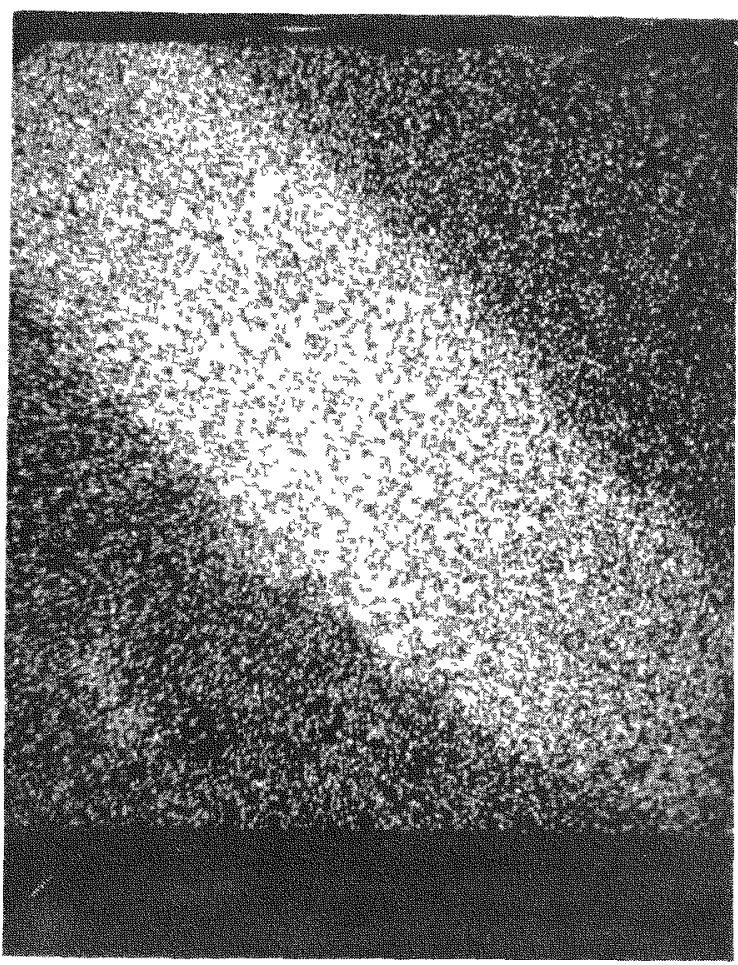

B. YTTERBIUM X-RAY SWEEP

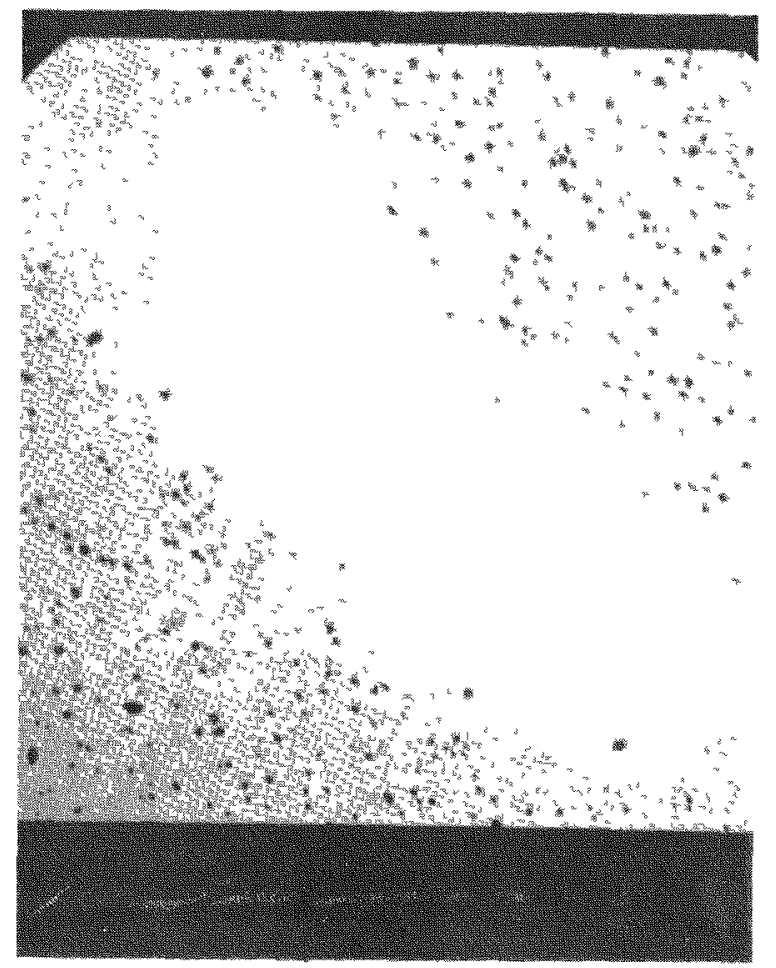

C. COMPOSITION IMAGE

Figure 4-46 80\% $\operatorname{Tm}_{2} \mathrm{O}_{3} / 20 \% \quad \mathrm{Xb}_{2} \mathrm{O}_{3}$ Wafers Aged for 500 Hours at $1600^{\circ} \mathrm{C}$ Followed by 20 Minute Rise to $2000^{\circ} \mathrm{C}$. 


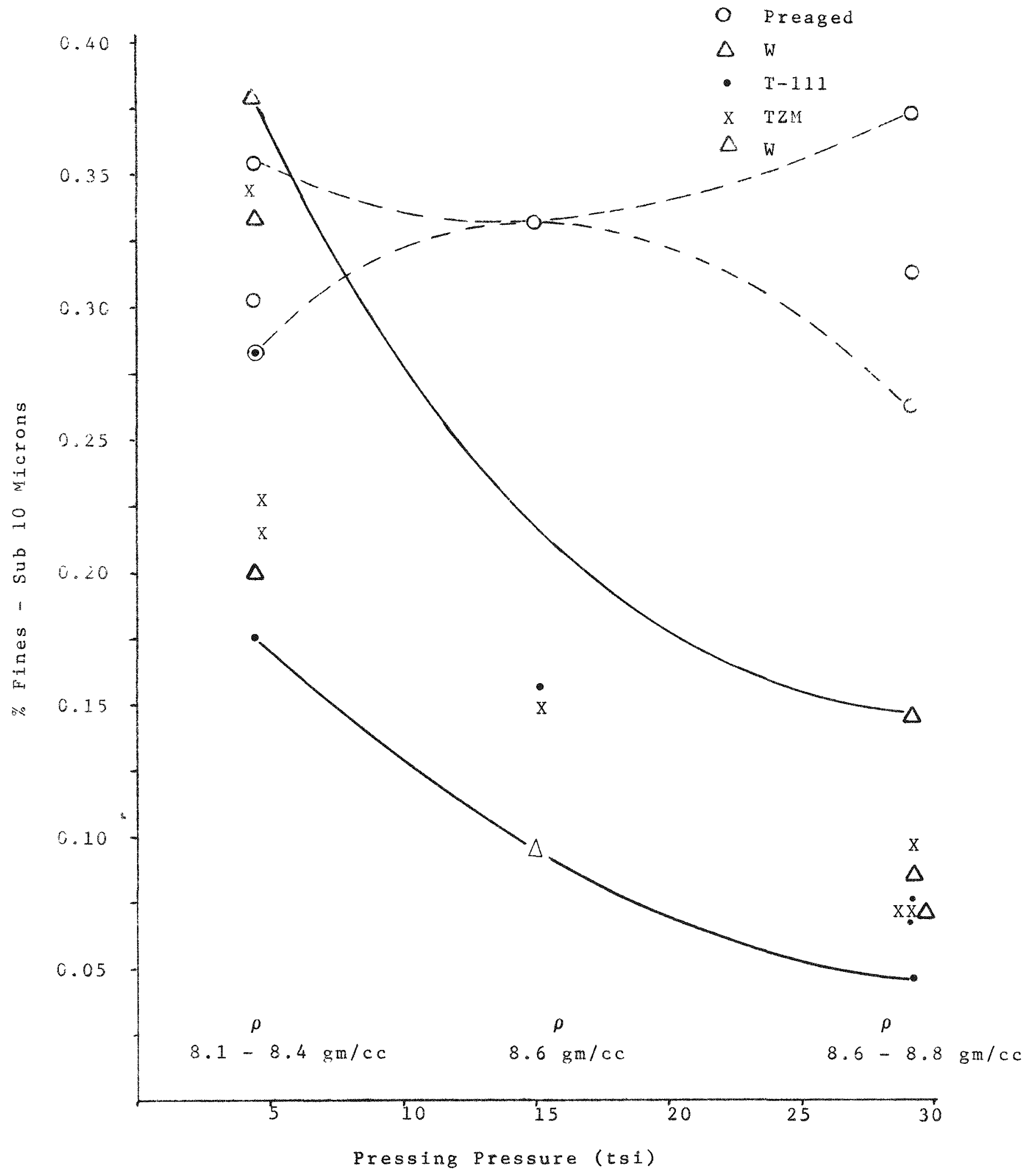

Figure 4-47 Pressing Pressure vs \% Fines-sub 10 Micon. Wafers Aged in T-111, TZM and Tungsten for 500 hrs at $1600^{\circ} \mathrm{C}$ 
with initial pressing pressure was considered tantalizing. COMPARISON OF WAIERS PROPERTIES - BENCH MARKS VS. PROCESS VARIABLE OPTIMIZATION WAFERS

Comparsion of properties of wafers produced from the process variable optimization study with bench marks showed the bulk sintered densities of bench marks to be the same as bulk sintered densities of wafers representative of several sets of processing concicions. Fines generation data of bench mark wafers aged for 500 hours at $1600^{\circ} \mathrm{C}$ were not available because of inter wafer bonding and hence comparison with wafers representative of optimal processing conditions, was impossible. A qualified compaxison suggest that of the several optimal processes selected for study any single process was capable of producing an equally acceptable $\mathrm{Tm}_{2} \mathrm{O}_{3}$ wafer. A more refined test matrix would be required to further grade the stability enhancement of these wafers.

\section{CONCLUSIONS}

The absence in $\mathrm{Tm}_{2} \mathrm{O}_{3}$ of infused elements related to the metal matrix and of any reaction products with the encapsulant were strong evidence of the chemical inertness of $\mathrm{Tm}_{2} \mathrm{O}_{3}$. The high degree of resistance of aged $\mathrm{Tm}_{2} \mathrm{O}_{3} / \mathrm{Yb}_{2} \mathrm{O}_{3}$ to a wide range of chemical etchants further support the conclusion that $\mathrm{Tm}_{2} \mathrm{O}_{3} / \mathrm{Yb}_{2} \mathrm{O}_{3}$ produced under. a variety of process conditions and subsequently aged at $1600^{\circ} \mathrm{C}$ for 500 hours will maintain a high degree of chemical stability.

Mechanical stability enhancement, as defined previously, was observed as a result of aging in the reduction of post impact fines (particles < 10 microns in diameter) particularly in those wafers pressed initially at pressures of 29 tsi. The relationship of fines and pressing pressure observed in aged samples suggests that further stability enhancement can be achieved once an understanding of this relationship is developed.

Excellent thermal stability of $\mathrm{Tm}_{2} \mathrm{O}_{3} / \mathrm{Yb}_{2} \mathrm{O}_{3}$ was maintained throughout the aging period. It was concluded that $\mathrm{Tm}_{2} \mathrm{O}_{3}$ was 
insensitive to thermal effects except for the possible interrelationship of temperatures with the fines generation pattern previously described. 


\subsection{METAL OXIDE ADDITIVES - A MEANS TO PRODUCT STABILITY ENHANCEMENT}

The introduction described the object of this task and the rationale for investigation. Criteria for selection were based on material roperties most likely to influence solubility.

Atomic size and valence state of the cation were prime factors, however, melting point, subsequent thermal neutron activation and its resultant radiation contribution (if cold encapsulated) and additive concentration were considered.

In general, a limited solubility would result if the atomic radius of the additive cation is $\pm 8 \%$ relative to thulium and very limited solubility (usually less than $1 \%$ ) if greater than $\pm 15 \%$. Limited solubility was also indicated if the valence state of the cation was different from that of the host cation.

Based on valence state and atomic size, aluminum oxide $\left(\mathrm{Al}_{2} \mathrm{O}_{3}\right)$, calcium oxide ( $\mathrm{CaO}$ ) and titanium dioxide (TiO ${ }_{2}$ were chosen. The melting points of these ceramics are given in Table 4-12 along with atomic size relative to thulium and valence state of the metal ion.

\section{TABLE $\quad 4-12$}

MELTING POINTS, VALENCE STATE OF CATIONS AND ATOMIC SIZE RELATIVE TO THULIUM OF 3 METAL OXIDE ADDITIVES

Oxide

$\mathrm{Al}_{2} \mathrm{O}_{3}$

$\mathrm{CaO}$

$\mathrm{TiO}_{2}$

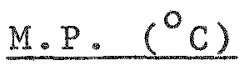

2045

2614

1838
Cation Valence

(as oxide)

$+3$

$+2$

$+4$
Atomic Size (\%)

$-18$

$+13$

$-16$

The concentration of additive to be used was $1 \%$, thus providing sufficient material for an insoluble grain boundary phase, but not sufficient to cause a significant melting point depression. Thermal neutron activation of $\mathrm{Tm}_{2} \mathrm{O}_{3}$ - additive in the severest case (production of $\mathrm{Ca}-45$ ) provides a separation of thulium 170 to impurity of $\sim 10^{5}$. Even at this level no significant 
contribution to Bremsstrahlung would result.

4.3.1 EXPERIMENTAL

Thulium oxide and ytterbium oxide $\left(\mathrm{Yb}_{2} \mathrm{O}_{3}\right)$ used in the preparation of samples was processed from "as received" $\mathrm{Tm}_{2} \mathrm{O}_{3}$ by the urea homogenous precipitation process $(4)$. Weighed quantities of $\mathrm{Tm}_{2} \mathrm{O}_{3} / \mathrm{Yb}{ }_{2} \mathrm{O}_{3}$ and reagent grade metal axide additive were allowed to mix overnight in individual containers. Appropriate amounts of material were removed for screening tests prior to addition of $4 \%$ Carbowax 4000 binder.

Melt samples were produced by placing a mixed oxide sample in a calcia stabilized zirconia crucible and thermally cycling the samples with an induction heater. An argon atmosphere prevailed throughout the controlled thermal cycing.

Wafers were pressed at 29 tsi and sintered in air at $1450^{\circ} \mathrm{C}$ for 17 hours. Impact tests and fines analyses were performed according to the methods described previously. A summary of experimental data is given in Table 4-13

\subsubsection{RESULTS AND DISCUSSION}

The melt samples were obtained as a preliminary screening test to observe the effects of additives on the stability of $\mathrm{Tm}_{2} \mathrm{O}_{3}$. Initial thermal arrests were observed to occur at points coincidental with those of pure $\mathrm{Tm}_{2} \mathrm{O}_{3}$ observed during phase diagram studies of the $\mathrm{Tm}_{2} \mathrm{O}_{3}-\mathrm{Yb}_{2} \mathrm{O}_{3}$ system. The presence of $1 \%$ of $\mathrm{Al}_{2} \mathrm{O}_{3}$, CaO or $\mathrm{TiO}_{2}$, respectively, did not depress the melting point of $\mathrm{Tm}_{2} \mathrm{O}_{3}$ or $\mathrm{Tm}_{2} \mathrm{O}_{3}$ ' $\mathrm{Yb}_{2} \mathrm{O}_{3}$ mixtures within experimental error nor was any phase change of $\mathrm{Tm}_{2} \mathrm{O}_{3}-\mathrm{Yb}_{2} \mathrm{O}_{3}$ cubic structure observed.

The melt samples were cross sectioned for evaluation. The $\mathrm{Tm}_{2} \mathrm{O}_{3}$ had wetted the $\mathrm{ZrO}_{2}$ crucible indicating melting had taken place. A grain boundary phase or phases was observed similar to that reported by Anderson in earlier work(17). These phases were lower melting than the $\mathrm{Tm}_{2} \mathrm{O}_{3} / \mathrm{Yb}_{2} \mathrm{O}_{3}$ as indicated by their shape. A scanning composition image of the cross section showed 
METAL OXIDE ADDITIVES - EXPERIMENTAL DATA

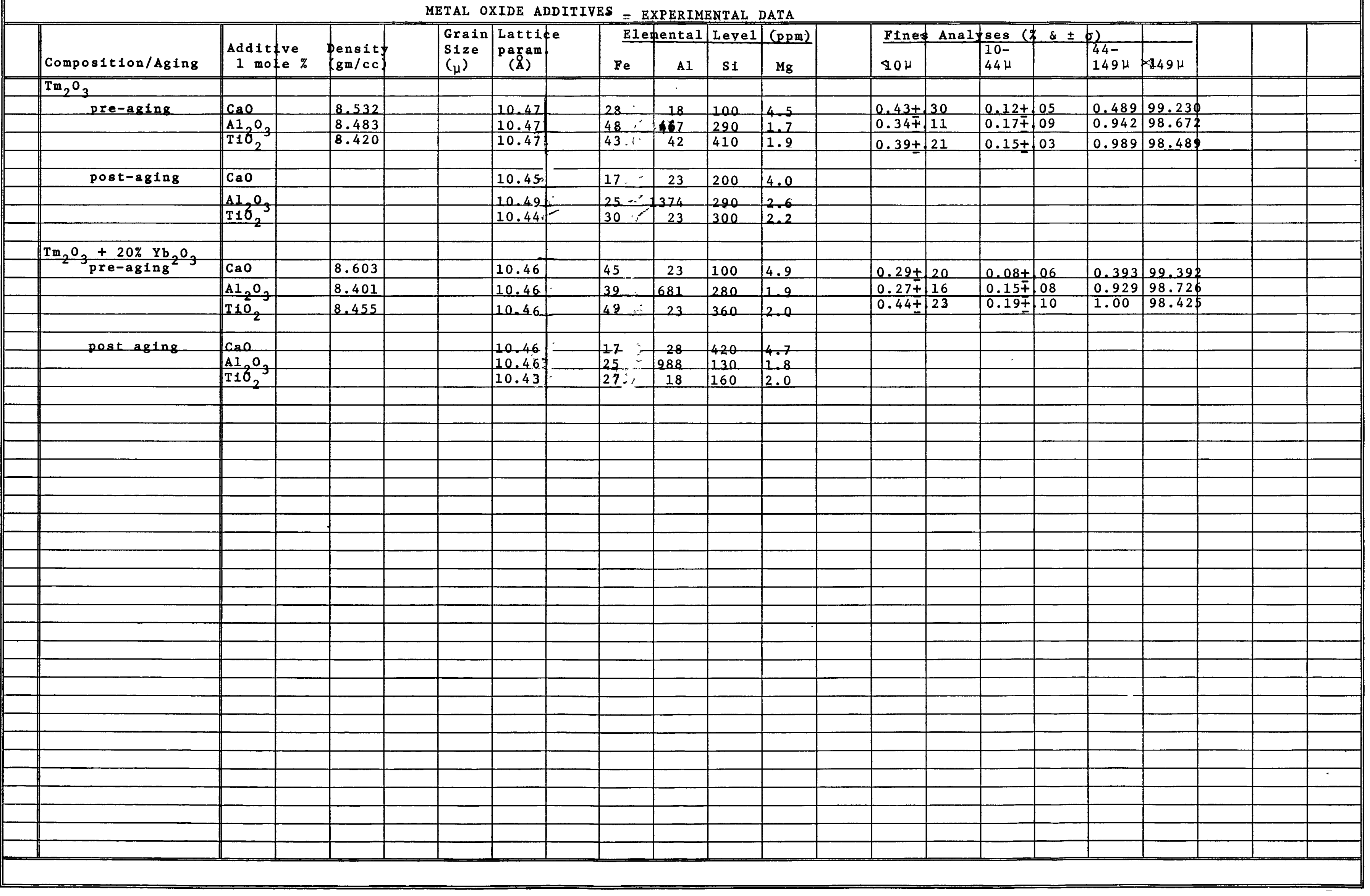



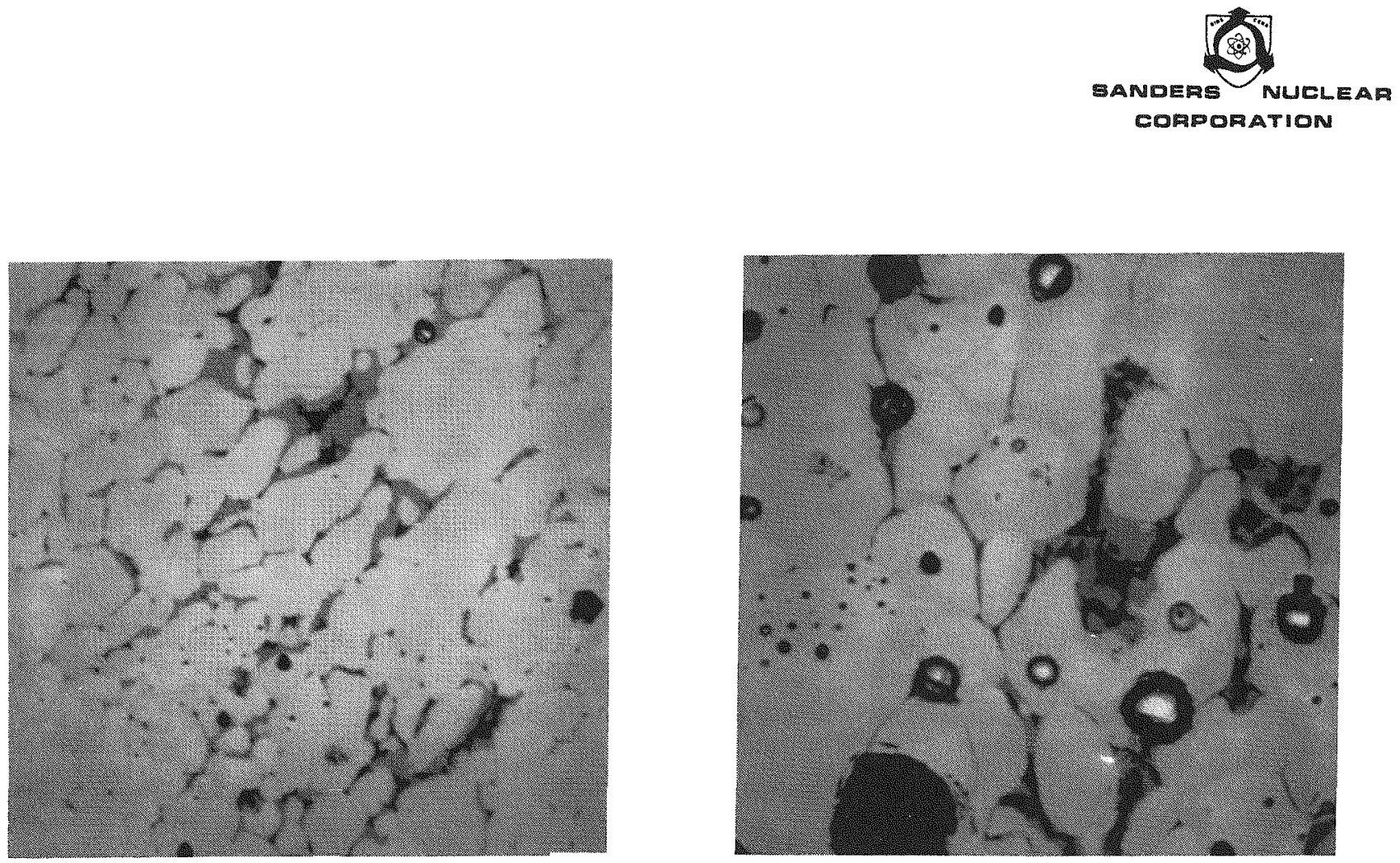
A. $\operatorname{Tm}_{2} \mathrm{O}_{3} / \mathrm{Yb}_{2} \mathrm{O}_{3}+1 \% \mathrm{TiO}_{2}$
B. $\operatorname{Tm}_{2} \mathrm{O}_{3} / \mathrm{Yb}_{2} \mathrm{O}_{3}+1 \% \mathrm{Al}_{2} \mathrm{O}_{3}$

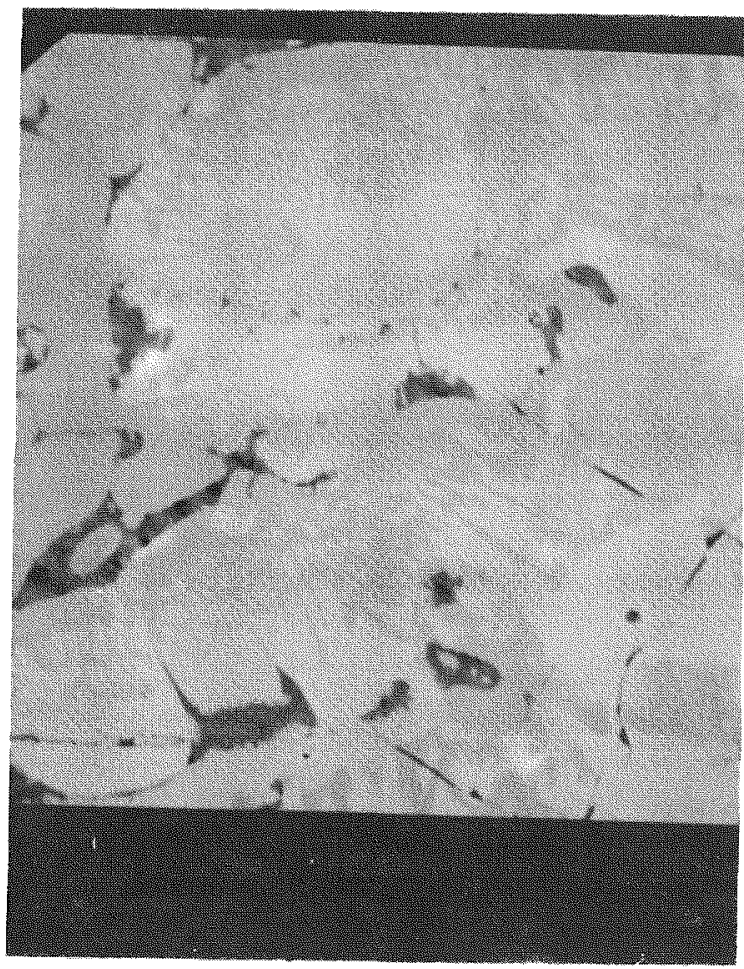

$$
\text { C. } \operatorname{Tm}_{2} \mathrm{O}_{3} / \mathrm{Yb}_{2} \mathrm{O}_{3}+1 \% \mathrm{CaO}_{2}
$$

Figure 4-48 $\mathrm{Tm}_{2} \mathrm{O}_{3} / \mathrm{Yb}_{2} \mathrm{O}_{3}+1 \%$ Additive, Melt Samples (300X). 

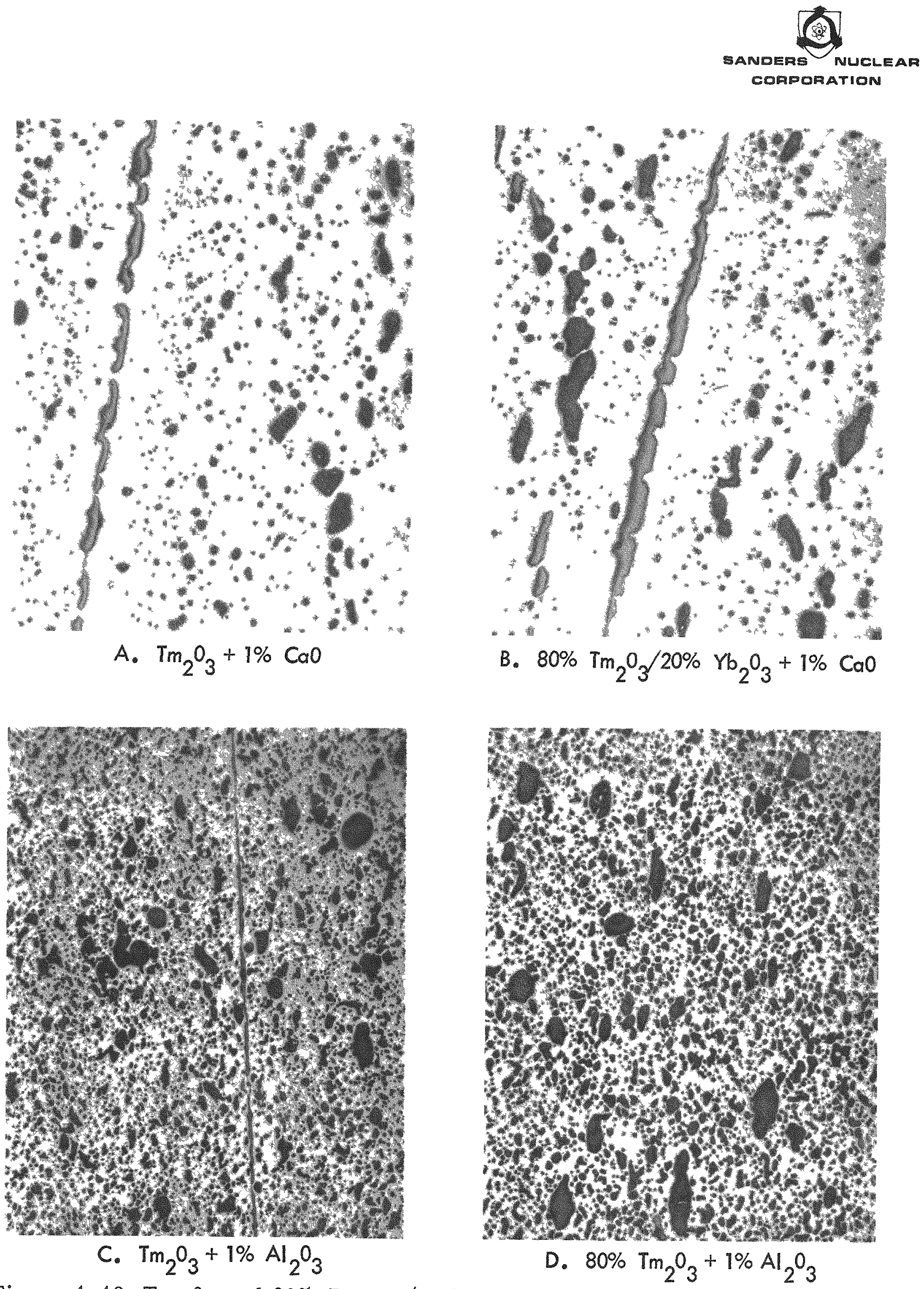

Figure 4-49 $\mathrm{Tm}_{2} \mathrm{O}_{3}$ and $80 \% \mathrm{Tm}_{2} \mathrm{O}_{3} / 20 \% \mathrm{Yb}_{2} \mathrm{O}_{3}+1 \%$ Additive. Wafers Aged 500 Hours in Tungsten Capsules at $1600^{\circ} \mathrm{C}$. 


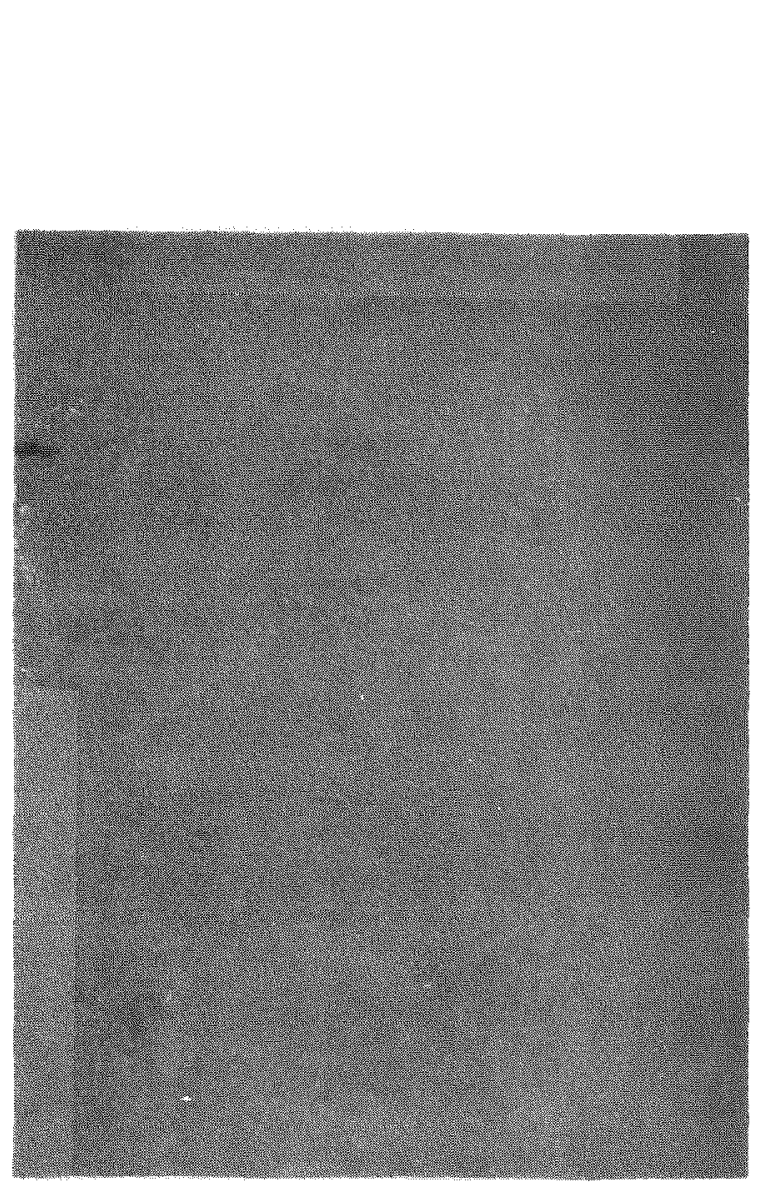

A. $100 \% \operatorname{Tm}_{2} \mathrm{O}_{3}+1 \% \mathrm{Al}_{2} \mathrm{O}_{3}$

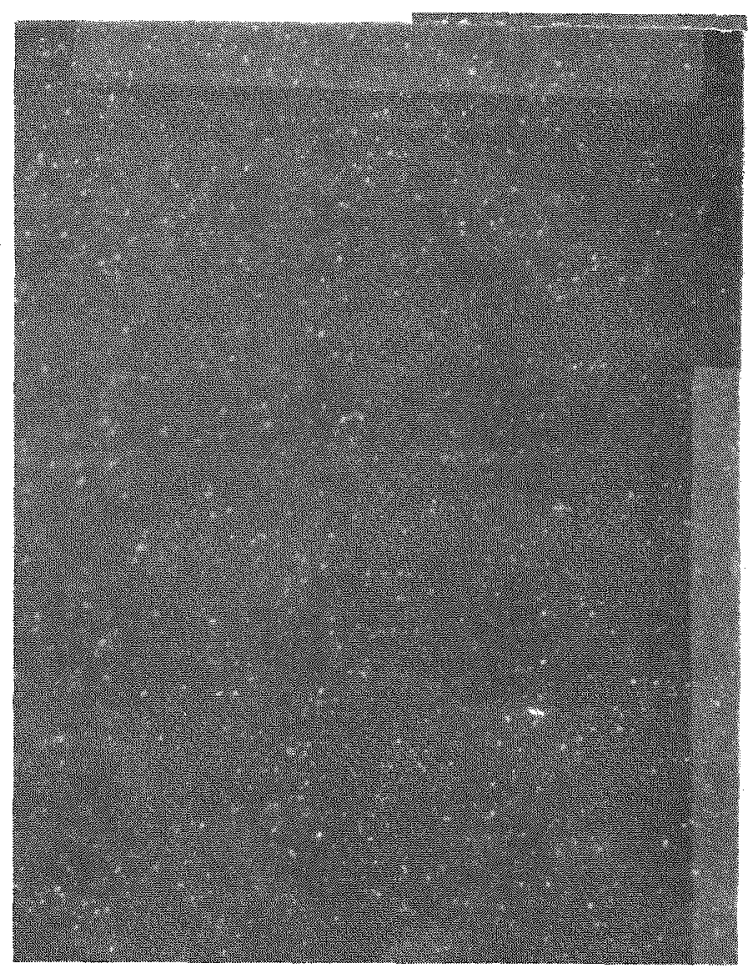

B. $100 \% \operatorname{Tm}_{2} \mathrm{O}_{3}+1 \% \mathrm{CaO}$

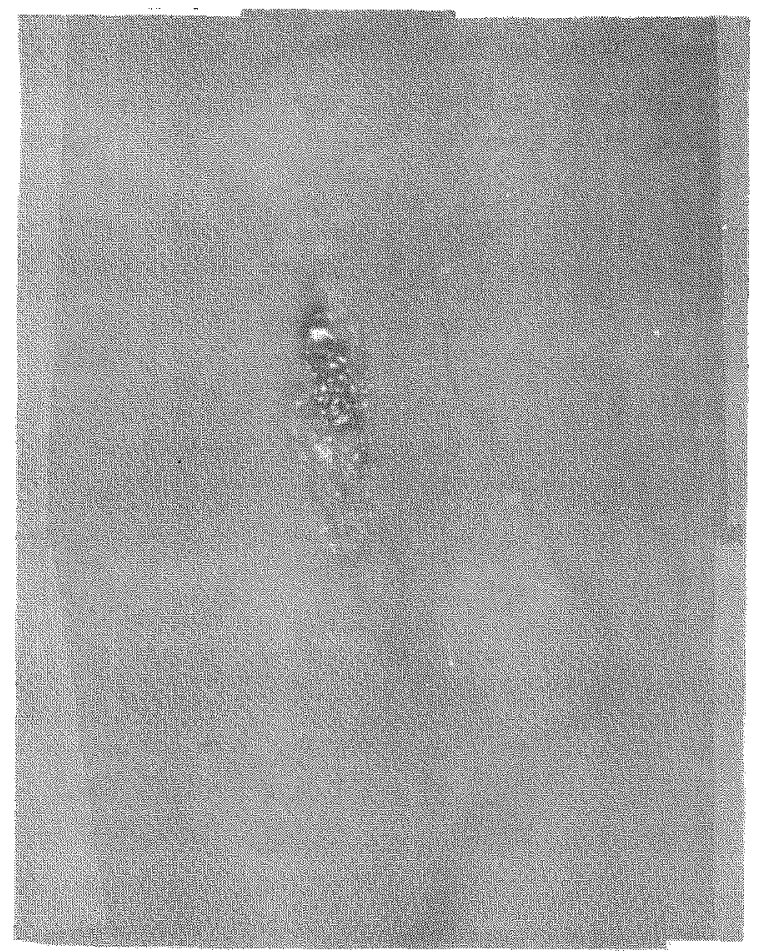

C. $100 \% \mathrm{Tm}_{2} \mathrm{O}_{3}+1 \% \mathrm{TiO}_{2}$

Figure 4-50 100\% $\operatorname{Tm}_{2} \mathrm{O}_{3}+1 \%$ Additive Sintered at $1450^{\circ} \mathrm{C}$ in Air for 17 Hours (100X). 
the segregate phases (Figure 4-48). A sufficient difference in atomic number existed between the matrix and the boundary phases to clearly depict the composition difference. In addition to thulium, each phase contained silicon, calcium and trace zirconium. The darker areas contained 15 - 20 times the levels of calcium found in the lighter areas. In those samples containing alumina and titania, the aluminum and titanium also appeared in the segregate phases. Microprobe evaluation of a pure $\mathrm{Tm}_{2} \mathrm{O}_{3}$ sample showed the same pattern found with the samples containing additives. An electron microprobe sweep showed the distribution of silicon and calcium throughout the sample (Figure 4-51). Trace amounts of $\mathrm{Ca}, \mathrm{Si}$, and $\mathrm{Zr}$ were detected in the thulium matrix in all melt samples. Aluminum and titanium were also detectable in trace amounts in the matrix of their respective melts. From these observations, it was concluded that the presence of $1 \%$ of $\mathrm{CaO}, \mathrm{Al}_{2} \mathrm{O}_{3}$ and $\mathrm{TiO}_{2}$ had no significant effect on the behavior of $\mathrm{Tm}_{2} \mathrm{O}_{3} / \mathrm{Yb}_{2} \mathrm{O}_{3}$ in a dynamic thermal system. However, the presence of calcium in a grain boundary phase gave speculation as to how it might behave in a sintered wafer.

Wafers representative of each of the additives were cross sectioned following sintering in air at $1450^{\circ} \mathrm{C}$ for 17 hours. Microprobe analysis showed each of the respective metal ions to be dispersed within the wafers, however, the dispersion patterns were different. The aluminum containing areas (grey) were dispersed through the wafer as shown in Figure 4-52. Calcium was wel1 dispersed in very small areas throughout the sample whereas titanium was found localized in only a few areas (Figures 4-52 f, i). X-ray diffraction patterns obtained from each representative wafer were characteristic of crystalline $\mathrm{Tm}_{2} \mathrm{O}_{3}$ or $\mathrm{Yb}_{2} \mathrm{O}_{3}$. The lattice parameter values were in good agreement with those values calculated from the data of Bommer (5) for $100 \% \mathrm{Tm}_{2} \mathrm{O}_{3}$.

The final test performed on the preaged wafers, the impact test, indicated a particle population pattern for the $\mathrm{Al}_{2} \mathrm{O}_{3} \& \mathrm{TIO}_{2}$ additives to be about the same as that for wafers containing no 


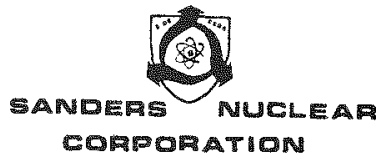

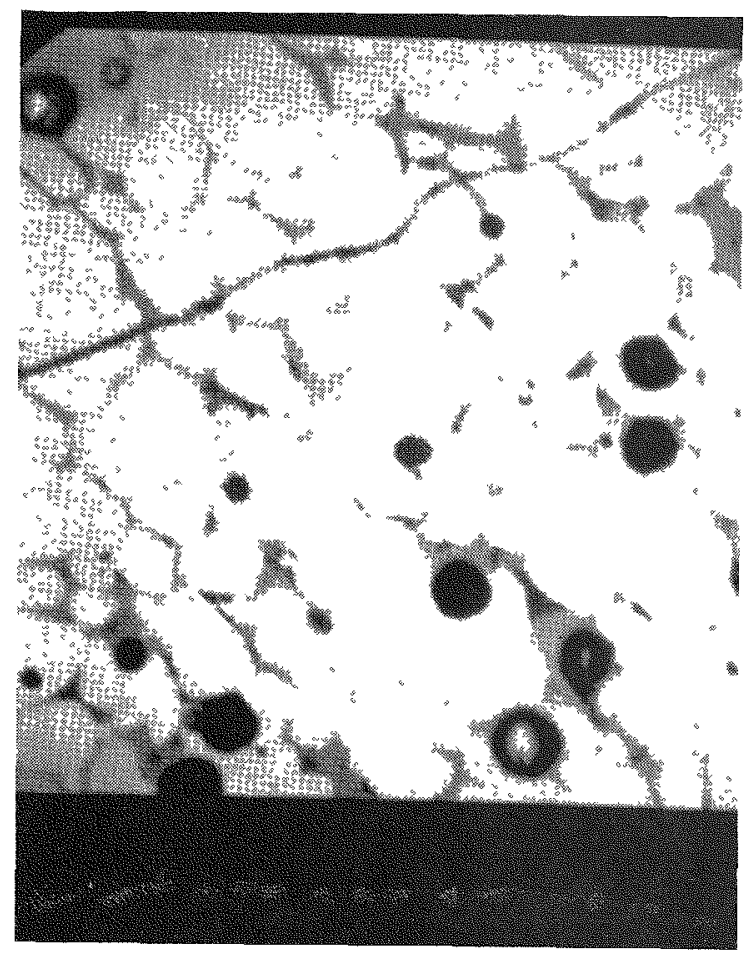

A. COMPOSITION (300X)

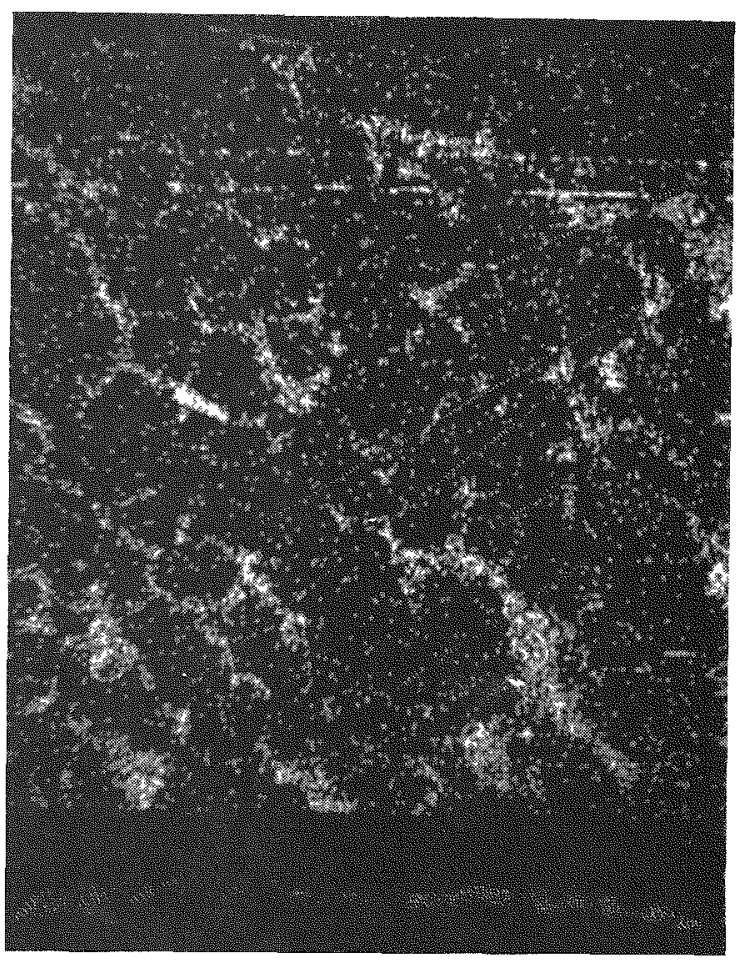

B. SILICON X-RAY (300X)

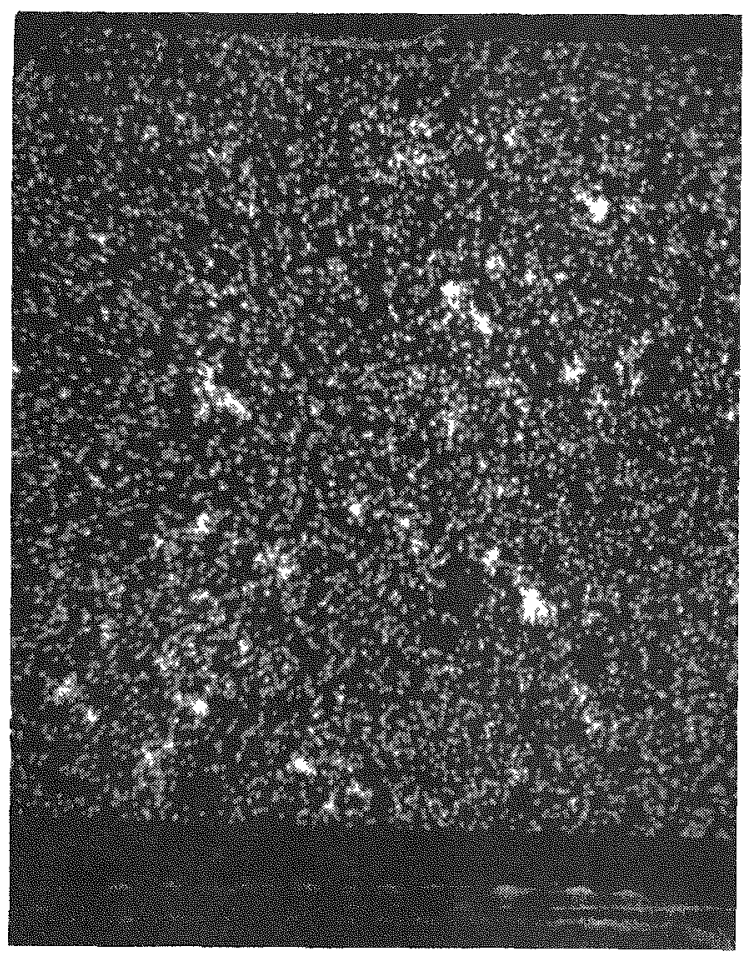

C. CALCIUM X-RAY (300X)

Figure 4-51 $\mathrm{Tm}_{2} \mathrm{O}_{3}$ Melt Sample Electron Microprobe Composition and Sweep (300X). 


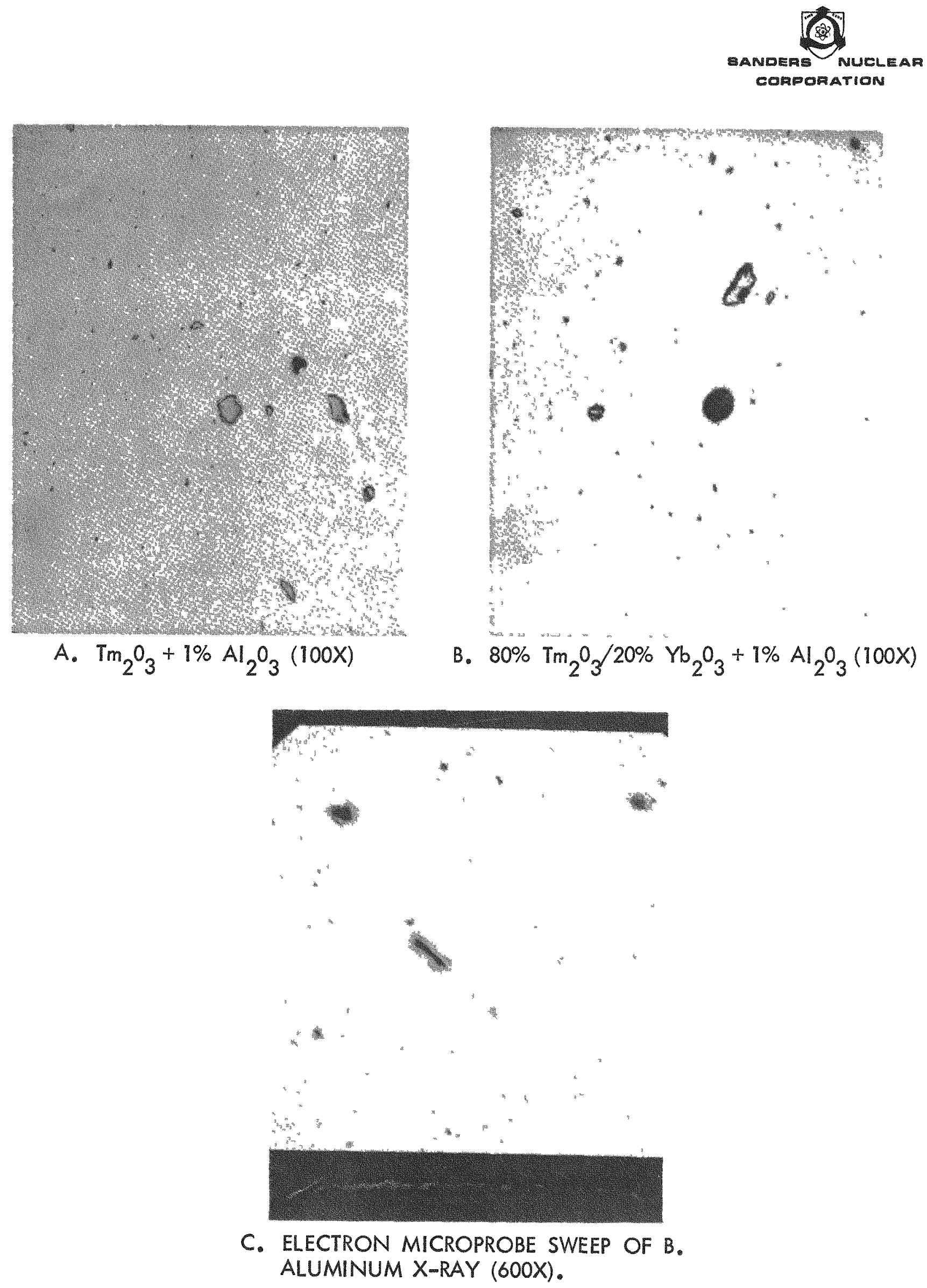

Figure 4-52 $\mathrm{Tm}_{2} \mathrm{O}_{3}$ and $80 \% \mathrm{Tm}_{2} \mathrm{O}_{3} / 20 \% \quad \mathrm{Yb}_{2} \mathrm{O}_{3}+1 \%$ Additive. Wafers Sintered in Air at $1450^{\circ} \mathrm{C}, 17$ Hours (3 of 3 Pages). 

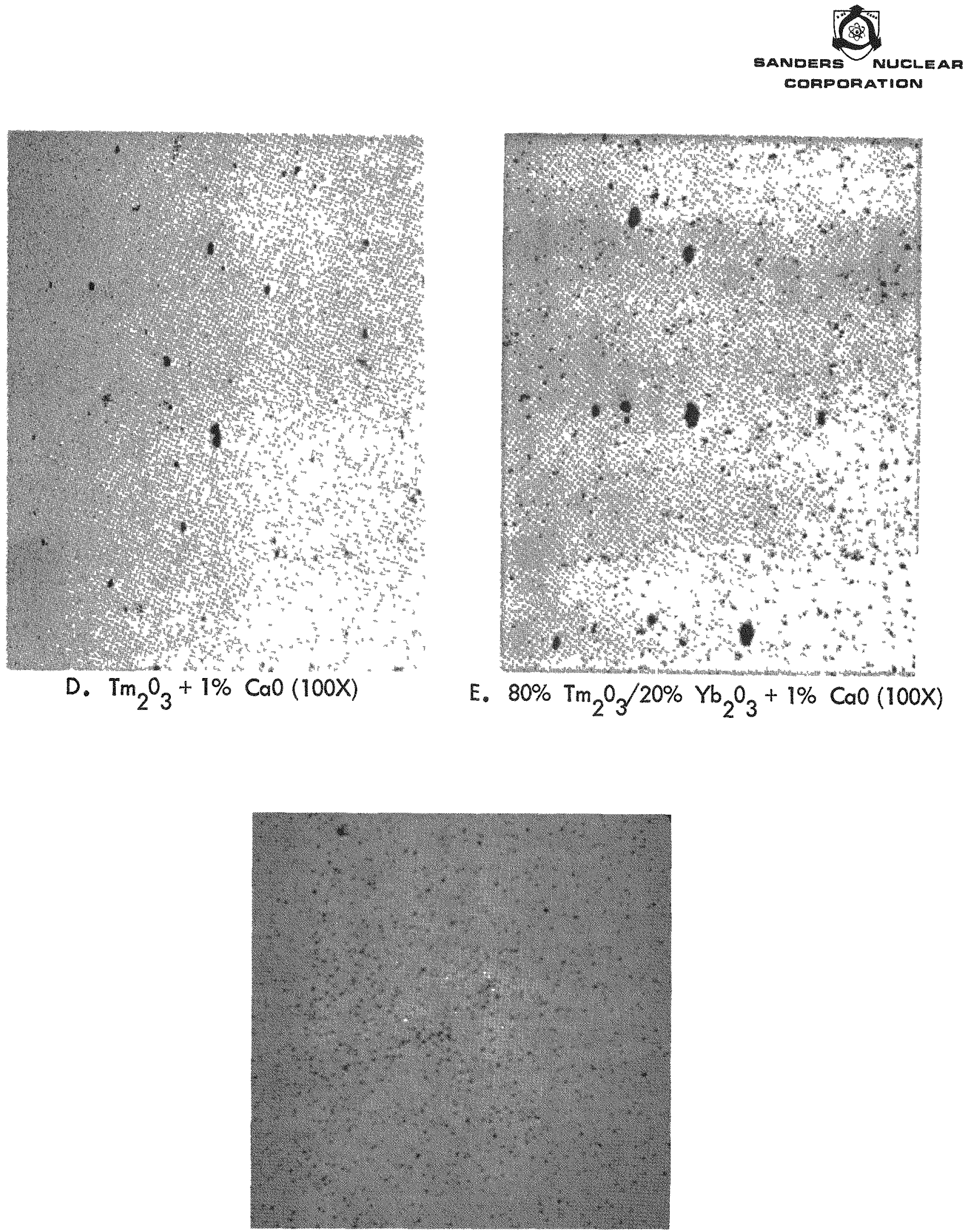

\section{F. ELECTRON MICROPROBE SWEEP OF E, CALCIUM X-RAY (100X)}

Figure 4-52 $\mathrm{Tm}_{2} \mathrm{O}_{3}$ and $80 \% \mathrm{Tm}_{2} \mathrm{O}_{3} / 20 \% \quad \mathrm{Yb}_{2} \mathrm{O}_{3}+1 \%$ Additive. Wafers Sintered in Air at $1450^{\circ} \mathrm{C}, 17$ Hours (1 of 3 Pages). 


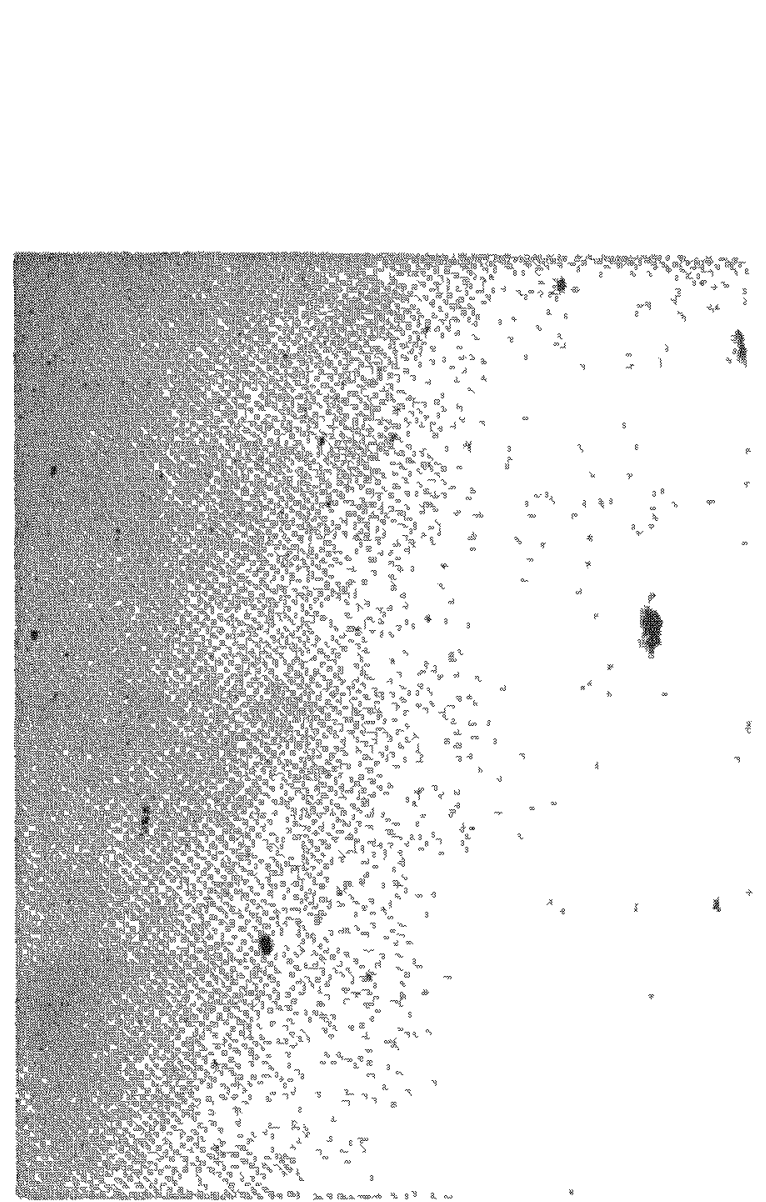

G. $\mathrm{Tm}_{2} \mathrm{O}_{3}+1 \% \mathrm{TiO}_{2}(100 \mathrm{X})$

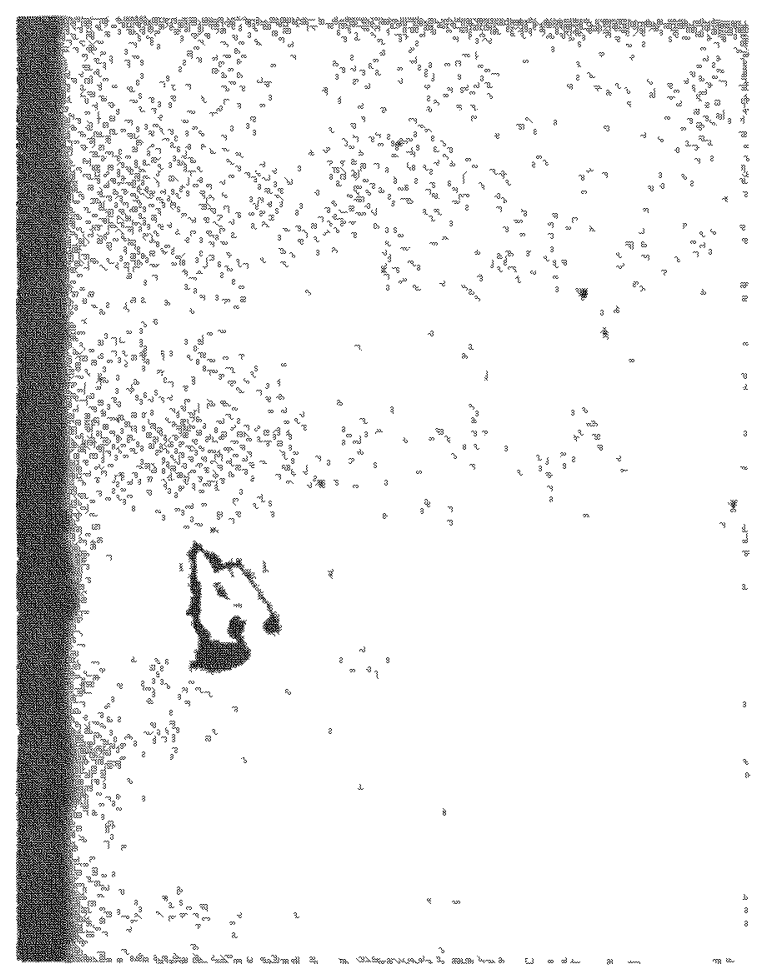

H. $80 \% \mathrm{Tm}_{2} \mathrm{O}_{3} / 20 \% \mathrm{Yb}_{2} \mathrm{O}_{3}+1 \% \mathrm{TiO}_{2}(100 \mathrm{X})$

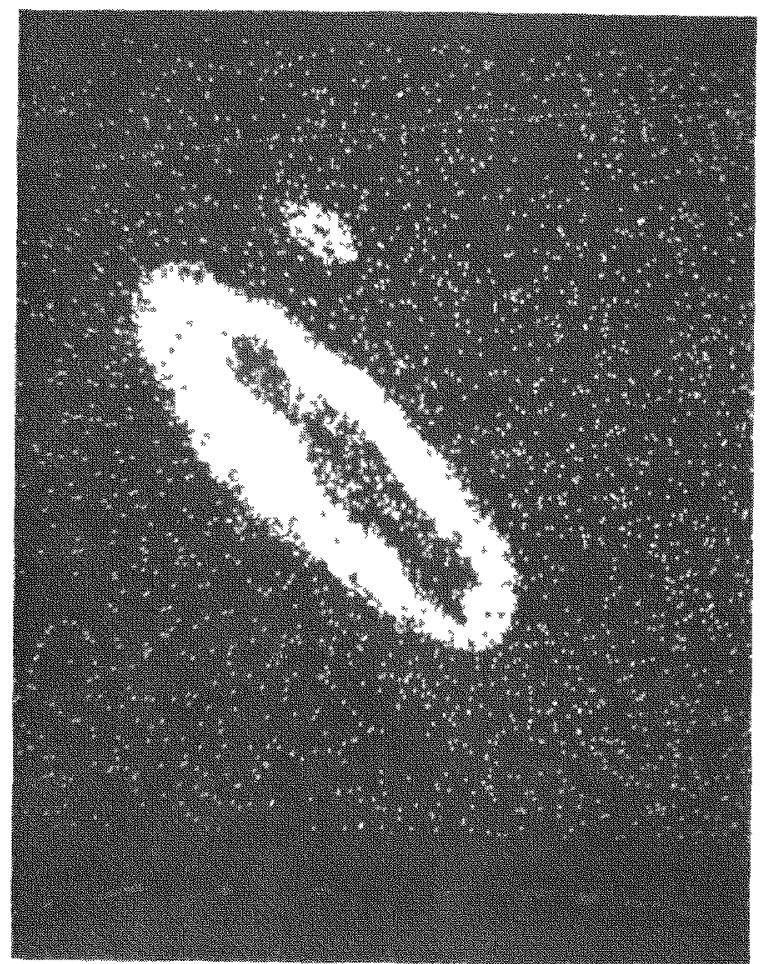

I. ELECTRON MICROPROBE SWEEP OF B. TITANIUM X-RAY (300X)

Figure 4-52 $\operatorname{Tm}_{2} \mathrm{O}_{3}$ and $80 \% \mathrm{Tm}_{2} \mathrm{O}_{3} / 20 \% \mathrm{Yb}_{2} \mathrm{O}_{3}+1 \%$ Additive. Wafers Sintered in Air at $1450^{\circ} \mathrm{C}, 17$ Hours (2 of 3 Pages). 
additive. However, the bulk sintered densities of the additive wafers were between 8.4 and $8.5 \mathrm{gm} / \mathrm{cc}$, about $10 \%$ higher than those cnntaining no aditive. The CaO additive showed a factor of 2 reduction in the particle population in the 44 - 149 micron range and a slight reduction in population in the 10 - 44 micron group. The less than 10 micron particle group was unchanged. Figure 4-52 are photomicrographs of fractured surfaces representative of each of the additive wafers and one control. The difference in grain size between the $\mathrm{CaO}-\mathrm{Tm}_{2} \mathrm{O}_{3}$ wafers and the others was striking and explained the increase in bulk density observed. An increase in grain size with a corresponding reduction in particle population in the $10-149$ micron range suggested a relationship between these properties.

Several wafers were aged in tungsten capsules at $1600^{\circ} \mathrm{C}$ for 500 hours. Wafers containing only the same additive were placed in each capsule. Post aging observation showed interwafer bonding had taken place, but no ceramic to metal bonding. The x-ray diffraction patterns contained no new lines and the lattice parameters remained the same within experimental exror.

Microscopic examination of cross sectioned wafers confirmed the presence of additive phases. The aging process had caused the titanium to segregate into a very few areas one of which was located at a wafer - wafer interface. Many voids had formed and the wafer thickness had increased $10-13 \%$ for $100 \% \operatorname{Tm}_{2}{ }^{0}$ and $6.5-10 \%$ for $80 \% \mathrm{Tm}_{2} \mathrm{O}_{3} / 20 \% \mathrm{Yb}_{2} \mathrm{O}_{3}$. Segregation and swelling were also noted in those wafers containing $1 \% \mathrm{Al}_{2} \mathrm{O}_{3}$. Thicknesses of wafers, although bonded, had increased $13 \%$ for the mixed oxide and $23 \%$ for $100 \% \mathrm{Tm}_{2} \mathrm{O}_{3}$. Many voids had formed, some quite large. Microprobe showed aluminum to have a greater distribution density than that of titanium and to be associated with voids. In rare instances, a third phase was observed, again associated with a void. This phase was not identified. Neither calcium nor silicon could be found in either aditive with microprobe analysis. 
The $\mathrm{Tm}_{2} \mathrm{O}_{3} / \mathrm{Yb}_{2} \mathrm{O}_{3}-\mathrm{CaO}$ additive wafers also contained voids, some very large. A grain boundary phase was observed that extended from the wafer surface into the matrix. Microprobe confirmed the presence of calcium in this phase. The swelling phenomena cculd be observed in both compositions. $100 \% \mathrm{Tm}_{2} \mathrm{O}_{3}$ had swelled in thickness from $0-10 \%$ and the mixed oxide from $0-36 \%$.

The swelling observed in these wafers was greatest in $100 \% \mathrm{Tm}_{2} \mathrm{O}_{3}$ when $\mathrm{Al}_{2} \mathrm{O}_{3}$ was the additive and greatest in the $80 \%$ $\mathrm{Tm}_{2} \mathrm{O}_{3} / 20 \% \mathrm{Yb}_{2} \mathrm{O}_{3}$ when $\mathrm{CaO}$ was the additive. The bench marks did not exhibit any swelling of this magnitude, although void formation was observed; the wafers did have calcium and silicon present. Since inter wafer bonding was observed in both sets of samples, it was concluded that the presence of these specific additives in conjunction with an unknown process related factor were responsible for this behavior.

The elemental levels of iron were reduced for each additive in the aged wafers. The data are presented in Table $4-14$ for each of the elements exclusive of silicon. The net increases in aluminum content observed were likely due to random sampling. The presence of $\mathrm{Yb}_{2} \mathrm{O}_{3}$ was not influential in determining the level of these elements.

TABLE $\quad 4-14$

NET CHANGES IN LEVELS (ppm) OF ALUMINUM, IRON AND MAGNESIUM IN $100 \% \mathrm{Tm}_{2} \mathrm{O}_{3}$ AND $80 \% \mathrm{Tm}_{2} \mathrm{O}_{3} / 20 \% \mathrm{Yb}_{2} \mathrm{O}_{3}$ WAFERS AS A CONSEQUENCE OF AGING FOR 500 HOURS AT $1600^{\circ} \mathrm{C}$ IN A TUNGSTEN CAPSULE

\begin{tabular}{|c|c|c|c|c|c|c|c|}
\hline & & & & & Iron & Aluminum & Magnesi \\
\hline \multirow[t]{3}{*}{$100 \%$} & $\operatorname{Tm}_{2}{ }^{\circ}+$ & $1 \% \mathrm{CaO}$ & & & -11 & +5 & -0.5 \\
\hline & & $1 \% \mathrm{Al}_{2} \mathrm{O}_{3}$ & & & -23 & +907 & +0.9 \\
\hline & & $1 \% \mathrm{TiO}_{2}$ & & & -13 & -19 & +0.3 \\
\hline \multirow[t]{3}{*}{$80 \%$} & $\operatorname{Tm}_{2} \mathrm{O}_{3} / 20 \%$ & $\mathrm{Yb}_{2} \mathrm{O}_{3}+$ & $1 \%$ & $\mathrm{CaO}$ & -28 & +15 & -0.2 \\
\hline & & & $1 \%$ & $\mathrm{~A}_{2}$ & $3-15$ & +307 & -0.1 \\
\hline & & & $1 \%$ & $\mathrm{TiO}_{2}$ & -17 & -5 & ---- \\
\hline
\end{tabular}


A comparison of some additive and bench mark data is presented in $\mathrm{Tab} 1 \mathrm{e} 4-15$ for $100 \% \mathrm{Tm}_{2} \mathrm{O}_{3}$. The only detectable grain growth in preaged samples was in those wafers containing $\mathrm{CaO}$. However, both $\mathrm{CaO}-\mathrm{Tm}_{2} \mathrm{O}_{3}$ and bench mark grains had grown markedly as a result of aging at $1600^{\circ} \mathrm{C}$ for 500 hours. As was indicated before, both the presence of calcium and another process factor might be involved. Alternatively, $\mathrm{Al}_{2} \mathrm{O}_{3}$ and $\mathrm{TiO}_{2}$ could be acting as controlling agents repressing grain growth. Thirdly, the role of the encapsulant material, in this case tungsten, is unknown and may be yet another factor.

These observed differences in grain growth were felt to be responsible for the reduction in population of grains in the 10 149 fraction in the preaged wafers. One can only speculate what the population pattern might be for the aged wafers, however, the inter wafer bonding precluded testing these wafers under identical conditions. It would seem, however, that a further gain in reductions could be anticipated by virtue of the grain size observed particularly for fines in the sub 10 micron fraction. SUMMARY

The behavior of three additive metal oxides support the correctness of the original selection criteria as each proved to be insoluble in the $\mathrm{Tm}_{2} \mathrm{O}_{3} / \mathrm{Yb}_{2} \mathrm{O}_{3}$ matrix and did not effect any of the major physical properties of the matrix. The original rational, the presence of a grain boundary phase that would provide an alternate means of dissipating the kinetic energy of impact so as to reduce transgranular cracking, was also successfully achieved by means of CaO addition. This additive produced a grain boundary phase that reduced the particle population in the $10-149 \mu$ range and proved to be a sintering aid as well.

Comparison of additives with bench marks suggested that mechanical stability was improved to some degree and offered potentially greater enhancement in the case of calcium oxide. The presence of $\mathrm{Yb}_{2} \mathrm{O}_{3}$ did not appear to influence behavior in any measurable way. 
TABLE $\quad 4-15$

COYPARISON OF BENCH MARK AND ADDITLVE DATA FOR PRE AND POST AGED $106 \% \mathrm{Tm}_{2} \mathrm{O}_{3}$

\begin{tabular}{|c|c|c|c|c|c|c|c|c|c|}
\hline \multirow[b]{2}{*}{ P. $\left(\operatorname{gn} / \mathrm{cc}_{1}\right.$} & \multirow[b]{2}{*}{ G.S. ( } & \multirow{2}{*}{$\begin{array}{l}\text { Lattice } \\
\text { Param. ( }(\AA)\end{array}$} & \multicolumn{3}{|c|}{ Elementat $(\mathrm{ppm})$} & \multicolumn{4}{|c|}{ Fines Analysus $(\% \pm 1 \%)$} \\
\hline & & & Ee & AI & $\mathrm{Mg}$ & $\leq 10 \mu$ & $13-44 \mu$ & $44-1424$ & $2142 \mathrm{t}$ \\
\hline 8.6 & $<1$ & 10.49 & 79 & 52 & 16 & $0.40+.14$ & $0.19 \pm .11$ & 0.73 & 98.92 \\
\hline 8.5 & $<1-5$ & 10.47 & 28 & 18 & 4.5 & $0.43 \pm .30$ & $0.12 \pm .05$ & 0.49 & 99.23 \\
\hline 8.5 & $<1$ & $10.4 ?$ & 48 & 467 & 1.7 & $0.34 \pm .11$ & $0.17 \pm .09$ & 0.94 & 98.67 \\
\hline 8.4 & $<1$ & 10.47 & 43 & 42 & 1.9 & $0.39 \pm .21$ & $0.15 \pm .03$ & 0.99 & 98.49 \\
\hline$k \quad-$ & $<200$ & 10.48 & 27 & 57 & 16 & & & & \\
\hline- & $<500$ & 10.43 & 17 & 23 & 4.9 & & & & \\
\hline - & $<10-30$ & 10.49 & 25 & 1374 & 2.6 & & & & \\
\hline - & $<10-20$ & 10.44 & 30 & 23 & 2.2 & & & & \\
\hline
\end{tabular}

$100 \% \mathrm{Tr}_{2} \mathrm{O}_{3}$ bench mark

$\mathrm{CaO}$
$\mathrm{AL}_{2} \mathrm{O}_{3}$
$\mathrm{TiO}_{2}$

bench maxk

CaO

$\mathrm{Al}_{2} \mathrm{O}_{3}$

$\mathrm{TiO}_{2}$
Latice

10.49

10.44

2.2 
4.4 AN ASSESSMENT OF MECHANICAL, THERMAL AND CHEMICAL STABILITY ENHANCEMENT

The thermal and chemical stability of the $\mathrm{Tm}_{2} \mathrm{O}_{3} / \mathrm{Yb}_{2} \mathrm{O}_{3}$ structure was consistently of high degree throughout the entire study. The products resulting from ranging process parameters and from adding metal oxide additives exhibited the same high degree of stability observed in the bench mark wafers. The interceramic bonding of $\mathrm{Tm}_{2} \mathrm{O}_{3}$ wafers that occurred during aging suggests the need for individually encapsulated wafers particularly in light of the very high centerline temperatures predicted for bulk encapsulated $\operatorname{Tm}_{2} \mathrm{O}_{3}$ Individual encapsulation would be expected to preserve the benefits of fines generation observed in aged wafers.

Both process variable optimization and metal oxide additive wafers influenced particle populations within certain size ranges; full assessment of the past aged metal oxide additive and bench mark wafers was precluded by interceramic bonding. The preaged fines behavior of the additive samples particularly in those wafers containing $1 \% \mathrm{CaO}$ however, suggest that aging may improve the post impact fines generation more favorably than the levels observed in the products of process variable optimization.

In the latter study, fines ranged from $0.04 \%$ to $0.38 \%$ of the total wafer weight and were related to initial pressing pressure after aging. Development of an understanding of this relationship would provide a valuable tool in selecting an ultimate set of process conditions for fabricating an actual fuel form, particularly when optimum wafer properties can be achieved from a wide range of process conditions. 
The objective of this study was to show the feasibility of $\mathrm{Tm}_{2} \mathrm{O}_{3}$ as an isotopic heat source embodiment. The basic behavioral patterns of $\mathrm{Tm}_{2} \mathrm{O}_{3}$ were established from containment compatibility studies, phase diagram and melting point determinations, theoretical dose rate calculation and experimental measurements, thermal profiles and enviromental exposure. Falling in these basic behavioral patterns was the effect of processing parameters on $\operatorname{Tm}_{2} \mathrm{O}_{3}$ properties. DESIGN AND PROPERTIES

The experimentation was designed to encompass with margin the anticipated operating temperatures and conditions of a $\mathrm{Tm}_{2} \mathrm{O}_{3}$ fueled capsule. Several encapsulant materials of current favor, Hastelloy $\mathrm{X}$, Haste11oy C-276, Haynes 25, T-111, TZM and tungsten were used in compatibility experiments and to generate the thermal profiles and centerline melt temperatures obtained in the fuel capsule parametric design study.

The melting points determined fox $\operatorname{Tm}_{2} \mathrm{O}_{3}$ and $\mathrm{Yb}_{2} \mathrm{O}_{3}$ were 2301 and $2327 \pm 33.5^{\circ} \mathrm{C}$. The cubic crystalline structure of both $\mathrm{Tm}_{2} \mathrm{O}_{3}$ and $\mathrm{Yb}_{2} \mathrm{O}_{3}$ was maintained up to the melting point and the system was typical of a solid solution system. Containment of $\mathrm{Tm}_{2} \mathrm{O}_{3} / \mathrm{Yb}_{2} \mathrm{O}_{3}$ over a wide range of temperatures to $2000^{\circ} \mathrm{C}$ for times to 10,000 hours was successfully achieved with the candidate encapsulant materials. Further, $\operatorname{Tm}_{2} \mathrm{O}_{3}$ was chemically inert with respect to the encapsulants, except for some $x$-ray evidence that tungsten interacts with $\operatorname{Tm}_{2} \mathrm{O}_{3}$. The thermal stability exhibited herein supported the fuel capsule design study. 
Thermal profiles generated from the fuel capsule parametric design study used the encapsulant materials previously mentioned, helium and argon as fill gases, three different power denstties, and two basic types of encapsulation, (1) individually encapsulated wafers and (2) a bulk encapsulant stack of wafers. The results showed that bulk encapsulation leads to centerline temperatures that exceeded the melting point of the encapsulant or fuel in many instances. Individual encapsulation provided a much lower and acceptable centerline temperature in nine of the sets of conditions studied, particulary where power densities were similar to the 17 watts/cc achieved at Savannah River Laboratory. These activated fuel sources were also in the form of wafers.

The environmental behavior of $\mathrm{Tm}_{2} \mathrm{O}_{3} / \mathrm{Yb}_{2} \mathrm{O}_{3}$ was assessed by analysing wafers exposed to air, dynamic vacuum and static vacuum (tungsten encapsulated) at temperatures to $2000^{\circ} \mathrm{C}$ for times to 100 hours. Under these conditions, the $\mathrm{Tm}_{2} \mathrm{O}_{3} / \mathrm{Yb}_{2} \mathrm{O}_{3}$ cubic structure was maintained. Vapor phase mass transport was observed in the encapsulated samples, the amount being related to the $\mathrm{Yb}_{2} \mathrm{O}_{3}$ content. Containment in these instances was unaffected.

From these data it was concluded that the $\mathrm{Tm}_{2} \mathrm{O}_{3} / \mathrm{Yb}_{2} \mathrm{O}_{3}$ cubic structure was stable up to the melting point of $2301 \pm 33.5^{\circ} \mathrm{C}$ and that $\mathrm{Tm}_{2} \mathrm{O}_{3} / \mathrm{Yb} \mathrm{O}_{3}$ can be successfully contained for times to 10,000 hours at temperatures to $1600^{\circ} \mathrm{C}$. Containment materials having demonstrated compatibiltiy with $\mathrm{Tm}_{2} \mathrm{O}_{3} / \mathrm{Yb}_{2} \mathrm{O}_{3}$ include Haynes 25 , Haste11oy $\mathrm{X}$, Haste110y $\mathrm{C}-276$, TZM and tungsten.

\section{FABRICABILITY}

Several sets of processing conditions were studied. These conditions included chemical processing of "as received" $\mathrm{Tm}_{2} \mathrm{O}_{3}$ " pressing pressure, sintering time/temperature/atmosphere (air, vacuum and hydrogen) and aging (500 hours at $1600^{\circ} \mathrm{C}$ followed by a thermal spike to $2000^{\circ} \mathrm{C}$ ). The results of these experiments showed that high quality, high sintered density $(95 \%$ of theoretical or better) wafers could be reproducibly fabricated by several different sets of conditions. From chemical processing to sintering the processes 
were easily carried out and did not require the use of exotic equipment on materials.

As raw material is readily available and fabrication of wafers easily achieved, subsequent thermal neutron activation of these wafers could provide a relatively low cost fuel with relatively short lead times.

\section{SAFETY}

Excellent containment of $\operatorname{Tm}_{2} \mathrm{O}_{3} / \mathrm{Yb}_{2} \mathrm{O}_{3}$ has been demonstrated. Aditionally a high degree of chemical resistance was experienced throughout these studies. The $\mathrm{Tm}_{2} \mathrm{O}_{3} / \mathrm{Yb}_{2} \mathrm{O}_{3}$ cubic structure was stable up to the melting point thereby eliminating the need to accommodate the expansion that results from phase changes. Excellent thermal, chemical and mechanical stability results after aging of samples. Initial studies show that fines generated upon impact may be controlled with process parameters including the use of additives. Improvement of mechanical strength in this sense coupled with the superior thermal, chemical stability already demonstrated would place $\mathrm{Tm}_{2} \mathrm{O}_{3}$ high on the list of viable fuel forms. 
1. C. A. Nelson, R. W. Anderson, C. R. Fink, A. Tse and W. J. Fretague, Thulium Oxide Fuel Characterization Study, Part 1 Materials Properties Measurements, USAEC Report, SNC-3693-5, Sanders Nuclear Corporation, Nashua, N. H. (1970).

2. R. W. Anderson, Compatibility Study of Containment Materials for Thulium Oxide, USAEC Report, SNC-3693-1, Sanders Nuclear Corporation, Nashua, N. H. (1970).

3. Private communication - S. Bronisz, Los Alamos Scientific Laboratory, Los Alamos, New Mexico.

4. C. A. Nelson, R. W. Anderson, M. Talbot and W. Bierds, Thulium oxide Fuel Characterization Study, Part II - Procedures, USAEC Report, SNC-3693-5, Sanders Nuclear Corporation, Nashua, N. H. (1970).

5. Bommer, National Bureau of standards Circular 539, Volume9, 58 (1959).

6. Spencer, J. F., "The Metals of the Rare Earths," Longmans, Green and Co., London, England, 1919.

7. Vickery, R. C., "Chemistry of the Lanthanides," pp. 92-7, 221, Academic Press, New York, 1953.

8. Sarver, L. A., Brinton, P.H.M., J.Am. Chem. Soc. 49, 943(1927).

9. Qui11, L. L., Rodden, C. J., "Analytical Chemistry of the Manhattan Project, : 1st edition, Chapter 22, p. 495, McGrawHi11, New York, 1950. 
10. Schoeller, W. R., Powell, A. R., "The Analysis of Minerals and Ores of the Rarer Elements," 3rd Edition, P. 103, Hafner Publishing Co., New York, 1955.

11. Broadhead, K. G., and Heady, H. H., "Radiochemical Precipitation Studies of Rare Earth Oxalates," Analytical Chemistry, 32, 1603-06, (November 1960).

12. Suggested in Private Commuication, J. Powel1, Rare Earth Information Center Ames, Iowa, May 1969.

13. Wendlandt, W. W., "Thermal Decomposition of the Rare Earth Metal Oxalates," Analytical Chemistry, 31, 409 (March 1959).

14. Head, E. L. and Holley, C. E. Jr., "The Preparation and Thermal Decomposition of the Carbonates of Tb, Dy, Ho, Tm, Yb, Lu, Y and SC," Proceedings of the Fourth Conference on Rare Earth Research, Rare Earth Research III, p. 712, Gordon and Breach, New York, 1965 .

15. B. Cina, "Some Decomposition Effects in Puo on Sintering," Journal of Nuclear Materials, 9, No. 1 p. 87-88 (1963).

16. J. R. Keski and P. L. Smith, Fabrication and Irradiation Behavior of Thulium Sesquioxide, USAEC Report, DP-MS-68-28, E. I. duPont de Nemours \& Co., Savannah River Laboratory, Aiken, S. C. (1968).

17. R. W. Anderson, Sanders Nuclear Internal Communication, July 1969.

18. N. H. DesChamps, C. R. Fink and C. A. Nelson, Thulium Oxide Euel Characterization Study (Thulium-170 Fueled Capsule Parametric Design), USAEC Report, SNC-3693-3, Sanders Nuclear Corporation, Nashua, N. H. (1970).

19. C. A. Nelson, R. W. Anderson and W. J. Fretague, Phase Diagram Determination of the $\mathrm{Tm}_{2} \underline{\mathrm{O}}_{3}-\mathrm{Yb}{ }_{2} \underline{\mathrm{O}}_{3}$ System, USAEC Report, SNC-3693-2, Sanders Nuclear Corporation, Nashua, N. H. $(1970)$. 